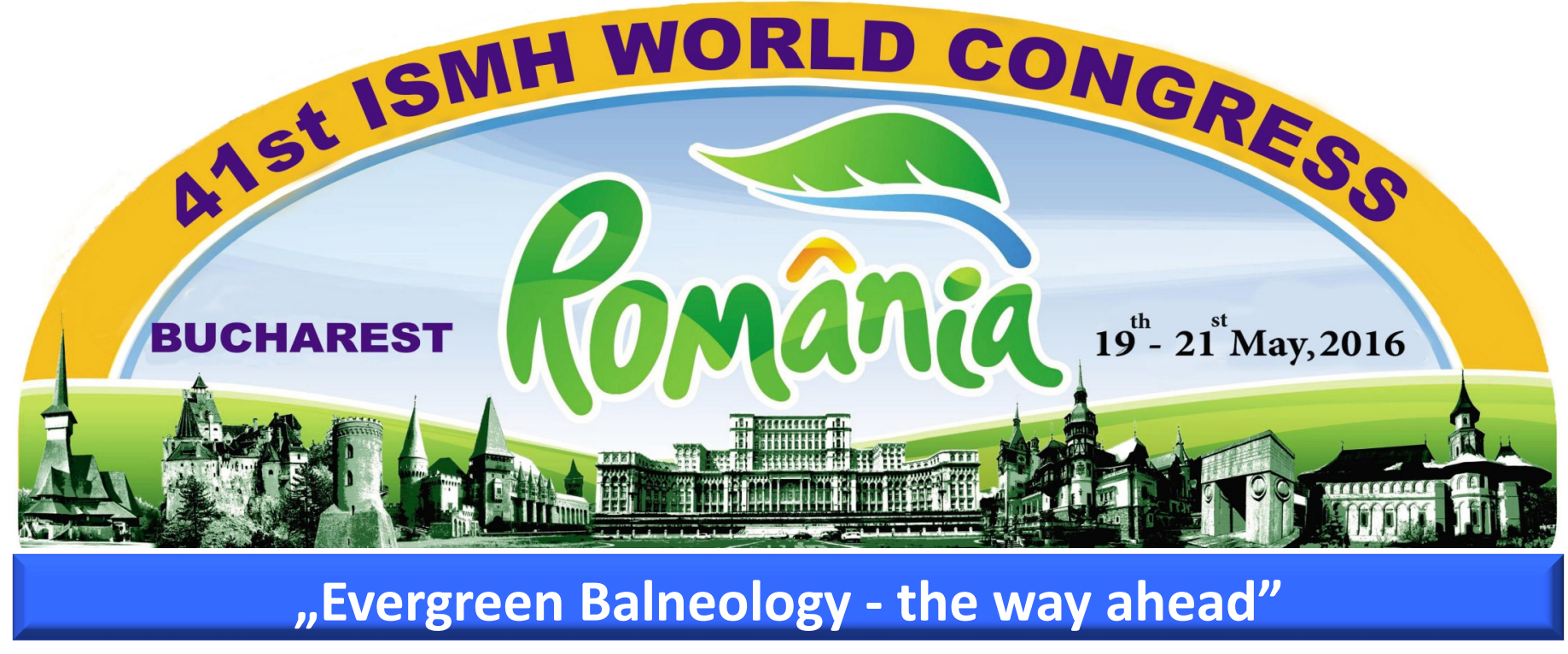

$\frac{\text { BALNEO }}{\text { KESEARCH }}$ BALNEO RESEARCH JOURNAL
EISSN 2069-7619 pISSN 2069-7597 ROMlish Edition
ROMANIANASSOMATION OF BALNEOIOCY

\title{
ABSTRACTS BOOK
}
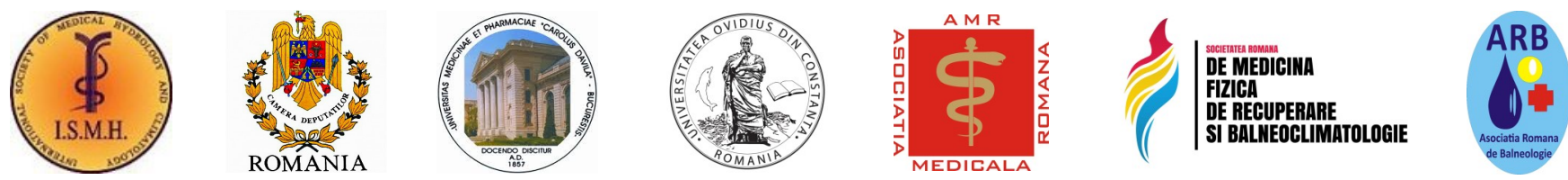

\section{inz}
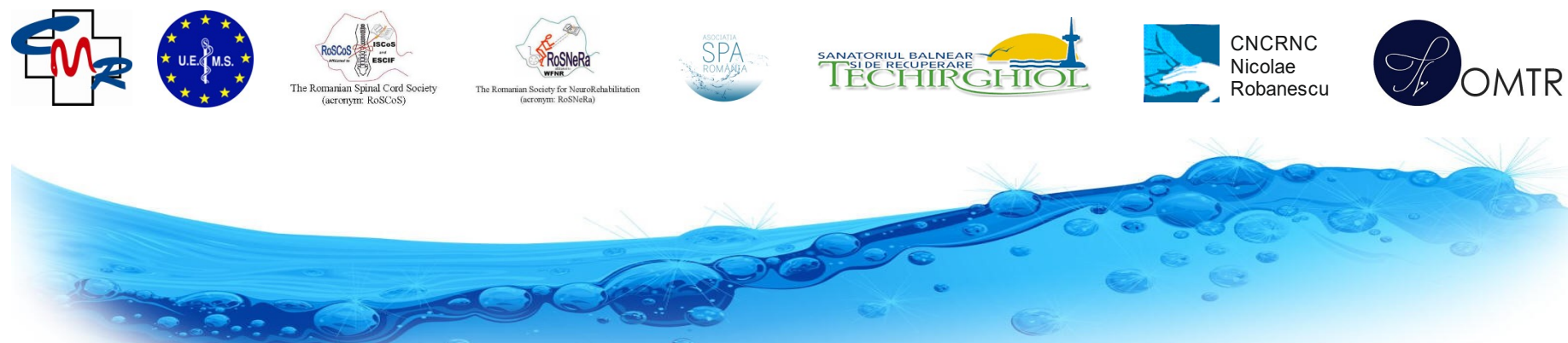


\section{„Evergreen Balneology - the way ahead"}

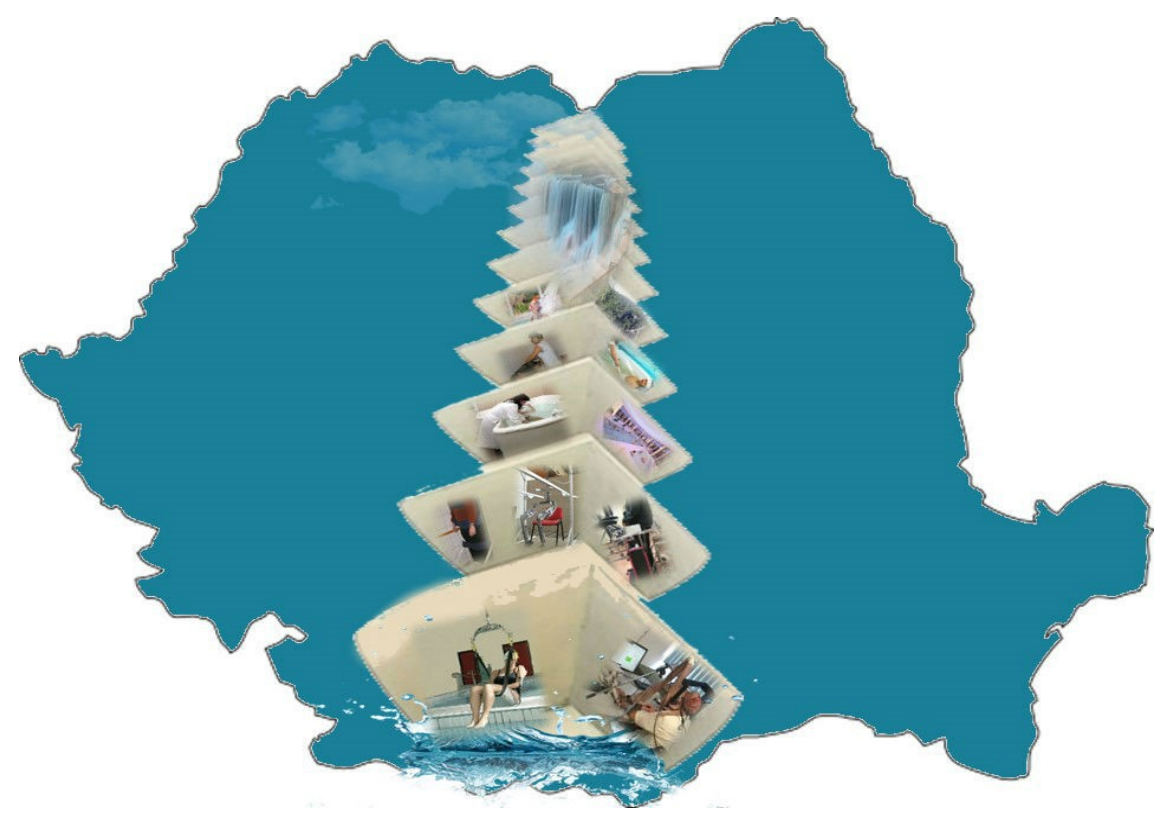




\section{INVITED SPEKERS}

ISO3 FINDINGS REGARDING RELATIONSHIPS BETWEEN SOCIO-DEMOGRAPHIC, PSYCHOLOGICAL AND CO-MORBIDITY, FACTORS, AND FUNCTIONAL STATUS, IN GERIATRIC INPATIENTS

A. Capisizu, S. Aurelian, A. Zamfirescu, I. Omer, M. Haras, C. Ciobotaru, L. Onose, T. Spircu, G. Onose

1504 BALNEOLOGICAL RESEARCH IN ROMANIA

Constantin Munteanu, Mihail Hoteteu, Diana Munteanu Zão, Ana, Pedro Cantista

IS06 "HEALTH BENEFITS IN PATIENTS WITH KNEE OSTEOARTHROSIS AFTER A THREE WEEKS BALNEOTHERAPY PROGRAM: RESULTS OF A NEW RANDOMIZED CONTROLLED TRIAL"

Cantista, Pedro. MD, PhD *, Maraver Eyzaguirre, Francisco, MD, PhD **

1507 THE AFRETH (FRENCH ASSOCIATION FOR THERMAL RESEARCH), AN EXPERIENCE OF TEN YEARS, ACHIEVEMENTS AND PROBLEMS

CF Roques-Latrille

1508 BALNEOTHERAPY FOR CHRONIC PAINFUL CONDITIONS - DATA OF EVIDENCE

Cf Roques-Latrille

IS09 Perception of Balneotherapy by General Practioners - A French survey

Thierry DUBOIS

IS10 $10-\quad$ WATERANDLFE

C. Ionescu-Tirgovist

IS10 OSTEOARTHRITIS, ADIPOKINES AND BALNEOTHERAPY

Antonella Fioravanti, Sara Cheleschi

IS11 EVOLUTION OF THE ISMH THROUGH ITS INTERNATIONAL CONFERENCES (1982 - 2015)

F. Maraver, J.M. Carbajo

IS12 SULPHUR WATERS OF SPANISH SPAS

F. Armijo, I. Corvillo, I. Vázquez, J.M. Carbajo, F. Maraver

IS13 MAGNESIUM CONTENT OF SPANISH NATURAL MINERAL WATERS

F. Maraver, I. Vitoria, J.M. Carbajo, C. More*, F. Armijo

IS14 SPA THERAPY FOR OLDER PATIENTS WITH OSTEOARTHRITIS

IS15 AMELIORATION OF THERMAL DISPARITY OF FINGERS BY WARM CO2 BATHING IN CONNECTIVE TISSUE DISEASE PATIENTS

IS16 Influence of balneotherapeutic program on microcirculation and total antioxidant status in diabetic patients

IS17 WATER IS LIFE, WELLNESS AND HEALTH - Manifesto

Prof. Umberto Solimene

IS18 L'HYROTHERAPIE EN TUNISIE

Mr. Rzig Oueslati

IS19 SPA THERAPY IN CHRONIC LOW BACK PAIN: A SYSTEMATIC REVIEW

IS20 DOES SPA THERAPY IMPROVE THE BACK PAIN MORE THAN EDUCATION PROGRAM IN SPINAL OSTEOARTHRITIS? A RANDOMIZED CLINICAL TRIAL. THE LOMBATHERM' STUDY

Dr Romain Forestier, Dr. Alain Françon, Dr F Begüm Erol Forestier,

1521

Why you should calculate the sample size?

Dr Alain Françon, Dr Romain Forestier, Dr F Begüm Erol Forestier

IS22 "International clinical practice guidelines (CPGs) in rheumatology: what is the place of spa therapy (or balneotherapy) in 2016?"

IS23 Updated database of the scientific results of hungarian balneology

Prof. Dr. Tamás Bender

IS24 MAIN TENDENCIES OF SCIENTIFIC DEVELOPMENTS IN THE RUSSIAN BALNEOLOGY 
Gabriela Dogaru, Alexandra Ispas, Marieta Motricală, Molnár Ákos

IS26 ASPECTS OF REHABILITATION IN ELDERLY PATIENTS

Liviu Lazar, Fl. Marcu, F. Cioara, C. Nistor Cseppento

IS27 COMPARATIVE ANALYSIS OF THE INFLUENCE OF BALNEOTHERAPY AND HYDROKINESIOTHERAPY OF BANJA KOVIUACA ON BLOOD PRESSURE VALUES

IS42 FLEXIBLE URETEROSCOPY - TOP MINIM INVASIVE ENDOSCOPIC SURGERY, MONDIAL FURS/RIRS/URS: INSTRUMENTS, DISPOSABLES, TIPS AND TRICKS, INDICATIONS, COMPLICATIONS, CASES 


\section{ORAL PRESENTATIONS}

OP01

Aurelian Anghelescu, Cristina Popescu, Cristina Octaviana Daia, Anca Sanda Mihaescu, Gelu Onose

OP02 CURRENT SITUATION OF POLICIES ON THE EMPLOYMENT OF PERSONS WITH DISABILITIES IN ROMANIA

Aurelian Anghelescu, Mihai Bușcă, Adina Constantin, loana Andone, Valentin-Titus Grigorean, Lucia Ana Maria Anghelescu, Oana Ilona David, Gelu Onose

OP03 EVOLUTION OF TRAUMATIC SPINAL CORD INJURY IN PATIENTS WITH ANKYLOSING SPONDYLITIS, IN A ROMANIAN REHABILITATION CLINIC

Aurelian ANGHELESCU, Liliana Valentina ONOSE, Cristina POPESCU, loana ANDONE, Cristina Octaviana DAIA, Anca Magdalena MAGDOIU, Aura SPANU, Gelu ONOSE

OP04 TYPICAL HEMIFACIAL SPASM (HFS) - INEDITED CONSERVATIVE TREATMENT; CASE PRESENTATION

Anghelescu A, Gorgan C, Petcu G, Neculae M., Radu R,Frecea I, Onose G

OP05 POSITIONING THE OFFER OF FOUR STARS HOTEL FROM FELIX SPA BETWEEN BALNEO AND WELLNESS TOURISM

Olimpia Ban, Șereș Luminița, Balaj Bianca

OP06 THE HANDS OF KINESIOTHERAPISTS - STUDY PROPOSAL AND PROFESSIONAL OPTIMIZATION

Neli-Claudia Bilha

OP07 VIRTUAL REALITY IN HAND EVALUATION AND REHABILITATION

CM Brailescu, AS Nica, RG Scarlet

OP08 RESULTS REGARDING THE USE OF PRM PROGRAM IN THE POST-SURGERY MANAGEMENT OF HAND TRAUMATIC INJURIES

CM Brailescu, I Lascar, RG Scarlet

OP09 BALNEOTHERAPY COMBINED WITH THERAPEUTIC EDUCATION IN LYMPHEDEMA PATIENTS

Patrick Carpentier, Bernadette Satger, Dominique Poensin, Christine Trens, Martine Arnold, Corine Trolliet, Janick Noilhetas, Eric Chauvin, Jérôme Laures

OP10 SIDE EFFECTS OF LEFLUNOMID, RESPECTIVELY OF CARRAGEENAN IN EXPERIMENTAL INDUCED RHEUMATOID ARTHRITIS

M. Chicu, E. Bitere

OP11 THORACIC SPINE TYPE C INJURIES ACCORDING TO THE AO CLASSIFICATION: INJURY PROFILE, MANAGEMNET AND OUTCOME

Gheorghe Checiu; Cristian Filip; Daniel Serban; Niki Adrian Calina; Marius Podea; Costica Zamfir; Florin Exergian

OP12 CORRELATIONS BETWEEN ANATOMO-PATHOLOGICAL, RADIOLOGICAL AND OSTEODENSITOMETRICAL ASPECTS IN EXPERIMANTAL INDUCED CHRONIC ARTHRITIS

M. Chicu, V. Vulpe, E. Bitere, O. Ciurcanu

OP13 IL1B - MARKER OF THE INFLAMMATORY PROCESS AND THE BONE-CARTILAGINOUS DESTRUCTION

M. Chicu, E. Bitere, O. Ciurcanu

OP14 HEART RATE VARIABILITY DURING EXERCISE TESTING

Călin Corciovă, Cătălina Luca, Doru Andriţoi, Daniela Matei

OP15 BRINE AEROSOL THERAPY IN THE "WIELICZKA" SALT MINE HEALTH RESORT

Jolanta Czerwik, Dorota Ankowska, Maria Kmiecik

OP16 ALTERNATIVE OF EDUCATION FOR BALANCE AND GAIT AT CHILDREN WITH CEREBRAL PALSY

Mihail-Alexandru Dumangiu, Liliana Padure

OP17 OBSERVATIONAL STUDY REGARDING TRANSIENT DIABETES INSIPIDUS ON PATIENTS WITH SPINAL CORD INJURY

Cristina Daia, Ana-Maria Bumbea, Cristina Popescu, Catalin Bicescu, Cristinel Dumitru Badiu, Gelu Onose

OP18 THE QUALITY OF LIFE EVALUATION OF PATIENTS WITH TRAUMATIC SPINAL CORD INJURY IN POST-ACUTE AND SUB-ACUTE STATE

Cristina Daia, Onose Gelu

OP19 USING ÇANKIRI SALT CAVE IN HEALTH THERAPY

Senayi DÖNMEZ, ibrahim DEMIRTAŞ

OP20 REHABILITATION ON KNEE OSTEOARTHRITIS ASSOCIATED WITH OBESITY AND THROMBOPHLEBITIS IN LOWER LIMB

Cristina Daia, Gelu Onose, Nicolae Potra, Diana Nita, loana Cazacu, Nicoleta Stoianoglu, Nicoleta Chiriloi, Anca Mihaescu

OP21 THE COMPLEX THERAPEUTICALLY APPROACH OF PATIENTS IN THE REHABILITATION HOSPITAL BRADET (ARGES, ROMANIA), INCLUDING THE NATURAL THERAPEUTIC FACTORS AND CLIMATE

Cristina Daia, Gelu Onose, Mihaela Chircu, Diana Nita, Doroteea Teoibas Serban, Nicolae Potra

OP22 OUR EXPERIENCE IN POST SPINAL CORD INJURY NEUROGENIC BLADDER REHABILITATION USING NONINVASIVE INTERFERENTIAL MEDIUM FREQUENCY CURRENTS

Cristina Daia, Gelu Onose, Tiberiu Spircu, Aurelian Anghelescu, Cristina Popescu, loana Andone, Cristinel Dumitru Badiu 
Florin Drăgan, Gelu Onose, Liliana Pădure

OP24 OPPORTUNITIES FOR IMPROVING QUALITY OF LIFE IN GERIATRIC PATIENTS USING PELOID THERAPY

Antoaneta Grozeva

OP25 INDICATIONS, CAUTIONS AND LIMITS OF BALNEAL TRETMENT IN PATIENTS WITH POST ARTHROSCOPIC STATUS

Sibel Demirgian, Olga Surdu $u_{x}$ Traian Virgiliu Surdu, Liliana-Elena Stanciu

OP26 CANKIRI SALT CAVE, IT IS A FIRS APPLICATION AS A THERAPY CENTRE IN TURKEY

ibrahim Demirtas, Senayi Dönmez

OP27 DEAD SEA CLIMATOTHERAPY: CONTROL OF SUN EXPOSURE THROUGH NARROWBAND REFLECTANCE IN ATOPIC DERMATITIS CHILDREN

M Harari, S Dikstein

OP28 TRADITIONAL CHINESE MEDICINE

David Ho, Dr. Ivyci (Chen Qian) Qian

OP29 REHABILITATION OF A PATIENT WITH PROXIMAL THIRD CALF PERIOSTEAL OSTEOSARCOMA OPERATED WITH GMRS PROSTHESIS

Irina lonică, Florina Ojoga

Atsuhiro Kishimoto, Kimiko Horiuchi, Koji Yamamoto

Hitomi Kanayama

OP32 SYSTEMIZATION OF APPLIED PELOID IN SERBIAN SPAS

Attila Klimó

OP33 COMPARATIVE ANALYSIS OF WATER-SALT COMPOSITION OF THE EURASIAN MINERAL WATERS, THERAPEUTIC MUD AND VENOUS HUMAN BLOOD

Nikolay Kornilov, Olga Surdu, Elena Kornilova, Traian-Verghiliu Surdu

OP34 COMPARASION OF THE BLOOD PRESSURE CHANGE IN YOUNG AND MIDDLE-AGED DURING THE WINTER HOME BATHING AT JAPANESE TRADITIONAL BATHING

Maeda Masaharu, Kogure Eisuke, Imai Mai, Kikkawa kouichi

OP35 STRESS-REDUCING AND HEAT-RETAINING EFFECTS BY FOOT BATH WITH SOLUBLE EXTRACTS FROM THE LEAVES OF ABIES SACHALINENSIS

Yoshinori OHTSUKA, TOSHIHIKO KANEKO

OP36 THE INFLUENCE OF REPEATED BALNEAL THERAPY WITHIN THE ADJUSTMENT OF THE ADIPOKINES LINKED PATHOGENIC MECHANISMS IN THE KNEE OSTEOARTHRITIS

E.V. Ionescu, E.R. Almaşan, C. Oprea, S. Albina, M.G. Iliescu, D.M. Iliescu

OP37 COLECTIV - THE MEDICAL BATTLE BEHIND THE TRAGEDY

Ruxandra Mihai, Ana Maria Boiangiu, Andrei Carantino, Ingrid Carantino, loana Apostolescu, Anca Oporanu, Eugen Turcu, Matei Gheorghiu, Andrei Marin, loana Dumitrescu, Anca Bordianu, Iris Popa, Mihai Predescu, Elena Martin, Catalin Bejinariu, Andreea Badeana, Olivia Constantinescu, Silviu Marinescu

OP38 THE REHABILITATION TREATMENT IN ADHESIVE CAPSULITIS OF THE SHOULDER

Florina Ojoga

OP39 COLECTIV - INTERMINGLING SURGERY AND REHABILITATION

Silviu Marinescu, Ruxandra Mihai, Olivia Constantinescu, Ana Maria Boiangiu, Andrei Carantino, Ingrid Carantino, loana Apostolescu, Anca Oporanu, Eugen Turcu, Matei Gheorghiu, Andrei Marin, Cristina Popescu, loana Dumitrescu, Anca Bordianu, Iris Popa, Elena Martin, Catalin Bejinariu, Andreea Badeana, Gelu Onose

OP40 EPIDEMIOLOGIC PARTICULARITIES IN CHILDREN WITH NEURO-PSYCHO-MOTOR DISORDERS HOSPITALIZED IN BALNEAL AND REHABILITATION SANATORIUM TECHIRGHIOL (SBRT)

M. Minea, L. Rizea, I. Bănărescu, M. Nedelea, A. Prăjitură, L. Stanciu, G. Radu, E.V. Ionescu OP41 COMPARATIVE STUDY REGARDING EFFICIENCY OF TRAINING WITH ROBOTIC DEVICES IN UPPER LIMB REHABILITATION AFTER STROKE TO ADULT AND CHILD

Moghioroiu C., Padure L.

OP42 THE TREATMENT OF SPASTIC HIP IN CHILDREN WITH CEREBRAL PALSY

L. Pădure, A. Oprea, A. I. Grigoriu

OP43 MEDICAL REHABILITATION HEALTH UNITS EMPLOYEES' SATISFACTION SURVEY IN THE CONTEXT OF LEGISLATIVE CHANGES

C. Oprea, P. Armean, E. R. Alımăşan, E. V. lonescu, M.G. Iliescu

OP44 MULTIFACTORIAL GAIT ANALYSIS IN THE PHYSICAL AND REHABILITATION MEDICINE OF THE GAIT DISORDERS IN CHILDREN

Liliana Padure, A.I. Grigoriu, A. Oprea, M. Bejan 
Liliana Pădure, Dana Necula

OP46 HEALTY-AGING PROPERTIES OF TECHIRGHIOL MUD THERAPY ASSESSED BY ENDOCRINE CHANGES OF PITUITARY-ADRENAL AXIS

E. L. Stanciu, E. I. Paşcu, E. V. lonescu, V. Marin, S. Demirgian, C. Oprea

OP47 GUIDED INJECTION OF BOTULINUM TOXIN TYPE A IN CEREBRAL PALSY (OUR EXPERIENCE)

L. Pădure, A. Oprea,A. I. Grigoriu

OP48 OUR EXPERIENCE ON INTERMITTENT CATHETERISATION (IC) IN POST SPINAL CORD INJURY (SCI) PATIENTS WITH NEUROGENIC BLADDER (NB), USING HYDROPHYLIC DEVICES

Aura Spinu, C. Popescu, I. Andone, A. Anghelescu, C. Daia, G Onose

OP49 STRUCTURAL ORGANIZATION AND THERAPEUTIC EFFECTS OF NATURAL AND ARTIFICIAL MINERAL WATERS

G. N. Ponomarenko

OP50 CLINICAL ASPECTS AND TERAPEUTICAL BENEFITS FOR CHILDREN WITH NEURO-PSYCHO-MOTOR DISORDERS UNDERGOING COMPLEX REHABILITATION TREATMENT USING TECHIRGHIOL AREAL NATURAL FACTORS

G. Radu, I. Rizea, I. Bănărescu, M. Nedelea, A. Prăjitură, N. Calotă, M. Minea, E.V. lonescu

OP51 TREATMENT OF CONGENITAL VARUS EQUIN FOOT THE PONSETI METHOD

Monica Surdu, T. Beiu

OP52 IMPLEMENTING STRATEGIES FOR LAKE TECHIRGHIOL - CURRENT LEGISLATION AND THE DEMANDS OF BALNEAL TOURISM

Elena Roxana Almasan, Madalina Gabriela Iliescu, Carmen Oprea

OP53 NATURAL HUMUS ACIDS WATERS - THEIR POSSIBLE USE IN MEDICINE

N. Veryho, I. Ponikowska, T. Latour

OP54 DETERMINATION OF RUBIDIUM IN MINERAL AND THERMAL WATERS IN THE PROVINCE OF OURENSE (SPAIN). POSSIBLE THERAPEUTIC USE

Souto Figueroa María G., Freire Magariños, A.

OP55 BENCHMARKING VALIDITY ANALYSIS OF RASTERSTEREOGRAPHY IN IDIOPATHIC SCOLIOSIS

A. Zaharia, G. Onose, L.Padure, C. Ciobotaru, S. Popescu, G. Viscopoleanu, C. Stoica

OP56 DO MINERAL WATERS HAVE ANTI-INFLAMMATORY EFFECTS? EVIDENCE FROM IN VITRO AND IN VIVO STUDIES

E.F. Burguera, S. Cheleschi, A. Vela-Anero, N. Gómez-Prieto, R. Meijide-Failde, A. Fioravanti, F.J. Blanco

OP57 CURRENT STATUS THASSOTHERAPY IN THE IBERIAN PENINSULA

A. Muela, C. Morer, A. Cerrada, S. Ramos, F. Maraver

OP58 ASSESSMENT OF QUALITY PARAMETERS AND OF NATURAL RADIONUCLIDES CONCENTRATIONS IN NATURAL MINERAL WATER IN

M. R. Calin, I. Radulescu, A.C. Ion

\section{E- POSTERS}

PI.01 REHABILITATION ON A PATIENT WITH COMPLETE TETRAPLEGIA AFTER POST SPINAL CORD INJURY ASSOCIATED WITH BILATERAL HIPS AND KNEES ANKYLOSIS DUE TO HETEROTOPIC OSSIFICATION

Cristina Daia, Gelu Onose, Cristina Popescu, Dumitru Cristinel Badiu, Diana Nita, Doroteea Teoibas-Serban, Nicolae Potra

PI.02 REHABILITATION ON A PATIENT WITH TETRAPARESIS DUE TO DERMATOMYOSITIS - CASE REPORT

Cristina Daia, Gelu Onose, Denisa Dragnea, Diana Nita, Doroteea Teoibas Serban, Nicolae Potra, Anca Mihaescu

PI.03 STUDY ON THE NUTRITIONAL IMPORTANCE IN THE RECOVERY OF LBP PACIENT

Sinziana Silisteanu

PI.04 EVALUATION OF RADON CONCENTRATION IN SOME NORTHERN ROMANIAN SALT MINES FOR SPELEO-THERAPEUTIC, MEDICAL PURPOSES AND BALNEO TOURISM

M.R. Calin, M. A. Calin, Ghe. Iuri SIMIONCA, I. Radulescu, O. MERA

PI.05 THE ROLE OF MARKETING RESEARCH IN PROMOTING A BALNEARY DESTINATION CASE STUDY: BAILE GOVORA

Victor-George Constantinescu

PI.06 PERSONALIZED BALNEOTHERAPY IN PATIENTS WITH DISEASES OF THE JOINTS

Gennady Ponomarenko, Irina Cherkashina

PI.07 SWALLOWING DISORDERS IN CHRONIC ISCHEMIC STROKE: A PREDICTOR OF UNFAVORABLE OUTCOME

loana Stanescu, Gabriela Dogaru

PI.08 EXPERIMENTAL STUDY ON THE HEPATOPROTECTIVE EFFECT OF BAILE TUSNAD CARBONATED MINERAL WATER ON ALCOHOLIC LIVER 
Gabriela Dogaru, Denisa Muresan, Marieta Motricală, Molnár Ákos

Marius Turnea, Dragos Arotaritei, Robert Filep, Andrei Gheorghita, Mariana Rotariu, Cristian Budacu

PII.02 OBJECTIVE MEASURE OF PERFORMANCE PROSTHETIC CUP ASSEMBLY BLUNT FOR A SPEEDY RECOVERY OF THE PATIENT WITH LEG AMPUTATION

Mariana Rotariu, Marius Turnea, Dragos Arotaritei, Andrei Gheorghita, Robert Filep

Andrei Gheorghita, Dragos Arotaritei, Mihail Ilea, Marius Turnea, Mariana Rotariu

PII.04 Use of Multi Joint System in recovery of scapulohumeral joint

Dragos Arotaritei, Gheorghita Andrei, Mariana Rotariu, Marius Turnea, Mihai llea

PII.05 THE INFLUENCE OF RECOVERY TREATMENT BASED ON HALOAEROSOLTHERAPY ON CELL-IMMUNE INDICIES AT FREQUENTLY ILL CHILDREN

Olha I. Lemko, Nataliya V. Vantyukh, Svitlana V. Lukaschuk

PIIOG BALNEOREACTIONS TO HALOAEROSOL IN CHILDREN WITH RECURRENT BRONCHITIS

Olha I. Lemko, Svitlana V. Lukaschuk, Vira I. Popova, Andriy A. Major

PII.07 QUANTITATIVE EVALUATION OF ALKALIZING FEATURES OF NATURAL MINERAL WATERS

Margarita O. Haysak, Lyudmila V. Dychka, Olena P. Holubka, Sergij T. Shubert

PII.08 INFLUENCE OF THE RECOVERY TREATMENT ON THE INDICES OF LIPID PEROXIDATION, ANTIOXIDANT PROTECTION AND ENDOGENOUS INTOXICATION AT FREQUENTLY ILL CHILDREN AND CHILDREN WITH RECURRENT BRONCHITIS

Magdalyna L. Gabor, Olha I. Lemko, Diana V. Reshetar, Olha M. Tymkanich

PII.09 METHOD OF BALNEOLOGICAL REHABILITATION TREATMENT OF THE RHEUMATOID ARTHRITIS

Ivan S. Lemko, Tatjana V. Chaikovska, Marianna V. Shvardak, Svitlana I. Horitska

PII.010 SUBSTANTIATION FOR THE INTERNAL USE OF BICARBONATE-SODIUM MINERAL WATER IN THE PREVENTION OF LATENT

Tatjana V. Chaikovska, Margarita O. Haysak, Viktoria G. Malinovska, Olena P. Holubka, Nadiya A. Jakovenko, Lyubov M. Gitter, Marina M. Lyahova PII.11 THE MODIFICATION OF QUALITY OF LIFE PARAMETERS IN CHRONIC LOW BACK PAIN UNDER SPECIFIC TECHIRGHIOL LAKE BALNEAL TREATMENT

Andreea Alexandra Lupu, Mihaela Botnarciuc, Camelia Ciobotaru, Elena-Valentina Ionescu, Sandica Albina, Irina Albadi, Madalina Gabriela Iliescu PII.12 CLINICAL TRIAL REGARDING SPASTICITY HYDRO-/THERMO-/KINESIO-/THERAPEUTICAL APPROACHES - STUDY DESIGN

Irina Albadi, Gelu Onose, Camelia Ciobotaru, A. Lupu, M. Iliescu

PII.13 RESEARCH ON POSSIBLE BONE METABOLIC, OF OSTEOPOROTIC TYPE AND FUNCTIONAL, IMPAIRMENTS IN CHILDREN WITH NEUROPSYCHOMOTOR PATHOLOGY (CEREBRAL PALSY) - PRELIMINARY RESULTS

Cristian Gabriel Morcov, Gelu Onose

PII.14 CLINICAL EVOLUTION PARTICULARITIES IN A SPINAL INJURY WITH SURGICAL TREATMENT GIVEN 7 YEARS AFTER THE TRAUMA - CASE REPORT

Doinita Oprea

PII.15 PARTIAL RESULTS REGARDING THE ANALYSIS OF AOFH RISK FACTORS IN INFLAMMATORY RHEUMATIC DISEASES

Mihaela Silvia Marinica, Consuela Brailescu, Anatoli Covaleov

PII.16 FIBROMYALGIA AND BALNEOTHERAPY. A RANDOMIZED CONTROLLED CLINICAL STUDY IN THE LUGO ROMAN BATH SPA (NW SPAIN)

Rosa Meijide-Failde, S López-Linares, MC López-Silva, A Sánchez-Carrion, M Seoane-Bouzas Á Vela-Anero, EF Burguera

PII.17 AQUATIC THERAPY IMPROVES THE MOBILITY IN PEOPLE WITH SEVERE MENTAL ILLNESS

Rosa Meijide-Failde, M Seoane-Bouzas, R Oberguggenberger, EF. Burguera 


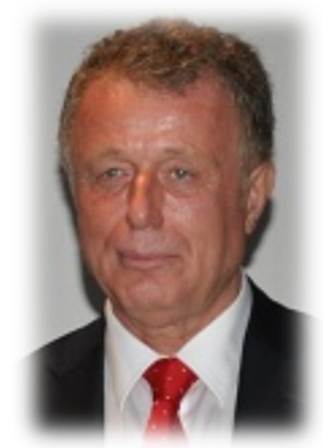

\title{
Prof. Dr. Müfit Zeki Karagülle - ISMH President
}

Dr. Karagülle is professor in medicine and the director of the Department of Medical Ecology and Hydroclimatology at Istanbul Medical Faculty of Istanbul University. Aside from directing undergraduate and post-graduate education and training programs, Prof. Karagülle has published research articles and has written and edited books and chapters on the therapeutic benefits of spa therapy, balneotherapy, and health resort/ thermal medicine. Karagülle has been president of the Turkish Association of Spa Thalasso and Health Resorts (TURKSPA) since 2005 and President of the International Society of Medical Hydrology Climatology (ISMH) since 2008. Being an expert on balneology and health resort medicine, medical ecology hydrology and climatology and working on health and thermal tourism and spa and wellness topics, he has participated in a number of symposiums, panel discussions, and workshops and organized congresses, meetings and summits including BalkanSpa Health \& Wellness Summit. Prof. Karagülle is a member of BalkanSpa Board of Founders and chairman of BalkanSpa Treatment and Medical Research Center.

\section{BALNEOLOGICAL MANAGEMENT OF RHEUMATIC DISEASES IN BALKAN HEALTH RESORTS}

Müfit Zeki Karagülle

\author{
Department of Medical Ecology and Hydroclimatology \\ Istanbul Medical Faculty, Istanbul University, Turkey
}

INTRODUCTION: Richness in type and wide usage of natural balneological and hydroclimatological sources for health and treatment are shared features in Balkans. This developed a common history and culture of treatment and rehabilitation of chronic disorders, in particular of the musculoskeletal system in Balkan health resorts. Furthermore, medical balneology has always been considered a discipline in mainstream medicine and spa therapy and balneological treatments have been included in health services and reimbursed by health insurance systems in Balkan states. With the fact that the effectiveness of balneological treatments at Balkan Spa Resorts for patients with major rheumatic diseases was not comprehensively evaluated, we aimed to review the published evidence systematically.

MATERIAL \& METHODS: We made a comprehensive search in main data bases for the last 20 years combined with hand search of our own collection of papers for systematic reviews, meta-analyses and/or randomized controlled trials (RCTs) or controlled trials conducted in spa establishments in Turkey, Romania, Serbia, Bosnia Herzegovina, Montenegro, Croatia, Greece, Bulgaria, Albania, Macedonia and Slovenia. We included all trials published in English (full text or abstract) reporting the effectiveness of balneotherapy or spa therapy programs for management of rheumatic diseases in Balkans.

RESULTS: Review of the all trials indicated that balneotherapy and spa therapy in Balkan Spas might be effective in the management of major musculoskeletal diseases. The level of evidence was relatively high; level $1 \mathrm{~A}$ evidence for osteoarthritis; fibromyalgia syndrome and chronic low back pain and level 1B evidence for ankylosing spondylitis and rheumatoid arthritis.

CONCLUSIONS: As a conclusion there is encouraging and compelling evidence -level 1A and 1B- that main rheumatic diseases can be effectively treated in Balkan balneological facilities. But it is noteworthy that there is still a need for more high-quality, randomized, controlled trials in all Balkan countries to confirm this conclusion. 


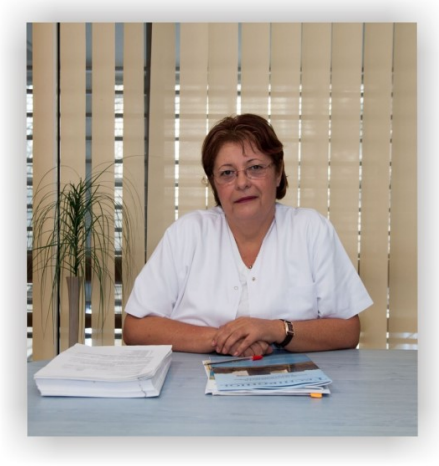

\title{
Assoc. Prof. Dr. Olga Surdu - Congress President
}

1. Academic/Education - teaching MD residents and students at Faculty of Medicin the following disciplines: rehabilitation, kinetotherapy, orthotics, geriatrics rehabilitation, muscle electrostimulation, balneology; 2. Medical activity - having patients with rheumatologic, neuro-muscular, musculoskeletal diseases, after stroke, post-trauma,post - spinal cord injuries; 3. Research for medical development. Competences in diagnosis, functional evaluation and treatment of patients with disabilities / Skills for complexes medical conditions that need holistic and integrative approach at crossroad between rheumatology, orthopedic, neurology, and balneology, physical medicine and rehabilitation/ skills for team work;

Research and medical development management, organizing team work, priorities setting, solving problems, follow up of results, basics in medical balneal tourism, wellness, and spa medicine; project management; teaching; Teamwork, communication, responsibility, leadership, appropriately management of time, setting priorities and tasks, results driven, problem solving. Advanced in medical balneology, rehabilitation, physical medicine, applying treatments with all medical devices used in Balneology and Rehabilitation, acupuncture, functional electro stimulation.

\section{EVERGREEN BALNEOLOGY - THE ROMANIAN PARADIGM: INCEPTION AND THE WAY AHEAD}

\author{
Olga Surdu ${ }^{1,2}$, Gelu Onose ${ }^{3,4}$, Dan Blendea, ${ }^{5,6}$, Daniela Coman ${ }^{7}$
}

1 "Ovidius" University - The Faculty of Medicine, Constanta, Romania; ${ }^{2}$ Techirghiol Balneary and Rehabilitation Sanatory, Romania; ${ }^{3}$ "Carol Davila" University of Medicine and Pharmacy, Bucharest, Romania; ${ }^{4}$ "Bagdasar-Arseni" Emergency Hospital, Bucharest, Romania; ${ }^{5}$ "Titu Maiorescu" University - The Faculty of Medicine, Bucharest, Romania; ${ }^{6}$ Teaching Emergency Hospital of Ilfov County, Bucharest, Romania; 7 "Ioan N. Roman” Technical High school, Constanța, Romania.

Introduction. Romania is one of the richest European countries in natural therapeutic resources known and effectively used in medicine, ever since ancient times, having balneal tradition and scientific knowledge to which innovations have been added continuously. The Romanian balneal medicine can be characterized by continuity and a scientific concept of practical applications. There is a single medical specialty: physical and rehabilitation medicine (PRM) \& balneoclimatology, with roots in ancient times and in a modern holistic and integrative relationship with the other medical specialties.

Materials and Methods. We searched in:

- databases of the Museum of National History and Archaeology of Constanta;

- documents from the National Archives Directorate of Constanta County;

- databases for information relating to the current situation/status and perspectives for balneology/PRM development;

specialty journals, books and monographs.

Results. In Romania, according to the persistent unified vision of this specialty, a good accessibility of the population to balneal services has been maintained, making our country one of the leaders in balneogeriatrics health tourism. This aspect has, unfortunately, a historical connotation (relating to the 1970s) which, despite the difficulties of the post-communist transition and the more recent economic crisis, we are trying to overcome/surpass. All this time the scientific research has been aimed at the highest possible standards. Therefore, the unanimously approval by the General Assembly of the ISMH that the 41st ISMH Congress should be organized by Romania, represents including, for us a recognition of the professional and academic level of this domain in Romania.

Conclusions. We consider with both historical and practical facts, as well as with a series of debates and contemporary conceptual guidelines, that the balneo-climatology activity in an unified, holistic and integrative manner, and in conjunction with PRM represents an appropriate/beneficial Romanian initiative that we are honoured to present to you as: "The Way Ahead of Balneology".

Key words: Romania, balneology/thermalism,,PRM, holistic medicine, integrative medicine, ancient times, modernity;

\section{Selected references:}

1.Drake DF. Schulman R.A. Daimaru D. Integrative medicine in Rehabilitation in Braddom"s Physical Medicine and Rehabilitation, fifth edition, (ed Cifu D.X.) Elsevier 2016;

2.Ring H, Giustini A, Bernadet HN, Ly LSW, Young M, Christodoulou N, Park C-il International aspects of the Practice of Rehabilitation Medicine in DeLissa"s Physical Medicine \& Rehabilitation, Principles and Practice (ed-in-chief Frontera W.R. ed emerit. DeLissa J.A), vol 1, fifth edition. Wolters Cluwer/Lippincott; Williams \&Wilkins, 2010

3. http://www.minac.ro/

4.http://www.arhivelenationale.ro/ 


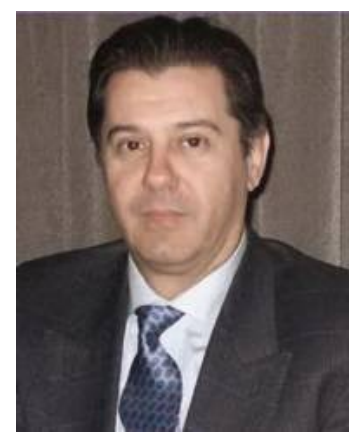

\title{
Prof. Dr. Gelu Onose / Scientific Committee President
}

Senior Physician in Physical and Rehabilitation Medicine (PRM) and Gerontology \& Geriatrics (GG)

$\mathrm{PhD} / \mathrm{Post}-$ Graduate Tutor - at the (State) University of Medicine and Pharmacy "Carol Davila", Bucharest, Romania

Head of the P(neural-muscular)RM Discipline/ Clinic Division - the National Reference Centre for NeuroRehabilitation - and of its RDI Nucleus, and RDI (ex) Director, at the Teaching Emergency Hospital "Bagdasar-Arseni", Berceni

President of the Romanian Society for NeuroRehabilitation (RoSNeRa) - affiliated to the World Federation of NeuroRehabilitation (WFNR) - and Member of the WFNR Council

President of the Romanian Spinal Cord Society (RoSCoS) - affiliated to the International Spinal Cord Society (ISCoS) and to the European Spinal Cord Injury Federation (ESCIF)

Rapporteur for Healthy and Active Ageing, and on chronic conditions management of the Comité Permanent/ Standing Committee of the European Doctors (CPME), Founder Member of the Honorary Editorial Board of the Journal of Neurorestoratology

\section{FINDINGS REGARDING RELATIONSHIPS BETWEEN SOCIO-DEMOGRAPHIC, PSYCHO- LOGICAL AND CO-MORBIDITY, FACTORS, AND FUNCTIONAL STATUS, IN GERIATRIC INPATIENTS}

\author{
A. Capisizu ${ }^{1,4}$, S. Aurelian ${ }^{3}$, A. Zamfirescu ${ }^{4}$, I. Omer ${ }^{4}$, M. Haras ${ }^{1,2}$, C. Ciobotaru ${ }^{5,6}$,

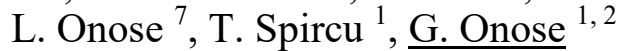

${ }^{1}$ The University of Medicine and Pharmacy "Carol Davila", Bucharest, Romania, ${ }^{2}$ The Teaching Emergency Hospital "Bagdasar-Arseni", Bucharest, Romania, ${ }^{3}$ The "Titu Maiorescu" University, Bucharest, Romania, ${ }^{4}$ The Hospital for Chronic Diseases "St. Lucas", Bucharest, Romania, ${ }^{5}$ The University "Ovidius", Constanța, Romania, ${ }^{6}$ The Teaching Emergency Hospital of the Constanța County, ${ }^{7}$ The Medical Service of "Metrorex", Bucharest, Romania

Introduction:"Disability is thus not just a health problem. It is a complex phenomenon, reflecting the interaction between features of a person's body and features of the society in which he or she lives." (http:// www.who.int/topics/disabilities/en/). Hence, in this study, have assessed the impact of socio-demographic, quantified depressive symptoms and co-morbidity, factors, on disability in older adult inpatients.

Materials and Methods: Observational cross-sectional study, including a number of 80 elderly (16 men, 64 women; mean age 72.48 years; standard deviation 9.95 years) admitted in the Geriatrics Clinic of "St. Luca" Hospital, Bucharest, between May-July, 2012. We used the Functional Independence Measure, Geriatric Depression Scale and an array of socio-demographic and poly-pathology parameters. Statistical analysis included Wilcoxon and Kruskal-Wallis tests for ordinal variables, linear bivariate correlations, general linear model analysis, ANOVA.

Results: FIM scores were negatively correlated with age (R1/40.301;95\% CI $1 / 40.4390 .163 ; \mathrm{p}^{1 / 40.007)}$; GDS scores had a statistically significant negative correlation $\left(\mathrm{R}^{1} / 40.322 ; 95 \% \mathrm{CI}^{1} / 40.3240 .052 ; \mathrm{p}^{1 / 4} 0.004\right)$ with FIM scores. A general linear model, including other variables (gender, age, provenance, matrimonial state, living conditions, education, respectively number of chronic illnesses) as factors, found living conditions $\left(p^{1 / 40.027)}\right.$ and the combination of matrimonial state and gender $\left(p^{1 / 40.004}\right)$ to significantly influence FIM scores. ANOVA showed significant differences in FIM scores stratified by the number of chronic dis-

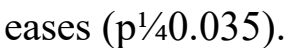

Conclusions: Our study objectified the negative impact of depression on functional status; inter estingly, education had no influence on FIM scores; living conditions and a combination of matrimonial state and gender had an important impact: patients with living spouses showed better functional scores than divorced/ widowers; the number of chronic diseases also affected the FIM scores: lower in patients with significant polypathology. These findings should be considered when designing geriatric rehabilitation programs, especially for home - including skilled - cares.

Keywords: Disability $\bullet$ Multi-poly-pathology • Functional Independence Measure $(\mathrm{FIM}) \bullet$ Geriatric Depression Scale $(\mathrm{GDS}) \bullet$ Geriatric inpatients 


\title{
Dr. Biol. Constantin Munteanu / Organizing Committee President
}

Scientific Researcher, biologist at BIOSAFETY LTD, Bucharest, engaged in scientific research in the field of physiology related to natural therapeutic factors. From November 2010 - Cofounder/General Secretary of The Romanian Association of Balneology. From November 2010 - Director of Balneo Publishing and Editor-in-Chief of Balneo Reserach Journal (http://bioclima.ro/ Journal.htm). From July 2014 - President of The Romanina Association of Balneology, http:// bioclima.ro/, March 2011 - October 2014 - Manager at Biosafety LTD, 02.2016 present - Chairman of the Board of Directors of Biosafety LTD, Project Manager "Correlation between the systemic impact of mineral waters rich in lithium-induced molecular changes in glial cells in vitro" - Project Director; Project funded by the Academy of Medical Sciences, 2003-2005, Nov 2009 - 2015: National Institute of Rehabilitation, Physical Medicine and Balneoclimatology - Researcher- Head of Laboratory Cell Culture; Secretary Advisor - Permanent Commission on Speleotherapy / Commission permanent spéléothérapie (PCS / International Union of Speleology CPS- UIS)

\section{BALNEOLOGICAL RESEARCH IN ROMANIA \\ Constantin Munteanu ${ }^{1}$, Mihail Hoteteu ${ }^{1,2}$, Diana Munteanu ${ }^{1,2}$}

\author{
${ }^{1}$ Romanian Association of Balneology, Bucharest, Romania, office@bioclima.ro \\ ${ }^{2}$ National Institute of Rehabilitation, Physical Medicine and Balneoclimatology, Romania
}

INTRODUCTION: Romania has the major advantage of managing a large range of natural treatment factors spread over almost the entire surface, exploitable the entire year and covering the entire range of sicknesses treatable by spa cure; The new criteria of evaluation show the impressive leap registered on the therapy with natural cure factors, from the crisis periods when there were no solid scientific substantiation, the methodology used to be based more likely on the empiricism, to the multiple studies and scientific examinations which proved the efficiency of therapeutic and rehabilitation cures for different groups of diseases. The modern evaluation of the health, the welfare, and the quality of life imposes the continuation and development of scientific study for the establishment of action mechanisms and curative effects of the natural therapeutic factors.

MATERIALS \& METHODS: Preclinical and clinical pharmacological methodologies developed by researchers are applicative focused towards checking the therapeutic character of the new developed product with geroprotector effect with significant practical relevance in medical terms to gerontology field and in social terms for the quality of elderly life. The experimental study design on cell cultures allows the direct biological evaluation at the cellular level, of the therapeutic effect that natural factors can play over the organism.

RESULTS: Combining the balneotherapy with using products with healthy-aging effect provides a significant advantage and represents the sustainability of the research in the context of which the spas is the ideal place for the application of new treatments. Peloids, used in peloidotherapy, in the treatment of various rheumatic, endocrine, dermatological or gynecological diseases, because of many biological, biochemical, physical, chemical and physico-chemical actions that have in the body, as described in the specific literature - represent the support for the design of new geroprotective products in combination with traditinal molecules..

CONCLUSIONS: Currently, health is understood as the removal of diseases in a defensive manner to the pathological process and with higher costs. Would be more effective the maintenance of health through prevention mechanisms identified by modern science. The study of the mechanisms by which various natural or health factors can influence positively or negatively the aging process opens the path to design and obtain new products for the benefit of elderly people to maintain health for a long time and so to have socially active and positive role 


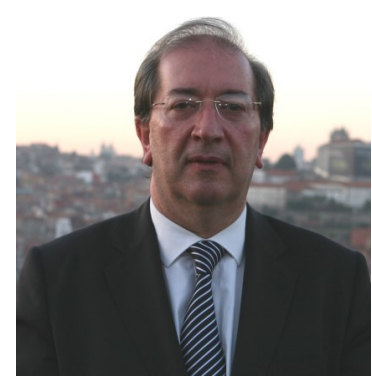

\section{Prof. Dr. Pedro Cantista - NEXT ISMH President}

European Specialist certified by the PRM European Board.

Official "Competences Titles" in "Pain Medicine" and "Medical Hydrology".

Senior Consultant in PRM Department of the "Hospital de Santo António", Porto.

Co-founder of the Diabetic Foot Multidisciplinary Unit in this hospital

Clinical Director of "Termas de S. Jorge" and "Termas de Luso".

Clinical and Scientific Chairman of the "Balneário Pedagógico de Vidago".

Professor at the University of Porto; Chair of Medical Balneology at the "Instituto

de Ciências Biomédicas Abel Salazar" (ICBAS) course of Medicine

European Society of PRM (ESPRM) Executive Board Member

Chairman of the ESPRM Guidelines Committee.

President of the Portuguese Society of PRM from 2001-2007

Former Regional Vice President for Europe of the International Society of PRM

President of the International Society of Medical Hydrology (ISMH-2016)

President of the 36th World Congress of ISMH in Porto Portugal, in 2008.

Delegate of the "Union Européènne des Médecins Spécialistes" (UEMS) PRM

Chairman of the "Balneology Permanent Working Group" of the UEMS PRM

Co-founder of the European Board of Medical Hydrology.

\section{"WATER EXERCISE IN ANKYLOSING SPONDYLITIS: A SYSTEMATIC REVIEW" Zão, Ana, MD *, Cantista, Pedro *, **, MD, PhD \\ * Hospital de Santo António, Porto, ** University of Porto, Portugal}

Introduction: The Ankylosing Spondylitis (AS) is a chronic and progressive inflammatory rheumatic disease, characterized by pain, decreased mobility and associated with disability and decreased quality of life. It is well known the interest of balneology and hydrotherapy in rheumatic diseases. Its physical and chemical action seems to favor very positively the evolution of the disease, particularly in the case of AS. Several studies have been conducted in this area.

Objectives: To evaluate the role of water exer cise in Ankylosing Spondylitis.

Material and Methods: Systematic review of the literature published in English, Portuguese, French, Spanish and Italian, until March 2016, on Medline, Embase, Cochrane Library, Web of Science and Scopus databases.

Results: Eight articles have been included for further analysis:

five randomized controlled clinical trials and three non-randomized controlled trials. Three studies evaluated the effect of a water exercise program when compared with a group control only under drug therapy; two compared the effect of water exercise with no water exercise program; a study assessed the additive effect of Stanger Bath Therapy in patients under supervised group exercise program; Another study assessed the additive effect of balneotherapy in patients undergoing exercise program at home and another study relating to the additive effect of Spa Therapy in two different locations in patients on non-water exercise supervised program. Overall, the studies showed a statistically significantly positive effect of water exercise and different modalities of hydrotherapy, particularly in terms of pain, mobility, disease activity, cardio respiratory function, functionality, well-being and quality of life.

Discussion: In this systematic review, conducted in order to understand and analyze what of most valid has been possible to study in relation to hydrotherapy and balneotherapy in AS, we found that these therapeutic modalities add significant clinical and functional benefit in various components of this disease. The variability of the interventions among studies and the small number of studies limit ours conclusions.

Conclusion: The literature highlights the central role of water exercise in AS. However, more studies with high methodological quality are needed, to increase the evidence of these findings and to define the specific characteristics of water exercise programs that determine better results. Taking into account the significant negative impact of AS in functionality and quality of life, potentially effective modalities such as hydrotherapy and balneotherapy should not be neglected when treatment is prescribed. 


\title{
"HEALTH BENEFITS IN PATIENTS WITH KNEE OSTEOARTHROSIS AFTER A THREE WEEKS BALNEOTHERAPY PROGRAM: RESULTS OF A NEW RANDOMIZED CON- TROLLED TRIAL"
}

\author{
Cantista, Pedro. MD, PhD *, Maraver Eyzaguirre, Francisco, MD, PhD ** \\ * Universidade do Porto , ** Universidade Complutense de Madrid
}

Objective: to evaluate health benefits on a population suffering from Knee Arthrosis after a three week balneotherapy program on Termas de S. Jorge , Portugal

Methodology: A sample of 150 patients satisfying the American College Criteria for Knee arthrosis was recruited for a randomized controlled trial with a therapeutic group receiving a $37^{\circ} \mathrm{C}$ tube hydro massage, a pool exercise session $\left(34^{\circ} \mathrm{C}\right)$ and a shower massage of the knees $\left(38^{\circ} \mathrm{C}\right)$ on a daily basis, during 21 consecutive days and a control group without these treatments. Patients were evaluated from their pain, functional and health status using the Visual Analogic Scale, the WOMAC scale, the SF-36 questionnaire and the "Timed Up and Go Test". A list of 16 exclusion criteria was approved and lead to 30 drop outs. Two groups of 60 patients each concluded the trial. We registered the evaluating data taken in different moments of both groups. The intervention group was evaluated at the beginning of the trial before the Balneology treatments (tE1), after finishing the 21 days program (tE2) and 3 months later (tE3). In the control group we also evaluated their participants at the very beginning of the trial (cE1) and then after 3 months (cE3). We compare the results within each group at different times of evaluation and then between the two groups, at the beginning and at 3 months. The data statistical analysis was performed using the SPSS (Statistical Package for Social Science) version 22.0. The analysis of the statistical meaning of the average differences among the evaluations was performed through the t Student test to dependent samples. The analysis of the differences of the found averages between the groups (control and experimental) also counted with the t Student test, but this time to independent samples. In both cases the null and the alternative hypothesis were implicit, and the assumed confidence interval was 95\% (the significance level was always maintained in 5\%: $\mathrm{p}<=0.05$ ). When we wanted to compare the statistical significance of percentages, we used the Chi-square $\left(\mathrm{x}^{2}\right)$, being also assumed the confidence interval of $95 \%$. Analysing the answers of the questionnaires with the Alpha of Cronbach $(\alpha)$ method, we could verify the existence of a good internal consistence in all the evaluations, so we concluded that there was enough validity to proceed to the statistical data treatment obtained in the two sample groups.

\section{Results}

It was verified an improvement in all the constant items of the evaluation instruments in our trial, in a statistically significant way. The referred improvements were maintained even after the ending of the therapeutic intervention, as demonstrated by the evaluation performed in the follow-up, on the third month after the beginning of the treatment. We also evaluate the percentage of patients in whom this improvement happened with clinical relevance. Having as reference the values that suggest that a decrease of the pain level is considered significant (from the clinical point of view) when it reaches a decrease of at least $19.9 \mathrm{~mm}$ in EVA, it was verified that effectively this decrease occurred in $75 \%$ of the patients $(n=45)$ between the first evaluation (tE1) and the moment after the treatment (tE2), having remained in time, because the equivalent to $68.3 \%(n=41)$ maintained this decrease of pain between $\mathrm{tE} 1$ and $\mathrm{tE} 3$. Both percentages found were significant $(\mathrm{p}<0.001)$.

Another clinical criteria to evaluate if there was a relevant clinical improvement, this time in terms of functionality of the patient, is based in the decrease of the WOMAC Physical Activity and WOMAC total values in $>=9.1$ points (when transformed dimensions from 0 to 100 points). After this procedure of values reconversion in a scale from 0 to 100 in WOMAC Physical Activity, we verified that $46.3 \%(n=26)$ of the patients decreased the difficulty in the performing of physical activity from tE1 to tE2 in at least 9.1 points. This effect lasted until the follow-up. Once 36. 7\% $(n=22)$ maintained this considerable decrease from tE1 to tE3. In both comparisons the found percentage is significant at level $p<0,01$. In what concerns the Total WOMAC, the decrease was even more evident. It was realized that, from $\mathrm{tE} 1$ to $\mathrm{tE} 2,71.7 \%$ of the patients $(n=44)$ lowered the score in $>=9.1$ points, demonstrating a reduction with clinical significance of the pain, the stiffness and the physical difficulties. The raise on the life quality in these dimensions maintained until the moment of the last evaluation, as the percentage of $66.7 \%(n=40)$ maintained the decrease of at least 9.1 points from tE1 to tE3. The found percentages are significant $(\mathrm{p}<0.001)$. 


\section{Discussion}

Despite the fact that this is not an intentional situation both samples have homogeneous sociodemographic characteristics. This situation may be due to the fact that analogue inclusion and exclusion criteria for both groups have been defined. The characteristics homogeneity of the samples demonstrates that the differences found in the results among evaluations must not be directly related to the personal characteristics of the patients, but associated to other factors, extrinsic to the participants. The most adequate statistic proceedings were adopted, in order to achieve the investigation goals, from the conception and adjustment of the database to the quotation and the inversion of the items and to the use of statistic tests more adequate to the type of variables in question. Rather acceptable internal consistence values were achieved in both scales, in both groups and in all the moments of the evaluation, and so we can finally affirm that there is internal validity of the obtained results. The obtained data correlate well with the previous studies, similar to ours, about the effects of balneotherapy in Gonarthrosis. There are, however, multiple aspects which motivate discussion of the results. The old and crucial question about the action mechanisms underneath the obtained effects deserves also a little of our attention, although it is not an objective to demonstrate in our trial.

\section{Conclusions}

The presented clinical trial is likely to demonstrate that the patients who have beneficiated from the thermal treatment improved in all the evaluated aspects after its conclusion, in comparison to the situation before the balneotherapy program and also in relation to the control group. We consider that this demonstration was achieved, regarding the validity of the performed clinical trial. Thus, the dimension of the study sample has proved to be adequate to the enunciated objectives and to the adopted methodology. It was verified a homogeneity of both the experimental and the control group in characteristics as important as the age, the gender and the body mass index, avoiding possible bias related with these coordinates. The statistical analysis if the obtains results was accurate and adequate. It was verified an improvement in all the items concerning the evaluation tools used in our trial, in a statistically significant way.

The referred improvements were maintained even after some time after the ending of the therapeutic intervention, as demonstrated by the evaluation in the follow-up, on the third month after the beginning of treatment. The percentage of patients in whom the improvements in pain (VAS) and in functionality (physical activity WOMAC and Total WOMAC) occurred in a considered clinically significant way was extremely relevant.

\section{Future Investigations}

The present conclusions lead us to possible and desirable future investigations. Among them we can consider the evaluation of health benefits of this balneotherapy program, separate and comparatively, according to the classification degree of Gonarthrosis; the comparison to other options of distinctive balneotherapy techniques; with different duration of treatments; in different ages; comparison of gender (masculine vs feminine); comparison to other types of waters (tap water, other mineral waters, sea water); comparison to programs composed by distinct therapeutic non-hydrotherapy or balneotherapy modalities (pharmacological and non- pharmacological) and finally cost-benefit studies.

\section{ISMH: which ways to the future}

Pedro Cantista, MD, PhD, (President-elected of the ISMH)

The history of the "International Society of Medical Hydrology" (ISMH) is made by a 94 year journey. Nearly a century. As with all institutions, a scientific society is not immune to the influence of political, social or economic throughout its existence; especially in this case, all this time. Despite the difficulties, which included a world war, the ISMH continues. This leads us to a logical conclusion, a very simple one: ISMH's right to exist. Our past has brought us famous people and significant progress in the knowledge of the subject of its essence: the Medical Hydrology. Progress was achieved by the results of research; by the dissemination of its results in numerous publications; by 40 international congresses organized; by educational actions through their own initiative courses or the participation of its members in scientific meetings; through its support to other institutions, associations, national scientific societies, universities.

At present its influence grows. Spread it out of Europe, their continent of origin. But their problems are serious. The arrival of new technological means requires changes in communication processes (particularly scientific communication) and traditional standards of the associations.

To prepare the future, we must go beyond this transition period. We need a strategy and operational means to continue to pursue all the objectives that led to the foundation of this society and that in essence are the same. We present this action plan, based on careful reflection on the past, the critical analysis of the present and a reliable prospect in the future.

Keywords: ISMH; hydrology; crenotherapy; balneotherapy; thermal medicine 


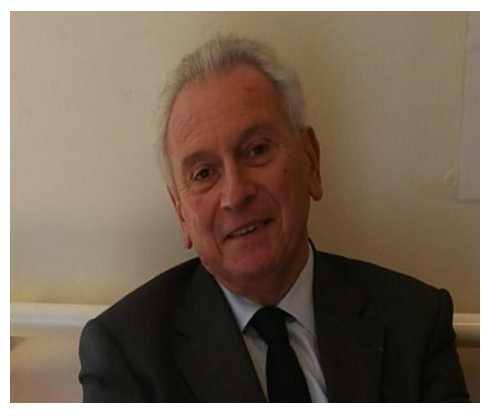

\section{Professor Christian-François ROQUES LATRILLE MD / France}

Emeritus professor of PRM - Toulouse University

AFRETH Scientific Committee President - Paris, cf.roques@gmail.com

Institut du Thermalisme President - University of Bordeaux - DAX

FEMTEC Vice-President

FTCF Vice President (french branch of the FEMTEC)

Educational Council Foreign Medical Graduate - USA - 1971

Certified in Rheumatology - 1974, Pathology - 1974, Immunology - 1975

Physical \& Rehabilitation Medicine - 1976, Public Health - 1977

\section{THE AFRETH (FRENCH ASSOCIATION FOR THERMAL RESEARCH), AN EXPERIENCE OF TEN YEARS, ACHIEVEMENTS AND PROBLEMS \\ CF Roques-Latrille MD}

AFRETH Scientific Committee President (Paris)

Emeritus Professor of Physical \& Rehabilitation Medecine, Toulouse-Sabatier University (Toulouse) France

Since its creation in 2005 October, the French Association for Thermal Research (AFRETH) fully implemented 11 call for projects. 113 Pre-projects were examined and 75 were made eligible to the programme ; 61 were validated by the scientific committee on the basis of specialized advices by external independant experts. Finally 41 projects were accepted for financial support; globally 11 Millions $€$ have been engaged and/or expanded.

23 studies have been fully implemented and 7 have been published in english speaking journals with impact factor ; 5 studies are still in the writing or submission time; the data of 4 studies are under assessment ; 6 $\mathrm{RCT}$ are in progress ; 5 RCT have still to be implemented.

The main scientific achievement can be summarized : i) a more comfortable body due to less pain from musculo-skeletal origin (Thermarthrose, Rotatherm) or venous origin (Thermes\&Veines) and more abilities in patients with musculo-skeletal conditions (Thermarthrose, Rotatherm), or after treated breast cancer (Pacthe). A better weight control in overweighted patients (Maathermes), in patients with metabolic syndrome (Prisme) or after treated breast cancer (Pacthe); ii) a stress under better control in patients with generalised anxiety disorders (Stop-Tag), or after treated breast cancer (Pacthe)(patients improved depression and sleep disturbances), allowing a psychotropic drugs (benzodiazepins) withdrawal (Specth); iii) a more healthy life style due to patients' education in metabolic conditions (Prisme), after treated breast cancer (Pacthe), in chronic venous conditions (Veinothermes), in elder with cognitive decline risk (MAPT) ; iiii) and at the end a better quality of life for patients after breast cancer (Pacthe), for patients with chronic cuff tendinitis (Rotatherm), chronic venous insufficiency (Thermes\&Veines), generalised anxiety disorder (Stop-Tag).

But studies concerning respiratory diseases, sickleave patients with chronic low back pain, deep venous thrombosis sequelae, failed to enrol a sufficient number of patients and were non contributive.

\section{BALNEOTHERAPY FOR CHRONIC PAINFUL CONDITIONS - DATA OF EVIDENCE}

Cf Roques-Latrille Md

Introduction. To assess the impact of balneotherapy on chronic pain, we examined randomized controlled trials (RCT) published in english journals with impact factor; they concerned relevant musculoskeletal (knee osteo-arthritis KOA -15 RCT-, chronic low back pain CLBP -10 RCT-, fibromyalgia FM -6 RCT-; globally 31 RCT enroling 2936 patients) and others conditions (vascular, neurological, digestive, gynaecological, post-cancer, dermatological: 15 trials). Material and method.For the patients with musculoskeletal conditions we could determine the effect size for KOA, CLBP and FM.The pain of patients with parkinson's disease or after treated breast cancer was not improved after balneotherapy; but pain was significantly improved in large cohorts of patients with digestive conditions assessed at 1 year (3872 patients with gastric dyspepsia and 3609 patients with iritable bowel syndrome); RCT showed that pain was significantly improved in patients with chronic peripheric arterial disease (balneotherapy with carbon dioxide), chronic venous insuficiency, pruritus in children with atopic dermatitis, women after treated breast cancer, women with gynaecological chronic pelvic pain. Results. The involved mechanisms concern pain control, other systems of defence of the body, action on the impairments. Conclusions. The role of the mineral dimension as been assessed comparing mineral water to tap water, mineral muds to inactive muds; these studies used to show a significantly better effect on pain for patients treated with the thermo-mineral products, but many of these trials have a limited statistical power. 


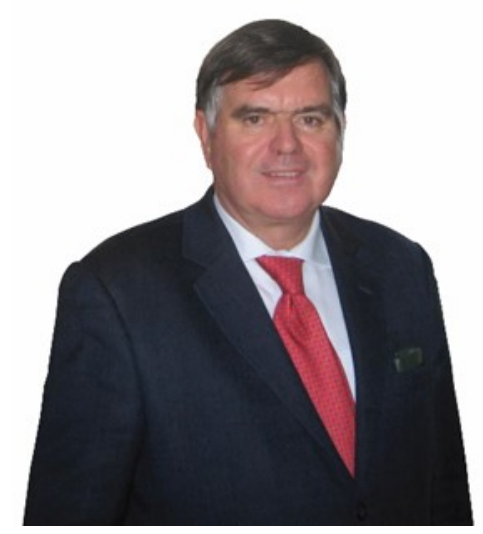

\section{Prof. Thierry Dubois}

Thierry DUBOIS has been the President of the French professional organization of health spa companies (CNETh) for six years. He is also the Chairman of the supervisory board of Thermes de Saujon (Charente-Maritime) and the Treasurer of the European Spas Association (ESPA).

\section{Perception of Balneotherapy by General Practioners A French survey by Thierry DUBOIS \\ President of the French professional organization of health spa companies (CNETh)}

Prescribing doctors of spa treatments are key partners in the balneotherapy field. Paradoxically, there are lots of unanswered questions as to the way they look at balneotherapy and their actual practices. This is the reason why the French union of spa companies decided to commission a survey 3 years ago with the goal of evaluating the perception and practices of General practionners. The survey was conducted via the internet among 500 doctors belonging to an access panel. The results show a positive assessment of balneotherapy but also plenty of opportunities to improve the knowledge and endorsement by GPs. One of the main lessons is the positive impact research undertaken to evaluate the actual medical benefit of spa cares had on the perception of balneotherapy. The final part of the survey elaborates on the expectations of GPs towards future developments in balneotherapy and the way it could contribute to manage chronic diseases.

\section{Prof. Albrecht Falkenbach, Bad Ischl}

\section{UV Exposure: Benefit and Risk \\ Albrecht Falkenbach, Bad Ischl}

Most publications deal with the risk of UV exposure, in particular with skin cancer development. On the other hand, there is growing evidence of the beneficial effects. Recently, possible benefits have gained growing attention, especially in oncology, osteology, angiology and cardiology.

Most benefits result from the UV-induced stimulation of vitamin D-precursors. After isomerisation of previtamin $\mathrm{D}$ in the skin, 25-hydroxylation in the liver and $1 \alpha$-hydroxylation in the kidney, the active form 1,25-dihydroxycholecalciferol may exert the beneficial effects in the prevention and treatment of several diseases, namely in rickets, osteomalacia and osteoporosis. Recent epidemiological studies point at benefits in colon-, breast- and prostate-cancer and arterial hypertension. Many more positive effects of UVexposure and higher vitamin D levels are under discussion, eg. an improved muscle function and a risk reduction of falls, improved fetal brain development and cognitive function in the elderly. Also, a risk reduction for metabolic diseases is being scrutinized. An UV-induced increase of vitamin D can be achieved by exposure to suberythemal doses of UVB-light, which, however, is deficient in northern Europe during wintertime. Humans at risk of vitamin D deficiency may benefit from winter sojourns in countries with abundant sunshine or exposure to artificial UV-light. 


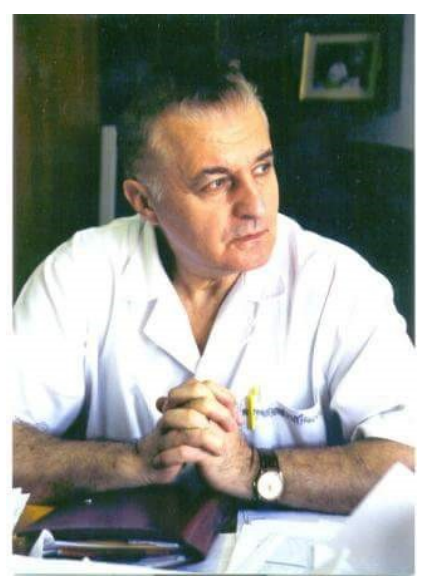

\section{Prof. Dr. Constantin lonescu Targoviste - Honorary President}

Current Occupation: Consultant Diabetes, Nutrition and Metabolic Diseases

Since 1972 teaching activity at the university clinic of Diabetes, Nutrition and

Metabolic Diseases in Bucharest, covering all levels up to the teacher. Lecturer at the Faculty of Medicine and Pharmacy in Bucharest (1976-1994)

Associate Professor (1994-1999); Professor 1999

Expert O.M.S. diabetes issues (1992-1995)

Expert of the European Community (1990) medical scientific research. Scientific research in the fields of diabetes (metabolic emergencies, epidemiological, etiopathogenic, genetics), diabetic neuropathy, nutrition, hypoglycemia, electrophysiology

PROFESSIONAL ACTIVITY:

2006-present Head of the Clinic for Diabetes, Diabetes Department Head 1997 -2006 Director of Institute of Diabetes, Nutrition and Metabolic Diseases "Prof. Dr. N. Paulescu ", Bucharest;

Since 1999 Professor of the University of Medicine and Pharmacy, Bucharest; Since 2000 Honorary Member of the Academy of Sciences in Chisinau; 2001-2003 President of the Society of Diabetes, Nutrition and Metabolic Diseases 2005 - present President of the Romanian Medical Association.

\section{WATER AND LIFE \\ C. Ionescu-Tirgoviste} National Institute of Diabetes, Nutrition and Metabolic Diseases N.C. Paulescu Bucharest, Roma-
nia;

Introduction.Water and Life is a conditional binom because what is called life on our planet depends on the presence of water in all its physical presentation: solid, liquid and gaseous. The evolution of life on our planet (plants, animals and humans) depends on the numerous chemical reactions which need the water molecule in the anabolic and catabolic processes associated with life. Otherwise, the great ancient philosophers (Aristotle, Plato, Thales, Heraclit, Empedocles and many others) included water in their philosophical debate. In all Chinese Medicine, water was one of the five elements (fire, metal, wood, earth and water) as a core of many old therapies including acupuncture and plant therapy.

Materials and methods.Despite its small molecule $(\mathrm{H} 2 \mathrm{O})$, the relationship between the atom of oxygen and the two atoms of hydrogen has some particularities which have not been so far clearly explained. It is interesting to see that the percentage of water on Earth is $71 \%$ which is quite similar with that in an adult human. Otherwise, historically speaking, all human civilization has flourished in proximity of major waterways. Romania is one of the blessed countries with numerous mineral drinking waters and also some mineral therapeutical waters.

Results.One of the most debated problems in the last decade was that of "memory of water", which was associated with the preparation of some homeopathic remedies. Considering the mysterious nature of its physical properties, this hypothesis is still on the table. The fact that the discovery of water channels in various tissues was made 1993 and awarded with the Nobel Prize

Conclusion.The freshwater (called also "the white gold of mankind") seems to be an exhaustible resource. If that is true, the far future generations will be obliged to move from the Earth to other more convenient planets. 


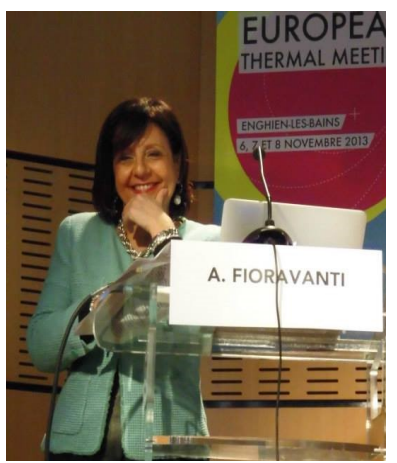

\section{Prof. Dr. Antonella Fioravanti}

Graduate in 1980 at the University of Siena (Italy) in Medical School, Major in Endocrinology, Rheumatology, $\mathrm{PhD}$ in Experimental Rheumatology, having since 1989 the charge of "Assistant of Professor" at the "Rheumatology Unit" of the General Hospital "Le Scotte" of Siena. Hold's office since 2004 for High Specialization in diagnosis and therapy of degenerative rheumatic diseases. Since 1982 is partner of "Italian Society of Rheumatology"(SIR), holding office of vice president of Tuscany Section of Rheumatology Italian Society ; from 2000 to 2004 President of the Tuscany Section of Italian League Against Rheumatic Diseases (LIMAR); since 2006 is member of Scientific Board of ISMH and since 2014 Scientific Leader (Vice-President) of ISMH.

The Dr holds teaching charges at Rheumatology Postgraduate School, Medical Hydrology, Genetics and Endocrinology. Her major research areas concern Osteoarthritis, Chondrocyte'culture and Medical Hydrology.

\section{OSTEOARTHRITIS, ADIPOKINES AND BALNEOTHERAPY}

Antonella Fioravanti, Sara Cheleschi

Department of Medicine, Surgery and Neuroscience, Rheumatology Unit, University of Siena, Italy Obesity constitute major risk factors for Osteoarthritis (OA) presumably due to excessive joint loading . However, several studies demonstrated that obesity is also a risk factor for nonweight-bearing joints. Obesity is nowadays considered as a chronic low-grade inflammatory status which is closely related to the release, by white adipose tissue, of many factors, most of them of proinflammatory nature, including classical cytokines such as interleukin (IL)-6, IL-1 $\beta$ and tumor necrosis factor (TNF)- $\alpha$, as well as adipokines. Adipokines, including leptin, adiponectin, resistin and visfatin may play an important role in the pathophysiology of OA. Leptin induces the expression of growth factors such as IGF-1 and TGF- $\beta$, stimulates proteoglycan and collagen synthesis, and increases the stimulatory effects of proinflammatory cytokines on nitric oxide (NO) production in chondrocytes. Leptin may also trigger cartilage destruction by increasing Metalloprotease (MMP)-9 and MMP-13. Adiponectin has been found to improve insulin sensitivity and to have anti-atherogenic properties. Adiponectin is detected in both synovial fluid and in plasma of OA patients and has been reported to increase the production of MMPs, cytokines and PGE2 by chondrocytes and synovial fibroblasts.

Resistin, has received attention for its involvement in insulin resistance in obesity and diabetes mellitus. Recent researches show that human resistin is expressed in immune cells and possesses many characteristics of a proinflammatory cytokine. Although the investigations regarding the role of resistin in OA are sparse, some studies showed its direct effect on cartilage matrix and cytokines production.

Visfatin has proinflammatory and immunomodulating functions and manifested a pro-degradative effect in cartilage by increasing the synthesis of MMP-3, MMP-13, thrombospondin motifs (ADAMTS)-4, and ADAMTS-5.

In two study we assessed the possible modifications of serum levels of leptin, adiponectin, visfatin and resistin in patients with knee OA treated with a cycle of mud-bath therapy. In the first study we showed at the end of the therapy, a slight but not significant increase of serum leptin concentrations and a significant decrease in serum adiponectin levels.

In a second controlled trial, at the end of the mud-bath therapy, serum adiponectin and resistin levels showed a significant decrease; no significant modifications were found in serum visfatin.

Partial contradictory data were observed in a recent pilot study conducted by Shimodozono et al. The differences might be due to the characteristic of the subjects studied and to the modalities of bathing.

In conclusion, these studies show that balneotherapy and/or mud-bath therapy can modify serum levels of adipokines. However, it remains to be clarified which of the mechanisms of action of mud-bath therapy could determine the changes observed.

\section{References}

$\mathrm{Hu}$ PF, et al (2011) The emerging role of adipokines in osteoarthritis: a narrative review. Mol Biol Rep 38:873

Fioravanti A,et al. (2011) Effects of spa therapy on serum leptin and adiponectin levels in patients with knee osteoarthritis. Rheumatol Int 31:879

Fioravanti A, et al (2015) Circulating levels of adiponectin, resistin, and visfatin after mud-bath therapy in patients with bilateral knee osteoarthritis. Int J Biometeorol 59:1691

Fioravanti A, et al (2014) One-year follow-up of mud-bath therapy in patients with bilateral knee osteoarthritis: a randomized, single-blind controlled trial. Int J Biometeorol 59:1333

Shimodozono M, et al (2012) Acute effects of a single warm-water bath on serum adiponectin and leptin levels in healthy men: a pilot study. Int J Biometeorol 56:933 


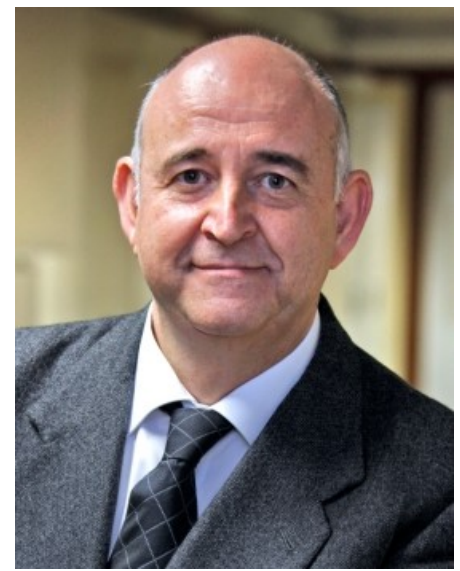

\title{
Prof. Francisco Maraver
}

MD specialist in Medical Hydrology

PhD from the Complutense University of Madrid (UCM)

Medical Hydrology Professor of Medicine Faculty of UCM

Director of Professional School of Medical Hydrology and Hydrotherapy

Director of "911757 Medical Hydrology" UCM Research Group

President of the Spanish Society of Medical Hydrology

President of the Iberoamerican Society of Peloids

FEMTEC Councellor

Member of Advisory Committee of Expourense-Termatalia

President - Scientific Committee of Instituto de Investigación A gua y Salud

Scientific Commitee Member of ISMH

Director of Anales de Hidrología Médica (2006-2012)

Director of Boletín de la Sociedad Española de Hidrología Médica

Director Monograph Series Balnea

President of $38^{\mathrm{th}}$ ISMH Congress

\section{EVOLUTION OF THE ISMH THROUGH ITS INTERNATIONAL CONFERENCES (1982 - 2015)}

\author{
F. Maraver*, J.M. Carbajo*
}

* Research Groups UCM-911757 (Universidad Complutense de Madrid, Medical Hydrology).

INTRODUTION: Since founded in London in 1921, the International Society of Medical Hydrology and Climatology (ISMH) has organized 40 world congresses. The aim of this work is to study the evolution of the ISMH through its international conferences from 1982 to 2015.

MATERIAL - METHODS: Sources used are different Abstracts Books of the meetings held during the period indicated: Ponta Delgada-Azores (Portugal) 2-6/5/1982; Vittel-Contrexeville-Nancy (France) 3-8/11/1986; Madrid (Spain) 5-9/6/1989; Bad Woerishofen-Bad Nenndorf (Germany) 2427/4/1994; Karlovy Vary-Prague-Luhacovice (Czech Republic) 4-11/10/1998; Budapest-Heviz (Hungary) 14-19/10/2002; Istanbul (Turkey) 6-10/6/2006; Porto (Portugal) 25-28/6/2008; Paris (France) 2326/6/2010; Lanjarón-Granada (Spain) 20-23/6/2012; Kyoto (Japan) 11-14/5/2014 and Rio de Janeiro (Brazil) 26-28/8/2015. Each Congress, are collected: number, types and topics of papers presented, as well as country of provenance.

RESULTS: Of the 12 congresses held, draws attention that at the beginning were held every four years, starting in 2006 every two years and from 2014 annually. We think that although a congress of the ISMH helps Thermal Medicine in the country where the congress is held, the General Assembly in Bucharest, must decide on the suitability of continuing to hold the congresses annually.

\section{REFERENCES:}

[1] Bulangé M. La presence française au sein de 1' ISMH. In: Florilege Thermal. Les 150 ans de la Societe. Paris: Societe Française d'hydrologie et de Climatologie Medicales. 2006: 19-26

[2] Cantista P. ISMH: which international socity for which aims?. Press Therm Climat 2015;152: 105-111

[3] Karagülle MZ. ISMH and Balneology Research. Proceedings of the VII Congresso International Soc. Portuguesa de Hidrologia Médica, 5-7 june 2014, Termas de Luso (Portugal)

[4] Messini M. History of the International Society of Medical Hydrology and Climatology (1922-1966). Pisa: Nistri-Lischi; 1966
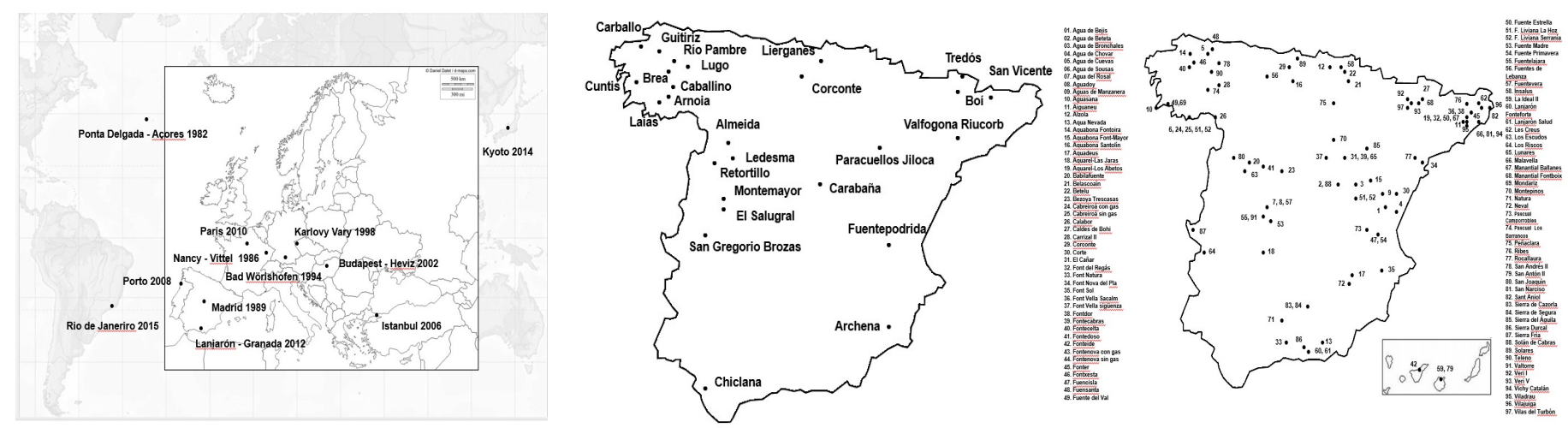


\title{
SULPHUR WATERS OF SPANISH SPAS
}

\author{
F. Armijo*, I. Corvillo*, I. Vázquez*/**, J.M. Carbajo*, F. Maraver* \\ * Research Group UCM-911757 (Complutense University of Madrid, Medical Hydrology) \\ ** Geological Survey of Spain (IGME)
}

INTRODUCTION: In Spain, sulphur mineral waters are considered those waters with more than $1 \mathrm{mg} / \mathrm{l}$ of reduced sulphur (valence $\left.2^{-}\right)$, as the sulfhydric acid $\left(\mathrm{SH}_{2}\right)$ and the bisulfide ion $\left(\mathrm{SH}^{-}\right)$. The aim of this work was to determine these substances in 91 mineral water samples of Spanish spas [1].

MATERIAL-METHODS: Samples were collected from springs mineral waters. The sulphur must be immediately fixed by adding $\mathrm{NaOH}$ and zinc acetate. At our laboratory, reduced sulphur content was iodometrically titrated. $\mathrm{SH}_{2}$ and $\mathrm{SH}^{-}$concentrations were calculated as a function of the temperature, dry residue, conductivity and $\mathrm{pH}$ value [2].

RESULTS - CONCLUSIONS: Out of the 91 spas waters analysed, 26 (28.5\%) can be classified as sulphur waters. Other 6 samples $(6.6 \%)$ present reduced sulphur but not at the required level to be considered as sulphur waters. The concentration ranges from 42 to $1 \mathrm{mg} / \mathrm{L}$. Out of the 26 sulphur water samples, 19 are oligomineral waters and from the seven samples that exceed $1000 \mathrm{mg} / \mathrm{l}$, three of them are sulphated, one chloride and three chloride sulphate water samples.

The attached map shows an important number of spas with sulphur waters located at north-west of Spain, in the regions of Galicia and Castilla-León, on the Hercynian Massif Domain formed by a great variety of Palaeozoic materials associated with deep water flows [3].

There are no correlations between the content of reduced sulphur and other analytes and parameters, such as dry residue, predominant mineralization, temperature and radioactivity.

\section{REFERENCES:}

[1] Armijo M, San Martín J. Curas Balnearias y Climáticas, Talasoterapia y Helioterapia. Madrid: Complutense Ed.; 2010.

[2] APHA, AWWA, WEF. Standard methods for examination of water and wastewater. 21st ed. Washington: Centennial Ed.; 2005.

[3] Maraver F, Armijo F. Vademecum II de aguas mineromedicinales españolas. Madrid: Complutense; 2010.

\section{MAGNESIUM CONTENT OF SPANISH NATURAL MINERAL WATERS}

F. Maraver*, I. Vitoria**, J.M. Carbajo*, C. Morer*, F. Armijo*

* Research Group UCM-911757 (Complutense University of Madrid, Medical Hydrology)

** Nutrition and Metabolopathies Unit, Hospital La Fe. Valencia

INTRODUCTION: An appropriate magnesium intake has proved to have beneficial effects on bone health, reduce insulin resistance and prevent atherosclerosis. Our objective was to determine the concentration of magnesium in bottled mineral water in Spain and assess its daily contribution to dietary recommendations.

MATERIAL-METHODS: We used ion chromatography to analyse the magnesium concentrations of 97 spanish natural mineral waters.

RESULTS - CONCLUSIONS: The average magnesium concentration of 97 brands of Spanish natural mineral water was $16.2 \mathrm{mg} / \mathrm{L}$ (range: $0.1-141.2 \mathrm{mg} / \mathrm{L}$ ). Of these, 33 contained between 15 and $45 \mathrm{mg} / \mathrm{L}$ of magnesium and four contained over $45 \mathrm{mg} / \mathrm{L}$.

Assuming water consumption is as recommended by the European Food Safety Agency, water containing 15 to $45 \mathrm{mg} / \mathrm{L}$ of magnesium provides between 9 and $76.5 \%$ of the recommended intake of magnesium for children aged one to thirteen, up to $25.7 \%$ in adolescents, between 7.5 and $25.7 \%$ for adults, and up to $27 \%$ for lactating women. Water with $60 \mathrm{mg} / \mathrm{L}$ of magnesium provides between 30 and $102 \%$ of the recommended dietary allowance, depending on the age of the individual.

The consumption of natural mineral water can be regarded as an important supplementary source of magnesium, given its bioavailability and usefulness as a healthy form of hydration

\section{REFERENCES:}

[1] APHA, AWWA, WEF. Standard methods for examination of water and wastewater. 21st ed. Washington: Centennial Ed.; 2005.

[2] EFSA. Panel on Dietetic Products, Nutrition, and Allergies (NDA); Scientific Opinion on Dietary reference values for water. EFSA Journal 2010; 8:1459.

[3] Maraver F, Vitoria I, Ferreira-Pêgo C, Armijo F, Salas-Salvadó J. Magnesium in tap and bottled mineral water in Spain and its contribution to nutritional recommendations. Nutr Hosp. 2015 May;31(5):2297-2312

[4] Petraccia L, Liberati G, Masciullo SG, Grassi M, Fraioli A. Water, mineral waters and health. Clin Nutr. 2006;25(3):377-85. 


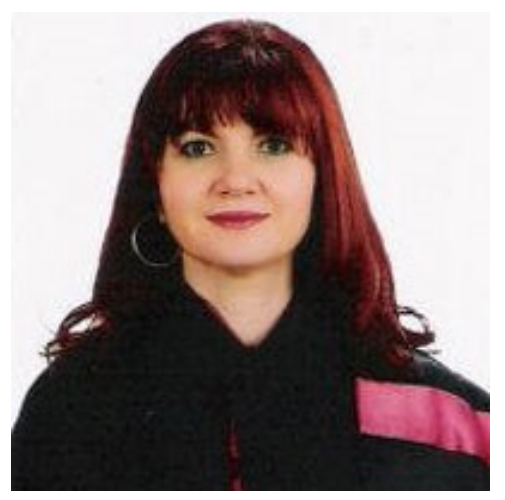

Assoc. Prof. Dr. Mine Karagülle

Istanbul University, Faculty of Medicine, Turkey

Department of Medical Ecology and Hydroclimatology

\section{SPA THERAPY FOR OLDER PATIENTS WITH OSTEOARTHRITIS}

Mine Karagülle

Istanbul University, Istanbul Medical Faculty, Department of Medical Ecology and Hydroclimatology

mkgulle@istanbul.edu.tr

INTRODUCTION. Very few studies tested the effectiveness of spa therapy in older patients with osteoarthritis. Therefore, we aimed to evaluate the short-term effects of spa therapy in patients aged 65 years and older with generalized, knee, hip and cervical and lumbar

spine osteoarthritis.

MATERIAL AND METHODS.In an observational retrospective study design at Medical Ecology and Hydroclimatology Department of Istanbul Medical Faculty we analyzed the records of 239 patients aged over 65 years with the diagnosis of all types of osteoarthritis who

were prescribed a spa therapy course in some spa resorts in Turkey between 7 March 2002 and 31 December 2012. They travelled to spa resort where they stayed at thermal spa hotel and followed usual therapy packages for two weeks. Patients were assessed by an experienced physician within a week before the spa journey and within a week after the completion of spa therapy.

RESULTS. As compared with baseline in whole sample statistically significant improvements were observed in pain (Visual Analogue Scale, VAS), patient's and physician's global assessments (VAS), Health Assessment Questionnaire Disability Index (HAQ-DI),

Lequesne Algo-Functional Index (LAFI) for knee, Western Ontario and McMaster Universities Index (WOMAC), Waddell Disability Index (WDI) and Neck Pain and Disability Scale (NPAD). According to Outcome Measures in Rheumatology - Osteoarthritis Research Society International (OMERACT-OARSI) Set of Responder Criteria, responder rate were 63.8\% (51/80) in generalized, 52\% (13/25) in knee, 50\% $(2 / 4)$ in hip, 66.7\% (8/12) in lumbar and 100\% (6/6) in cervical osteoarthritis subgroups.

CONCLUSIONS. Spa therapy improved pain and physical functional status in older patients with osteoarthritis especially generalized osteoarthritis and multiple-joint osteoarthritis with involvement of knee. This improvement was clinically important in majority of the patients. To confirm the results of this preliminary study there is a need of a randomized controlled clinical study comparing spa therapy with usual care in elder population with osteoarthritis. 


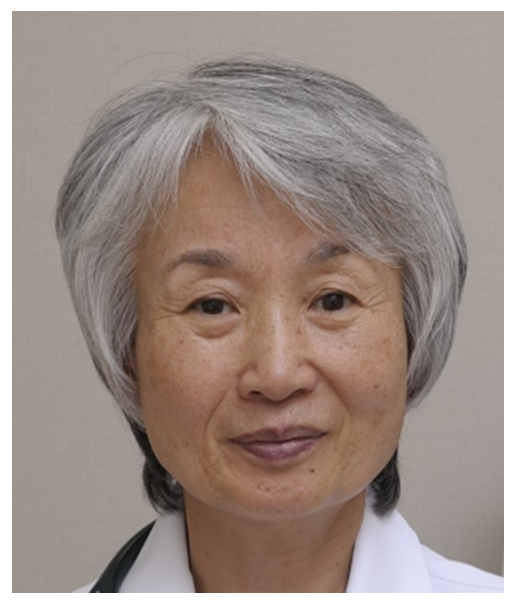

Prof. Shigeko Inokuma, M.D.

Chiba Central Medical Center,

1835-1 Kasori-cho, Wakaba-ku, Chiba-shi, Chiba, 264-0017 Japan

Tel: +81-4-3232-3691, Fax: +81-4-3232-9100, E-mail: inokuma-

alcl@umin.ac.jp

WORK Chiba Central Medical Center, Chiba

Director, Department of Allergy and Rheumatic Diseases

Kohnodai Hospital, National Center for Global Health and Medicine,

Chiba

Japanese Red Cross Medical Center, Tokyo

Dokkyo Medical University, Tochigi

Showa University, Tokyo

ACADEMIC SOCIETY ACTIVITY

The Japanese Society of Balneology, Climatology, and Physical Medicine

Former Chairperson of the Board

Chairperson, Authorized Balneotherapy Doctors' Association

The Japanese College of Rheumatism

Former Board Member

The Japanese Society of Allergology

Former Board member

EDUCATION

\title{
AMELIORATION OF THERMAL DISPARITY OF FINGERS BY WARM CO2 BATHING IN CONNECTIVE TISSUE DISEASE PATIENTS.
}

\author{
Shigeko Inokuma ${ }^{12)}$, Yasuo Kijima ${ }^{3)}$, \\ Department of Allergy and Rheumatic Diseases, Japanese Red Cross Medical Center, Japan \\ Department of Allergy and Rheumatic Diseases, Chiba Central Medical Center, Japan \\ Laboratory Center, Japanese Red Cross Medical Center, Japan
}

\section{INTRODUCTION AND OBJECTIVES}

Disparity in temperatures of fingers has been shown as a useful parameter for vascular involvement in connective disease (CTD) patients (Horikoshi, M \& Inokuma, S Intern Med 55:461,2016). To study whether the disparity might be ameliorated by balneotherapy, hands immersion in warm CO2 water was adopted and evaluated.

\section{PATIENTS AND METHODS}

CTD patients who underwent thermographic observation of fingers before and after $\mathrm{CO} 2$ bathing were included. After resting in a room at a temperature of $25^{\circ} \mathrm{C}$, hands were immerged in $42^{\circ} \mathrm{C}$ bath containing 1000 ppm CO2 for 10 minutes. From prior to $30 \mathrm{~min}$. after the bathing, 10 nailfolds temperatures were measured by thermography. Standard deviation (SD) of nailfold temperatures was adopted as indicator of disparity.

\section{RESULTS}

Nine patients were included, who were all females. Mean SD prior to $\mathrm{CO} 2$ bathing was $1.14^{\circ} \mathrm{C}$. It became 0.47 just after bathing, and 0.51 (3 min.), 0.51 (5 min), 0.42 (10 $\mathrm{min}), 0.47$ (15 $\mathrm{min}), 0.57$ (20 $\mathrm{min})$, and 0.80 (30 min after bathing). Patients with a larger SD prior to bathing showed a more decrease after bathing (data not shown).

\section{CONCLUSION}

$\mathrm{CO} 2$ bathing ameliorates disparity of finger temperature, which was reported as an indicator of vascular disturbance in CTD patients. 


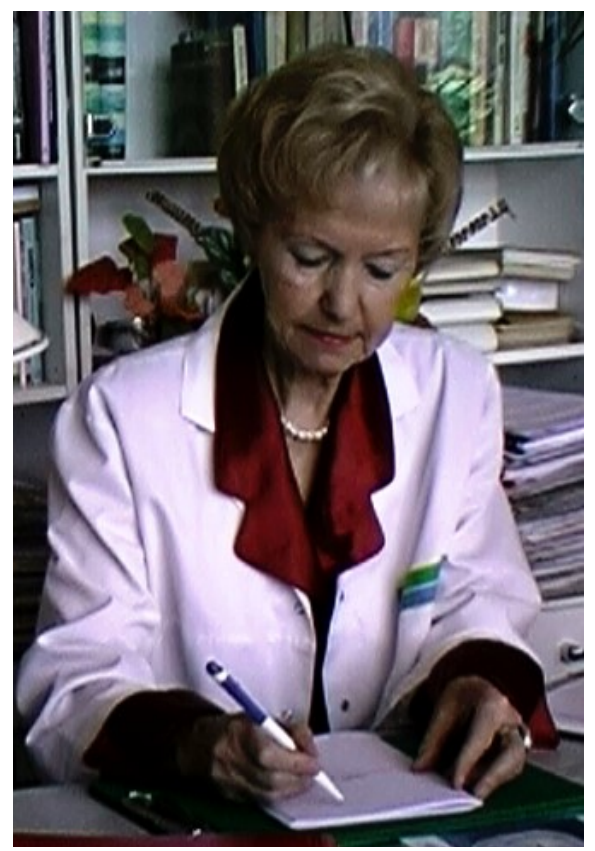

\section{Prof. dr hab med. Irena Ponikowska}

Address: 87-720 Ciechocinek, Chopina 23, Poland email: iponikowska@poczta.onet.pl tel.+48606184821

Presens appointment

Head Of Chair and Dep. Balneology and Physical Medicine

Collegium Medicum in Bydgoszcz Copernicus University Torun

Head of Hospital Thermal Medicine in Ciechocinek

President Elect of Polish Balneology and Physical Association Quolifications:

Full Professor of medicine, from 1999

Specialist in Balneology and Physical Medicine and Diabetology

Beckground, Publications:

Articles published i medical journal 198 and Books 13,

Monography 8

Chapter of books 17, total 236

Supervision (promotor) af doctoral dissertations 12

Influence of balneotherapeutic program on microcirculation and total antioxidant status in diabetic patients

Ponikowska Irena, Tolodziecki Michat

Chair and Department Balneology and Physical Medicine Collegium Medicum University in Toruń, Poland

Introduction and aim. In diabetic patients disturbens in mircrocirculation can observe since initial stage of disease. It is a reason of many serious arterial complications of diabetes. In diabetic patients oxidative stress is associated with metabolic and vascular complications. Some balneological procedures have influence on microcirculation but there is not much scientific evidences.

The aim of our study was to define influence of balneotherapy on two very important processesmicrocirculation and oxidative stress.

Material: 25 diabetics type 2 without clinical symptoms of microcirculation disorders in lower extremities. The time of diabetes was everage 21,8 years. Most of them were treated by insulin injections. All patients have been well controlled of diabetes.

Methods: Treatement program consist with 3 balneological procedures which were, applied everyday for 21 days (a period of thermal therapy). The following procedures were provided: CO2 bath, salt bath with exercise and peat paste poultices. Microcirculation and Total Antioxidant Status 1(TAS) had been done before and after treatment. Microcirculation was determined by laser-doppler methode in oclusion test. TAS was examined in serum by immunological test (ELISA)

Results: We received high statistical important changes in most parameters of the test microcirculation: increased of MAX ( $0,82857 \mathrm{pu}-0,950571 \mathrm{pu})$ increased of TL and TM. In every patients there were increased level of TAS( average 158,82- 378,98 micromol/1). The differences between these value were very strong statisticly significant. In addition we observed the decrease of average values of toatl and LDL cholesterol after the treatment, but not chanege in the level of uric acid.

Conclusion: Our study has proven beneficial effect of balneotherapy on microcirculation and increase of total antioxidant staus in diabetic patients. Increasid TAS we can explain with improvement of microcirculation and decrease of oxidant stress 


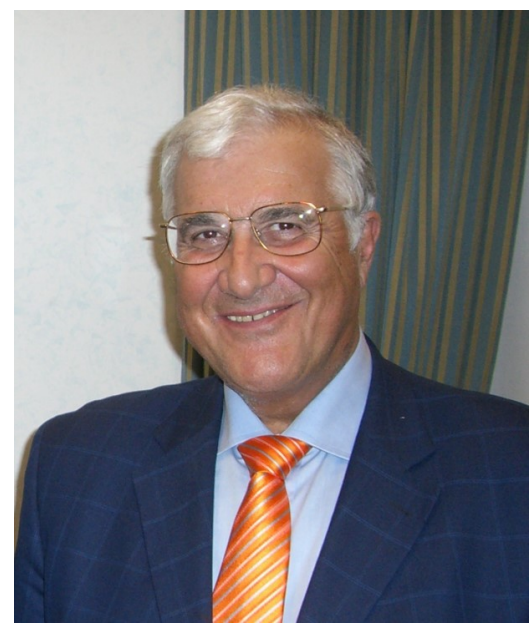

\section{Prof. Umberto Solimene}

Prof. Uumberto Solimene, born in Milan (Italy)

Professor of Medical Therapy and Thermal Medicine, at the Medical School of the State University of Milan ( Italy) TERAPIA MEDICA E MEDICINA TERMALE

Director of the World Health Organization Collaborating Center fo Traditional Medicine

President of the World Federation for Hydrotherapy and Climatotherapy (FEMTEC, NGO,in official relations with WHO (www.femteconline.org)

President of the European Association of Medical Wellness(AEMB) President of the Steering Scientific Committee of " THERMAE CAMPUS “ ( www.thermaecampus.it)

Editor in Chief Journal on online " THERMAE \& SPA MEDICINE " (www.spamedjournal.org )

President IItalian Chinese Medical Society ( founded in the 1973)

Scientific Cohordinator of the Agreement between State Milan University and STAR City ( Moscow), concerning the researches and use of Medical Spa for Cosmonauts rehabilitation after the flight mission.Agreement between Milan ( Italy) State University and Russian Training Center fo Cosmonauts

Author of more then 350 pubblicazions and 8 monographs in the field of medical Hydrotherapy and Bioclimatology and Complementary Medicine General Scientific Cohordinator for the "Consultations" WHO.:on Traditional medicine ( www.who.int) and Bench Marking for the training in Traditional medicine; Expert of WHO ( Geneva)

Cohordinator del Master Course 2 Level "Medicina termale, Talassoterapia e Climatologia Medica

\section{WATER IS LIFE, WELLNESS AND HEALTH}

Manifesto

Water is essential for our body to function. It helps digestion, absorption of nutrients and elimination of indigestible metabolic wastes, and also facilitates blood circulation. Water carries nutrients and all other substances across our body and regulates body temperature. Water is essential for human life as physically and biochemically all biological processes need water to occur.

As part of a healthy diet, water ensures proper hydration at any age. Drinking the right amount of quality water is vital considering how important hydration is for people's health and wellness, cognitive abilities, physical performance and regulation of body temperature.

By removing toxins, water detoxifies our body and makes it stronger, reinforcing its self-healing ability and enhancing health. As a detoxifying agent, water is crucial to prevention and cure.

The World Health Organization (WHO) sees water as a resource that is key to promote health and wellness of individuals and communities around the world. In 1994, the European Commission's Scientific Committee on Food (Italy's Daily Reference Intakes -LARN - 1996) stated that a healthy diet is to include not only vitamins but also minerals and water in the respective recommended daily intake amounts, to maintain fluid and electrolytes balance. That was the first time dietary reference intakes included water, recognizing its key role in human diet and body functions.

Water is the best fluid for hydrating the human body. This is to be made clear, especially in Western countries where obesity is on the rise and has been associated with high-calorie drinks that often replace water as a source of fluids. 


\section{Mr. Rzig Oueslati}

\section{Public Service Counselor}

General Manager of the National Office of Thermalism and Hydrotherapy Vice-President of The International Federation of Thermalism and Climatism

Bachelor's degree in Public Law

Bachelor's degree in Hospital Management

Diploma in Public Management

President of the Medical Committee - President of the National Commission of Packaged Waters

President of the National Commission of Thermalism and Fresh Water Therapy

President of the National Commission of Thalassotherapy

Member of the Management Board of the Informatics Center of the Ministry of Health

\section{HYDROTHERAPY IN TUNISIA}

\section{Mr. Rzig Oueslati}

Hydrotherapy is the external use of thermal water or Sea water or tap water in all forms and ways. Water can be used in solid form, liquid or gas and at varying temperatures for therapeutic purposes

Thermalism is defined as the implemented set of medical, social, sanitary, administrative and hospitality means to use mineral and thermal waters, thermal gases and mud for therapeutic purposes. Thermalism as a term denotes the use of a water whose curative virtues are recognised by the medical profession. In Tunisia, thermalism is not a new mission. It is a millenary heritage which, with time and the civilisations that marked the country's history, was enriched time and again. To this day, the vestiges of Phoenician baths are still standing in the town of Outhna, but it was in the Carthaginian and Roman times that thermalism lived its heyday: Bulla Regia, Dougga, Makthar, Sbeïtla, Capsa and Carthage with its grandiose Antonine Baths. With the Arab Conquest, the nature of thermalism did not change. Hammams became part of the thermal vocabulary. They are the worthy inheritors of the Roman lifestyle. Their relaxing virtues account for their popularity among Tunisians. During the colonial period, hammams supported the development of contemporary thermalism, thermal centres and spas. Tunisia's economic growth and the new needs generated by its economic development have stimulated the sector of thermalism as a treatment and a recreation. There are more than 100 thermal water springs in Tunisia. Their particular chemical composition gives them widely recognized therapeutic virtues. Patients are directed to thermal centres with a water mineral composition that is adapted to their pathologies.

Thalassotherapy - It is defined as the combined use of the benefits of the marine environment, under medical supervision, for preventive or curative purposes. Such benefits include marine climate, seawater, algae, sand and other sea extracts. Tunisian thalassotherapy is renowned for the quality of its centres, open for the pleasure of curists all year round. The specificity of Tunisian thalassotherapy is that it knew how to combine the requirements of rigour and quality with the tourism stakes of a sunny destination. Its originality lies in using ancestral traditions to renew the practice of thalassotherapy. Between tradition and top-level performance, pleasure and medical treatment, Tunisia found a perfect balance. Thus, it has seduced the knowledgeable customer rather than the novice. The thalassotherapy is an important development factor in regional development, medicine and alternative medicine. Thanks to the excellent level of Tunisian medical know-how, top-quality service and strict sanitary standards, Tunisian thalassotherapy has achieved a great success. Since 1994, thalassotherapy as a new orientation for a Medical tourism of excellence has considerably evolved. State support for investors encouraged operators to engage with this new concept, turning thalassotherapy into a structuring product. Combining the most advanced technology and the high performance of competent professionals and ensuring the balance between hotel and medical management in terms of utmost rigour and quality, site beauty and weather ildness, destination safety and reputed hospitality, thalassotherapy has become a full-blown activity and an intrinsic value of Tunisia as a tourist destination.

Spas-The well-being sector and more specifically the Spa sector has experienced unparalleled growth in Tunisia over 340 spas centers were identified in 2015 distributed between hotels and urban spas. 


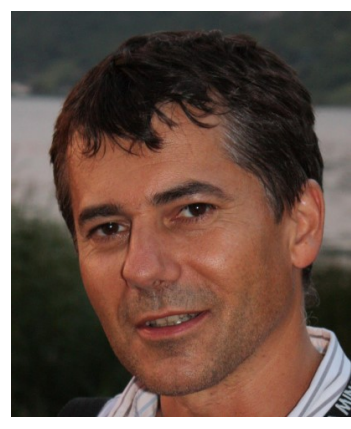

\section{Dr Romain FORESTIER}

\section{Spa Therapy in chronic low back pain: a systematic review}

\section{Dr Romain FORESTIER, Dr F. Begüm EROL FORESTIER, Dr. Alain FRANCON,}

Centre de recherche rhumatologique et thermal, Aix-Les-Bains, France

Introduction

Chronic back pain is a public health issue which has an impact on the functional abilities of patients and causes high economic and social cost.

Considering that approximately $80 \%$ of people have lumbar pain at one time or another in their life chronic back pain is a common condition [WHO 2003]. On the other hand, low back pain frequently affects patients during the periods when they are most productive [erilch 1999]. In addition, epidemiological studies show an increase in the prevalence of low back pain (3.9\% in 1992 to $10.2 \%$ in 2006 in the US population [freburger 2009]). In a study performed in 2010, it was estimated that low back pain was the $6^{\text {th }}$ most common disease between 271 disease studied with a prevalence of $9.4 \%$ and the $1^{\text {st }}$ cause of disability in the world with 58.2 million DALYs (number of years lived with disability) [Hoy 2014].

Some clinical practice guidelines suggested spa therapy in the treatment of chronic low back pain [sbu 1998] [HAS 2000] due to the studies conducted by the University of Nancy in the 90's [guillemin 1994] [constant 1995] [constant 1998].

The purpose of this review is to identify the best level of evidence on the impact of spa therapy and its components on chronic low back pain.

\section{Method}

Systematic research was performed in January 2016 on MEDLINE by Pub Med, Cochrane Central Register of Controlled Trials database and PEDRO databases.

Trials were included if they were comparative, if at least one of the groups had low back pain, if the results were reported separately for low back pain, if the spa treatment or any of its components using mineral water was compared to any other intervention or to no treatment.

The statistical validity, external validity, quality assessment of adverse effects are evaluated by personal checklist. The risk of bias (internal validity) is evaluated by the CLEAR NTP checklist.

Publication bias was assessed by the graphical method of Sutton. When the heterogeneity of the proposed programs, care durations and control treatments were considered, it was not relevant to perform a metaanalysis.

\section{Conclusions}

Multi components programs in spa centers seem to be able to improve pain, functional capacity and sometimes drug consumption and quality of life in chronic low back pain. Radon baths and CO2 injections do not appear to provide any additional benefit to multi components programs delivered in spa centers.

Overall, the level of proof is not sufficient for any definitive conclusion and more rigorous trials are needed to determine the effect of spa treatment in chronic low back pain. 


\section{Does spa therapy improve the back pain more than education program in spinal osteoarthritis? A randomized clinical trial. The LOMBATHERM' Study}

Dr Romain FORESTIER, Dr. Alain FRANCON, Dr F Begüm EROL FORESTIER, CENTRE DE RECHERCHE RHUMATOLOGIQUE ET THERMAL, Aix-Les-Bains, France

The document below describes a clinical trial on spa therapy in chronic low back pain related to spinal osteoarthritis.

\section{Justification for this search}

Chronic back pain is a public health issue which has an impact on the functional abilities of patients and causes high economic and social cost.

\section{Research Objectives}

To evaluate therapeutic effects of spa therapy in chronic low back pain

\section{Study population:}

Patients with painful low back pain for at least three months and spinal osteoarthritis on X-Ray. To facilitate the procedure, the recruitment will target a radius of $30 \mathrm{~km}$ around each spa center.

European patients in a European spa center agreeing to participate in the study (France, Portugal, Spain, Italy, Hungary, Austria, and Turkey)

\section{Method of investigation}

It is probably necessary to include around 400 randomized patients in order to observe a clinically relevant difference between the two groups, taking into account the various specificities of each center participating.

Patients in the first group will receive a full spa treatment under medical supervision while patients in the second group will receive a therapeutic education program.

Patients will be evaluated by the examining physician at the $1^{\text {st }}$ and $6^{\text {th }}$ months. The physician will have no conflict of interest with spa therapy).

\section{Methodological characteristics}

The Declaration of Helsinki $(\mathrm{DoH})$ rules will be followed: approval of the ethics committee, informed consent of the patients, and the insurance of the trial will be maintained.

It will be a preference randomized trial: patients who prefer the spa treatment will receive the spa treatment, and those who prefer the therapeutic education program will receive the therapeutic education program. Only patients having no preference will be randomized. Randomization will be stratified according to the spa center and to the possibility of a professional activity (retired and not retired patients).

Blinding: There will be a blinding of randomization for patients examining physicians, care providers and statisticians. The examining physician will not have any knowledge about the patients' groups or their previous answers. Intention to treat analysis: patients will be analyzed in the group in which they were randomized. They will be analyzed even if they have not received all the planned treatment. The loss to follow up will be considered as failures. The protocol will be registered in the www.clinicaltrial.gov site in order to have the possibility of publication in high impact factor journals.

The study duration is 6 months for each patient.

\section{Judgment Criteria}

PRIMARY ENDPOINT

Number of patients with clinically relevant improvement at 6 months in pain (VAS $=15 \mathrm{~mm})$ and $/$ or function (Oswestry Disability Index $=30 \%$ ).

\section{SECONDARY ENDPOINTS}

Number of patients finding themselves in a clinically acceptable condition (=Patient acceptable Symptom State).

Variations in pain (VAS) and Oswestry Disability Index

Variations in FABQ Scale (Fear Avoidance Belief Questionnaire)

Functional test: Five-Times-Sit-to-Stand Test

Change in lumbar mobility: Schöber index, hand ground distance

Patient's and physician's opinions on improvement

Changes in Quality of Life Questionnaires EQ5D

Changes in associated treatments: drug consumption, physical therapy, local injections, hospitalization, health care consumption. 


\title{
Dr. Alain Françon
}

MD, Rheumatologist, Aix-les-Bains (France)

Treasurer of the International Society of Medical Hydrology (ISMH)

General Secretary of the French Medical Society of Thermal Medicine (FMCTM)

General Secretary of the Aix-les-Bains' Rheumatologic and Thermal Research Center

Secretary of the "Semaine de Rhumatology" (Aix-les-Bains' Rheumatology Congress)

Member of the French Society of Rheumatology

Graduate from the Certificate of Study Statistics Applied to Medicine

Former Paris Hospitals Intern and former Head of clinic of the Universities, Assistant of the Hospitals of Paris

\section{Why you should calculate the sample size?}

\author{
Dr Alain Françon, Dr Romain Forestier, Dr F Begüm Erol Forestier \\ Centre de recherches rhumatologiques et thermales, Aix-Les-Bains, France
}

Calculating the sample size (number of patients to include in a study) is a key step in the construction of the protocol of a randomized clinical trial (RCT). Unfortunately only few RCTs on balneotherapy present a preliminary sample size calculation.

The sample size can be estimated by the Casagrande \& Pike method. It depends on various parameters: The expected difference in response to the treatment, to the control intervention and their variability for the primary endpoint,

Two percentage chosen by the statisticians:

The a risk is the risk of finding a between group difference by chance. It is usually 5\%

The risk $b$ is the risk of lack of difference by lack of statistical power; usually ranging between 5-20\%. The value " $1-b$ " is the "power"; the probability to find a between group difference that is real.

The type of comparison: The unilateral comparison answers the question "Is A more effective than B?". The bilateral comparison needs a higher number of patients and answers the question "Is A more effective or less effective than B?"

The expected percentage of lost to follow-up. It is usually estimated as 5-20\% of the included patients and is influenced by duration of follow up.

If the number of patients included is not sufficient, it can lead the investigators to erroneously conclude that the treatment is ineffective.

As a conclusion, the calculation of the sample size, when designing the study, is essential. It should be reported in the chapter "Methodology" of any RCT's publication. 


\title{
"International clinical practice guidelines (CPGs) in rheumatology: what is the place of spa therapy (or balneotherapy) in 2016?"
}

Alain Françon (Centre de Recherches Rhumatologiques d'Aix-les-Bains, Société Française de Médecine Thermale)

Introduction: CPGs are defined as "systematically developed statements to assist practitioners and patient decisions about appropriate health care for specific circumstances". They are based on scientific levels of evidence (mainly randomized clinical trials (RCTs) and experts' opinion.

Objective: Identify the international CPGs in rheumatology in witch spa therapy or balneotherapy (both include care with mineral water) is recommended

Method: First we searched in Pubmed databases the CPGs in rheumatology, then we examined in theses CPGs whether spa therapy or balneotherapy was recommended and, if so, what was their grade of recommendation.

Results: Balneotherapy or spa therapy are recommended in very few CPGs.

In chronic low back pain only 2000 French Haute Autorité de Santé (HAS)'s CPGs recommended spa therapy with rank B.

In knee osteoarthritis (OA) balneotherapy is recommended in the 2014 OARSI (OsteoArthritis Research Society International)'s CPGs but only to a limited extent: "only for the sub-phenotype with multiple joint OA and co-morbidities, due to paucity of treatment alternatives for that group".

In rheumatoid arthritis (RA) only French HAS in 2007 recommends spa therapy for stabilized RA rank C.

Discussion: Despite the publication of a lot of RCTs, spa therapy is very few present in international CPGs in rheumatology. Several reasons can be given: $1^{\circ}$ ) in $\mathrm{CPGs}$ there was often no exhaustive or even no bibliographic research on balneotherapy's trials, $2^{\circ}$ ) balneotherapy is still not well known by the experts from many countries, so their opinion is most often not favourable,

Conclusion: More high quality balneotherapy's RCTs need to be published in scientific reviews with high impact factor to convince experts to include spa therapy or balneotherapy in CPGs

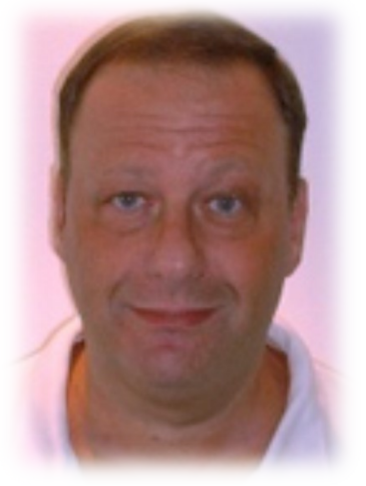

\author{
Prof. Dr. Tamás Bender \\ Hospitaller Brother of Saint John of God \\ 1023 Budapest Árpád fejedelem u. 7., Hungary \\ Telefax \& -phone: (36 1) 3360266 \\ E-mail: bender@mail.datanet.hu, \\ bener.tamas@irgalmas.hu
}

\section{Updated database of the scientific results of hungarian balneology}

In 2013 we published a review and metaanalysis about the clinical and exeperimental effect of the Hungarian thermal water. Since that time, 7 new studies have been prepared (published or under publication). These new studies dealing with the effect of balneotherapy on the OA of the shoulder, knee, hand and hip, along with a few experimantal studies. To summarize the results, we can declare that the Hungarian thermal waters have benefical effects on the pain of the musculosceletal system, and the quality of life for patients, independent of the concentration, and the inorganic contents of the the waters. 


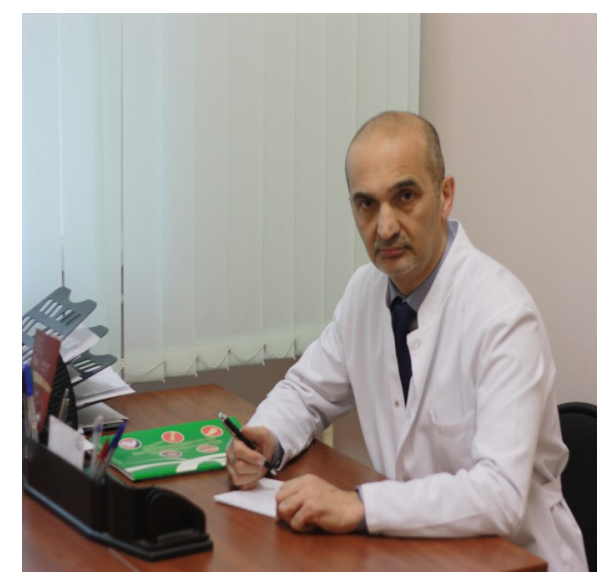

\section{Prof. Badalov Nazim,}

Doctor of Medical Sciences, born in 1957, since 1984 has been working in Russian Scientific Center for Medical Rehabilitation and Balneology.

Since 2008 - Head of the Department of Balneology in Russian Scientific Center for Medical Rehabilitation and Balneology, also - a Professor of the Department of Rehabilitation Medicine at I. M. Sechenov First Moscow State Medical University.

- a member of the Expert Council of SWIC (SPA and WELLNESS INTERNATIONAL COUNCIL).

- a member of the editorial board of the journal "Physiotherapy, balneology, rehabilitation" (Russia).

Since 2012 - collaborates with the ISMH.

- a regional representative of ISMH.

- an author of more than 150 scientific works and tractates.

\section{MAIN TENDENCIES OF SCIENTIFIC DEVELOPMENTS IN THE RUSSIAN BALNEOLO- GY}

Badalov N.G.

INTRODUCTION: The analysis of the scientific literature in the field of balneology recent years allowed to distinguish such relevant research directions as the development of modern research methods in the field of balneology; prophylactic direction with a focus on fight against the risk factors of chronic diseases' development; realization of therapeutic education programs on various nosologies in resort conditions including balneotherapy ; "Anti-aging" trend (the risk group of dementia development); modified balneotherapy and traditional directions (dose-effect, the specificity of action, learning new aspects of the mechanism of action and others.).

METHODS: Finding new methodological approaches conducting researches in the field of balneology, development of strategies to increase the accuracy of researches' results in our view, is the most relevant today. Researchers need to understand the methods of organizing clinical trials especially in balneology, and therapeutists should know the ways of interpretation and assessment of the accuracy of these studies. It'll give the opportunity to publish research results in journals with with high impact factor and inclusion of these studies into systematic reviews and metaanalyses.

Prophylactic direction with a focus on the fight against chronic disease risk factors implies the use of active preventive measures and lifestyle changes for patients from risk group, thereby morbidity rate decreases.

RESULTS: Development of programs for various nosologies with inclusion of therapeutic education and balneo-spa treatment promotes increase of treatment compliance, prevention of complications, greater autonomy of patients, psychological acceptance of disease by the patient. Realization of this program in balneotherapy institutions has several advantages: a sufficient duration of a course for the program, the availability of contact with a group of patients with the same nosology, separation from familiar surroundings. This leads to increasing of motivation and patient susceptibility.

Anti-aging strategy focuses on prevention and slowing the aging process, increase physical and intellectual working capacity and quality of life. The main aim of this direction is to maintain the physical shape and function, muscle tone and muscle mass, bone density, cognitive functions, fight against balance and coordination disorder, prevention of falling and progression of degenerative diseases, prolongation of the active period.

CONCLUSIONS: With regard to traditional studies conducted in our country, we can distinguish the researches of the effectiveness of general carbon dioxide baths (concentration of $1.2 \mathrm{~g} / 1$ ) with different mineralization (10 and $20 \mathrm{~g} / 1)$ on patients with hypertension and coronary heart disease, siliceous baths of various concentrations 50-100 -150 mg / 1 on the patients with arterial hypertension of varying severity. 


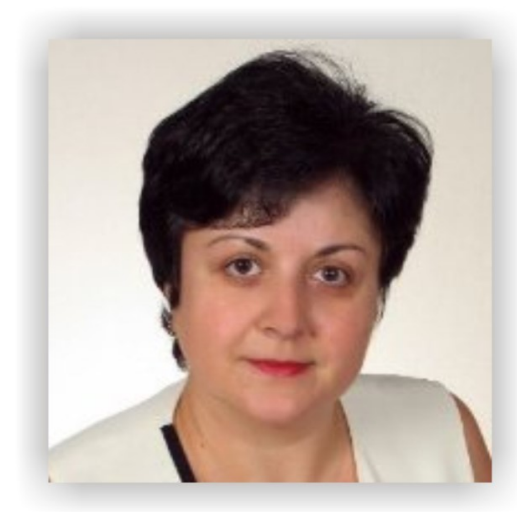

Dr. Gabriela Dogaru is Vice-President of the Romanian Association of Balneology, Vice-President of the Romanian Society for Physical and Rehabilitation Medicine\& Balneoclimatology, consultant in rehabilitation, physical medicine and balneology at the Clinical Rehabilitation Hospital Cluj-Napoca, Doctor in medical sciences. She is Assist.Prof. at Reabilitation and Physical Medicine Department the "Iuliu Hatieganu" University of Medicine and Pharmacy, Cluj-Napoca, Romania. Bachelor's degree in law and legal sciences. Member of the Editorial Board and peer-reviewer of the Balneo Research Journal, BDI and Member of the Editorial Board of the Studia Universitatis Babes-Bolyai Bioethica Journal. Member of the Ministry of Health Advisory Committee on Medical Rehabilitation and Balneology. Work and research areas: neurological rehabilitation, cardiovascular rehabilitation, molecular and cellular medicine, e-health systems, balneology and thermalism with the scientific research of natural therapeutic factors and their use, development of spa tourism, study of medico-legal aspects in disabled people, law projects.

\title{
IMPROVEMENT OF THE QUALITY OF GAIT AND BALANCE BY TREATMENT WITH NATURAL THERAPEUTIC FACTORS IN BAILE TUSNAD IN POST-STROKE PATIENTS
} Gabriela Dogaru ${ }^{1}$, Alexandra Ispas ${ }^{1}$, Marieta Motricală ${ }^{2}$, Molnár Ákos ${ }^{2}$

\author{
1. "Iuliu Hatieganu" University of Medicine and Pharmacy Cluj-Napoca \\ Clinical Rehabilitation Hospital Cluj-Napoca \\ 2. Tusnad Spa Complex - Baile Tusnad
}

INTRODUCTION. Stroke is one of the main causes of morbidity and mortality worldwide. Carbonated mineral waters in Baile Tusnad are used for their peripheral and cerebral vasodilator effects in the rehabilitation of cardiovascular patients. Aim. This clinical study was aimed at monitoring the efficiency of natural therapeutic factors with the purpose of continuing rehabilitation treatment in a balneoclimatic resort.

MATERIAL AND METHODS. The study included 30 patients with a history of stroke, treated in the Baile Tusnad treatment facility. The patients underwent rehabilitation treatment consisting of kinesitherapy, carbonated mineral baths for 15 minutes, aerotherapy for 30 minutes, massotherapy, all performed daily for 16 days. Each patient was clinically evaluated before and after treatment based on the Tinetti Balance Assessment Tool, the 10-m walking test, the Motor Assessment Scale, the Barthel Index, the Quality of Life Scale, and adverse reactions.

RESULTS. At the end of treatment, a statistically significant improvement in the walking speed, in the quality of gait was found, $p<0.001$. Statistically significant results, $p<0.01$, were also obtained when evaluating balance. A statistically significant value was obtained for the Motor Assessment Scale. The evaluation of the patients' performance in ten activities of daily living depending on the required external help, using the Barthel Index, evidenced a statistically significant $\mathrm{p}$ value $<$ 0.05 . For the Quality of Life Scale, a $\mathrm{p}$ value $<0.05$ was obtained. There were no side reactions to the treatment.

CONCLUSIONS. Natural therapeutic factors influenced the clinical and functional picture, determining a significant improvement of the quality of gait and balance, an increase of independence and an improvement of the quality of life in these patients. 
University of Oradea, Faculty of Medicine and Pharmacy, Department

Neurology, Psychiatry-BFK; Head of Department / 2008 - present; Felix Rehabilitation Hospital / Clinic chief SECS II.

2000-2009 present: Medical Director Medical Rehabilitation Hospital Felix.

\author{
ASPECTS OF REHABILITATION IN ELDERLY PATIENTS \\ Liviu Lazar, Fl. Marcu, F. Cioara, C. Nistor Cseppento \\ UNIVERSITY OF ORADEA, FACULTY OF MEDICINE AND PHARMACY \\ CLINICAL HOSPITAL OF MEDICAL REHABILITATION OF FELIX SPA, ROMANIA
}

INTRODUCTION.Cardiovascular diseases have aroused considerable interest partly as a result of their increased morbidity and mortality, and partly because of their social and economic impact. Cardiac rehabilitation includes various activities necessary for slowing down the progress of the disease and for ensuring that the patients get the best physical, mental, social and professional status. Thus the patients can maintain a better level of importance in society through their own efforts.

MATERIAL AND METHODS. Recently US Public Health Service has described cardiovascular rehabilitation as a long- term comprehensive program which includes medical evaluation, education and counseling, risk reduction and modification, and exercise prescription. The goals of cardiac rehabilitation are to reduce the symptoms caused by effort, limit or reverse the physical disability, increase the patient"s functional capacity, identify and modify risk factors and lead to reduction of morbidity and mortality subsequent cardiovascular diseases. The final goal of cardiac rehabilitation is to restore and maintain the physical, psychological, social and vocational status of patients with cardiovascular disesases.Cardiovascular rehabilitation needs a team of experts formed of cardiologist, dietitian, nurse, social worker, occupational therapist, physiotherapist, phsychologist and case manager. Traditionally the program of rehabilitation is divided into three phases : phase I (inpatient or hospital phase ), phase II (outpatient or ambulatory phase) and phase III (maintenance phase) which theoretically can last all the patient"s life.

RESULTS. Elderly patients show limited endurance at stress testing because of their various diseases: pulmonary, metabolic, neurological diseases or osteoarthritis. Therefore, it is important that the physician should prescribe submaximal stress tests for this category of patients, particularly for coronary patients. It is also important to recommend moderate aerobic training, limbering exercises (35 times per week) to increase joint flexibility. Besides, the elderly patients should change their lifestyle and receive medical treatment in order to prevent potential secondary cardiac disease.

CONCLUSION. In conclusion, cardiac rehabilitation has proved beneficial to the older patients ; considerable evidence shows that they have improved their functional capacity and life quality on one hand, and their social, family and professional reinsertion on the other hand.

\title{
BIBLIOGRAPHY:
}

1. Suaya JA, Stason WB, Ades PA, et al. Cardiac rehabilitation and survival in older coronary patients. J Am Coll Cardiol. 2009;54:25-33.

2. Lavie CJ, Milani RV, Arena RA. Particular utility of cardiac rehabilitation in relation to age. Curr Cardiovasc Risk Rep. 2011;5:432-439.

3. Lavie CJ, Milani RV, Littman AB. Benefits of cardiac rehabilitation and exercise training in secondary coronary prevention in the elderly. J Am Coll Cardiol. 1993;22:678-683.

4. Menezes AR, Lavie CJ, Milani RV, et al. Psychological risk factors and cardiovascular disease: is it all in your head? Postgrad Med. 2011;123:165-176. 


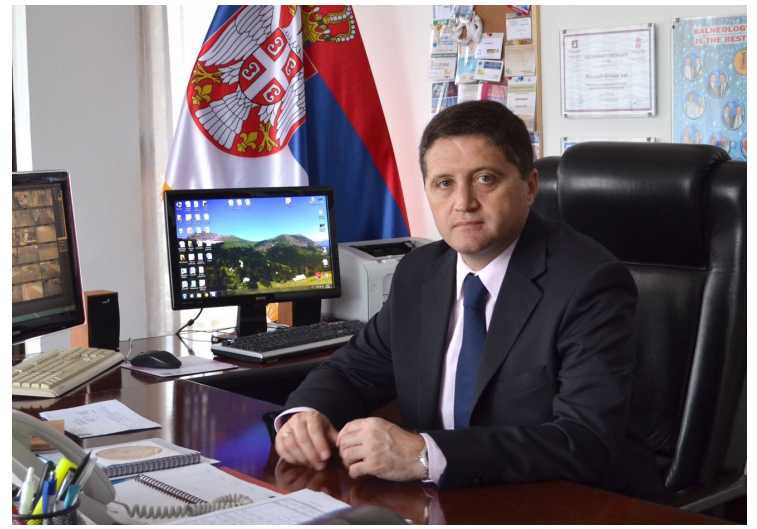

\section{COMPARATIVE ANALYSIS OF THE INFLUENCE OF BALNEOTHERAPY AND HY- DROKINESIOTHERAPY OF BANJA KOVILJACA ON BLOOD PRESSURE VALUES} AleksandarJOKIC ${ }^{1}$, Aleksandra TODIC ${ }^{1}$, Svetlana CICEVIC $^{2}$, ZekiKARAGULLE $^{3}$

\section{Memberships:}

International Society of Medical Hidrology and Climatology

Physiatrists Association of Serbia

Section of the Serbian Medical Society for physical and rehabilitation medicine

Scientific committee of the International Society of Medical Hidrology and Climatology

Permanent Working group for balneology (PWG UEMS)

European Board for Medical Hydrology

${ }^{1}$ Specialized Rehabilitation Hospital Banja Koviljaca, Serbia

${ }^{2}$ Faculty of Transport and Traffic Engineering, University of Belgrade, Serbia

${ }^{3}$ Istanbul Medical Faculty, Department of Medical Ecology and Hydroclimatology, Turkey

INTRODUCTION. Unregulated blood pressure can be counter-indicated for the application of general hydro and balneo procedures.

PURPOSE. To examine the influence of bathing in pools with sulphuric and hygienic water on blood pressure values.

METHOD. The resear ch was conducted at Specialized Rehabilitation Hospital Banja Koviljaca, in Serbia, during 2013 and 2014. There were 60 participants included in the study, who were divided into two groups. One group used the pool with sulphuric thermo-mineral water, temperature $35^{\circ} \mathrm{C}$, depth $115 \mathrm{~cm}$, and the other group used the pool with hygienic water, temperature $32^{\circ} \mathrm{C}$, depth $140 \mathrm{~cm}$. Blood pressure values were measured using automatic digital device.The measurements were done on the left upper arm before bathing, 5 minutes into bathing, at the end of the bathing in the pool (20 minutes), and after 15-minute rest. The results were statistically processed (Student T-test and variance analysis).

RESULTS. In patients that used sulphuric thermo-mineral water, we have noted a constant and statistically significant drop in systolic and diastolic pressure which is the most prominent after bathing and short rest. In patients who used hydrokinesiotherapy in thermal hygienic water, we have observed a statistically significant drop in systolic blood pressure after 5 minutes of therapy, which after bathing and short rest returns to the original values. A similar occurrence happens with diastolic pressure as well, only without a statistically significant result.

DISCUSSION AND CONCLUSIONS. Bathing in sulphuric thermo-mineral water of Banja Koviljaca causes the decrease in blood pressure, both systolic and diastolic. Bathing in warm water should not be counter-indicated in patients with mild increase in blood pressure. 


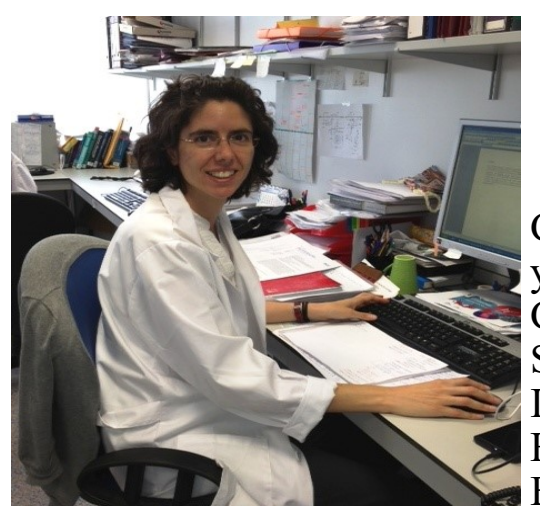

\section{Elena F. Burguera, PhD}

Centro de Investigación Biomédica en Red en Bioingeniería, Biomateriales y Nanomedicina (CIBER-BBN). Grupo de Bioingeniería Tisular y Terapia Celular (GBTTC-CHUAC)

Servicio de Reumatología

Instituto de Investigación Biomédica de A Coruña (INIBIC). Complexo Hospitalario Universitario de A Coruña (CHUAC).

tigación Biomédica en Red-Biomedicina, Biomateriales y Nanomedicina (CIBER-BBN) at the Instituto de Investigación Biomédica de A Coruña (INIBIC), A Coruña, Spain.

She has a degree in Chemical Engineering and a $\mathrm{PhD}$ in Material Science, both from the University of Santiago de Compostela, Spain. She worked as a postdoctoral researcher in the Material Science and Engineering Dept., at Virginia Tech, Blacksburg, VA, USA and in the Materials-Biology Interactions Group, at EMPA-Materials Science and Technology, St Gallen, Switzerland, before becoming a member of the Rheumatology Group in INIBIC.

\section{EFFECTS OF SULFUROUS MINERAL WATERS ON ARTICULAR CHONDROCYTES IN VITRO: ANTI-INFLAMMATORY EFFECTS}

Noemi Gómez-Prieto ${ }^{1}$, Ángela Vela-Anero ${ }^{2,3}$, Lucía Gato-Calvo ${ }^{1,3}$, Francisco J. Blanco ${ }^{1}$, Rosa Meijide Failde $^{2}$, Elena F. Burguera ${ }^{1,3 *}$

${ }^{1}$ Rheumatology Group, Instituto de Investigación Biomédica de A Coruña (INIBIC). Complexo Hospitalario Universitario A Coruña (CHUAC). Sergas. A Coruña, Spain., ${ }^{2}$ Cellular Therapy and Regenerative Medicine, Department of Medicine, University of A Coruña (UDC), A Coruña, Spain, ${ }^{3}$ CIBER de Bioingeniería, Biomateriales y Nanomedicina (CIBER-BBN), A Coruña, Spain.

OBJECTIVE: Here we evaluated the effects of several sulfurous mineral waters in an in vitro model with human articular chondrocytes isolated from osteoarthritic cartilage. The parameters of study were the viability of the cells, the production of nitric oxide (NO) and the gene expression of known mediators of inflammation, namely, the inducible NO synthase (iNOS), cyclooxygenase 2 (COX2), microsomal prostaglandin synthase (PTGES), IL6 and metalloproteinase (MMP) 13.

MATERIALS \& METHODS: Cell viability was evaluated with the alamarBlueÒ method using a chondrocytic cell line (T/C-28a2). For the rest of the experiments we used primary human articular chondrocytes stimulated with IL1-b $(5 \mathrm{ng} / \mathrm{mL})$. Cell culture media was prepared by dissolving powdered Dulbecco's minimum essential medium in either distilled or sulfurous water, plus the needed supplements. This two stocks were used as prepared or mixed in different concentrations $(25 \%, 50 \%$ and $75 \%)$. NO was quantified by the Griess reaction and the RNA expression of OA characteristic inflammation markers was quantified with qRT-PCR.

RESULTS: The viability of the cells was not affected by the exposure to different proportions of sulfurous water in the culture media. NO production and iNOS mRNA expression were reduced down to as low as $13 \%$ of the stimulated values, but there were important donor-to-donor variations. With respect to the mRNA expression of the rest of inflammation mediators, there were marked reductions in IL6 and MMP13 with media prepared with $75 \%$ and $100 \%$ sulfurous water. On the other hand, we found no effect on the expression of COX2 or PTGES, both implicated in the synthesis of prostaglandin E2.

CONCLUSIONS: The present results demonstrate that sulfurous mineral water can exert antioxidant and anti-inflammatory effects on osteoarthritic human chondrocytes, when the cells are exposed to it in their culture medium. These results are similar to those previously obtained by our group using synthetic hydrogen sulfide sources [1].

KEY WORDS: Sulfurous mineral water, hydrogen sulfide, osteoarthritis, chondrocytes

REFERENCES: [1] Burguera EF, Vela-Anero A, Magalhaes J, Meijide-Failde R, Blanco F. Effect of hydrogen sulfide sources on inflammation and catabolic markers on interleukin 1 beta-stimulated human articular chondrocytes. Osteoarthritis Cartilage 2014;22:1026-35. 


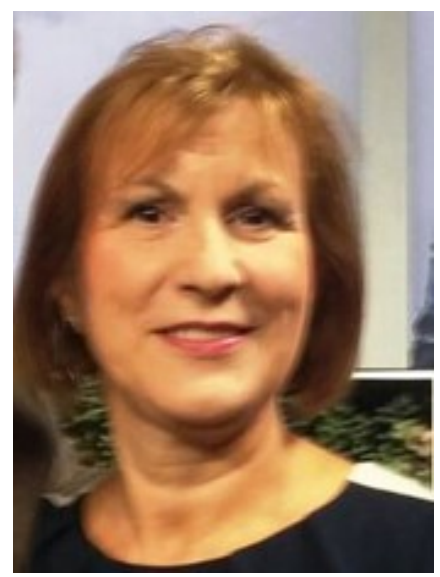

Professor Mihaela Bălgrădean (Advisers). Pediatric Clinic, Emergency Hospital for Children "M.S. Curie", Department 7 Pediatrics, Genetics, Faculty of Medicine and Pharmacy - "Carol Davila". Chief Pediatric Clinic, Emergency Hospital for Children "M.S. Curie" Nephrology Unit Head - Dialysis, Emergency Hospital for Children "M.S. Curie" MD Pediatrician with specialization in Pediatric Nephrology

Professional experience was carried out until now, over 36 years of academic activities (undergraduate teaching experience from 1980) and 40 years of medical activity (practice and hospital clinical experience since 1976).

249 publications: 64 articles in ISI journals (impact factor IF), NURC - B + (BDI indexed, PubMed), NURC B, D, and 183 abstracts in proceedings ISSN / ISBN, mostly as sole author or author, citations in journals BDI NURC invitations as a speaker at various scientific national / international accredited and 127 scientific papers / posters in the national / international level.

\section{RENOURINARY PATHOLOGY IN CHILDREN AND THE NEED OF URINARY DIURESIS CURE}

Prof. Dr. Mihaela Balgradean

\section{Summary}

INTRODUCTION: Urinary tract infection in children (ITU), and especially its high form, acute pyelonephritis, is a pathology on how often, on so complex and problematic.

The association, common, UTI various obstructive abnormalities of the kidney and urinary tract, as well as common disorders of water and electrolytes that usually accompany these infections, especially in young child, is a constant concern of various pediatric specialists. Hypercalciuria, renal tubulopathy and urinary stones are entities and complications commonly associated UTI.

METHODS: Clinical and therapeutics of all these diseases, often associated, requires a complex interdisciplinary approach that involved specialists, paediatricians, neonatologists, pediatric urologists and nephrologists, family doctors, specialists in pediatric imaging, nutrition, physio therapists and pediatricians.

RESULTS: Team pediatric multi and interdisciplinary aims to establish an early diagnosis and therapeutic strategy appropriate for the prevention and slows the evolution of all these diseases that chronic kidney disease, and chronic renal failure terminal, in which the only means of treatment are dialysis and transplantation renal.

CONCLUSION: The lecture subject in this issue Nephrology face complex common in children. 


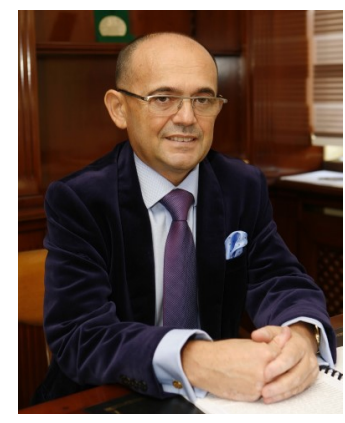

Dafin F. Muresanu, MD, PhD, MBA, FANA

Professor of Neurology, Senior Neurologist, Chairman of the Neurosciences Department, Faculty of Medicine, University of Medicine and Pharmacy "Iuliu Hatieganu" Cluj-Napoca, President of the Romanian Society of Neurology, President of the Society for the Study of Neuroprotection and Neuroplasticity (SSNN), member of the Academy of Medical Sciences, Romania, secretary of its Cluj Branch. He is also member of 13 scientific international societies (being member of the American Neurological Association (ANA) - Fellow of ANA (FANA) since 2012) and 7 national ones, being part of the executive board of most of these societies.

Professor Dafin F. Muresanu is a specialist in Leadership and Management of Research and Health Care Systems (specialization in Management and Leadership, Arthur Anderson Institute, Illinois, USA, 1998 and several international courses and training stages in Neurology, research, management and leadership). Professor Dafin F. Muresanu is coordinator in international educational programs of European Master (i.e. European Master in Stroke Medicine, University of Krems), organizer and co-organizer of many educational projects: European and international schools and courses (International School of Neurology, European Stroke Organisation summer School, Danubian Neurological Society Teaching Courses, Seminars - Department of Neurosciences, European Teaching Courses on Neurorehabilitation) and scientific events: congresses, conferences, symposia (International Congresses of the Society for the Study of Neuroprotection and Neuroplasticity (SSNN), International Association of Neurorestoratology (IANR) \& Global College for Neuroprotection and Neuroregeneration (GCNN) Conferences, Vascular Dementia Congresses (VaD), World Congresses on Controversies in Neurology (CONy), Danube Society Neurology Congresses, World Academy for Multidisciplinary Neurotraumatolgy (AMN) Congresses, Congresses of European Society for Clinical Neuropharmacology, European Congresses of Neurorehabilitation). His activity includes involvement in many national and international clinical studies and research projects, over 350 scientific participations as "invited speaker" in national and international scientific events, a significant portfolio of scientific articles (134 papers indexed on Web of Science-ISI) as well as contributions in monographs and. Prof. Dr. Dafin F. Muresanu has been honoured with: the Academy of Romanian Scientists, "Carol Davila Award for Medical Sciences / 2011", for the contribution to the Neurosurgery book "Tratat de Neurochirurgie" (vol.2), Editura Medicala, Bucuresti, 2011; the Faculty of Medicine, University of Medicine and Pharmacy "Iuliu Hatieganu" Cluj-Napoca "Octavian Fodor Award" for the best scientific activity of the year 2010 and the 2009 Romanian Academy "Gheorghe Marinescu Award”.

\section{ADVANCES IN BRAIN PROTECTION AND RECOVERY AFTER STROKE - NEW DATA Dafin F. Muresanu}

BACKGROUND AND PURPOSE: The aim of this early neuror ehabilitation trial was to investigate whether patients randomized to hydrolyzed peptide from porcine showed improved motor function of the upper extremities over 90 days in comparison with patients randomized to placebo.

METHODS:This study was designed as a prospective, randomized, double-blind, placebocontrolled, multicenter and parallel-group study. Patients were treated with hydrolyzed peptide from porcine (30 $\mathrm{ml} /$ day) or placebo (saline) once daily over 21 days starting the treatment $24-72$ hours after stroke onset. In addition, patients participated in a standardized rehabilitation program over 21 days starting within 72 hours after stroke onset. Primary endpoint was the action research arm test (ARAT) score on day 90. Safety assessment was based on adverse events, vital signs and laboratory parameters.

RESULTS: The nonparametric effect size on the ARAT score on Day 90 indicated a large superiority of hydrolyzed peptide from porcine as compared to placebo (MW=0.71, 95\%CI 0.63-0.79). The multivariate effect size on the global status, as assessed by twelve different outcome scales, showed a small superiority (MW 0.60, $P<0.0001$ ). The rate of premature discontinuations was below $5 \%$ $(3.8 \%)$. Hydrolyzed peptide from porcine was safe and well tolerated.

CONCLUSIONS: Hydrolyzed peptide from porcine had a beneficial effect on function and global outcome in early rehabilitation patients after stroke. The safety aspects of hydrolyzed peptide from porcine were comparable to placebo, thus suggesting a favorable benefit-risk ratio. Due to the size of the study the results should be confirmed by a high precision, large-scale randomized clinical trial. 
Prof. Dr. Crina Sinescu

Carol Davila University of Medicine and Pharmacy, Bucharest with expertise in

Cardiology,

Romanian Society of Cardiology

European Society of Cardiology

Fellow of the European Society of Cardiology

American Heart Association (AHA)

\section{CARDIOVASCULAR REHABILITATION IN ACUTE ISCHEMIC HEART DISEASE}

\section{Prof. Dr. Crina Sinescu}

INTRODUCTION: Exercises have been demonstrated to be beneficial for patients with coronary artery disease (CAD). However, vigorous exercises can have disastrous effects. Therefore, it is essential to have a gradation of the exercises. Cardiac rehabilitation (CR) programs are complex services that include medical evaluation, supervised exercises, education, nutritional and psychological counselling. They limit the physiologic and psychological effects of cardiac disease, reduce the risk of sudden death or reinfarction, help in controlling the cardiac symptoms, stabilize or reverse the atherosclerotic process and accelerate the patient reinsertion process into the social circuit.

METHODS: CR has been conventionally divided into three phases: phase-1 involves the hospitalized period of the patient following an acute myocardial infarction (MI); phase- 2 is the immediate post-discharge period of around 6-12 weeks depending on patient's evolution and phase-3 is the maintenance phase (all life longue).

RESULTS: Statistical data related to CR use are scarce. In spite of the well-documented benefits, only $10-20 \%$ of eligible patients following MI participate in CR programs in the United States and the United Kingdom. The main reason is represented by the low rates of referral by the medical practitioners. Other predictors of suboptimal participation include poor functional status, overweight, tobacco use and depression, long-distance to facilities, low health literacy and inflexible work schedules. In many European countries (including Romania) the CR programs are not covered by the National House Insurance Companies, making the access to this kind of services very difficult for the general population, due to the high costs that are implied by the private ambulatory or inpatient rehabilitation centres.

CONCLUSION: One possible solution for fighting the economic reasons and the other low attendance predictors could be the involvement of the e-Cardiology (Telemedicine) into the rehabilitation field. This kind of e-programmes will subsequently translate the classical rehabilitation programmes from the medical centres into the patient's personal environment. 


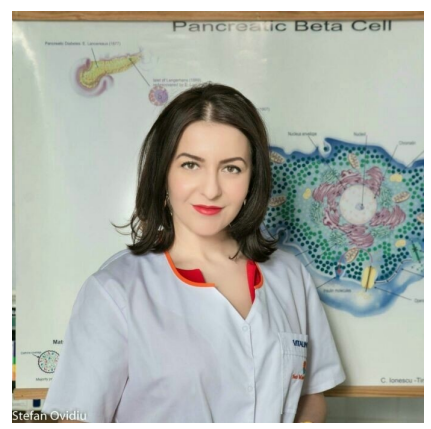

\section{Dr. Simona CARNICIU}

\section{Doctor in Medical Sciences}

Specialist diabetes, nutritional and metabolic diseases

Family medicine specialist

Trainer

Award of Excellence 2010, Section Doctoral, Romanian Medical Association Annual Congress, Bucharest, 6-8.05.2010 - I Mention

- Prize for the best poster - (works list, section 12) - The 7th International Workshop Electromagnetic Compatibility EMC 2010 Odorhellen - Romania 2 - 09.04.2010

- Award 2011 Doctoral Section, Romanian Medical Association Annual Congress, Bucharest, April 14 to 16, 2011.

- Excellence Award for PhD, Doctoral Section, Romanian Medical Association Annual Congress, Bucharest, 2012, 2013.2014

- Nomination Gala Medica, Sixth Edition, Bucharest, June 25, 2014, at the "Best Communicator physician," Dr. Alis Grasu with Dr. Irina Badrajan and Prof. Luke Clancy

- a cross "Healthy and happy" in the National Program for Prevention of Metabolic Pathology and Cardiovascular program initiated in 2007 by the Romanian Medical Association and that concerns me as secretary of the Association.

- Numerous (over 30) participation in national and international congresses and symposia in the period 2009-2016

- Scientific Session at the Romanian Academy on prevention through proper nutrition and applied technology in the food industry, where we presented the current problem and the need for interdisciplinary collaboration in the National Programme for Prevention of Cardiovascular Disease and Metabolic Romanian Medical Association (2013).

- Voluntary medical - The "Health for villages" - humanitarian campaign of prevention in health - started after signing the Protocol of Cooperation between the Romanian Patriarchate and the Ministry of Health. It was signed on September 3, 2015 and aimed at disadvantaged rural people, older people, people with low educational level, social cases.

\section{Interdisciplinary approach of the diabetic foot - transcending from "a specialist and apparatus dis- eases" to "specialist team and one disease" Simona Carniciu, M.D., PhD}

Objective: The term diabetic foot represents a syndrome that affects one or more levels in a diabetic patient's foot like skin, blood vessels, nerves, bone structure or muscles. This complex disease needs a complex approach, a team of specialists, mostly interdisciplinary.

Material and methods: To better determine what the correct and complete team is, reaching to international literature and study results is needed. There are a lot of studies aiming prevention, risk factors, factors of worsening, tissue regeneration, nerve preservation, bone architecture, and so on.

Results: In the pathology and also treatment of the diabetic foot, must be consider ed: metabolic control, treatment of diabetic peripheral neuropathy and arteriopathy, lesion treatment, especially impaired wound closing, surgical debridement or intervention where is needed. Very important is the use of personalized footwear, with major implication in treatment and prevention. Every diabetic foot must be revised by a complete team and so the approach will be the mostly correct.

Conclusion: Transcending the classic medical approach of diseases that targeted the specialist and a disease or a system of organs, there is the interdisciplinary team that focuses on one disease as a whole view. In diabetic food syndrome the team must be of diabetologist, family practitioner, surgeon, dermatologist, podologist, PRM physician, vascular surgeon, psychologist, footware technician, and so on, depending of the identified affected levels of this syndrome. 


\title{
Dr. Cristian Ioan Stoica
}

U.M.F. Carol Davila - Bucharest - Romania - Assoc. Prof. Cristian Ioan Stoica "Foisor" Orthopaedic Clinical Hospital - Bucharest - Romania - Manager / Head of Department

Romanian Society of Arthroscopy and Sports Trauma - President

Romanian Arthroplasty Register www.rne.ro - Vice-president/Coordinator Romanian Orthopaedic and Trauma Association S.O.R.O.T.- member/national delegate

European Board Orthopaedic and Trauma EBOT (UEMS) - S.O.R.O.T. national delegate

The Societe Internationale de Chirurgie Orthopedique et de Traumatologie (SICOT) - Member

International Society of Arthroscopy, Knee Surgery and Orthopaedic Sports Medicine (ISAKOS) - Member

International Cartilage Repair Society (ICRS) - Member

The American Academy of Orthopaedic Surgeons(AAOS) - Member

\section{PERIPROSTHETIC FRACTURES COMPLICATED BY THE NEED OF REVISION}

\author{
Work paper based on the National Arthroplasty Registry data www.rne.ro \\ I.C.Stoica - Ioan Cristian Stoica - "Foisor" Orthopaedic Clinical Hospital; Bucharest; Romania; \\ cristi.stoica@,foisor.ro; stoicacristianioan@gmail.com
}

OBJECTIVE: Increase the number of periprosthetic fractures revision endoprosthetic that reason, in our clinic, led to the need to analyze the phenomenon nationwide.

MATERIAL AND METHODS: The analysis is based on data from the National Arthroplasty Registry. Comparison of data generated a database that confirms the initial finding, there is an increase both in the our clinic and nationwide periprosthetic fractures, studied period, between 2002 - 2013 in August.

RESULTS: Increasing number of cases at the clinic was 2 cases per year in 9 cases in eight months 2013 while nationally was 20 cases annually to a total of 47 , can say overall that there are at least a doubling of that ground for revision. Most periprosthetic fractures are usermedium endoprosthetic deadline (according to the types endoprosthetic survival curves).

CONCLUSIONS: Delaying revision endoprosthetic components leads to complications and bone fractures around endoprosthetic components. The case became an emergence, complicating the surgical endoprosthetic revision both the inability programming revision, and by providing the necessary means for its (supply of blood transfusion material endoprosthetic specific case, delaying other surgeries through longer duration of revisions, unable added compensation pathology, financial and human cost increases, etc.). It requires advertising the need endoprosthetic joint implant postoperative periodical controls mandatory. There is a risk of a DRG coding revisions as endoprosthetic fracture, changing character programmable endoprosthetic revision in emergency scale intervention type of surgery is in the background.

BIBLIOGRAPHY:

1) Streit MR, Merle C, Clarius M, Aldinger PR., Department of Orthopaedic and Trauma Surgery, University of Heidelberg, Schlierbacher Landstrasse 200a, 69118 Heidelberg, Germany, Late peri-prosthetic femoral fracture as a major mode of failure in uncemented primary hip replacement, J Bone Joint Surg Br.

2011 Feb;93(2):178-83. doi: 10.1302/0301-620X.93B2.24329

2) Cibu Mukundan, Faizal Rayan, Ehab Kheir, D Macdonald, Leeds Teaching Hospitals, Leeds, UK., Management of late periprosthetic femur fractures: a retrospective cohort of 72 patients., International Orthopaedics (impact factor: 2.03). 07/2009; 34(4):485-9. DOI:10.1007/s00264-009-0815-01)

3) Annual Report National Endoprosthetic Register 2001-2011 


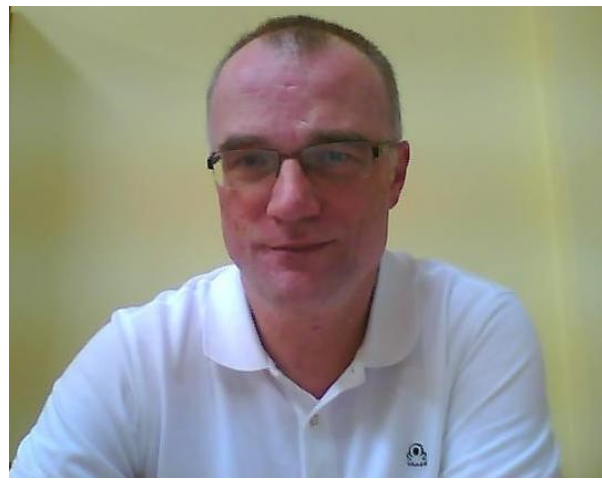

Jacek Chojnowski Ph.D. Chairman of the Board of the Polish Association of Balneology and Physical Medicine

Specialist Balneology and Physical Medicine and Internal Medicine. Author and co-author of 55 indexed publications in the field of spa treatment, physiotherapy, diabetes and metabolic diseases. Author and co-author of 120 papers in the field of spa treatment, diabetes and metabolic diseases presented at national and international scientific meetings and training. Co-author of three textbooks in the field of physical therapy and metabolic diseases. Since 1997 lecturer in courses for physicians specializing in the field of balneology and physical medicine. In 2007, a member of the ministerial committee of experts of the Agency for Health Technology Assessment for the guaranteed benefits in terms of balneology and physical medicine. Since 2008, member of the State Examination Commission in the field of Balneology and Physical Medicine.

A member of the scientific journal of Polish Association of Balneology and Physical Medicine "Acta Balneologica"

From 2013 Chairman of the Board of the Polish Association of Balneology and Physical Medicine

Member of the Scientific Committee last 5 Conventions and Congresses of Polish Association of Balneology and Physical Medicine. Member of Scientific Societies: Polish Diabetes Association, Polish Society of Internal Medicine, the Scientific Society for Treatment of Obesity.

\title{
THERMAL TREATMENT OF OBESE PATIENTS WITH, DIABETES TYPE 2 TREATED WITH INSULIN - PHARMACOECONOMIC ASPECTS
}

\author{
J.Chojnowski, I.Ponikowska
}
Nicolaus Copernicus University, Ludwik Rydygier Collegium Medicum in Bydgoszcz, Faculty of Healh Sciences, Depertment od Balneology and Physical Medicine 87-720 Ciechocinek, Leśna 3, Poland

INTRODUCTION: The aim of the our study was to assess whether the thermal treatment of obese diabetic patients treated with insulin has the effect of reducing the cost of treatment of diabetes.

METHODS: Clinical examination was carried out in 100 patients (64 woman) between 38 to 74 years of life. The mean age was 58,6 $\pm 8,2$ years, body weight was $99,5 \pm 8,6 \mathrm{~kg}$, the mean BMI 35,4 \pm $4,3 \mathrm{~kg} / \mathrm{m} 2$. The mean duration of diabetes type 2 was 9,5 years, the mean duration of obesity was 18 years. During 3 weeks of thermal treatment the balneokinesytherapy and low calorie diet (1000-1400 kcal) were applied. Before and after therapy average dose of insulin, the degree of control of diabetes, number of tablets were evaluated. We convert the contents of medicine by the current market price and was calculated a reduction in direct costs of treatment.

RESULTS: During the treatment the doses of insulin were gradually reduced and glucose level and blood pressure were well controlled. The mean body weight loss $5 \mathrm{~kg}$ was achieved. The exogenous insulin dose in patients decreased from 54 iu to $22 \mathrm{iu}$. The number of tablets were reduced from 5 to 3 in hypertension treatment. This means reducing the cost of insulin for 77 PLN (18 euros) per month and the cost of drugs for 46 PLN (11 euros) per month. In addition to the direct costs of treatment we expect that because of the good metabolic control of diabetes and hypertension hospitalizations and medical consultations will be reduced.

CONCLUSION: Our research has shown that a modest reduction in body weight during the thermal treatment in obese patients with diabetes type 2 is very beneficial to reduce the cost of treatment. 


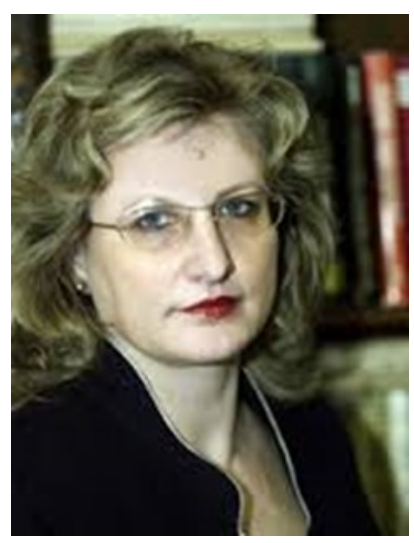

Assoc. Prof. Diana Loreta Paun

State Adviser-Presidential Administration

Manager - C. I. Parhon" National Institute of Endocrinology,

Endocrinologist Primary Doctor, Associate Professor for Endocrinology

Department

Management, Healthcare services, Research

Hospitals evaluation-National Commission for Hospitals Accreditation

"C. I. Parhon" National Institute of Endocrinology, 34-36 Aviatorilor,

011863, Bucharest, Romania

University of Medicine and Pharmacy „Carol Davila”, No. 2 Dionisie Lupu

Street, Bucharest

\section{THE ROLE OF PHYSICAL ACTIVITY IN PREVENTING OSTEOPOROSIS AND SARCOPENIA}

\section{Assoc. Prof. Diana Loreta Paun \\ Carol Davila University of Medicine and Pharmacy, Bucharest, Romania}

INTRODUCTION: Bone and muscle tissues are in close relationship and the aging process involves the loss of the functionality of both of them.Osteoporosis is defined by the World Health Organisation (WHO) as a bone mineral density (BMD) of less than 2.5 standard deviations below the sex-specific young adult mean. The term sarcopenia has been used conversely to describe low muscle mass, function and strength.Complementary to osteoporosis being defined as 'low bone mineral density', sarcopenia could be referred for 'low muscle mass'.

Furthermore, sarcopenia is an important risk factor for osteoporosis. It decreases bone strength by diminishing mechanical loading of the skeleton and thus bone formation/osteogeniceffect is reduced due to the minor mechanical stimulation imposed on the bone structure by the low muscle mass.In addition, sarcopenia induces a lower physical activity causing the reduction of the mechanical stimuli on the skeleton.

METHODS: The role of physical activity in preventing osteoporosis and sarcopenia has been investigated in numerous studies. It has been demonstrated that muscle contractions are associated with anabolic effects on the skeleton and also an increase in anti-inflammatory and antioxidative substances.

RESULTS: General physical activity may be of benefit in the prevention of sarcopenia, maintaining the strength and the muscle tone of muscular fibers and particularly through preservation of healthy body composition. Moreover particular types of physical exercises were indicated to prevent against BMD reduction of the lumbar spine or of the femoral neck.

CONCLUSION: Exercises type sit-ups were recommended as a preventive factor against BMD reduction of the lumbar spine and ante-flexion exercises in a sitting position were indicated as a protective factor against BMD reduction of the femoral neck.

\section{References}

Verschueren S, Gielen E, O’Neill TW, Pye SR, Adams JE, Ward KA, et al. Sarcopenia and its relationship with bone mineral density in middle-aged and elderly European men. Osteoporos Int. 2013;24(1):87-98

$\mathrm{Wu} \mathrm{CH}$, Yang KC, Chang HH, Yen JF, Tsai KS, Huang KC. Sarcopenia is related to increased risk for low bone mineral density. J ClinDensitom. 2013;16(1):98-103

Coin A, Perissinotto E, Enzi G, Zamboni M, Inelmen EM, Frigo AC, et al. Predictors of low bone mineral density in the elderly: the role of dietary intake, nutritional status and sarcopenia. Eur J ClinNutr. 2008;62:802-9

Genaro PS, Pereira GA, Pinheiro MM, Szejnfeld VL, Martini LA. Influence of body composition on bone mass in postmenopausal osteoporotic women. Arch GerontolGeriatr. 2010;51(3):295-8

Marcell TJ. Sarcopenia: causes, consequences, and preventions. J Gerontol A BiolSci Med Sci. 2003;58 (10):911-6 


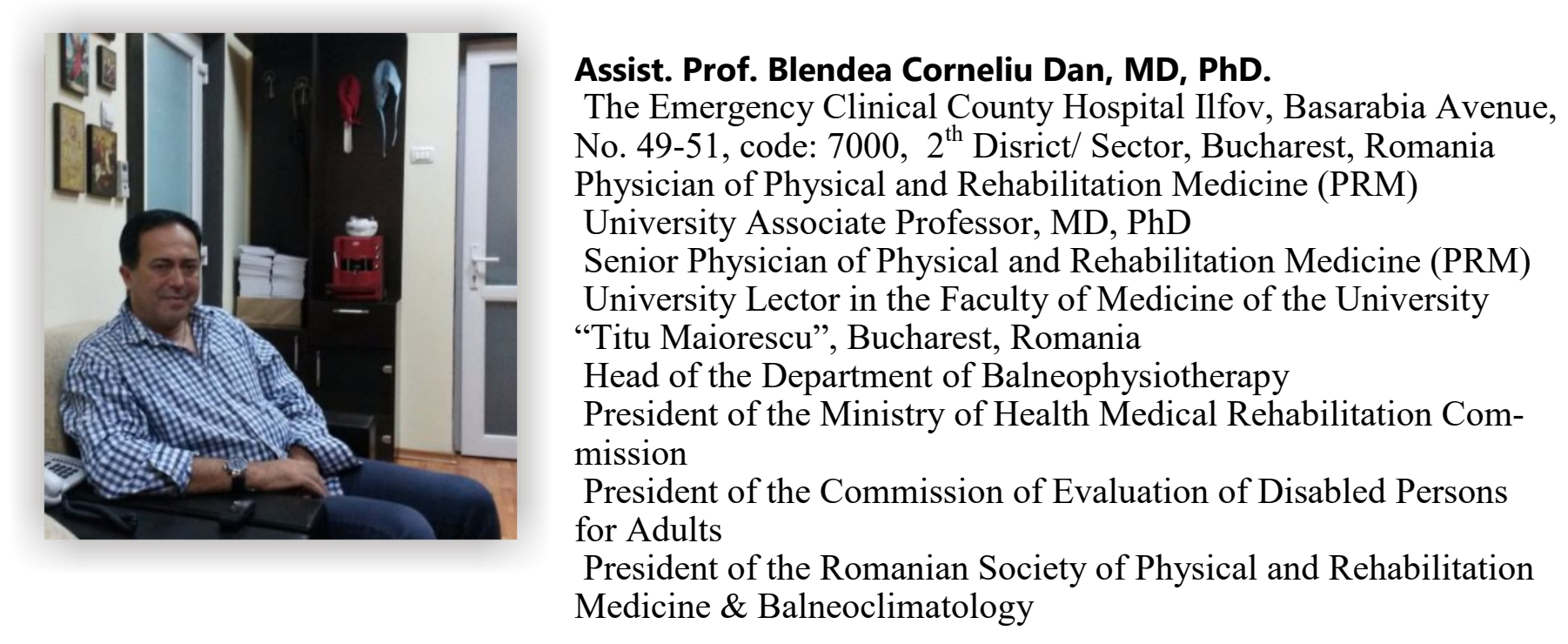

MODULATED RADIOFREQUENCY THERAPY IN MEDICAL REHABILITATION

Assist. Prof. Bleandea Corneliu Dan, MD, PhD

Emergency Clinical County Hospital Ilfov, Basarabia Avenue, No. 149-151, $2^{\text {th }}$ District/ Sector, Bucharest, Romania

danblendea@gmail.com

\begin{abstract}
This paper presents our interest in new therapies like Modulated Radiofrequency Therapy. Modulated Radiofrequency Therapy distributes high-frequency electromagnetic energy into the desired tissue which leads to selective tissue hyperthermia. Thanks to his mechanism patients experience instant pain relief, muscle relaxation, edema reduction, tissue regeneration support and healing. The most common indications include: local muscle spasm, trigger points, myalgia, tendinitis, cervical pain, and posttraumatic edema. The immediate therapeutic effect is noticed by the patient instantly and lasts long after the therapy. For elderly people to continue to function independently and perform daily activities, it is essential they maintain sufficient muscle strength and cardiorespiratory fitness. The effect of myorelaxation is primarily based on vasodilatation, which occurs immediately during the therapy and is responsible for higher supply of nutrients into the tissue. The goal of the present is to highlight the medical effect in recovery by using the Modulated Radiofrequency Therapy. The main method used to fulfill this study has been even the implementation of the mechanism of actions of healing pain relief. So, the Modulated Radiofrequency Therapy helps relieve trigger point and muscle spam that prevent regaining the full range of joint movement. For example of the Modulated Radiofrequency Therapy in combination with passive stretching of the shortened structures leads to their relief and immediately broadens the range of motion in the given segment. Combining the Modulated Radiofrequency Therapy and isometric or isotonic muscle contraction focuses the hyperthermia into the contracted muscle. Delivered radiofrequency energy facilitates these fibers and leads to their incorporation in the performed muscle stereotypes.
\end{abstract}

Keywords: Modulated Radiofrequency; therapy; medical rehabilitation; medical effects. 


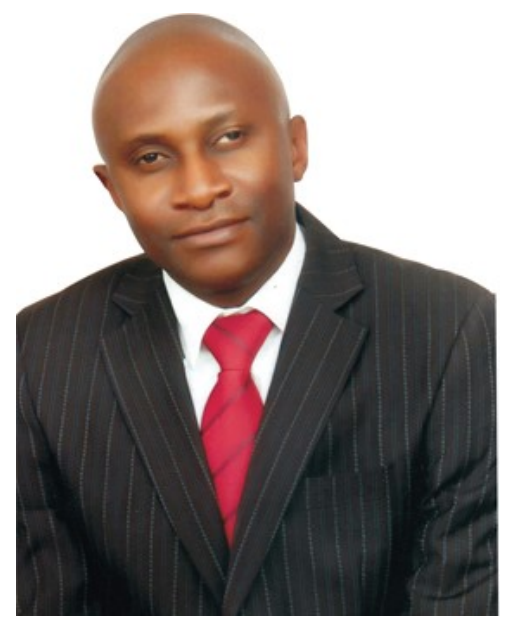

\section{Dr. Nghargbu K'tso,}

Lecturer/researcher, is a 41 year old Nigerian Medical Geologist who graduated in 2014 with distinction from The Ahmadu Bello University, Zaria, Nigeria. His doctoral programme was co-anchored by The University of Silesia in Poland, with Support from The Clinic of Balneology, College of Medicine, Nicholas Copernicus University in Torun, Poland. He is a recipient of many academic awards/ grants, and in 2011 became a fellow of the Polish National Commission for UNESCO. Dr. Nghargbu is widely travelled, and currently has to his credit eighty six scholarly articles/artistic works. Apart from being the African and Middle East representative on the board of the International Society for Medical Hydrology and Climatology, he also chairs the Nigerian Chapter of The Polish Balneology and Physical Medicine Association. Dr. Nghargbu is happily married to Rifkatu, lecturer and Health Economist. At the moment, this pioneer medical geoscience researcher seeks a post-doc position in any well established research/academic institution in order to advance his quest towards the understanding of both the beneficial and harmful effects of geologic materials and processes around the globe.

\section{BALNEO-ECONOMICS: A PROPOSED SCIENTIFIC THEME FOR BALNEOLOGICAL RE- SEARCH}

Rifkatu Nghargbu $1, K^{\prime}$ 'so Nghargbu ${ }^{2}$

1 Department of Economics, Usmanu Danfodiyo University, Sokoto, Nigeria

2 Department of Geology \& Mining, Nasarawa State University, Keffi, Ngeria

Corresponding Author: nghargtbu@gmail.com, +2348036063841

\section{Abstract}

\section{Introduction}

Balneological research has progressed more rapidly in the 21 st century with deepened scientific approach to the understanding and application of Balneological materials and procedures in the health care and pharmaceutical industries. Based on the increasing appearance of balneological products in the medical, pharmaceutical, cosmetics, and food/beverages markets, and their attendant contributions to the economies of their host countries/communities, the need to dedicate special economic tools towards quantifying/measuring variables is vital.

\section{Materials and methods}

In quantifying economic variables, health economic theories, econometrics and other Social Science statistical tools will be employed.

\section{Results}

Suggested areas of Balneo-Economic research include; cost effectiveness of SPA/Thermal medicine, profitability of balneological related industries, demand/supply and market size of balneological products, quantification of the contribution of balneological industries to Gross Domestic Products (GDP), health impacts, as well as the mineral/mining economics of geomedical resources and other related fields. These ought to be put together in a proposed new area of research titled Balneo-Economics.

\section{Conclusions}

The proposed theme is important in balneology because it quantifies the direct economic impact of SPA medicine and Balneological resources on humans and the national economies. Teaching such a subject to economic, medical and health professionals will not only broaden the knowledge horizon of such practitioners, but will also widen their job scope upon graduation.

Keywords: Balneo-Economics, cost effectiveness, industries, economic tools, $S P A$ /thermal medicine 

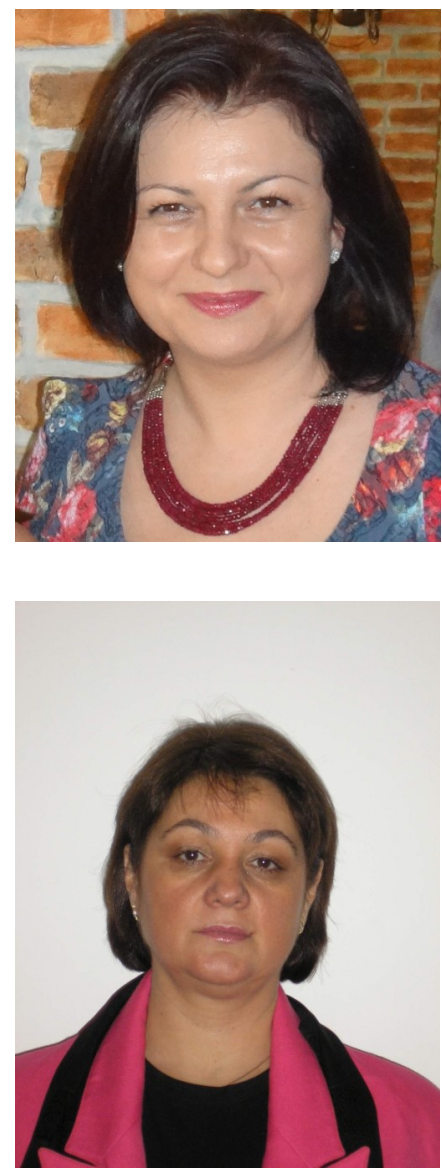

Sorina Martin, MD, PhD,

"Carol Davila" University of Medicine and Pharmacy, Elias Hospital, Endocrinology Department, Bucharest, Romania.

Sorina Martin, $\mathrm{PhD}$ in Endocrinology with the thesis "Clinical and Biochemical Factors Associated with the Prognosis and the Therapeutic Response in Graves' Disease" (2014) at "Carol Davila" University of Medicine and Pharmacy, Bucharest. She is currently Lecturer at "Carol Davila" University of Medicine and Pharmacy and Senior Consultant in Endocrinology at Elias Hospital, Endocrinology Department, Bucharest. She is specialized in thyroid ultrasound and clinical osteodensitometry (ISCD certificate 2007). Her major fields of clinical and research interest are thyroid autoimmunity, neuroendocrine tumors and osteoporosis.

Simona Fica, MD, PhD, is currently Professor of Endocrinology at Carol Davila University of Medicine and Pharmacy, Bucharest, Romania. In 2003 she founded the Endocrinology, Diabetes and Nutrition Disease Department at Elias University Hospital and she has been the Head of this Department ever since. She is Senior Consultant in Endocrinology and Diabetes, with more than 35 years of clinical, educational and research experience. She received her medical degree (1980) and her PhD (1989) from "Carol Davila" University of Medicine and Pharmacy. Her main clinical and research interest focuses on obesity and its metabolic consequences, the results of bariatric and metabolic surgery, infertility, polycystic ovary syndrome and neuroendocrine tumors. Between 2010 and 2013, Professor Simona Fica was the President of Romanian Society of Endocrinology and she also represented the Romanian Society of Endocrinology at the ESE Council of Affiliated Societies (ECAS). In 2009 she was elected Fellow of the American College of Endocrinology. .

\section{IODINE \& THYROID: THE GOOD, THE BAD AND THE UNEXPECTED} Sorina Martin $^{1,2}$ Simona Fica ${ }^{1,2}$

"Carol Davila" University of Medicine and Pharmacy, Endocrinology Department Elias Hospital, Endocrinology Department

Bucharest, Romania

Iodine is widely but unevenly distributed in the earth's environment, most iodide being found in the oceans. Iodine deficient soils are most common in inland regions, mountainous areas and areas of frequent flooding, but can also occur in island states and coastal regions. This arises from the distant past through glaciation, compounded by the leaching effects of snow and heavy rainfall, which removes iodine from the soil. Recommended daily iodine intake is $150 \mu \mathrm{g}$ in adults. Iodized salt is widely available, salt iodination beings legally mandated in many countries, including Romania.

Iodine is an essential component of the thyroid hormones. Thyroid hormones affect every organ system and are critical determinants of brain and somatic development in infants and of metabolic activity in adults. Thyroid dysfunction is one of the leading endocrine disorders. It represents around $30 \%$ to $40 \%$ of the patients seen in an endocrine practice.

Both insufficient and excessive iodine intake can result in thyroid disease. Iodine deficiency is a major public health problem for populations throughout the world. The term "iodine deficiency disorders" refers to the several important consequences that iodine deficiency imposes on individuals: goiter, hypothyroidism, and intellectual disability. Excess iodine exposure is generally well-tolerated, but can induce, in certain susceptible individuals, transient or permanent thyroid dysfunction. High iodine intake also seems to increase the prevalence of autoimmune thyroiditis. Sources of iodine excess include iodine supplementation to prevent iodine deficiency at a population level, the diet, vitamins and supplements, medications, contrast media and topical iodine. Moreover, iodine baths are used in balneology and iodine waters in internal cures.

The introduction of universal iodine prophylaxis in population previously in chronic iodinedeficiency led to a changing pattern of more prevalent papillary thyroid cancer and declining of follicular and anaplastic thyroid cancer. 


\section{Dr. Manuela Simona Pop}

Medical rehabilitation physician at Hospital Municipal G.Curteanu Oradea, head of section 2012 and currently

Rehabilitation Therapy MD, chief medical rehabilitation Laboratory Emergency Hospital Oradea, 2008-2012

medical rehabilitation physician, Emergency Clinic Hospital Oradea, 19912008

Associate Professor FMF Oradea, from 2002 to present

FMF lecturer Oradea, 1997-2002

Assistant Professor 1994-1997 MFF Oradea

\section{THE IMPORTANCE OF POSTURAL REALIGNEMENT IN OBESE PATIENTS}

Pop Manuela Simona, Farago Monica Adriana

\section{University of Oradea, Faculty of Medicine, The Municipal Hospital of Oradea}

OBJECTIVES. The consequences of obesity are found at three levels: physical, psychological and social, always interrelated. At physical level, cardiovascular diseases, type II diabetes and cancer are frequently mentioned and less are musculoskeletal function limitations. Aim of the study: to identify the consequences of postural malalignment in obese patients.

MATERIAL AND METHODS. The subjects $(n=31)$ were hospital in and out obese patients. Patient demographic data, subjective complaints, concurrent illnesses, body measurements were recorded. A physical exam including postural alignment, joint range of motion, muscle palpation and testing were completed. Applied questionnaire were: Pain Visual Analogue Scale, Baeck Physical Activity Measurement, and Quality of life. For lung function testing Spirometry was done.

RESULTS. Patients most frequent complaints were: musculoskeletal pain, fatigue, exercise intolerance, anxiety, sleep disturbances. Mean Body Mass Index (BMI) was 37,9 8,2. 90,32\% had posture malalignment, mostly at spine level, head, shoulders and knee and decreased flexibility and chest respiratory expansion. Joint and muscle pain in all patients Sedentary work in 77,4\% patients, more than 2 hours screen time/day and passive travel in 70,99\% patients. No sport activity. Altered quality of life in almost all domains.

Forward head posture, kyphosis, rounded shoulders and hiperlordosis with the concurrent muscle inbalances, muscles which are also respiratory muscle reflect in pain, spine and shoulder range of motion limitation, decrease in chest expansion. Consequently, lungs volumes are lower (reduced Vital Capacity and Forced Expiratory Volume in 1 second (FEV1)) with secondary oxygen deficiency, with consequences at all functional levels, the motor and the mental level being reflected in the limitations in physical activity and quality of life. The same postures are the reflection of stress, insecurity and low self-esteem and negative self-image.

CONCLUSIONS. Obese persons long term complex rehabilitation programs should be organized. In order to promote efficient respiration and movement, with increase in effort capacity and positive interference on mental level, the starting point might be posture control.

KEY WORDS: obesity, pain, physical activity, postur e control. 


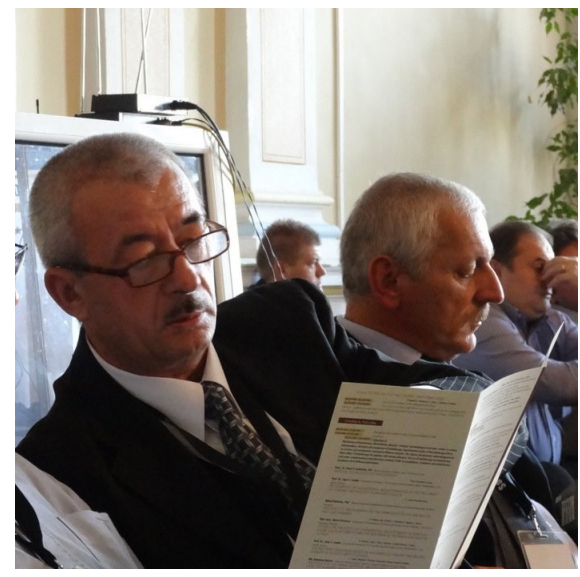

MSRII, Dr. (microbiol.), PhD, Pr. immunologist luri Simionca

President of PCS/CPS-UIS;

National Institute of Rehabilitation, Physical Medicine and Balneoclimatology, Bucharest

Chairman of International Scientific Committee at the XV International Symposium of Speleotherapy \& Organizing Committee of Permanent Commission on Speleotherapy (PCS) / Commission permanente de spéléothérapie (CPS) - UIS for Organizing Committee of XV ISS; President of the PCS/CPS-UIS; National Institute of Rehabilitation, Physical Medicine and Balneoclimatology, Bucharest

\title{
50 YEARS OF SPELEOTHERAPY IN SUBTERRANEAN SALT ENVIRONMENT AND 30 YEARS OF HALOTHERAPY ON THE SURFACE)
}

\author{
Iu.Simionca ${ }^{1}$
}

${ }^{1}$ Permanent Commission on Speleotherapy (PCS) / Commission permanente de spéléothérapie (CPS) of the UIS (ICSU \& UNESCO), Bucharest, Romania

INTRODUCTION: The Speleotherapy (ST) in salt mines and other galleries is practiced empirically. The development of ST promoted of halotherapy (HT) in artificial spaces.

MATERIALS \& METHODS: Were analyzed own and other authors scientific and bibliographic data in the field.

RESULTS: In the 50's in Germany appeared the first medical reports about efficacity of speleotherapy (Yang B., Schubert G., 1962). The first treatment in Wieliczka Salt Mine (Poland) basis for people with pulmonary diseases was set up in 1958, the first section of underground therapy being opened in 1964 (M. Skulimowski, 1968).

Have appeared scientific studies, treatment and recovery centers in caves and salt mines in Germany, Austria, Poland, Italy, Czech Republic, Slovakia, Slovenia, Ukraine, Romania, Russia, Armenia, Belarus, Iran, Nakhichevan and other countries. There are about 60 known caves and salt mines or other origin investigated or already used for speleotherapy.

HT has its origins in alergology hospitals Solotvino (Ukraine, "Zakarpatie") with "subterranean therapeutic sections" in salt mines. In the years 1975-1977 was specialy excavated a room where the disperse ground salt for inhalation by the asthma patients. The artificial analogy "salt room" was experimented and used in 1978 at Uzhgorod Branch of the Balneology and Physical Therapy Institute (Odessa,Ukraine) and has patented under the name "Ionotron". The concept of "halo chamber" for treatment in artificial salt microclimate, it was conducted by the Union Institute of Pneumology (St. Petersburg, Russia) in 1985 ("Galokamera", P.P.Gorbenko and coauthors), equipped with salt aerosol generator, as well as the methodology for medical use.

In the field of ST and HT they were achieved multidisciplinary scientific studies, international symposiums of PCS/CPS.

CONCLUSIONS: Have established the development of Speleoterapy in salt mines and caves, and Halotherapy in artificial salt chambers for use in health purposes. 


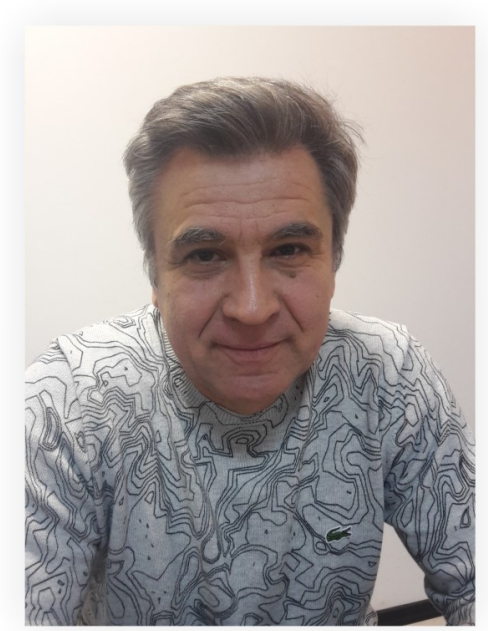

\title{
Dr. Liviu lordache
}

Primary physician, member of the Committee for the Evaluation of Adult Persons with Disabilities in Ilfov County

Medical activities pertaining to granting of certificates and internment into residential centres

Primary physician R.M.F.B.

Coordinating physiotherapy and emergency medical activity

Managing and coordinating ambulance service activities

Ilfov County Emergency Clinical Hospital, Bucharest

\section{A STUDY ON THE EFFECT OF PHYSICAL- BALNEARY THERAPY ON THE PACIENTS WITH DEGENERATIVE RHEUMATISMAL AND CEREBRO- VASCULAR, PATHOLOGIES}

\author{
Liviu Iordache
}

INTRODUCTION: A prospective study on 548 patiens diagnosed with residual hemiparesis and associated arthritic disease (gonarthrosis, coxarthrosis, hand arthrosis, cervical and lumbar spinal tract stenosis, spondilarthrosis).

METHODS: The study was conducted over 18 months (march 2005-march 2012).

Three evaluations were conducted:

* initial evaluation (spital)

* 6 and 12 months after the initial evaluation ( first balneary treatment)

* 6 months after the second balneary treatment

RESULTS: The recuperatory therapy in the resorts consisted of two annual treatments of 18 daily sessions, 6 months apart.

For both batches, comparison of different intervention types show that the therapies present no statistically significant differences for any of the three stages

CONCLUSION: Physio-kinetic therapy after 6 months, in a specialized recuperation centre, is efficient in reducing pain and improving the general status of pacients with residual hemiparesis and arthrosis disease. 


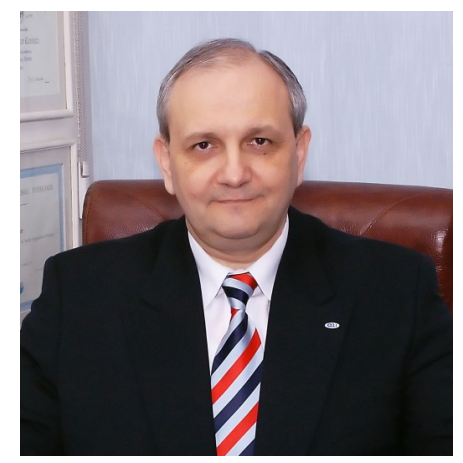

Professor Petrișor GEAVLETE

Academician (Corresponding Member) - Romanian Academy of Medical Sciences

Professor of Urology, MD, PhD ( "magna cum laude"), first degree Romanian specialist in Urology, Chief of Clinical Department, "Saint John" Emergency Clinical Hospital, Bucharest, Romania, Vice-President of the Romanian Association of Urology. Member/Board member in 15 International Urological Societies: Full Member - European Association of Urology; EAU Officer (Clinical Research Office 2002-2004); Board member - EAU Video Committee (20052013), Board member - European Society of Imaging in Urology (ESUI); Full Member - Société Internationale d'Urologie - Romanian representative (Deputy Delegate); Correspondent Membership - American Association of Urology; International Member - British Association of Urological Surgeons; Membre étranger - Association Française d'Urologie; Full Member - Endourological Society; Associate Member - EAU Section of Urolithiasis (EULIS); Board of Directory Member - Société Internationale d"Urologie (2015-2016).

Member in the Board of Doctorate School (PhD leadership former) - "Carol Davila" University of Medicine, Bucharest.

Author or co-author in over 1,200 papers published in journals, national and international congresses or meetings, abstract books of the most important urological publications and congresses in the world.

Editor, Author or co-author in 22 books. Some examples: Urologie (vol. I şi II), (Under Redaction), Editura Copertex SRL, Iunie 1999: Atlas of Endourology. Images and Techniques. (Editor in Chief), Editura Universitară „Carol Davila" Bucureşti, 2006, Bladder Calculi - An Evidence-based review. Chairman: Michael Wong, Members: Mohamed Al. Omar, Nor Azhari, Petrisor Geavlete, Gerald Haupt, Tricia Kuo, Zhou Liqun, Seiji Naito, Gyung Tak Sung, Chong Tsung Wen, Ureteroscopia, Under Redaction: P.Geavlete, Ed. Univ. C. Davila Buc, 2008, Chirurgia endoscopică a aparatului urinar inferior, Under Redaction: P.Geavlete, Ed. Univ. C. Davila Buc, 2010, Smith's Textbook of Endourology, Edited by Arthur Smith (redactor), Gopal Badlani, Glenn Preminger, Louis Kavoussi. Wiley-Blackwell Editure, 3rd Edition, 2012. 1808 pagini, Cap. 47, Ureteroscopy Complications. Petrișor Geavlete, The Stone Handbook EULIS Book, Scripta Manent Editioni, 2013, Percutaneous nephrolithotomy: Antegrade access to the ureter, Percutaneous nephrolithotomy: Combined intrarenal surgery (Galdakao-Valdivia position), Stone tratment in renal anomalities, Tratat de Endourologie, Vol. 1, 2 i 3, Under Redaction: P.Geavlete, Editura Universitara „Carol Davila” Bucuresti, 2013. 1788 pagini, Handbook of Endourology: Endoscopic diagnosis and treatment in urethral pathology, Endoscopic diagnosis and treatment in prostate pathology: Handbook of endourology, Endoscopic diagnosis and treatment in urinary bladder pathology: Handbook of endourology, Retrograde ureteroscopy: Handbook of endourology, Percutaneous surgery of the upper urinary tract: Handbook of endourology, Edited by Prof.dr. Petri or Aurelian Geavlete, Elsevier, 20152016

Over presented 300 videos (first author or co-author) and published 22 books (author, co-author or Editor).

Faculty in over 250 meetings during International Congresses.

Reviewer for the most inter national publications and urological meetings. 35 national and international distinctions.

Granted with "Health High Order" ("Commander" grade) offered by Romanian President in 2004.

FLEXIBLE URETEROSCOPY - TOP MINIM INVASIVE ENDOSCOPIC SURGERY, MONDIAL FURS/RIRS/URS: INSTRUMENTS, DISPOSABLES, TIPS AND TRICKS, INDICATIONS, COMPLICATIONS, CASES 


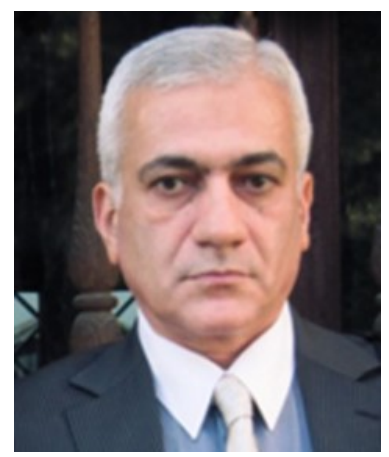

Alexandru Tascu, MD, PhD.

ASSOC. PROFESSOR OF NEUROSURGERY

HEAD OF $1^{\text {st }}$ NEUROSURGICAL CLINIC

"BAGDASAR-ARSENI" CLINICAL HOSPITAL

"CAROL DAVILA" UNIVERSITY OF MEDICINE AND PHARMACY"

BUCHAREST, ROMANIA.

Dr. A. Tascu is currently working as neurosurgeon - Head of $1^{\text {st }}$ Neurosurgical Clinic, and academic staff at "Bagdasar-Arseni" Clinical Hospital, "Carol Davila" University of Medicine and Pharmacy", Bucharest Romania. His main clinical interest focuses on pediatric neurosurgery.

Training and scholarships: Tel-Aviv, Israel, Tel-Aviv University - "Sackler Faculty of Medicine", CME School - Beilinson Hospital; Brussels, Belgium, "Hopital Universitaire Erasmus"; Marseille France, "Hopital de la Timone" - Pediatric Neurosurgical Department; Head of Neurosurgical Dept. 50 ${ }^{\text {th }}$ Military Field Hospital as member of UN Peace Keeping Forces, "RESTORE HOPE" Operation, UNOSOM II, Mogadishu, Somalia. His research has been published in high-level academic journals including: Child's Nervous System, Journal of Neurological Surgery, Pediatric Blood \& Cancer, Neuro-Oncology, Journal of Neurosurgery, et.al. As academic staff he has authored or co-authored in 15 books (27 chapters), 45 articles and abstracts published in ISI indexed journals, 76 articles and abstracts published in IDB indexed journals, 73 international presentations, 184 national presentations, obtaining over 118 citations. (ISI Web of Science Thomson Reuters, PubMed-NCBI, Science-Direct Elsevier B.V., etc.) National and international professional memberships: RSN, ROSCOS, ROSNERA, ARCE, EANS, WFNS, ESPN. ISPN, WEDNS, IHIWG, SeENS, etc.

\section{TRAUMATIC SPINE INJURIES IN CHILDREN - PARTICULARITIES OF DIAGNOSIS, TREATMENT, OUTCOME AND REHABILITATION \\ Alexandru Tascu ${ }^{1.2}$, Daniel Serban ${ }^{1 .}$ \\ 1. "Bagdasar-Arseni" Clinical Hospital \\ 2. "Carol Davila" University of Medicine and Pharmacy}

Objective: In childhood, the growing spine has some anatomical and biomechanical particularities that result in age specific traumatic patterns. Until the age of 15-16 years old, the spine is submitted to progressive anatomical and biochemical changes, spinal rigidity increasing gradually. The authors' attempt is to perform an extended study regarding this subject.

Material and method: A retrospective study has been performed, including over 400 pediatric patients with traumatic spine injuries, admitted in Bagdasar-Arseni Clinical Emergency Hospital in the last ten years, from 2006 to 2015 . The diagnosis has been established by clinical examination and neuroimaging techniques as CT and/or IRM. The study group has been divided in 4 age-related categories: 0-3 y., 4$7 \mathrm{y}$, , 8-14 y. and 15-18 y., taking into consideration some specific developmental age aspects and related risk factors. Neurological status has been established by Frankel Classification grading system. Also the ethology, injury mechanism, localization of the spinal injury level and lesion type have been analysed. According to particularities of traumatic spine injury in children, over $60 \%$ of the patients have been treated in a conservative way, while the rest of patients needed surgery approaches.

Results: Following the medical observation records study, a distinct injury profile, explained by anatomical and biomechanical features, distinguishes the young patients with an immature spine from the older teen-agers with a more mature, adult-like spine.

Conclusions: Traumatic spine injuries in children and young adults have a lower incidence than in adults, mainly due to a more flexible spine. The outcome and quality of life depends on the severity of spinal cord injuries, with neuro-functional recovery noticeably increased in paediatric population compared to adult population. Anatomical particularities in children spine allows a better applicability of conservative treatment. If we compare paediatric and adult spine injury we can certify that identical situations lead to different prognosis and outcome is better in children with spine trauma, decreasing toward adolescence and young adults. Neurosurgeons and neuro-rehabilitation staff have to collaborate more closely than usual, aiming a better outcome of this special category of patients. 
Anca Mirela Ionescu, Senior Physician Specialist in Sports Medicine, Professor and Head of the Sports Medicine Department at the University of Medicine and Pharmacy "Carol Davila", Bucharest, Romania and also a European trainer (UEMSMJC on Sports Medicine). Since 2006, I have been a National Coordinator for Sports Medicine Specialty Training. I am working at the National Institute of Sports Medicine in the Laboratory for Testing the Effort Capacity. I am also giving lectures at the National Center of Coaches Formation. I am focusing my activity on sports physiology, sports physiopathology and sports nutrition, particularly on applying basic science concepts to physical activities in order to optimize sports performance and promote health. So far, I have published 7 articles and books (as a coordinating author or a coauthor). Since 2005, I have annually organized in Bucharest National and International Conferences and courses of Sports Medicine. Regarding my publishing activities, I am a Managing Editor of the Romanian Sports Medicine Journal (www.medicinasportiva.ro) and a reviewer for Exercise Physiology and Sports Nutrition (the Asian Journal of Exercise \& Sports Science). I am also a member of the editorial board of Palestrica of the Third Millennium, the Hellenic Sports Medicine Journal, Timisoara Physical Education and Rehabilitation Journal, the Sport Science Review and the European Journal of Sports Medicine (EUJSM) - the official journal of European Federation of Sports Medicine Associations (EFSMA).

National Manager Sports Medicine MJC - UEMS (2011-present)

President of the Romanian Sports Medicine Society (2005-present)

President of the Balkan Sports Medicine Association (2006-2008)

Member of the Executive Committee of the EFSMA (2009-present), member of the Scientific and Education Commission of the European Federation of Sports Medicine Associations (2007-2009)

European Scientific Advisor for Gatorade Sports Science Institute (2006-2009)

Foreign languages: French and English

\title{
EXERCISE PRESCRIPTION in PREVENTION, REHABIITATION AND THERAPY
}

\author{
A.M.Ionescu ${ }^{1 *}$ A. Caramoci ${ }^{1}$
}

Faculty of Medicine, UMF “Carol Davila” - Sports Medicine Department

National Institute of Sports Medicine, Bucharest

* corresponding author: anca_mirela_ionescu@yahoo.com

\section{Introduction}

Sports Medicine was recognized during the past years as a specialty dealing with the prevention of chronic diseases caused by sedentary lifestyle. Physical activity is essential to good health and quality of life. Developing a recommended exercise prescription for sports medicine physicians in Europe is the goal of EFSMA.

Material and Methodes

In order to generate the expected outcome and not to produce adverse reactions, physical exercise must be exactly prescribed (drug!). It must have a specific intensity, duration and volume. Exercise physiology and its principles are the basis of a exercise prescription and it is not an alternative to drugs for BP, DM-II, obesity, hypercholesterolemia but a complementary form of therapy. Sports Medicine doctors play a pivotal role with exercise prescription.

Physical activity in the elderly is strongly recommended, it is and beneficial. Sports in the aged should be versatile including endurance, strength, mobility and coordinative training. Arthrosis in the leg joints should not be a barrier to activity and has therapeutic value It can reduce the number of required medications and/or enhance their efficacy. Medication needs to be adapted to activity.

Original prescription should contain FITT: Fr equency /week, Intensity (METS), Type of exercise, Time/ minutes) and also warm-up, cool down and flexibility recommendations. The exercise prescription is signed by both doctor and patient. The patient is called-in after 6 weeks to evaluate his evolution and accommodation to the exercise.

Conclusions

Prescribing exercise is not enough! Offer your patients a practical aid as to how more exercise can be integrated into their daily life. Motivate the patients to adopt healthy lifestyle and better exercise habits. 


\section{CIOROIANU VIRGIL-STEFAN-DAN}

- Conf. Univ. Dr., Disciplina de Neurologie,

Doctor în Ştiinţe Medicale

Societatea Română de Ştiinţe Fiziologice, din 1994

FEPS (Federaţia Societăţilor Europene de Fiziologie), din 1994

IUPS (Uniunea Internaţională a Ştiinţelor Fiziologice), din 1995

Societatea Română de Neurologie, din 1996

Centrul de Cercetare - Servicii Medicale - UMF Craiova

\section{STANDING AND WALKING REHABILITATION IN PATIENTS WITH HEMIPARESIS}

D. S. Cioroianu*, E. Paun*, A. M. Bumbea*, L. R Paun**, C. Stoica***, A. M Albu***, B. S. Bumbea***

* Medical Rehabilitation Md, PhD, Neuropsicyatry Hospital, Neurological Rehabilitation Department

$$
\begin{aligned}
& * * \text { Medical Rehabilitation Resident } \\
& \text { *** Medical Rehabilitation Physician }
\end{aligned}
$$

OBJECTIVES: The authors want to evaluate the role of kinetotherapy early applied to patients with hemiparesis after stroke for recovering standing and walking. The ability to walk is considered the most important aspect of recovery in stroke. Walking speed is considered the significant marker, sensitive and stable severity and ability to waking deficit.

MATERIAL AND METHOD: We have evaluated 50 patients (age between 50 and 70 years) divided in two groups: one, named lot A, with patients who have started the recovery program during the first 6 months from the stroke and a second group patients, named lot B, who have started their recovery program 6 months after their cerebral vascular accident.

Patients were evaluated at first and at six months, following a physical therapy program 15 days in the first phase, then its continuation at home. After the 6 months was made final evaluation. They were evaluated according walking and standing scales: Tinetti Balance Score, TUG test (Timed Get Up and Go Test) and Six Minute Walk Distance.

RESULTS: The group A which began physical therapy program in the first six months after stroke achieved superior results compared to group B, both standing and walking in recovery, and the results were maintaining durig our observtional study.

CONCLUSION: Physical therapy applied early in the first 6 months after stroke shown better results and that could be a guide for this category of patients. 


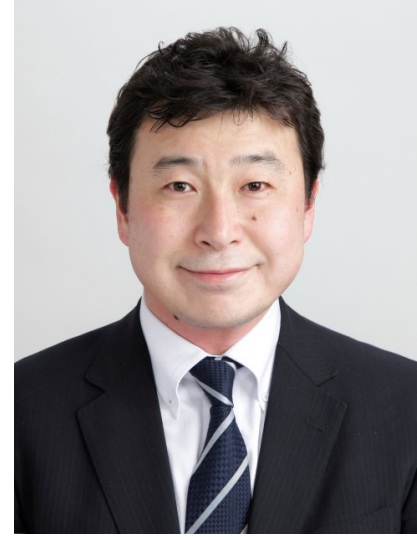

\title{
Yasuaki Goto
}

Senior Research Scientist, ONSEN Medical Science Research Center, Japan

Health \& Research Institute, Tokyo, Japan

E-mail: ygoto@onsen-msrc.com

Research Interest:

Aging Science, Psychophysiology, Balneology and Behavior science

Awards

Excellent paper in 2012, The Japanese Society of Balneology, Climatology and Physical Medicine

Recent Publications:

Yasuaki Goto, Shinya Hayasaka, Yoshikazu Nakamura.

Health Effects of Seasonal Bathing in Hot Water, Seasonal Utilization of Hot

Spring Facilities, and High Green Tea Consumption.

J Jpn Balneol Climatol Phys Med, 77(2), 171-181, 2014

Yasuaki Goto, Shinya Hayasaka, Yosikazu Nakamura.

Bathing in Hot Water, Bathing in Japanese Style Hot Spring and Drinking

Green Tea May Contribute to the Good Health Status of Japanese.

J Jpn Balneol Climatol Phys Med, 75(4), 256-266, 2012

\section{PHYSIOLOGICAL AND PSYCHOLOGICAL BENEFITS OF BATHING STYLE IN JAPAN}

\author{
Yasuaki Goto \\ ONSEN medical science research center, Japan Health \& Research Institute, \\ Tokyo, Japan, ygoto@jph-ri.or.jp
}

The daily bathing routine is usually a soaking in hot water heated to approximately $40^{\circ} \mathrm{C}$. Because of this habit, we think that Japanese bathing style is very unique from a global perspective. For Japanese, the main purpose of bathing is not only to clean and to wash the body, but also to warm the body in the hot water. It is known that bathing has many positive effects and the greatest benefit is the thermal effect which could improve blood flow via the dilation of blood vessels, followed by reducing $\mathrm{CO} 2$ and increasing $\mathrm{O} 2$ levels of the extremities. We therefore believe that a bathing can refresh ourselves physically and mentally.

We hypothesized that bathing in hot water may be one reason for Japanese good health status. Several cross-sectional studies have been shown the good effects of bating in hot water on health. We will present several our studies in which we compared the effects of bathing in hot water and taking shower in daily.

We conducted three intervention studies in 2011, 2012 and 2013.

In the first study, we investigated self rated health status and found that subjects with bating in hot water for 2 weeks showed better condition with respect to subjective health status such as self-rated health, skin condition, stress and fatigue compared with those with taking shower for 2 weeks. In the second study, we investigated the sleep quality by EEG and found that the delta band power density known as an indicator of deep sleep for resting brain in the first sleep cycle was significantly increased in the subjects with bathing in hot water compared with those with taking shower. In the last study, we collected the data in terms of the gene expressions related to bathing, we showed that GABRG2 (anti-stress), SIRT4 (anti-aging), DEFA4 (anti-bacteria), and IRF4(anti-virus) were increased after bathing in hot water for two weeks. From these studies, we think that bathing in bathtub with hot water daily may contribute to the good health status of Japanese. 


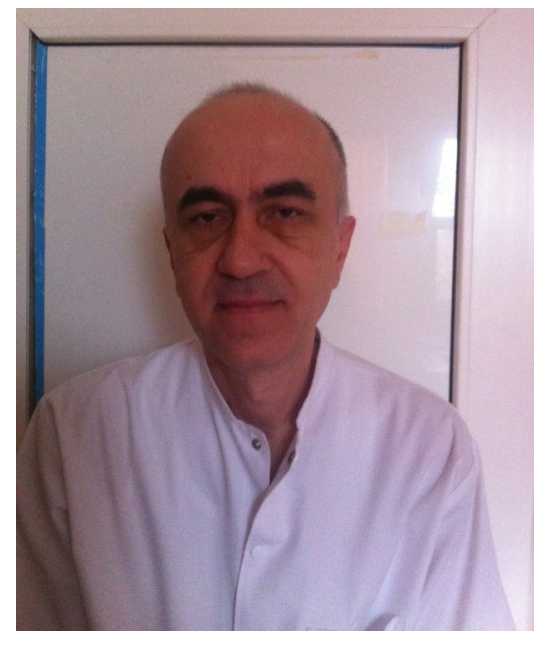

\title{
Prof. GRIGOREAN Valentin Titus
}

Professor in general surgery

Specialist in cardiovascular surgery

Senior specialist in general surgery

Habilitation thesis : Interdisciplinary collaboration between general surgery and neurosurgery, borderline pathology and new surgical techniques" University of Medicine and Pharmacy "Iuliu Hatieganu”, Cluj-Napoca, Romania

I published 73 articles (19 articles ISI rated, 29 articles indexed in IDB, 25 articles not indexed in IDB)

I published 8 books, 34 book chapters and I was contributor to one book

I had 416 scientific communications in national/international congresses, conferences, courses

I participated in 11 research projects (as a project manager in one, as a project responsible manager in one and as a research team member in eight)

\section{ALTERNATIVE SURGICAL THERAPY TO STANDARD TREATMENT FOR HYDRO- CEPHALUS: VENTRICULO-EPIPLOOIC SHUNT AND VENTRICULOPORTAL EXTRA- PERITONEAL TRANSOMPHALIC SHUNT}

\author{
Valentin Titus Grigorean ${ }^{1}, \mathrm{MD}, \mathrm{PhD}$; Aurelia Mihaela Sandu ${ }^{2}, \mathrm{MD}, \mathrm{PhD}$ \\ ${ }^{1}$ Professor at University of Medicine and Pharmacy "Carol Davila", $10^{\text {th }}$ Department of General \\ Surgery; Head of the Department of General Surgery, Emergency Clinical Hospital Bagdasar-Arseni, \\ Bucharest, Romania \\ ${ }^{2}$ Emergency Clinical Hospital Bagdasar-Arseni, Fourth Department Of Neurosurgery, Bucharest, \\ Romania
}

\begin{abstract}
Introduction: Hydrocephalus is an extremely invalidating disease with high impact on population, requiring frequent medical care.

Material and methods: Over the times many different surgical procedures were tried, but even though ventriculoperitoneal and ventriculocardiac shunts proved their feasibility, they have high risk of complications. We propose two new surgical techniques, ventriculo-epiplooic and ventriculoportal extraperitoneal transomphalic shunts for treatment of hydrocephalus. First, we performed the two surgical techniques, ventriculo-epiplooic and ventriculoportal extraperitoneal transomphalic shunt, on experimental animals with highly similar anatomy (pigs), according with the laws in force. Latter, we performed ventriculo-epiplooic shunt on humans, and we retrospectively reviewed medical records of these patients.

Results: Experimental animals in both studies had favorable outcome, with no postoperative early or late morbidity.

Between 2008 and 2012 we performed ventriculo-epiplooic shunt in 12 patients, 6 men and 6 women. The technique was performed in 10 patients with multiple classical shunt revisions and in two was done per primam. The outcome was favorable in all cases, with no significant postoperative complications.

Conclusions: Ventriculo-epiplooic and ventriculoportal extraperitoneal transomphalic shunts are two new, safe and efficient surgical techniques for treatment of hydrocephalus. They can be performed as a saving solution in patients with repetitive classical shunt failures. Complications specific to classical shunt systems can be successfully avoided. Ventriculo-epiplooic and ventriculoportal shunts have multiple advantages compare to other classic shunt techniques, with no additional stipulated complications. In case of ventriculoportal shunt further research is needed and this surgical technique must be performed on human subjects with hydrocephalus.
\end{abstract}




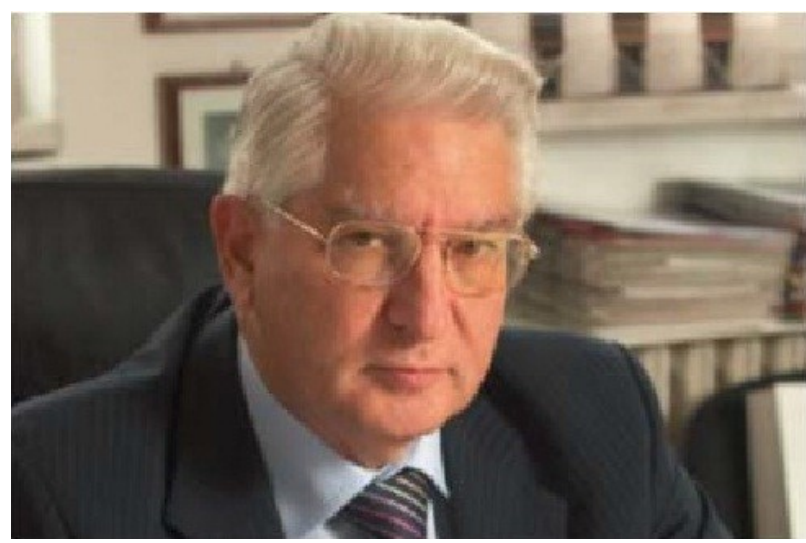

\section{Prof. Ciurea Alexandru Vladimir}

Profesor of Neurosurgery

2004-2008 University of Medicine and Pharmacy "Carol

Davila" Bucuresti-Pro Dean

University of Medicine and Pharmacy "Carol Davila"

Bucuresti, Decision 15209/07.07.2004

Member of the Board of Professors (2000-2004) (2004-

2008)

Member of the University Senate (2004-2008)

94 articles published in Pub. Med. \& Thomson ISI and 36 books published in Romania and abroad Hydatidosis of the Central Nervous System Ed. Turgut M. - Cap. 21. Ciurea AV. In: Springer Wien New York, 2014

Intracranial Hypertension. Ciurea AV, M. St. Iencean. Nova Biomedical, New York, 2009.

Essential Practice of Neurosurgery Ed. K.K.N. Kalangu, Y. Kato; Traumatic Brain Injury in Children \& Physiopathology of Intracranial Hypertension;Ed. Hishigen Co., 2009

Practical Handbook of Neurosurgery Ed.M. Sindou; Cranial traumas in children; Ed Springer Wien New York, 2009

Pediatric Hydrocephalus - Capitol: Postinfections Hydrocephalus in Children Authors: G.Cinalli, W. J.

Maixner, C.Sainte-Rose, Ed. Springer, New York, 2004

18 Research projects

National Presidential Order " Faithful Service " with the grade of Commander (2000)

Romanian Academy Award for the "Neurosurgical Pediatric Pathology" monography; 1981.

\section{MOTILITY OR MORBIDITY IN NEUROSURGERY AND NEUROLOGY \\ Motto: „I move, therefore I am” \\ (Haruki Murakami, Japanese Writer)}

\section{AV. Ciurea ${ }^{1,2}$ MD., PhD., MSc., Dr. h.c. Mult., H. Moisa ${ }^{1}$ MD, A. Mohan ${ }^{3}$ MD., PhD, G. David ${ }^{4}$ MD., PhD, I. Luca-Husti ${ }^{2}$ MD}

1: Department of Neurosurgery, Carol Davila University School of Medicine, Bucharest, Romania.

2: Department of Neurosurgery, Sanador Medical Center Hospital, Bucharest, Romania.

3: Department of Neurosurgery, County Hospital Oradea

4: Department of Neurosurgery, Military Hospital Brasov

\section{Background :}

„The lack of motion is a basic process in the birth of diseases". (Hipocrat anii)

Biological motility is the capacity of an organism to move spontaneously and voluntary at the expense of energy and represents one of the crucial traits (if not the most important trait) of all living matter. Motility is a key process present in unicellular organisms as well as multicellular organisms and is the basis of embryonic development, would healing, immune response, tumor formation, metastasis, cell migration, digestion, circulation, respiration and reasoning and various other critical processes including biological evolution itself.

\section{Materials and methods :}

All surgical interventions (cheiron+ergon = gesture done by hand) represent - in broad lines - small controlled traumas with the sole purpose of removing tumors (surgical oncology), removing foreign bodies and restoring organ integrity (trauma surgery), restoring vascular flow to the body (cardiac surgery and vascular surgery), decompressing the brain (neurosurgery) and so on. In all areas of surgery cell and tissue motility is singlehandedly the key to healing and succes.

Conclusions - we believe that motility is the key to limiting and improving worldwide morbidity while also limiting the effects of other diseases and increasing the healing rates of other pathologies while also preventing thrombosis. Neurosurgical and neurovascular pathologies are prime targets for early motility of patients. Under these circumstances a modern medicine without early postoperative mobilization of the patient is no longer concievable, a fact which is in strict accordance with the old saying in the bible ,, Take up your bed and walk"(John 5:8).

Key Words: Neurosurgery, Mobility, Morbidity, Neuror ehabilitation, Evolution, Outcome 


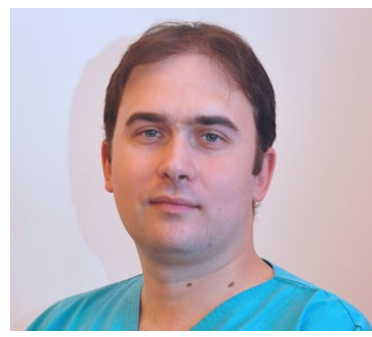

Razvan Multescu MD, PhD

Dr. Razvan Multescu is senior urologist and has a $\mathrm{PhD}$ in Medicine. He is member in 11 national and international organizations including Romanian Association of Urology, European Association of Urology, Societe Internationale D'Urologie, Endourological Society, European Society for Sexual Medicine. His training included 37 national and international courses and training sessions including a MasterClass in Urology organizaed by European School of Urology and Weill Cornell, training in the Department of Urology of St. Elisabeth Hospital in Leipzig and postdoctoral studies with the theme „Optimizing retrograde flexible ureteroscopic approach in the treatment of pyelocaliceal calculi". He is author or co-author in nine urological books, including "Endoscopic Diagnosis and Treatment in Urethral Pathology", "Endoscopic Diagnosis and Treatment in Prostate Pathology" amd "Endoscopic Diagnosis and Treatment in Urinary Bladder Pathology" published in Elsevier - Academic Press, UK, 2016. He is author or coauthor in 406 papers, posters or videos presented in national or international Congresses, and in 84 articles published in natioal or internationals journals. He is reviewer for several journals and Congresses, among them Urology Annals and Engineering and Urology Society Congress (best reviewer in 2015). Dr. multescu received six national and international prizes for his scientific contribution, among which $1^{\text {st }}$ Prize in $5^{\text {th }}$ International Meeting "Challenges in Endourology and Functional Urology" for "Long term efficacy of the bipolar plasma enucleation of the prostate in large size BPH patients - a clinical parallel to standard open prostatectomy" and the "C.C. Iliescu" Prize of Romanian Academy of Medical Sciences for "Textbook of Endourology".

\section{MANAGEMENT OF UROLITHIASIS IN IMMOBILIZED PATIENTS}

\section{Multescu R, Geavlete P}

INTRODUCTION: Immobilized patients present an increased risk of urolithiasis, with some management particularities. Immobilization hypercalciuria, recurrent urinary tract infections, indwelling catheters or vesicoureteral reflux may be among the risk factors in these patients.

METHODS: Urolithiasis should be identified and treated as soon as possible, in order to prevent complications (especially septic ones) and to preserve the renal function. The treatment alternatives should be as minimally invasive as possible, one of the reason being the high recurrence rates.

Bladder calculi are frequent in these patients due to various factors including neurogenic bladder dysfunction, catheterization or urinary tract infections. The incidence of upper urinary tract lithiasis is also high, a significant proportion having infectious stones.

RESULTS: Although all the therapeutic alternatives can be employed, there are also some particularities that may influence their outcome. SWL may have a high success rate but clearance of stone fragments may be mediocre. Interventional alternatives such as retrograde intrarenal surgery using flexible ureteroscopes or percutaneous surgery, although have success rates similar to those in general population, may be difficult to perform due to musculoskeletal abnormalities, muscular contractures etc.

CONCLUSION: Surgical treatment should be associated with antibiotherapy or other medical treatment to decrease the risk of recurrence. 


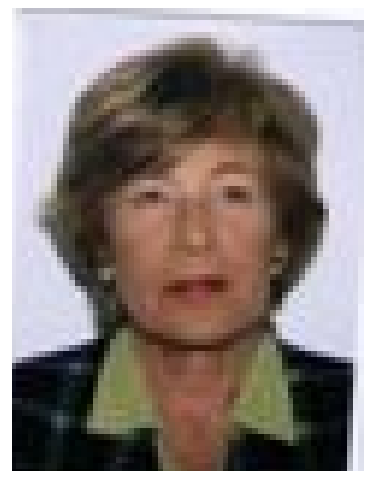

Natalia Chaurskaya

Natalia CHAURSKAYA ,BORN IN TUAPSE ( RUSSIAN FEDERATION)

DEGREE IN PHYLOLOGY AND FOREIGN LANGUAGES

( FRENCH,GERMAN) ( University of Foreign languages ,Moscow)

POST DEGREE IN MEDICAL BIOLOGICAL SCIENCES (Moscow State Univer-

sity)

Specialist in medical translation of the Ministry of Health of USSR

Coordinator of the medical biological programs between USSR and France

Translator professional of many medical handbooks

Coordinator of some international programs of the Russian Academy for Tourism (RMAT)

Director of the International Training Center FEMTEC-RMAT in Moscow

Head of the Int.Dep.of FEMTEC ( Wordl Federation of Hydrotherapy and Climato-

therapy) (www.femteconline.org)

President of the EUROPEAN ASSOCIATION OF PATIENTS AND USERS OF

THERMAL CENTERS (www.eaptc.net)

\section{THERMAL CLUSTERS IN RUSSIA}

\section{Natalia Chaurskaya,Russina International Academy for Tourism,Moscow}

The modern term "cluster" refers to large districts within the Country that are formed and developed around the activity of a community of people that share a geographic, historical, industrial, social, and cultural background. Therefore, the use of the term "thermal clusters" should first and foremost take into account existing natural and historical factors.

The early development of the thermal sector in Russia dates back to the era of Peter the Great, who opened the first thermal establishment Marcial'nye vody - "Martial Waters" - with a decree of 1719 near the present city of Petrozavodsk, where mineral sources characterized by high iron and arsenic levels had been discovered. It was the start of studies on hydro-mineral resources in Russia. (slide 1)

Other mineral water sources were found in the northern Caucasus, also during the reign of Peter the Great, but their exploitation and the foundation of the Caucasian Mineral Waters thermal station only started almost one century later when, by order of Alexander I, indoor thermal establishments were first built to use mineral waters and muds for therapeutic purposes in the Pjatigorsk district, where "hot water with the typical acid smell gushed in huge spurts from the mountain." (slide 2)

During the $20^{\text {th }}$ century, new sources of mineral water and thermal mud were discovered across the Russian territory, and the health care facilities founded in their neighbourhood promoted the quick expansion of cities and the creation of broad thermal regions. These huge districts included the thermae on the Caucasian shore of the Black Sea, of Crimea, of the Altai region, of the Urals, and of the far East. Thus, 36 thermal establishments were in place by the end of the $20^{\text {th }}$ century, with a total bedplace capacity of 3,000 . (slide 3)

The sector further developed during the Soviet era with the foundation, in 1926, of the Central Institute of Balneology in Moscow, upon initiative of N. Semaško, Minister of Public Health. Fourteen Centres for Research on balneology and physiotherapy were in place by 1970, whose tasks included research on thermal sources, studies on their properties and action mechanisms, design of therapeutic approaches, studies on their efficacy, indications, and contraindications, etc. (slide 4)

At present Russia includes 10 large thermal districts:the North-Western region, central Russia, the Volga region, the Ural region, the Altai region, lake Baikal, the far East, the Caucasian shore of the Black Sea, the Caucasian Mineral Waters region, and Crimea. There are a total of 2,147 thermal resorts with 410,000 bedplaces in Russia, where more than 5 million people relax and seek treatment every year. The Ministry of Health operates 51 thermal care centres. The others are owned by the region, the state, or private parties. Today, 8 centres for research on balneology and physiotherapy operate within the present Russian territory - in Moscow, Pjatigorsk, Ekaterinburg and Ufa (Urals), Tomsk (Siberia), Vladivostok, Šoci, and Yalta respectively. (slide 5) (slide 6 map of Russia)

- marketing \& advertising, as well as use of web resources. 


\section{OP 001- EARLY POST-ACUTE CLINICAL PARTICULARITIES OF ELDERLY WITH CERVICAL SPINAL CORD INJURY}

Aurelian Anghelescu ${ }^{1,2}$, Cristina Popescu ${ }^{1,2}$, Cristina Octaviana Daia ${ }^{1,2}$, Anca Sanda Mihaescu ${ }^{1}$, Gelu Onose ${ }^{1,2}$ 1. Neuromuscular Rehabilitation Clinic, Teaching Emergency Hospital "Bagdasar-Arseni", Bucharest

2. "Carol Davila" University of Medicine and Pharmacy, Bucharest

INTRODUCTION: Evaluation of early post acute evolution after cervical spinal cord injury (CSCI) at elderly ( $\geq 65$ years), first time admitted in NeuroRehabilitation, during 2004-2013.

MATERIALS AND METHODS: Retrospective analysis of medical files. There were 281 subjects, 201 males, 80 females (ratio 2.5); the average age was 71.5 years (range 65-86). Most of the patients $(79 \%)$ were from rural regions; $56 \%$ of the CSCI happened during agricultural activity. Etiology was dominated $(79 \%$ ) by accidental falls [same level $(22.8 \%)$ or height (falls from chariot $41.3 \%$, trees $5.7 \%$, ladder $9.2 \%$ )]; traffic accidents in $21 \%$.

RESULTS: The evolutive trends during rehabilitation phase, pointed a seminificatively neurological improvement $(\mathrm{p}<0.01$ ) towards the incomplete lesional status (AIS C+D group at admission $59.4 \%$ vs.discharge $75 \%$ cases) compared to the totally paralised group (AIS A+B at admission $40.5 \%$ vs. discharge $25 \%$ cases).

Comparing the evolutive direction (amelioration vs. agravation or stationary status) a significant improvement $(\mathrm{p}<0.01)$ was noticed at the surgicaly approached group (68.6\% patients) vs. conservative treatment ones $(31.4 \%)$.

Most of the survivors 170 (63.9\%) were discharged at home, whereas 51(18.6\%) were admitted in nursing home, aspects significantly correlated $(\mathrm{p}<0.01)$ with the marital status vs. single (widow or divorced).

Miscellaneous medical complications were acquired: transient postural hypotension $(68.3 \%)$, asymptomatic urinary infections $(89 \%)$, haematuria $(14.4 \%)$, bronchopneumonia $(11.3 \%)$, enterocolitis (13\%), deep-vein thrombosis (5.6\%), mild decubitus ulcer $(2.5 \%)$; depression $(58.7 \%)$, central pain (44\%). Mortality rate during hospitalization was $2.5 \%$.

CONCLUSIONS: Early post-acute admision after spinal surgical stabilization and comprehensive rehabilitative approach, favored a better outcome and a low mortality rate of elderly CSCI.

KEY WORDS: cervical spinal cord injury (CSCI), elderly, etiology, early post acute evolution, comprehensive rehabilitation, outcome, medical complications, mortality rate.

\section{OP 002 - CURRENT SITUATION OF POLICIES ON THE EMPLOYMENT OF PERSONS WITH DISABILITIES IN ROMANIA}

Aurelian Anghelescu ${ }^{1,2}$, Mihai Bușcă ${ }^{3}$, Adina Constantin ${ }^{4}$, Ioana Andone ${ }^{1}$, Valentin-Titus Grigorean ${ }^{1,2}$, Lucia Ana Maria Anghelescu, , Oana Ilona David ${ }^{1,2}$, Gelu Onose ${ }^{1,2}$

${ }^{1,2}$ Teaching Emergency Hospital "Bagdasar-Arseni", Bucharest, "Carol Davila" University of Medicine and Pharmacy, Bucharest, Legal adviser, SC Fiatest SRL, Bucharest, General Directorate of Social Assistance and Child Protection, District 3, Bucharest, Anthropology department, of the Sociology and Social Work University of Bucharest

INTRODUCTION: Promoting optimal social integration of people with disabilities represents a major objective of the Romanian health, social and political strategies.

MATERIAL AND METHODS: Review of the official data and studies on employment of disabled people, actualized to 2015.

RESULTS: The total number of disabled people was 759,019 (3.41\% of the Romanian population). About 415,852 (59.58\%) were aged between 18 and 64 years. Rate of employment of disabled persons is very small (14\%). People with somatic disability represent the most employed category $(38.4 \%)$; least employed were the mental $(3.1 \%)$ and psychiatric $(5.2 \%)$ categories.

CONCLUSION: This paper is an updated integrative approach to the Romanian current policy and situation regarding (re-)employment of people with disabilities. It underlines the main improvements and limitations of the continuous endeavor to implement the legislative framework concerning: protection, integration, promotion and inclusion of handicapped / disabled persons in Romania, actualized to 2015 .

KEYWORDS: disability, handicap, inclusion, social assistance, Romanian law 448/2006, republished 2008) 


\section{OP 003 - EVOLUTION OF TRAUMATIC SPINAL CORD INJURY IN PATIENTS WITH AN- KYLOSING SPONDYLITIS, IN A ROMANIAN REHABILITATION CLINIC}

Aurelian ANGHELESCU ${ }^{1,2}$, Liliana Valentina ONOSE ${ }^{3,}$ Cristina POPESCU ${ }^{\mathbf{1 , 2}}$, Ioana ANDONE ${ }^{\mathbf{1}}$, Cristina Octaviana DAIA ${ }^{\mathbf{1 , 2}}$ Anca Magdalena MAGDOIU ${ }^{4}$ Aura SPANU ${ }^{\mathbf{1}}$ Gelu ONOSE ${ }^{\mathbf{1 , 2}}$

Teaching Emergency Hospital "Bagdasar-Arseni", Bucharest, Neuromuscular Rehabilitation

University of Medicine and Pharmacy "Carol Davila", Bucharest

Metrorex SA, Medical Department, Bucharest

CMI Dr Magdoiu AM, Bucharest

INTRODUCTION: The ankylosing spondylitis (AS) is a systemic, multi-factorial, chronic rheumatic disease. Patients are highly susceptible to vertebral fractures with or without cord injury (AS$\mathrm{SCI}$ ), even after a minor trauma.

MATERIAL AND METHODS: The study is a retrospective descriptive survey of post-acute, traumatic AS-SCI patients, transferred from the neurosurgical department and admitted in a Romanian Neurorehabilitation Clinic, during 2010-2014. There were 11 males associating AS-SCI $(0.90 \%$ of all consecutive SCI admitted cases), with an average age of 54.6 years (median 56, limits $42-73$ years).

RESULTS: The average duration between the medically diagnosed AS and the actual associated spinal fracture(-s) moment was 21.4 years (median 23; limits 10-34 years). Low-energy trauma was incriminated in $54.5 \%$ cases. The spinal level of fracture was: cervical (4 cases), thoracic (3), lumbar (4), assessed at admission as: AIS-A (4 subjects), C (5), D (2). By the time of discharge neither patient has neurologically deteriorated; 5 patients $(45.5 \%)$ improved of at least grade 1 (AIS). The overall complications were mainly infections: symptomatic urinary tract infections ( 7 patients; $63.6 \%)$, pulmonary (3 subjects; $27.3 \%$ ), spondylodiscitis ( 1 case; $9 \%$ ). The average follow-up period was 15.3 months (median 12; limits 1-48 months) after discharge; three subjects gained functional improvement to AIS E.

CONCLUSION: The clinical profile (different risk factors, mechanisms, types and levels of spinal fractures, additional encephalic and/or cord lesions, comorbidities), different post-surgical and/or general complications acquired during admission in our rehabilitation ward, served us for future prevention strategies and a better therapeutic management.

KEYWORDS: ankylosing spondylitis, spinal cord injury, rehabilitation, complications, prognostic

\section{OP 004- TYPICAL HEMIFACIAL SPASM (HFS) - INEDITED CONSERVATIVE TREAT- MENT; CASE PRESENTATION \\ Anghelescu $A^{1,4}$, Gorgan $C^{2}$, Petcu G ${ }^{3}$, Neculae M. ${ }^{1}$, Radu R ${ }^{1}$,Frecea I ${ }^{1}$, Onose $\mathrm{G}^{1,4}$}

1 Clinical Hospital "Bagdasar-Arseni”, Neuromuscular Rehabilitation Clinic, 2 Clinical Hospital

"Bagdasar-Arseni”, Electrophysiology Department, 3 Clinical Hospital "Bagdasar-Arseni”, Radiology

Department, 4 University Of Medicine And Pharmacy "Carol Davila” Bucharest

INTRODUCTION: Hemifacial spasm (HFS) is an involuntary twitching or contraction of the facial muscles on one side of the face, rare entity, with an incidence of approximately 0.8/100,000 people. In most cases the pathophysiological mechanism is represented by a neurovascular conflict.

MATERIAL AND METHODS: It is presented a typical case of HFS in a female patient of 62 years old, who accuses vertigo, bilateral tinnitus (especially on the left), walking instability, agoraphobia and HFS, started with the eyelid (blepharospasm), dizziness, tinnitus (November 2009), topographically extended to the entire left hemiface (2013), including platysma (end of 2014).

The etiologic diagnostic approach is illustrated by clinical, electrophysiological and magnetic resonance imaging aspects. The aetiology of the neurovascular conflict is represented by a dolichoectasia of the left vertebral artery (AV). The patient refused conventional standard therapies (functional neurolysis with botulinum toxin, or microvascular surgical decompression).

It was applied an original conservative therapeutic method: ionogalvanoterapy with potassium iodide (KI) applied to the cathode, in 30 minutes sessions, during 10 days.

RESULTS: The paper report a favourable effect (diminished spasms), on medium duration. The particularities of the case are:

Paradoxically improvement of the HFS, by an excitatory facial stimulus (IK at the active electrode)

the neuro-microvascular conflict syndrome was alleviated and HFS improved, through a self- ecompressive manoeuvre, consisting in cervical hyperextension (changing the anatomic conflicts between the AV-nerves VII,VIII)

CONCLUSIONS: Iontophor esis with IK represents an unprecedented, alternative rehabilitation method, with symptoms alleviation of average duration, applied to a patient who refused the conventional treatment for HFS. 


\section{OP 005- POSITIONING THE OFFER OF FOUR STARS HOTEL FROM FELIX SPA BE- TWEEN BALNEO AND WELLNESS TOURISM \\ Olimpia Ban, University of Oradea, oban@uoradea.ro \\ Șereș Luminița, International Hotel, seresluminita@gmail.com \\ Balaj Bianca, University of Oradea, balaj.bianca@,gmail.com}

INTRODUCERE/OBJECTIVE: In Romania, around consistent thermal water sources were developed centers / resorts profile SPA, spas named. Balneology is regarded as a branch of medicine dealing with disorders using mineral water. Completing the offer of hotels climatic spa resorts, in response to worldwide trends, it was done with wellness services. In this study we intend to investigate to what extent a four star hotel in the largest spa in the country, has an offer wellness not only name but also as content and consumer perception.

MATERIALS \& METHODS: The research methods used were: analysis of secondary data, research direct investigation based on a questionnaire applied among customers. Data were statistically analyzed primary and deepened.

RESULTS: The first two hypotheses were validated. The third hypothesis was validated in demand limit imposed by the observation unit. Hypotheses are: H1: Offer wellness services unit studied is one incomplete H2: Customer is not the specific Wellness Hotel H3 : Consumer preference is for hotel guests balnear services, especially.

CONCLUSIONS: The results reflect a partial understanding of the concept of wellness by the hotel management.

KEYWORDS: Balneotourism, wellness tourism, hotel, Băile Felix, Romania

\section{OP 006 - THE HANDS OF KINESIOTHERAPISTS - STUDY PROPOSAL AND PROFESSIONAL OPTIMIZATION Neli-Claudia Bilha}

INTRODUCTION. The hands of kinesiotherapists have an essential and specific contribution in the patients' rehabilitation process. In the same way that Pygmalion was profoundly transformed while he was sculpting Galatea, the kinesiotherapist, including his hands, are subject to changes over the course of their activity.

AIM. Analyzing the practical importance and the role of the kinesiotherapists' hands in their own view and in the context of rehabilitation.

Studying the interest of the working kinesiotherapists' to improve their manual abilities.

Evaluating the morphofunctional particularities of the studied hands.

MATERIAL AND METHOD. I devised a 10-item self-evaluation questionnaire on the professional importance of one's own hands to which 20 active kinesiotherapists with variable ages and years of work experience.

Also, images of the kinesiotherapists' hands were taken for comparison purposes.

In the future, measurable dynamic parameters (power, tonus, endurance, agility, velocity, ambidexterity etc.) will be analyzed, similar to studies undergone by pianists.

RESULTS. Kinesiotherapists are instructed towards patient-centered rehabilitation and less so towards self-care. Usually, there is no special algorithm that is applied for one's own hands, with the best case scenario being some empirical measures. Side-by-side photographical comparison of the hands allows for a preliminary analysis.

CONCLUSIONS. The kinesiotherapists' hands are the actual tool for their work.

I observed the studies' focus on the rehabilitation of patients' hands and a complete neglect towards the quality of the therapist's hands. On their morphofunctional particularities depends a significant part of the rehabilitation's success.

I propose a comprehensive study of the role of kinesiotherapist's hands, measuring anatomophysiological and biomechanical characteristics and comparing them with an appropriate control group from the general population.

It is necessary to raise the awareness and teach young kinesiotherapists the importance of their hands' development, relaxation and recovery.

Homo faber heals patients, is self-edifying, protects and perfects himself. 


\title{
OP 007 - VIRTUAL REALITY IN HAND EVALUATION AND REHABILITATION
}

\author{
CM Brailescu ${ }^{1,2}$, AS Nica ${ }^{1,3}$, RG Scarlet $^{1,3}$ \\ 1 ,Carol Davila”University of Medicine, Bucharest \\ ${ }^{2}$ Clinic Hospital of Rehabilitation, Physical Medicine and Balneology, Eforie Nord \\ ${ }^{3}$ National Institute of Rehabilitation, Physical Medicine and Balneology, Bucharest
}

INTRODUCTION. The virtual world is based on simple, artificial computer-aided systems (CAD models) which transform environmental reality into virtual reality. Due to the capacity of creating and controlling static and dynamic tridimensional surrounding stimuli, noninvasive and reproducible for the patient, with measurable response, Virtual Reality represent a new option of evaluation and treatment used in many medical fields (reabilitation, psychiatry, psychology, ORL, telesurgery). The Virtual Reality concepts have been used in creating special devices with useful medical application, including Rehabilitation medicine.

MATERIAL AND METHODS. We used in clinic a VR system that consists in a special device with sensors that allows accurate measurement of all kind of prehension and grips and of all ROM of shoulder/elbow/fist/fingers, with computerized evaluation and graphic evaluation during recovery process. All the 54 cases of traumatic hand injuries that needed surgery and followed a functional rehabilitation program in National Institute were tested before, during and at the end of the rehabilitation period and some of them used the VR device aditionally to the classic kinetic therapy.

RESULTS. All the patients in the study had significant improvement of all measured parameters regarding muscular force, ROM, grips and pinches and functional scores, but the patients who used additionally the VR device for treatment had better results than the other.

CONCLUSIONS. Virtual Reality-based systems represent modern options for evaluation of hand deficits and dysfunctions, with objective measurement replacement of classic goniometry and dynamometry, with computerized data base of patients with monitoring of clinical and functional parameters during the recovery program and with better muscular and neuro-cognitive feedback during the interactive therapeutic modules.

KEY-WORDS: hand evaluation; Virtual Reality device; functional rehabilitation.

\section{OP 008 - RESULTS REGARDING THE USE OF PRM PROGRAM IN THE POST-SURGERY MANAGEMENT OF HAND TRAUMATIC INJURIES \\ CM Brailescu ${ }^{1,2}$, I Lascar ${ }^{1,3}$, RG Scarlet $^{1,4}$ \\ 1 „Carol Davila”University of Medicine, Bucharest \\ ${ }^{2}$ Clinic Hospital of Rehabilitation, Physical Medicine and Balneology, Eforie Nord \\ ${ }^{3}$ Floreasca Hospital Bucharest, Plastic and Reconstructive Surgery Department \\ ${ }^{4}$ National Institute of Rehabilitation, Physical Medicine and Balneology, Bucharest}

INTRODUCTION. The idea for this study was based on the lack of objective measurements and accurate statistic results concerning the evolution of the patients with hand surgical interventions for traumatic injuries, who were integrated in a rehabilitation program, to sustain the medical reality (positive feed-back from the patients and from the plastic surgeons) and the results published in the literature regarding these aspects.

AIMS. Objective quantification of sensorial and motor neurologic deficit recovery, social readaptation, professional re-integration, functional independence and better quality of life after the Rehabilitation program.

MATERIAL AND METHODS. We conducted a prospective study based on 54 patients with surgical interventions for traumatic hand injuries, who followed three series of rehab program consisting in three weeks of daily PRM therapeutic protocol in the National RPMB Institute, between Jan 2011Aug 2012.

RESULTS. Confirmed the international epidemiologic datas, with statistic significant improvement of all the local post-surgical conditions, better QoL and FIM scores.

CONCLUSIONS. Rehabilitation program proved to be an essential sequence after or between surgeries for traumatic hands, with benefits for the functional independence of the patients.

KEY-WORDS: hand traumatic injuries; PRM program; post-surgery rehabilitation. 


\section{OP009-BALNEOTHERAPY COMBINED WITH THERAPEUTIC EDUCATION IN LYMPHEDEMA PATIENTS.}

Patrick Carpentier, Bernadette Satger, Dominique Poensin, Christine Trens, Martine Arnold, Corine Trolliet, Janick Noilhetas, Eric Chauvin, Jérôme Laures

Centre de Recherche Universitaire de La Léchère, Université Joseph Fourier, Grenoble (France)

BACKGROUND. Lymphedema is a chronic disabling condition whose prognosis strongly depends upon the ability of the patient to actively participate in his care. Our experience with balneotherapy in patients with advanced chronic insufficiency showed a synergistic effect with therapeutic education resulting in substantial improvement of health related behaviors, quality of life and health status [1, 2]. We report here the first results obtained with a similar program developed for patients with lymphedema.

METHODS. Balneotherapy is organized during a traditional thermal spa treatment course of 18 days with four balneotherapeutic sessions per day including massage shower, rehabilitation pool and two other patient customized cares. The education program includes two education consultations before and after a course of three interactive workshops in small groups aiming at improving the knowledge and motivation of the patients, and six training session for auto-bandaging and auto-drainage. It includes a systematic evaluation of the achievement of changes in health related behaviors, quality of life through a Lickert scale, and multi-level limb mensurations allowing the calculation of the limb volume. Subjects included in this study were the patients with ISL stage 2 or 3 lymphedema of upper or lower limbs, who volunteered to participate in the therapeutic education program on the occasion of their thermal spa treatment course.

RESULTS. Forty-four patients participated (42 women, 2 men, median age 65 years) were enrolled. At the end of the program, $96 \%$ of the patients thought it would help them deal better with their lymphedema. The mean reduction of limb volume was $151( \pm 26) \mathrm{ml}$. Three months after the treatment course, $87 \%$ had fully achieved at least one objective regarding their health behaviors and only $4 \%$ did not achieve any behavioral improvement; the quality of life was significantly improved $(\mathrm{P}<0.01)$.

CONCLUSION. These results are promising but have to be confirmed in a controlled study with longer follow-up.

1. Carpentier PH, Satger B. Randomized trial of balneotherapy associated with patient education in patients with advanced chronic venous insufficiency. J Vasc Surg 2009;49:163-70

2. Carpentier PH, Blaise S, Satger B, Genty C, Rolland C, Roques C, Bosson JL. A multicenter randomized controlled trial evaluating balneotherapy in patients with advanced chronic venous insufficiency. J Vasc Surg 2014;59:447-454

Work supported by a grant of the Association Française pour la Recherche Thermale (\#2012-07)

KEY-WORDS: lymphedema, balneology, therapeutic education of the patient

\section{OP010-SIDE EFFECTS OF LEFLUNOMID, RESPECTIVELY OF SULFATED POLYSAC- CHARIDE EXPERIMENTAL INDUCED RHEUMATOID ARTHRITIS \\ M. Chicu ${ }^{1}$, E. Bitere ${ }^{2}$ \\ ${ }^{1}$ University of Medicine and Pharmacy "Gr.T. Popa" Iasi, Clinical Emergency County Hospital "Sf. Spiridon" Iasi, ${ }^{2}$ Institute of Cardiovascular Diseases "Prof. Dr. I.M. Georgescu” Iasi}

INTRODUCTION: The study aimed to highlight both the Leflunomid and sulfated polysaccharide effects on the bone marrow, liver, heart, kidney and bone in experimental animals .

MATERIALS \& METHODS: The study took place over a period of 6 weeks on Wistar rats breed, which arthritis were induced by $1 \%$ sulfated polysaccharide injection and then were administered Leflunomid by gavage once every 2 days for 42 days. At the end of the experiment were collected fragments of heart, liver, lung, kidney, bone.

RESULTS: The experiment showed the visceral toxic effects of Leflunomid on the liver, heart, kidne. Hepatic impairment was particularly intense, confirming data from the specialty literature. For the first time in the specialty literature, it was proved the toxic effect of Leflunomid on the heart. Anatomo-pathological examination of the kidney has revealed the changes caused by both administration of Leflunomid and sulfated polyccharide.

CONCLUSIONS: The present obtained data comes to confirm and complete the specialty literature date obtained on human groups. 


\title{
OP 011- THORACIC SPINE TYPE C INJURIES ACCORDING TO THE AO CLASSIFICA- TION: INJURY PROFILE, MANAGEMNET AND OUTCOME
}

Gheorghe Checiu MD; Cristian Filip MD; Daniel Serban MD; Niki Adrian Calina MD; Marius Podea MD; Costica Zamfir MD; Florin Exergian MD;

\section{"Bagdasar-Arseni” Clinical Emergency Hospital, Spine Surgery, Bucharest} Keywords: thoracic, fracture, type C , AO classification

Introduction. In the last years we observed an increased number of patients with multiple lesions after high energy accidents. Type $\mathrm{C}$ injuries of the thoracic spine are the most severe lesions, with the worse prognosis.

Material and methods. The study analyzes the injury profile, management and outcome of all patients with thoracic spine, from T1- to T10, type C injuries treated in the Spinal Surgery Department of " Bagdsar- Arseni” Emergency Hospital, in the last 5 years.

There were 26 patients admitted in the study, mostly male, $77 \%$, with a mean age of 33.8 years. All of them were victims of high energy accidents, and all had spine injury associated with multiple lesions (head, thoracic, abdominal and limbs). We have chosen a posterior approach in all cases, with laminectomy or hemilaminectomy, permitting us to achieve all the major objectives of surgery, with the advantage of a lower blood loss and a reduced operating time. The purpose of surgery was to achieve decompression of the spinal cord and stability of the thoracic spine. We treated 19 patients surgically and 4 patient conservative.

Results.Thoracic spine type $\mathrm{C}$ fractures remain a challenge for the spinal surgeon. These lesions require a multidisciplinary team approach for the treatment of associated lesions. The main goal of surgery is to achieve stability of the fractured segments. The timing for surgery is indicated mainly by associated respiratory problems.

Conclusions.All patients required long term neuromotor rehabilitation after the surgical treatment, representing a very important aspect of our multidisciplinary team approach.

\section{OP012 - CORRELATIONS BETWEEN ANATOMO-PATHOLOGICAL, RADIOLOGICAL AND OSTEODENSITOMETRICAL ASPECTS IN EXPERIMANTAL INDUCED CHRONIC ARTHRITIS}

\author{
M. Chicu ${ }^{1}$, V. Vulpe ${ }^{2}$, E. Bitere ${ }^{3}$, O. Ciurcanu ${ }^{4}$ \\ ${ }^{1}$ University of Medicine and Pharmacy "Gr.T. Popa" Iasi, Clinical Emergency County Hospital "Sf. \\ Spiridon" Iasi \\ ${ }^{2}$ University of Agricultural Sciences and Veterinary Medicine "Ion Ionescu de la Brad" Iasi \\ ${ }^{3}$ Institute of Cardiovascular Diseases "Prof. Dr. I.M. Georgescu" Iasi \\ ${ }^{4}$ University of Medicine and Pharmacy "Gr.T. Popa” Iasi
}

INTRODUCTION: The aim of the experiment was to track the evolution of articular inflammatory phenomena to experimental animals of different ages (young, adult respectively) by determining radiological and osteodensitometrical parameters, and their correlation with anatomo-pathological aspects.

MATERIALS \& METHODS: The study was conducted over a period of 4 weeks on 8 female groups of Wistar rats breed, who were induced arthritis with $1 \%$ sulfated polyccharide solution injected into the tibio-femoral joint 3 times a week. The animals have received standard food and were properly hydrated. During the experiment were determined in dynamic the levels of IL1 $\beta$, the radiological Larsen scores, the osteodensitometrical parameters (DEXA), and at its end were emphasized portions of the tibio-femoral, myocardium, kidneys, liver.

RESULTS: The IL $1 \beta$ levels, determined in national premiere, on a lot of lab animals were significantly greater in the group of young animals compared to adult. Deaths phenomena, recorded during the experiment, were due to acute liver failure, bleeding, infections, decrease appetite and weight loss.

CONCLUSIONS: The intensity of the articular inflammatory phenomena is correlate with the data highlighted by anatomo-pathological examination and were more intense in the group of young animals compared to adult. 
OP013-IL1B - MARKER OF THE INFLAMMATORY PROCESS AND THE BONECARTILAGINOUS DESTRUCTION

M. Chicu ${ }^{1}$, E. Bitere ${ }^{2}$, O. Ciurcanu ${ }^{3}$

${ }^{1}$ University of Medicine and Pharmacy “Gr.T. Popa” Iasi, Clinical Emergency County Hospital "Sf. Spiridon" Iasi

${ }^{2}$ Institute of Cardiovascular Diseases "Prof. Dr. I.M. Georgescu" Iasi

${ }^{3}$ University of Medicine and Pharmacy "Gr.T. Popa” Iasi

INTRODUCTION:Rheumatoid arthritis (RA) is a chronic inflammatory infiltrating-proliferative disease of synovial in diartroidal joints. Its cause is unknown. As other chronic diseases, its etiology is most likely multifactorial. Cytokines have been implicated as important mediators of inflammation and osteoarticular destructions in RA. The study aimed to determinate the levels of IL1 $\beta$ at woman with RA in various stages of evolution and their correlation with clinical and biological main parameters.

MATERIALS \& METHODS: The study took place between 2014-2015 at Recovery Clinic of "Sf. Spiridon" Hospital in Iasi, on a batch of 80 women with RA, that were divided into two groups: (1) onset of disease occurs under the age of 60 years and (2) the onset of disease which occurs after age 60 years. Were determined NAT, NAD, DAS28, VAS, HAQ, VSH, CRP, T-score, the score Sharp and IL1 $\beta$ levels.

RESULTS: IL1 $\beta$ levels correlate directly proportional to the value of ESR, CRP and indirect val$\mathrm{ue} \mathrm{Hb}$ and Sharp scores for pinching and erosion.

CONCLUSIONS: Determination of IL-1 levels, made for the first in Romania, may be a marker of the inflammatory process intensity and destruction of bones and cartilage in RA.

\title{
OP014- HEART RATE VARIABILITY DURING EXERCISE TESTING
}

\author{
Călin Corciovă ${ }^{1}$, Cătălina Luca ${ }^{1}$, Doru Andriţoi ${ }^{1}$, Daniela Matei ${ }^{1}$
}

${ }^{1}$ Department of Biomedical Sciences, University of Medicine and Pharmacy "Grigore T. Popa" Iasi

INTRODUCTION: Isometric exercises are known to produce an overload on the cardiovascular system due to pulsatile contraction followed by a significant increase in muscle blood flow.

MATERIALS \& METHODS: Power spectrum analysis of heart rate variability (HRV) is a non-invasive method that analyzes cardiac autonomic control in rest and during exercise period.

RESULTS: The aims of this study were to measure heart $r$ ate variability (HRV) parameters and blood pressures before and after two set of exercise: one set of isometric exercises and one set of dynamic exercise in healthy young persons.

CONCLUSIONS: Using standard cardiovascular reflex tests we managed to analyze the heart rate variability and demonstrated the influence of the autonomic nervous marking parasympathetic dysfunction and sympathetic predominance in young people. Isometric exercise produces a more increased sympathetic activation and reduced vagal activity than dynamic exercise.

\section{REFERENCES:}

1. Hallman DM, Lindberg LG, Arnetz BB, Lyskov E., Effects of static contraction and cold stimulation on cardiovascular autonomic indices, trapezius blood flow and muscle activity in chronic neck-shoulder pain, Eur J Appl Physiol. 2011;111(8):1725-35.

2. Moreno IL, Pastre CM, Ferreira C, de Abreu LC, Valenti VE, Vanderlei LC, Effects of an isotonic beverage on autonomic regulation during and after exercise, J Int Soc Sports Nutr. 2013;10(1):2.

3. Raimundo RD, de Abreu LC, Adami F, Vanderlei FM, de Carvalho TD, Moreno IL, et al., Heart rate variability in stroke patients submitted to an acute bout of aerobic exercise, Transl Stroke Res. 2013;4 (5):488-99. 


\title{
OP015- BRINE AEROSOL THERAPY IN THE "WIELICZKA" SALT MINE HEALTH RE- SORT
}

Jolanta Czerwik ${ }^{1}$, Dorota Ankowska ${ }^{1}$, Maria Kmiecik ${ }^{1}$

\author{
${ }^{1}$ The "Wieliczka" Salt Mine Health Resort, Park Kingi 1, building I, Wieliczka, Poland \\ e-mail: uzdrowisko@kopalnia.pl
}

Aerosol therapy holds a prominent position in treatment of upper and lower respiratory tract diseases. Aerosols are relatively stable systems of solid, liquid or gaseous particles, dispersed and suspended in a gaseous medium. In healthcare, one kind of aerosols is particularly used, namely liquid droplets dispersed in a gaseous medium, usually in air. Aerosol therapy is an efficient and convenient method for medicine administration into respiratory tract. Currently it is possible to take some medication and curative mineral waters, such as brine, in the form of an aerosol. Among the main advantages of aerosol therapy there are: direct and non-invasive access to the target organ, using a lower dose of a medicine compared to systemic therapy, quicker onset and less significant effects on the organism.

In medicine, the size of the aerosol particles is essential, as it determines the place where the substance gets to and operates. The smaller the aerosol particles are, the deeper they can get into the respiratory tract. Three deposition areas for the aerosol in respiratory tract are assumed: aerosol penetrating lung alveoli, the so-called respirable fraction $(<5 \mu \mathrm{m})$; aerosol reaching trachea, bronchi and bronchioles (particle size between 5 and $8 \mu \mathrm{m}$ ) and finally, aerosol penetrating the throat and larynx (particles larger than $8 \mu \mathrm{m})$

The mineral waters from the X-VII-16 intake in the "Wieliczka" Salt Mine are certified to have medicinal properties. The waters have $68.9 \mathrm{~g} / \mathrm{dm}^{3}$ mineralisation, $\mathrm{pH}$ of 6.94 , and temperature of $16.9^{\circ} \mathrm{C}$. The efficiency of the intake is $9 \mathrm{~m}^{3} / \mathrm{h}$. C. They are used for individual inhalations, as well as for producing aerosol in the graduation tower. Moreover, inhalations of salt aerosol present in underground mine workings are also used. Subterraneotherapy - exposure to a set of factors of physical, chemical and biological nature, present in the underground spaces and its effects on the human body - is beneficial in treatment of chronic diseases of the respiratory tract (including bronchial asthma).

The post-inhalation procedure, consisting of a set of activities with the goal of clearing the bronchi of excess secretions, which are the reason for recurrent inflammatory conditions of the airways, is an important aspect of aerosol therapy and is especially significant in the therapies using mucolytics and hypertonic brine. Removing the excess secretions from the airways ensures their patency and prevents breath-

\section{OP016- ALTERNATIVE OF EDUCATION FOR BALANCE AND GAIT AT CHILDREN WITH CEREBRAL PALSY}

\author{
Kt. Phd. Mihail-Alexandru Dumangiu', Conf. Md. Phd. Liliana Padure ${ }^{2}$ \\ ${ }_{1,2}$ National Medical Neuropsychomotor Rehabilitation Centre for Children, "Dr. Nicolae Robănescu" \\ FIELD REFERENCE: Pediatric rehabilitation \\ INTRODUCTION : Cerebral palsy is a non progressive disorder. The brain injury makes the re- \\ sponse to be altered, the temporo-spatial integration of the body being made with difficulty. \\ It is necessary to influence the cerebral cortex with afferent stimuli and also to integrate the informations \\ from different levels, such that the response to be a modulated stimulus, adapted
} one and in accordance with desired aim.

MATERIALS \& METHODS: The studied group is composed of 15 children with cerebral palsy who had undergone a rehabilitation programme in the Clinical National Medical Neuropsychomotor Rehabilitation Centre for Children "Dr. Nicolae Robănescu", with a follow-up of at least 3 years.

The purpose of this paper is to present the differentiated changes (at the lower limbs) which have arisen by influencing the joint amplitude and by increasing affected muscle strength in the treatment of balance and gait in children with cerebral palsy in the lot.

RESULTS: Were included in the SPSS statistical analysis program; they were processed and interpreted so we could establish an EFFICIENT FORM OF STIMULATION for children under study. 


\section{OP017- OBSERVATIONAL STUDY REGARDING TRANSIENT DIABETES INSIPIDUS ON PATIENTS WITH SPINAL CORD INJURY \\ Cristina Daia, Ana-Maria Bumbea, Cristina Popescu, Catalin Bicescu, Cristinel Dumitru Badiu, Ge- lu Onose}

1 The University of Medicine and Pharmacy"Carol Davila", Bucharest, Romania

2 The Teaching Emergency Hospital "Bagdasar Arseni”, Bucharest, Romania

OBJECTIVE: The associtation between polyuric polydipsic syndrome/ diabetes insipidus on patients with spinal cord injury (SCI) is a rare pathological condition with few references in specific literature (citation for one to five cases, Iob, 2011,Kuzeyl, 2001 Prasad, 1995) Matherial and methods It have been made an observational, prospective study between 2005-2013, including 12 patients: 7 admitted in Teaching Emergency Hospital "Bagdasar-Arseni", Physical Neural-muscular Clinic Division and 7 in NeuroRehabilitation Clinic Division of the Neuropsychiatry Teaching Hospital, Craiova. All patients were diagnosed with acute/post-acute traumatic spinal cord injury, 10 with complete lesion and 2 incomplete B, C4-T1 level and associated polyuric (average 61 ) polydipsic (average 6,75 1) syndrome. Exclusion criterion was: traumatic brain injury, tumors, acute or chronic renal failure, and diabetes mellitus. Results All patients had SCI cervical or T2 above, occurred after car accidents, diving or falls and had low AIS sensitive (average of 62 points), motor (average of 26 points) and functional (Funtional Independence Measure, FIM, average of 60 points) scores. Dibetes insipidus syndrome appear after a variable period (average of 34 days) after traumatic SCI and shall be remitted after a treatment period (average of 3 weeks) with desmopresin (medium average doses 0,2 $\mathrm{mcg}$ ). Conclusion and discussions Our scientific information is similar with those in the specific literature. Based on patient's low AIS motor and FIM scores correlate with orthostatic hypotension (specific on patients with T6 levele and above) Krassioukov, 2010 on mobilization in wheelchair, we think about baroreceptors intervention (placed in atrium, aortic arch and big venues) to rise arterial tension, through vasopressin stimulation Wass, 2011 Claydon 2006, which will be exhausted in this vicious circle. The mobilization and maintaining the supine position in wheelchair overlap on diabetes insipidus syndrom disappearing, and also on ceasing of these compensatory pathological mechanisms.

INDEXING: Academic discipline and sub-disciplines, Neurological \& Communicational and/ or Psycho-Cognitive pathology

KEYWORDS: spinal cord injury, diabetes insipidus

REFERENCES

1. Iob I, Salar G, Mattisi G, Ori C, Rampazzo A, Diencephalic syndrome following cervical spinal cord trauma, Acta Neurochirurgica, 1989, Volume 97, Issue 3-4, pp 123-127 2. Kuzeyli K, Çakr E, Baykal S, Karaarslan G, Diabetes Insipidus Secondary to Penetrating Spinal Cord Trauma: Case Report and Literature Review, Spine,1 November 2001 - Volume 26 - Issue 21 - pp E 510-E 511 3. Prasad VSSV, Raju BSV, Dinakar I Diabetes insipidus in cervico-dorsal spinal cord injury, Neurology India, 1995, Vol 43, issue 4, pg 206-208 4. Wass JAH, Stewart PM. Oxford Textbook of Endocrinology and Diabetes. Oxford University Press, 2nd edn 2011: 82-87 5. V E Claydon, J D Steeves1 and A Krassioukov, Spinal Cord (2006) 44, 341-351. 6. A Krassioukov, M S Alexander, A-K Karlsson, W Donovan, C J Mathias. F Biering-Sørensen, Spinal Cord (2010) 48, 586-590 


\title{
OP018 - THE QUALITY OF LIFE EVALUATION OF PATIENTS WITH TRAUMATIC SPI- NAL CORD INJURY, IN POST-ACUTE AND SUB-ACUTE STATE Cristina Daia, Onose Gelu
}

\author{
1 The University of Medicine and Pharmacy"Carol Davila”, Bucharest, Romania \\ 2 The Teaching Emergency Hospital "Bagdasar Arseni”, Bucharest, Romania
}

STUDY DESIGN AND OBJECTIVE: We have assessed Quality of Life (QoL) in a retrospective study, comprising 132 patients (over 18 years old) admitted in our unit, between December 2014 and May 2015, diagnosed with Traumatic Spinal Cord Injury (T-SCI), only in sub-acute and post-acute state.

SETTING: The Physical and Rehabilitation (Neuro-Muscular) Clinic Division at the Teaching Emergency Hospital Bagdasar-Arseni, in Bucharest, Romania

METHODS: We evaluate QoL (Flanagan scale) and correlate it with epidemiological (age, gender, the cause of T-SCI, hospitalization duration, comorbidities), clinical (neurological level, motor deficit: AIS motor score, sensitive deficit: AIS sensitive score, severity level: AIS/ Frankel score), therapeutic (need for surgery) and functional (Functional Independence Measure, FIM score) parameters.

(MAIN) RESULTS: The studied patients are predominant young adults (minimum age 18, maximum age 88 , average age 43 , median age 39 , standard deviation 19,05 ; most of them - $29 \%$ - between 31 45 years old ) males (104 cases, $79 \%)$ and have car accident as main cause of SCI (40\%, 53 cases). The Qol of complete paraplegia (mean 71.62, st dev 12.07) is statistically significant better than complete tetraplegia (mean 85.96, st dev. 12.22), $\mathrm{p}=0.001$; patients with incomplete lesions and similar severity AIS/ Frankel grade have no statistically difference between mean value of QoL, no matter they have cervical (C) or toraco-lumbar (TL) lessions (C QoL mean 79.41, st dev 11.56, TL QoL mean 79.66, $\mathrm{p}=0.72$ ). $48 \%$ (63 cases) of patients with T-SCI are content regarding their QoL at discharge (being "satisfied" or "delighted") and another 33\% (44) are "ratherer satisfied".

DISCUSSIONS: This study is collecting data regarding first admission of a patient with SCI in a rehabilitation clinic division after a traumatic event. A second better opinion regarding patient' QoL is necessary after one or two years (a follow-up) when the patient is being aware of his sequelae state and disabling condition.

\section{OP019- USING ÇANKIRI SALT CAVE IN HEALTH THERAPY}

Senayi DÖNMEZ*, İbrahim DEMİRTAŞ**

* Department of Civil Engineering, Faculty of Engineering, Çankırı Karatekin University, Çankırı** Department of Chemistry, Faculty of Science, Çankırı Karatekin University, Çankırı, Turkey

INTRODUCTION: Potential capacity of a small, pleasant city in Turkey, Çankırı, in Health Therapy will be presented. Three major facilities available in Çankırı will be introduced. These are 1-Salt cave facilities 2- Natural thermal springs 3- Traditional Turkish baths. Furthermore, touristic places and winter sports facilities of the city will be shown in addition to its old history.

MATERIAL \& METHODS: Salt cave in Çankır1 got back to existence with the opening of the galleries of an old salt cave for truism. Currently construction works are under progress in the salt cave. Measurements related with radiation, heavy metals and ion levels will be performed as the construction works reach a certain level. Past and current conditions of the salt cave will be presented. Available thermal springs and Traditional Turkish bath facilities within Çankırı city will be shown. The availability of the combined triple in one city i.e. salt cave, thermal springs and hot salty clay mud application in Çankırı will be highlighted.

RESULTS: Measurements performed in Çankırı salt cave will be analyzed in ICP-MASS available in chemistry department within the University and conclusions will be derived. Obtained results will be compared with those belonging to other salt caves.

CONCLUSIONS: Derived results will be discussed with the experts and potential capacity of Çankırı city in Health Therapy will be investigated. Çankırı salt cave will be made available for all those that want to use either in therapy or as a sports activity. This will be a main step of Çankırı city in becoming an important health therapy center. 


\section{OP020 - REHABILITATION ON KNEE OSTEOARTHRITIS ASSOCIATED WITH OBESITY AND THROMBOPHLEBITIS IN LOWER LIMB \\ Cristina Daia, Gelu Onose, Nicolae Potra, Diana Nita, Ioana Cazacu, Nicoleta Stoianoglu, Nicoleta Chiriloi, Anca Mihaescu \\ 1 The University of Medicine and Pharmacy"Carol Davila”, Bucharest, Romania \\ 2 The Teaching Emergency Hospital "Bagdasar Arseni”, Bucharest, Romania}

INTRODUCTION: obesity is a proven risk factor for knee osteoarthritis (ko). The majority of actual studies reveals the association of thrombophlebitis with ko mainly after knee arthroplasty, needing anticoagulant prophylaxis. The aim of this study was to determine the association of ko with obesity and thrombophlebitis in our rehabilitation clinic division. Material and methods: we analysed in a descriptive study 112 patient diagnosed with ko admitted between january 2014 and december 2015; we evaluated all patients according range of motion (rom), body mass index (bmi) quality of life (qol), and the numeric difference between calves diameter and we made anova to compare means. All patients benefited for a specific rehabilitation program; $p=$ value under 0.05 was considered statistically significant. Results: mean age 65.08 ( $\mathrm{sd}=10.6$ ), $\min 41 \max 96$, male: $40,17 \%$ female: 59,82\%. Among analysed patients shows that: 41 individuals $(36.60 \%)$ had obesity, 17 patients $(15.17 \%)$ had thrombophlebitis and only $10(8.92 \%)$ had both association. Most contributively for ko are rom (97.14), than qol (92.3) and age (65.8) p-value $<0.001$. Conclusions: the association of ko with obesity and thrombophlebitis is a condition which should be considered. Important predictor factors for ko are obviously articular mobility but as well patient's qol which interfere with the functional prognostic and results of rehabilitation program.

\section{REFERENCES:}

KEYWORDS: knee osteoarthritis, obesity, thrombophlebitis

- zheng h, chen c. Body mass index and risk of knee osteoarthritis: systematic review and meta-analysis of prospective studies. Bmj open. 2015 dec 11;5(12)

* squizzato a, lussana f, cattaneo m. Post-operative arterial thrombosis with non-vitamin k antagonist

\section{OP021- THE COMPLEX THERAPEUTICALLY APPROACH OF PATIENTS IN THE REHA- BILITATION HOSPITAL BRADET (ARGES, ROMANIA), INCLUDING THE NATURAL THERAPEUTIC FACTORS AND CLIMATE}

Cristina Daia, Gelu Onose, Mihaela Chircu, Diana Nita, Doroteea Teoibas Serban, Nicolae Potra

1 The University of Medicine and Pharmacy"Carol Davila”, Bucharest, Romania

2 The Teaching Emergency Hospital "Bagdasar Arseni”, Bucharest, Romania

INTRODUCTION: The objective of this work (and also its particularity) is the complex approach of patient from medical standpoint: the application of the specific rehabilitation procedures and using, at the same time, the natural local factors and climate.

MATHERIAL AND METHODS: We evaluated all patients admitted in the Rehabilitation Hospital Bradet between January 2 and 29 of February 2016 regarding demographic data, etiology and state at admission. Additionally we evaluated the natural therapeutic factors in the village Bradetu in the context of therapeutic balneary factors from our country.

RESULTS: Brădetu is located on the Upper Vâlsan river, in Arges county, $28 \mathrm{~km}$ from Curtea de Arges and $59 \mathrm{~km}$ from Pitesti, in a sedative climate (sparing) at $626 \mathrm{~m}$ altitude, with average temperatures of 17.5 degrees Celsius and rainfall about $700 \mathrm{~mm}$. One of natural therapeutic factor is the mineral waters: sodium bicarbonate, sulfur, chlorine, iodine (with a total mineralization of 0.84 to $3.08 \mathrm{~g} / 1$ ), discovered in 1888. In two months were admitted 375 patients, 54\% female, 46\% male with mean age 67 year old, min 25 , max, 84 ; the main pathology admitted was low back pain $32 \%$ followed by knee $17 \%$ and hip $8 \%$ osteoarthritis than periarthritis of the shoulder 7\%. All patients were improved at discharge according to related asserts within their medical records and discharge forms.

This study is collecting data about less known Rehabilitation Hospital from Bradetu village, Arges, Romania, a place with large therapeutic and prophylactic indications regarding the potential benefit of combining multiple therapeutic factors from the vast domain of balneotherapy.

CONCLUSION: In the Romanian balneary heritage include The Rehabilitation Hospital Bradet, located in a place with natural therapeutic factors and specific climate, Bradetu, which should be promoted and known also internationally.

KEYWORDS: sedative climate, mineral water, natural therapeutic factors, Bradet sedative climate, mineral water, natural therapeutic factors, Bradet

REFERENCES: 


\section{OP022 - OUR EXPERIENCE IN POST SPINAL CORD INJURY NEUROGENIC BLADDER REHABILITATION USING NONINVASIVE INTERFERENTIAL MEDIUM FREQUENCY CURRENTS}

Cristina Daia ${ }^{1,2}$, Gelu Onose ${ }^{1,2}$, Tiberiu Spircu ${ }^{1}$, Aurelian Anghelescu ${ }^{1,2}$, Cristina Popescu ${ }^{1,2}$, Ioana Andone $^{1}$, Cristinel Dumitru Badiu ${ }^{1,2}$

1 The University of Medicine and Pharmacy"Carol Davila”, Bucharest, Romania

2 The Teaching Emergency Hospital "Bagdasar Arseni”, Bucharest, Romania

INTRODUCTION: A comparative retrospective study, on 332 patients (over 18 years old), admitted to our unit, between September 2006 and April 2011, diagnosed with Neurogenic Bladder (NB) mainly after traumatic Spinal Cord Injury - T-SCI - only in sub-acute and post-acute states, divided in two groups (study and control) regarding the outcomes on micturition dis-control, through a physiatric method. The aim was to objectify the results on NB micturition control recovery, using a standardized non-invasive external electro-stimulation method.

MATERIAL AND METHODS: We used Interferential Medium Frequency Current (IMFC) Electrical Stimulation (ES) therapy which consists in generating a deep, intra-tissue energy field that acts, using a "spectrum" formula, on the bladder structures, with their various degrees of denervation, as a training intervention, due to frequency changes and values.

RESULTS: For incomplete post SCI patients, with NB - ASIA Impairment Scale (AIS) B-C ( $p$ value $<0.001, T$ test) - IMFC ES therapy is effective. For complete post SCI patients, with NB - AIS A, C1-C8 and T1-S5 - IMFC ES therapy seems not efficient.

CONCLUSION: This IMFC ES is a non-invasive rehabilitative therapy which can be applied on any type of NB, being effective in incomplete post SCI patients; it is safe, cheap and accessible.

KEYWORDS: neurogenic bladder, spinal cord injury, interferential medium frequency, electrical stimulation therapy

\section{REFERENCES:}

Onose G, Cardei V, Ciurea AV, Ciurea J, Anghelescu A, Daia C et al. Achievement of an experimental mechatronic orthotic device to assist/ rehabilitate orthostatism and walk in patients with complete paraplegia and other specific severe disabling conditions. Proceedings of the 7th Mediterranean Congress of Physical and Rehabilitation Medicine, Portorose, Slovenia, Edizioni Minerva Medica 2008; 4042.

Onose G, Daia C, Spircu T, Onose L. Validation of Customized Assessment Method and Our Outcomes With Interferential Medium Frequency Electrical Stimulation Therapy for Micturition (Dis-) Control in (Mainly) Post Spinal Cord Injury Patients, Am J Phys Med Rehabil., 2014; 6: 156. 


\section{OP023- PLANTAR SUPPORT A NEW ASSESSING WAY IN SCOLIOTIC PATIENTS}

WITHOUT PODAL PRIMARY PATHOLOGY

Florin Drăgan **Gelu Onose*, Liliana Pădure**, * SCUBA ** CNCRNC"Dr.Nicolae Robănescu”. ** CNCRNC Dr.Nicolae Robănescu"

SCOPE. BACKGROUND: To present a new way of assessing a patient with scoliosis. Plantar support is the leg contact with the support surface, at rest or in motion, revealed in our study using an an evaluation unit of the latest generation, unique, at the onset of the study, in hospitals in our country.

MATERIAL \& METHODS: The number of evaluable subjects in the study is approximately 150, which we will assess unitary quantified over at least 3 hospitalizations between 2013 2016.

RESULTS: Plantar support is altered in patients with scoliosis, in terms of weight distribution on the feets, the pressures from the foot on the surface support and behavior of the different parts of the foot during the steps on the evaluation board. Corsetry has spectacular effects revealed by specific device imaging and measurements resulting from software (mathematical values).

Body weight in children with scoliosis is unevenly distributed on the lower limbs, focused on lower limb from the primary curvature

There is a link between the severity of the posture alteration in scoliosis and pressure exerted by the primary curvature at the plantar support level.

According to the imaging aspects, to the pressure calculations related - as presented above - the scoliotic curve affects the foot contact with support area: when the curve, passively falls by more than 15 degrees, by applying the Cheneau brace, the plantar support shall be corrected by standardizing pressures both at the forefoot and the calcaneal region level, by increasing contact surface with the floor - towards normality amounts (more evident in dynamics).

Support improving can be performed after a sustained treatment (corrective posture in Cheneau brace, physiotherapy Klapp, Cotrel, Schroth techiques) in inpatient and continued at home (in the medium and long term.).

\section{OP024- OPPORTUNITIES FOR IMPROVING QUALITY OF LIFE IN GERIATRIC PA- TIENTS USING PELOID THERAPY}

Antoaneta Grozeva, Professor Assen Zlatarov University, Bourgas, Bulgaria

INTRODUCTION: The increase in numbers of elderly patients poses a challenge for prophylaxis and rehabilitation services in the 21 st century. The proven beneficial effect of Pomorie mud on the musculo-skeletal system, peripheral nervous system and skin underpin its use in the rehabilitation of this group of patients.

MATERIALS \& METHODS: The study was conducted on 47 patients in the spa town of Pomorie. The patients were divided into two subgroups according to the method of mud therapy: group 1 received mud baths at $37 \mathrm{oC}$, and group 2 received local mud applications at $38 \mathrm{oC}$. The patients had osteoarthritis affecting different joints and complicated by co-morbidities such as hypertension and coronary insufficiency (NYHA I, II) and type 2 diabetes. The following parameters were monitored: pain VAS, WOMAC, blood pressure, heart rate, blood glucose, C-reactive protein, and plasma lipid levels.

RESULTS: Following the 8-day course of treatment, there were beneficial effects in both groups, which were more pronounced in the group receiving mud baths. In addition to an improvement in VAS and WOMAC, there was a reduction in blood pressure and blood glucose levels.

CONCLUSIONS: Peloid therpy is not contraindicated in elderly patients and when applied using suitable methods leads to an improvement in the main symptoms of osteoarthritis, hypertention, diabetes mellitus, in addition to improving quality of life. 


\section{OP025-SAPROPELIC MUD FROM TECHIRGHIOL LAKE- THERAPEUTIC ELEMENT IN POSTTRAUMATIC CONDITION \\ Sibel Demirgian \\ Balneal and Rehabilitation Sanatorium of Techirghiol}

Introduction: Non-conventional therapies using natural factors (as mineral salted water and peloid/sapropelic mud from Techirghiol Lake) are used on empiric basis from old times and has unchallenged benefits in rheumatic pathology, but the intimate biological mechanisms of action are yet not known.

The Techirghiol therapeutic mud is black deposit, rich in colloidal iron hydro sulfur, from the bottom of the salty lake, formed under the action of microorganisms, from the inorganic substance of the soil, the flora and fauna of the aquatic basin, as the consequence of some biological and chemical transformations, during the biological ages ${ }^{1}$.

After a trauma(fractures), the most of patients remain with a chronic pain, located in the area of the affected extremities. The CRPS type I is the most frecvent syndrome developed in these patients.

In CRPS type I there is no single pathophysiological mechanism to explain the diversity and heterogeneity of symptoms (such as edema, vasomotor disturbances, limited range of motion). Currently, several mechanisms are accepted to be involved in the appearance and development of this syndrome.

Methods: The study was performed on 41 patients (22 women and 19 men; mean age 47,68 years, range 20-80 years) with diagnosis of unilateral CRPS I, according to Budapest criteria, who were hospitalized in Balneal and Rehabilitation Sanatorium from Techirghiol, between 2010 - 2011.

Conclusion: We found that physical therapy, alone, does not influence clinical features (pain, swelling, range of motion, temperature). The mean values of these clinical features, measured at admission, did not reveal significant difference between two groups, with or without physical treatment before the balneal cure.

Bibliography: 1.Tuculescu. I Biocenozele si geneza nămolului. Ed. Academiei Republicii Socialiste România, 1965.

Keywords: sapropelic mud, chronic pain.

\section{OP026- CANKIRI SALT CAVE, IT IS A FIRS APPLICATION AS A THERAPY CENTRE IN TURKEY İbrahim Demirtas* And Senayi Dönmez**}

* Department Of Civil Engineering, Faculty Of Engineering, Cankiri Karatekin Üniversity, Cankiri/ ** Department Of Chemistry, Faculty Of Science, Cankiri Karatekin University, Cankiri/Turkey.

INTRODUCTION: Complementary and alternative medicine is widely used in the treatment of asthma. Inhalation of hypertonic saline aerosol $(7 \%)$ has been shown to increase mucociliary clearance in patients with bronchitis (2) and cystic fibrosis (3) who have impaired baseline mucociliary clearance.

MATERIAL \& METHODS: A 5,000-year-old salt cave from the Hittite civilization will start operating to offer therapy to heal asthma, bronchitis and other respiratory illnesses in central Anatolian Cankiri province. The salt cave facility is arranged to be run by a private firm.

In spite of being more than centuries old, the salt mine is still in use today. The mine produces more than 500 tons of salt each year for use in cooking and for a range of unique souvenirs. There is still more than one billion tons of ore left in the mine, which is extracted using machines and underground blasting, according to a 1971-79 survey. This is the salt mine outside of Cankiri in Turkey which began being mined in 300BC and is still in use today. I thought to myself: 'What happens if it collapses?'

RESULTS: The original miners were Hittites, an ancient race of people who had an empire in the Middle East and used primitive tools and their hands to extract the salt. "The cave is cool and scentless, which is because it is a very old salt cave. The walls are all made of rock salt and the texture is varied because of the digging machines used. "I've never seen anything like it before. The most striking part of the caves is the old gallery, it's interesting because they dug this gallery with simple tools and their own hands, unlike today's methods." While temperatures in Cankiri can reach a balmy 92 degrees, the temperatures in the salt mines never stray above a crispy 59 degrees.

CONCLUSIONS: The mine produces about 500 tons of salt every day which is sold on for use in cooking and as souvenirs. The mine today has 16 workers and contains a small canteen, a mosque, repair room, workshop and a first aid room. All the ore extracted from the mine, which measures in at around 90 percent purity, is taken by diggers to nearby railway tracks where it is transported to a factory for processing. 


\section{OP027- DEAD SEA CLIMATOTHERAPY: CONTROL OF SUN EXPOSURE THROUGH NARROWBAND REFLECTANCE IN ATOPIC DERMATITIS CHILDREN \\ M Harari ${ }^{1}$ and S Dikstein ${ }^{2}$ \\ ${ }^{1}$ Dead Sea and Arava Center, Ein Gedi and DMZ Medical Center, Ein Bokek, Israel. \\ ${ }^{2}$ Hebrew University, Jerusalem, Israel.}

INTRODUCTION: Erythema induced by ultraviolet Ultraviolet B light is a common skin reaction. Dead Sea Climatotherapy (DSC) which includes mainly large amounts of sun exposure under medical supervision has the potential risk to induce such side effects. Evaluation of UVB-induced erythema was not done until nowadays.

MATERIALS \& METHODS: To investigate the impact on short-term results of DSC in moderate to severe Atopic Dermatitis (AD) children from the Czech Republic treated 4 weeks at the Deutsches Medizinisches Zentrum (DMZ), Israel and to correlate their results to the presence of erythema on the skin. Seventy-one patients aged less than 19 years were divided into 3 groups and treated in March 2014, October 2014 and March 2015 with Dead Sea baths and gradually increasing sun exposure during 28 consecutive days. The SCORing Atopic Dermatitis (SCORAD) index was recorded before and immediately after DSC by the same dermatologist and as well erythema index through narrowband spectrometry, using a validated photometric reflectance device. Statistical analysis was performed.

RESULTS: The overall improvement in SCORAD reached $87.5 \pm 13.4 \%$, with a drop of SCORAD values from $49.29 \pm 25.765$ to $8.27 \pm 9.3$. No side effects were observed during the treatments. As expected, the erythema index was correlated to sun exposure amount and disease severity; however, the highest average values after treatment reached only $339.42 \pm 48.83$.

CONCLUSIONS: Reflectance spectrophotometry measurements confirm the safety of Dead Sea Climatotherapy in children.

\begin{tabular}{|l|l|c|c|c|c|}
\cline { 3 - 6 } \multicolumn{2}{c|}{ Erythema Index } & \multicolumn{2}{c|}{ Before DSC } & \multicolumn{2}{c|}{ After DSC } \\
\cline { 3 - 6 } \multicolumn{2}{c|}{} & Mean & \multicolumn{1}{c|}{ SD } & \multicolumn{1}{c|}{ Mean } & \multicolumn{1}{c|}{ SD } \\
\hline \multirow{2}{*}{ Elbow } & Right & 240.2 & 65.7 & 295.2 & 54.0 \\
\cline { 2 - 6 } & Left & 239.9 & 63.9 & 299.9 & 48.7 \\
\hline \multirow{2}{*}{ Knee } & Right & 267.4 & 55.6 & 330.8 & 56.9 \\
\cline { 2 - 6 } & Left & 277.5 & 58.1 & 339.4 & 48.8 \\
\hline
\end{tabular}

\section{OP028 - TRADITIONAL CHINESE MEDICINE}

David Ho, Dr. Ivyci (Chen Qian) Qian

INTRODUCTION: Traditional Chinese Medicine is a part of Chinese Traditional culture in 5000 years, its unique basic theory system emerged 2000 years ago. A lot of diagnosis and treatment experiences and the unique treatment methods have been accumulated in long-term clinical practice. It is a science of researching human physiology, pathology, disease diagnosis, prevention and treatment.

MATERIAL AND METODS: Traditional Chinese medicine theory originated from the ancient Taoist philosophy thinking.

China has rich tradition in non-mechanical thinking of system in philosophy and medicine.

RESULTS: Traditional Chinese medicine makes yin-yang and five elements as the theory basis, it seeks the pathogeny and changes of internal organs, meridians and joints by "Inspection, auscultation and olfaction, inquiry and pulse-taking and palpation" four diagnostic methods, to summarize the type of syndrome, and according to the principle of treatment based on syndrome differentiation, use a variety of traditional treatment methods to reconcile Yin and Yang of the human body to rehabilitation.

CONCLUSION: The meridian theory (including acupoint theory), soul theory and theory of internal organs are three important parts for I ching biotics (traditional Chinese medicine, qigong), concerning the origin and evolution, composition and structure (distribution), nature and function, phenomenon and application of the organism, the three parts constitute the life dynamics system to reveal the essence of life and correctly reflect life phenomenon and law of activity. 


\title{
OP029- REHABILITATION OF A PATIENT WITH PROXIMAL THIRD CALF PERIOSTE- AL OSTEOSARCOMA OPERATED WITH GMRS PROSTHESIS
}

\author{
Dr. Irina Ionică ${ }^{1}$, Dr. Florina Ojoga ${ }^{2}$ \\ ${ }^{1}$ INRMFB. \\ ${ }^{2}$ INRMFB, Carol Davila University.
}

INTRODUCTION: The case study presents a 40 years old female patient case with right calf periosteal osteosarcoma treated with GMRS prosthesis.

MATERIALS \& METHODS: Patient: GG, 40 years old, female, with no significant past medical history, non-smoker, over weighted

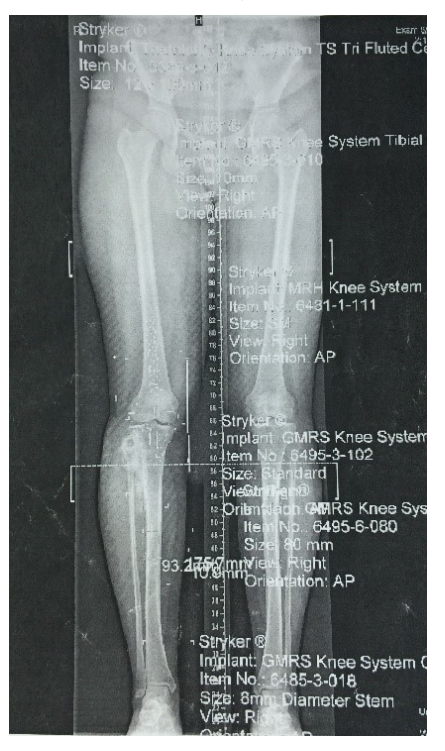

Case history: Three years ago (in 2013) the patient noticed venous insufficiency accompanied by a painless, slightly endured, $4 \mathrm{~cm} \times 5 \mathrm{~cm}$ sized, localized swelling, situated on the proximal third of anterior right calf, ignored as venous insufficiency.

In April 2015 MRI and biopsy diagnosed the tumor as periosteal osteosarcoma.

In July 2015 - surgery performed was osteosarcoma ablation and GMRS prosthesis. The figure represents the pre-operatory orthopedic analysis of GMRS knee system adapted to patient's case. The external popliteal sciatic nerve was included in the tumor, and therefore surgically sectioned.

The patient started rehabilitation having increased calf muscles hypotrophy, 30 degrees mobility of knee on passive mobilization, impossible active flexion, pain on mobilization, resulting in improvement of physical parameters.

September 2015 - the patient falls from her own height and has subpatellar ligament injured and operated in October 2015 with tenoraphia.

February 2016 Symptoms: right knee pain with mixed characteristics, distal right leg edema, local heat on right knee tegument, locomotion disorder.

Local examination: knee flexion 110 degrees, complete extension, slight hypotrophy of calf and foot muscles, impossible active dorsal and plantar flexion of the foot, sensibility disorder on right calf, sensibility unmodified on right sole; the patient walks wearing ankle-foot orthosis and two crutches.

RESULTS: Rehabilitation consisted in physical therapy, electrostimulation procedures and massage. It leaded to muscular force increase, knee ROM improvement, use of crutches instead of walking frame, increase of ADL score.

CONCLUSIONS: External popliteal sciatic nerve paresis associated to periosteal osteosarcoma, as well as added traumatic tendon injury influenced rehabilitation results.

\section{OP030- EFFECTS OF THORON SPA OR BATH ON CANCER PATIENTS Atsuhiro Kishimoto, Kimiko Horiuchi, Koji Yamamoto}

INTRODUCTION. It is generally received that the low dose irradiation is effective for the improvement of the lifestyle diseases including cancers and diabetes. In this meeting, we will report some examples about the effects of the Thoron spa or bath on cancer patients.

MATERIALS AND METHODS. The thor on hot water was prepared using our devices based on the weak acid leaching method. The cancer patients took a bath in the thoron hot water from six to eight times a day for each ten minutes every day. We judged the evaluation from a blood test, an examination for tumor marker, image diagnosis and so on.

RESULTS. A patient of anaplastic carcinoma of thyroid received taxol treatment (130 $\mathrm{mg} /$ body/ times) after surgery. The myelosuppression is a side effect of the taxol treatment. The bone marrow activity recovered after the thoron hot bath, and the taxol schedule of 11 times of once a week could be performed. In addition, the peripheral nerve disorder accepted as a serious side effect of taxol was minimal. In the example of a prostate cancer patient, the remarkable rise of the PSA, a prostate cancer marker, and the ALP, a bone metastasis marker, level were measured in his blood. However, the PSA level decreased almost to the normal level after taking the thoron hot bath. Furthermore, the ALP level was delivered to the normal range. In the case of a malignant mesothelioma patient, he was diagnosed that the progress of the tumor was not observed in approximately one year of the thoron schedule. In addition, we will report about the effects on other cancer patients.

CONCLUSIONS. The mechanism of the Thor on spa or bath's effectiveness was still unknown, but it would be suggested of the good results for the improvement of the cancer. 


\section{OP031 - HOKURIKU SHORT VERSION CLIMATOTHERAPY PROGRAMME}

Hitomi Kanayama*

* Division of Environmental Health, Department of International Social and Health Sciences, Faculty of Medical Sciences, University of Fukui

INTRODUCTION: Japanese people can seldom have a time for long stay in the health resorts. We had originated the Hokuriku short version climatotherapy programme to fit anyone who has no enough time and aims for disease prevention and health promotion.

MATERIAL \& METHODS: Our study was conducted in 2015 at Yatsusugi forest in moderate-altitude mountain and Fukui Prefectural Green Center in lowlands. Subjects were recruited in our open lecture on climatotherapy. Our programme consists of health education, climatotherapy guided by climatotherapist, individual report and advice, and self-practice. Climatotherapy was carried out in spring and autumn; 3 times half-day climatotherapies every other week respectively. A half-day climatotherapy included 2 hours' climatic terrain cure and 20 minutes' fresh-air rest cure. Physiological and environmental measurements conducted. Subjects answered the questionnaire on physical condition and exercise habits, ASHRAE scales, and POMS short form. Course measurements were conducted with GPS data logger.

RESULTS: Fourteen inhabitants ( 7 males and 7 females, average 64.4 yrs) were participated. Skin temperature significantly descended after the start and significantly ascended after the fresh -air rest cure. Heart rate significantly increased after the start and on the uphill, and significantly decreased after the fresh-air rest cure. Physiologically these results can be explained well. Three of six POMS mood statuses significantly improved after a half-day climatotherapy. These results tend to be clearer at Yatsusugi forest than at Green Center. Regarding to blood lactic acid, there was no significant increase after a half-day climatotherapy. Heart rate and blood lactic acid results suggest the appropriate load amount had been applied to subjects during climatic terrain cure, suite for our purpose of aerobic endurance exercise.

CONCLUSIONS: Our results suggest the effectiveness and usefulness of the Hokuriku short version climatotherapy programme.

ACKNOWLEDGEMENTS: The author thanks H. Inoue, T. Hirai and Y. Kusaka for their cooperation and expert advice.

\section{OP032 - SYSTEMIZATION OF APPLIED PELOID IN SERBIAN SPAS \\ Attila Klimó \\ Specialized Hospital for Rehabilitation "Banja Kanjiža" Kanjiža}

INTRODUCTION: The typology of natural geological sediments, which make peloids with potential therapeutic application, is based on several parameters: the origin, the formation and composition of the solid stage of the soil, the chemical composition and temperature of the thermomineral water, and the process of mixing and maturation of peloids. The features of peloids depend on pedogenesis and on mutual action of rock mass and water under the influence of high temperature, pressure and organic living matter. In Serbia, for now there is no accepted classification of usable peloids with consensus.

OBJECTIVE: Based on the integrity of Lüttig's classification of peloids, on the genetic and WRB classification of types and classes of soil, and the hydrogeological regionalization of thermomineral waters of Serbia, the study wants to envisage the partition of applied peloids in spas in Serbia.

METHODS: Based on the available physical and chemical analysis peloids shown analytical overview of the phenomens, prospecting and soil properties and mineral water to the hydrogeological regions of the active spas in Serbia.

RESULTS: Lüttig's classification of peloids which is amended by soil properties defined by the general principles of the World Reference Base for Soil Resources (WRB) contributes to a better characterization of the natural soil materials, taking into account their relationship with the processes that take place during the formation of the soil. Based on available complete physical and chemical analysis of peloid samples in seven of the fifteen spas in Serbia where peloidotherapy is applied are classified by grades and forms of soil formation.

CONCLUSION: It is necessary to execute a new or renovate existing physical and chemical analysis applied peloids in spa centers of Serbia order to complete the existing data on their composition, quality and value of balneotherapy, which would be complete the deficiencies in the proposed classification peloids to accept the same result.. KEYWORDS: pedogenesis, peloid, typology. 


\title{
OP033 - COMPARATIVE ANALYSIS OF WATER-SALT COMPOSITION OF THE EURA- SIAN MINERAL WATERS, THERAPEUTIC MUD AND VENOUS HUMAN BLOOD
}

\author{
Nikolay Kornilov $^{a^{*}}$, Olga Surdu , Elena Kornilova ${ }^{c}$, Traian-Verghiliu Surdu ${ }^{\text {b }}$ \\ ${ }^{a}$ Stavropol State Agrarian University, Stavropol, Russia \\ ${ }^{\mathrm{b}}$ Ovidius University, Constanta, Romania \\ ${ }^{\mathrm{c}}$ North-Caucasian Social Institute, Stavropol, Russia
}

INTRODUCTION. The effectiveness of the biological effects of hydromineral resources and therapeutic mud on the human body is determined by the compatibility of water-salt composition of mineral waters, mud and blood of the patient.

The purpose of research:

- establishment of quantitative correlations of structure and properties of venous blood in the form of mathematical models.

MATERIALS AND METHODS. Evaluation of the effectiveness effects on the body hydromineral resources and therapeutic mud was carried out using the characteristic index $\varphi$ of the blood in the form of equation

$$
\varphi=\alpha\left({ }^{x} \mathrm{Cl}^{-} / x_{\mathrm{HCO}_{3-}^{-}}\right)^{\delta}, \alpha \text { и } \delta \text { - constant values, }{ }^{x_{\mathrm{Cl}^{-}}} / \mathrm{x}_{\mathrm{HCO}_{3}} \text { - the ratio of the molar fractions of the ions } \mathrm{Cl}^{-} \text {и }
$$

$\mathrm{HCO}_{3}^{-}$, contained in the venous blood of the patient. The characteristic index of the composition of mineral waters chloride-hydrocarbonate type, $\Phi$, was calculated according to [1].

RESULTS. Comparative analysis the content of ions $\mathrm{Cl}^{-}$и $\mathrm{HCO}_{3}^{-}$in the plasma human venous blood before and after treatment of mud and mineral waters chloride-carbonate type was performed using

1. Initial state $\left(\varphi^{\circ}\right)$ analytical dependencies:

$$
-\log \varphi^{\circ}(\text { blood })=2,5718-1,1506 \log \left(x^{C^{-}} / x_{\mathrm{HCO}_{3}^{-}}\right)
$$

2. After adopting mud therapy $\left(\varphi^{*}\right)$

$$
-\log \varphi^{*}(\text { blood })=2,5718-1,1506 \log \left(x^{C^{-}} / x_{\mathrm{HCO}_{3}^{-}}\right)
$$

3. Mineral water chloride-bicarbonate type $(\Phi)$

$$
-\log \Phi(\text { mineral water })=2,5807-1,1524 \log \left(\mathrm{Cl}^{-} / \mathrm{x}_{\mathrm{HCO}_{3-}}\right)
$$
clusions:

CONCLUSIONS. According to the results of chemical studies can draw the following con1. The chemical composition of a patient's blood prior to the adoption of procedures of mud treatment is identical to the composition of mineral waters.

2. of therapeutic muds on the person is accompanied by a decrease in the content of ions ${ }^{\mathrm{HCO}_{3}^{-}}$and increased content ion $\mathrm{Cl}^{-}$.

3. The change in the ionic composition of venous blood as a result of balneological procedures increases the solubility of oxygen, increase of hemoglobin and decrease of glucose.

\section{REFERENCE}

1. Vasiltseva O. N., Kornilov N. and., Kornilova E. N. Classification of natural mineral waters chloridehydrocarbonate type (mathematical model and principles of forming of composition and properties): Stavropol, 2009, 180 p. 


\title{
OP034- COMPARASION OF THE BLOOD PRESSURE CHANGE IN YOUNG AND MIDDLE -AGED DURING THE WINTER HOME BATHING AT JAPANESE TRADITIONAL BATH- ING \\ Maeda Masaharu, Kogure Eisuke, Imai Mai, Kikkawa kouichi
}

\author{
Department of Rehabilitation, International University Health \& Welfare, graduate school , Tochigi- \\ ken ,Japan \\ $\underline{\text { mm@iuhw.ac.jp }}$
}

INTRODUCTION: The winter of from December to February has much bathing death, and the most occur in home. Therefore we measured changes of the blood pressure in winter home bathing and compared them between young and middle-aged.

METHODS: Objects are three groups, young low temperature group (YL) of 6 persons (3 male,3 female, mean 20y) with 11.7 degrees Celsius of bathroom, young severe cold group (YS) of 6 persons ( 2 male, 4 female, m19y) with 6.1 degrees Celsius, and middle-aged low temperature group (ML) of 3 persons ( 3 male, m49y) with 10.2 degrees Celsius.

In the temperature environment, YL was for A living room 18.4 degrees Celsius, B dressing room 10.2, $\mathrm{C}$ bathroom 11.7, D bathtub 42.0 at bathing start, E bathtub 42.0 degrees Celsius ten minutes after start bathing, F dressing room after bathing 12.2. And YS was for A17.8, B6.7, C6.1, DE42.0, F7.0, ML was for A20.2, B10.2, C10.2, DE42.0, F11.7. We measured them for winter from January to February.

RESULTS: The rise of the mean systolic blood pressure were observed at a dressing room and a bathroom as A111mmHg, B114, C116, D105, E133, and F110 in YL.

In addition, more $10 \mathrm{mmHg}$ rises were observed in $\mathrm{YS}$ at the dressing room and the bathroom as A111, B123, C126, D110, E97, and F101.

Furthermore, a steep rise was seen in the dressing room and the bathroom in ML as A127, B155, C167, D155, E111, and F132.

CONCLUSION: It was thought that a rise in blood pressure was controlled as seen in the YL if room temperature was slight warm at the dressing rooms. Careful attention is necessary as the cold environment of the dressing room and bathroom in the ML. Furthermore, even if young, we thought that attention was necessary.

\section{OP035- STRESS-REDUCING AND HEAT-RETAINING EFFECTS BY FOOT BATH WITH SOLUBLE EXTRACTS FROM THE LEAVES OF ABIES SACHALINENSIS Yoshinori OHTSUKA, TOSHIHIKO KANEKO}

INTRODUCTION: " Shinrin-yoku" (walking in a forest) is very comfortable and gives a feeling of relaxation by breathing fresh and aromatic forest air. Foot bath with soluble extracts from the branches and leaves of Abies sachalinensis (Todo fir) was conducted to clarify the characteristics of such aromatic components of ferest air.

MATERIALS AND METHODS: Ten normal subjects were divided into 2 groups. Each group took a foot bath for $15 \mathrm{~min}$ at $41 \square$ everyday for a week with or without fir extracts in bath water. After one week interval, cross over foot bath was performed for additional one week. Questionaries concerning mood profile was taken and changes of skin temperature on the instep during foot bath were measured in our laboratory before starting serial foot bath and after the last foot bath. Fir extracts was generous gift from Japan Aroma Laboratory.

RESULTS: By foot bath with tap water, only pleasant feeling tended to incease at first and last bathing experiments $(p<0.1)$. On the contrary, after one week serial foot bath containing fir extracts, feeling of pleasantness increased $(p<0.05)$ and that of relaxation increased $(p<0.01)$. Heat retaining effets were more strongly observed after foot bath with fir extracts $(p<0.0001)$.

DISCUSSION: Though underlining mechanisms were not elucidated, foot bath with fir extracts have a beneficial effects on human both mentally and physically. 

OARTHRITIS

\author{
E.V. Ionescu ${ }^{1,2}$, E.R. Almaşan ${ }^{1}$, C. Oprea ${ }^{1}$, S. Albina ${ }^{3}$, M.G. Iliescu ${ }^{2,3^{*}}$, D.M. Iliescu ${ }^{2}$ \\ ${ }^{1 .}$ Balneal and Rehabilitation Sanatorium of Techirghiol, Romania, ${ }^{2}$ "Ovidius” University of Constanţa, \\ Faculty of Medicine, ${ }^{3}$. Rehabilitation Hospital of Eforie Nord, Romania
}

INTRODUCTION. Our study aims to determine some direct correlation between the frequency of the balneal treatment and serum adiponectin in patients diagnosed with osteoarthritis of the knee.

MATERIAL AND METHOD. We evaluated 78 patients, aged between 30 and 80 years, diagnosed with knee osteoarthritis, hospitalized for rehabilitation treatment in Balneal and Recovery Sanatorium Techirghiol, for a period of 2 weeks. The patients were divided into 5 groups according to the frequency of balneal treatments: biannually, annually, once every 2-3 years, occasionally and patients at the first hospitalization. They were evaluated on 3 groups: the control group that did not receive treatment with natural factor (WG), the group that received treatment with warm mud baths (WMBG) and a group that received treatment with cold mud baths $(\mathrm{CMBG})$. In all patients we dosed the adiponectin in the first and the tenth day of treatment. The data were processed and statistically analyzed, making correlations between the assessed variables.

RESULTS. In patients who received biannually treatment, at the end, the adiponectin values in the WG and WMBG increased compared to initial levels. This increase may be the result of the biannual balneal therapy (according to the prescribing protocols) in patients with generally elevated levels of this bio-humoral constant, the adiponectin secretion being controlled by peloidotherapy.

CONCLUSIONS. Repeating balneal cures is an important element in shaping the pathogenic mechanisms that involve adipokines in knee osteoarthritis, a fact that proves which the undeniable role of the peloidotherapy, emphasizing in this way the therapeutic value of chondroprotective and decreased inflammation of the balneal therapy.

\title{
REFERENCES
}

1. A. FIO RAVA NTI, L CA NTA RINI, M. BACA RELLI, A. de LALLA, L. CECCATELLI, P. BLARDI: Effects of Spa Therapy on Serum Leptin and Adiponectin Levels in Patients with Knee Osteoarthritis. Rheumatol Int, 31 (7), 879 (2011).

2.J. CONDE, M. SCOTECE, R. GOMEZ, V. 1. LOPEZ, J. J. GOMEZ-REINO, O. GUALILLO: Adipokines and Osteoarthritis: Novel Molecules Involved in the Pathogenesis and Progression of Disease, June, (2011); ID 203901.

3. R. LAGO, R. GOMEZ, M. OTERO, F. LAGO, R. GAlLEGO, C. DIEGUEZ, J. J. GOMEZREINO, O. GUALILLO: A New Player in Cartilage Homeostasis: Adiponectin Induces Nitric Oxide Synthase Type II and Pro-inflammatory Cytokines in Chondrocytes. Osteoarthritis Cartilage, 16 (9), 1101 (2008). 


\section{OP037- COLECTIV - THE MEDICAL BATTLE BEHIND THE TRAGEDY}

Ruxandra Mihai*, Ana Maria Boiangiu*, Andrei Carantino*, Ingrid Carantino*, Ioana Apostolescu*, Anca Oporanu*, Eugen Turcu*, Matei Gheorghiu*, Andrei Marin*, Ioana Dumitrescu*, Anca Bordianu*, Iris Popa*, Mihai Predescu*, Elena Martin*, Catalin Bejinariu*, Andreea Badeana*, Olivia Constantinescu*, Silviu Marinescu*

*Department of Plastic and Reconstructive Surgery,” Bagdasar Arseni““ Clinical Emergency Hospital, Bucharest, Romania

INTRODUCTION. In the evening of $30^{\text {th }}$ October 2015 a night club was subject to a mass casualty. There was a fire involving the whole club at the gala of a rock concert. A number of over 100 burned people were transported to 11 Bucharest hospitals. In our hospital, the on call doctors mobilized all their colleagues and proceeded in immediate urgency to wound and intensive care of all patients.

MATERIAL AND METHODS. In our hospital there were admitted 23 patients. All the burns were severe due to the involvement of the face and hands. The surfaces varied between 5 and $90 \%$. The vast majority of them presented also airway burns. The burns were surgically approached by early excision and grafting, conservative methods, enzymatic debridement and grafting. The surgery procedures intermingled with the intensive care of these patients.

RESULTS. A number of 15 patients were admitted in the intensive care unit and the rest of them in the clinic of plastic surgery. Two of them, with large burned surfaces and airway burns died in the first 48 hours, and another 3 in the first 2 weeks. A number of 5 patients were transferred abroad; one of them died from respiratory failure. The rest of them remained in our hospital. After a long journey of medical and surgical surveillance they succeeded. Rehabilitation interventions began immediately after injury to prevent long term complications.

CONCLUSIONS. The involvement of all the members of our clinic, anesthesiologists, psychologists, rehabilitation doctors, doubled by the help of other European burn centers allowed the survival and satisfactory results of the majority of our patients. Burn care continued after surgery addressing complex issues such as contractures, keloid and hypertrophic scarring, pain, neuropathy and psychosocial problems.

Corresponding author

Andrei Marin, marin_dpt@yahoo.com ," Bagdasar Arseni“ Clinical Emergency Hospital, 10-12 Berceni Str, Bucharest, Romania

\section{OP038 - THE REHABILITATION TREATMENT IN ADHESIVE CAPSULITIS OF THE SHOULDER Florina Ojoga}

\section{UMF Carol Davila INRMFB, Rehabilitation Department inaojoga@gmail.com}

INTRODUCTION Primary adhesive capsulitis of the shoulder is an idiopathic, progressive and self-limited restriction of active and passive range of motion, which occurs in $3 \%$ of general population, with a course of 1 to 2 years, predominantly in women after 50 years.

MATERIAL AND METHODS The symptoms are progressive pain with worsening at night, reduction of range of motion and decreased use of the arm in the daily activities. Diagnostic studies include radiographs to rule secondary causes, arthrograms, MRI or arthroscopy of the shoulder for diagnostic purpose.

RESULTS The goals of the treatment are to decrease pain and inflammation and increase the shoulder range of motion in all planes. The rehabilitation treatment is ruled out by kinetotherapy, physiotherapy, subacromial space injections and acupuncture. The decision to perform surgery is based on failure of the conservative treatment or a great decrease in the patient daily activities and quality of life.

CONCLUSION The rehabilitation treatment of primary adhesive capsulitis of the shoulder is very important because in many cases can lessen the pain, increase the passive and active mobility of the shoulder and the patient can return afterwards to his daily activities by regaining the function of his arm. 


\section{OP039- COLECTIV - INTERMINGLING SURGERY AND REHABILITATION}

Silviu Marinescu *, Ruxandra Mihai*, Olivia Constantinescu*, Ana Maria Boiangiu*, Andrei Carantino*, Ingrid Carantino*, Ioana Apostolescu*, Anca Oporanu*, Eugen Turcu*, Matei Gheorghiu*, Andrei Marin*, Cristina Popescu**, Ioana Dumitrescu*, Anca Bordianu*, Iris Popa*, Elena Martin*, Catalin Bejinariu*, Andreea Badeana*, Gelu Onose**

*Department Of Plastic And Reconstructive Surgery,” Bagdasar Arseni““ Clinical Emergency Hospital, **Department of Rehabilitation and Physical Medicine," Bagdasar Arseni“" Clinical Emergency Hospital,

Bucharest, Romania

INTRODUCTION. It has been a while from the tragedy involving over 100 young people caught in a fire in a Bucharest night club. In our hospital, after a long journey of general and local therapy we arrived to the point of reestablishing patient's best skills and cooperation with the outside world, but our struggle continues.

MATERIAL AND METHOD. It was organized an integrated group for crisis intervention that created a scale for patient's follow-up. The scale referred to the present state, burn severity, medical history, state of mind, social problems, rehabilitation plan, home care and arguments for abroad transfer. The rehabilitation plan included positioning, splinting, exercise, gait followed by physio and hydrokinetotherapy, diapulse, laser, bioptron and occupational therapy. All 20 patients enrolled presented severe burns due to the involvement of hands and face.

RESULTS. The whole group presented severe burns. None of them had tracheostomy, was intubated or needed ventilatory support. They were not dialyzed. As for now they were not subject to any secondary surgical intervention. These will be postponed beyond 6-9 months allowing scar maturation. All of them needed individual and adapted plans of rehabilitation ie hydrokinetotherapy, high frequency electrical currents in inductor field emitted, laser, polarized light and occupational therapy. They received both social and psychological support. None of them needed home care but we must emphasize that they benefited from a strong family support. All of them had a satisfactory improvement according to our scale.

CONCLUSIONS. Beyond surgical therapy, rehabilitation plays a major role in burn patients lives, being a long multistage process that often takes years. Rehabilitation and hand therapy paralleled and mingled surgery with the target of achieving best results.

\section{OP040- EPIDEMIOLOGIC PARTICULARITIES IN CHILDREN WITH NEURO-PSYCHO- MOTOR DISORDERS HOSPITALIZED IN BALNEAL AND REHABILITATION SANATO- RIUM TECIRGHIOL (SBRT)}

M. Minea ${ }^{1}$, L. Rizea ${ }^{1}$, I. Bănărescu ${ }^{1}$, M. Nedelea ${ }^{1}$, A. Prăjitură ${ }^{1}$, L. Stanciu ${ }^{1}$, G. Radu $^{1}$, E.V. Ionescu ${ }^{1,2}$

${ }^{1}$ Balneal and Rehabilitation Sanatorium Techirghiol; ${ }^{2}$ Ovidius University of Constanţa

INTRODUCTION: Chidren's neuro-psycho-motor disorders is a major public health issue, since thousands of cases are detected every year. The aims of the study are to evaluate the intellectual and motor development of children hospitalized in the Department of Pediatric Neuro-psycho-motor Rehabilitation of SBRT and to identify risk factors for these diseases.

MATERIAL \& METHODS: The study group contained 679 patients admitted 02-12.2016. All patients underwent an initial clinical examination, and the doctors filled out a questionnaire conceived by a group of physicians from the sanatorium that included personal data, associated diseases, the main symptom. Data from the questionnaires were statistically processed and plotted using SPSS 23.0.

RESULTS: In the study group, $27,26 \%$ of patients do not have risk factor for neuro-psychomotor disability, prematurity, as risk factor, was identified in in $27,70 \%$ of cases, congenital malformations in $23,70 \%$ of cases, postnatal pathology in $14,22 \%$ of cases, while obstetrical trauma in only $7,11 \%$ of cases. Most of them (74\%) had normal intellect, while 5,76\% were diagnosed with severe intellectual disability. The association between risk factors to develop a neuro-psycho-motor disorders and locomotor disability was statistically determined $(\mathrm{p}<0.001)$. A connection between risk factors and level of intellect was also identified $(\mathrm{p}<0.001)$.

\section{CONCLUSIONS:}

1. Neuro-psycho-motor disorders in children are a complex health issue due to the increase incidence and family and social support that these patients need.

2. Locomotor disability reduces the chances of accessing regular tuition systems, situation portrayed vividly by the fact that $74 \%$ of our group have normal intellect, only $61 \%$ followed regular school.

Considering that $27,26 \%$ of study group do not have any risk factor for neuro-psycho-motor disability (obstetrical trauma, postnatal pathology, congenital malformation, prematurity), further studies to establish illness aetiology are needed. 


\title{
OP041- COMPARATIVE STUDY REGARDING EFFICIENCY OF TRAINING WITH RO- BOTIC DEVICES IN UPPER LIMB REHABILITATION AFTER STROKE TO ADULT AND CHILD \\ Moghioroiu C. ${ }^{1}$, Padure L. ${ }^{2}$
}

\author{
1,2 University of Medicine and Pharmacy „Carol Davila” Bucuresti / National Clinical Center for Chil- \\ dren Neuro-Psycho-Motor Rehabilitation „Dr. Nicolae Robanescu”,
}

INTRODUCTION: The use of robotic therapies / virtual reality in upper limb (UL) rehabilitation after stroke offers a number of advantages, in an attempt to make the process of learning and recovery more effective: real time feedback on execution performance with the possibility of correction, interest and motivation generated by the game resulting in increasing compliance to therapy and high number of repetitions. Theoretically these advantages are enormous, but how effective really is virtual reality only clinical trials can say.

MATERIALS \& METHODS: For this study we will select a number of 15 adults and 15 children imagistically diagnosed with a single stroke. Patients who will participate in the study will receive 2 weeks of conventional therapy (two sessions of 30 minutes of daily physical therapy) and 10 session of therapy with the robotic device lasting 15-30 minutes depending on individual tolerance. We will perform three assessments - at the beginning, after two weeks and after three months. We will evaluate UL control and coordination using Fugl-Meyer scale; mobility on basic movements of the shoulder, elbow and wrist; pain with VAS and spasticity of elbow and hand muscle with Ashworth scale. To these assessments will add video recording and parameters registered by computer, including a synthesis of exercises performance. The opinion of the ethics committee and obtaining informed consent from patients are a sine qua non of this study.

CONCLUSIONS: Acquisition of a robotic device dedicated to UL control and coordination training at „Dr. Nicolae Robanescu” National Rehabilitation Center opened the possibility of conducting a comparative study on neuroplasticity to adult and child. The main purpose of this study is testing the effectiveness of robotic devices use in the recovery of UL motor deficits secondary to stroke, the secondary aim is to identify age-dependent differences in the processes of learning and recovery.

\section{OP042-THE TREATMENT OF SPASTIC HIP IN CHILDREN WITH CEREBRAL PALSY L. Pădure*, A. Oprea*,A. I. Grigoriu*,
* National Clinical Center of Neurological Rehabilitation for Children “Dr. N. Robanescu”, Bucharest, Romania

SCOPE. BACKGROUND: The spastic hip is one of the most important aspects, regarding complications of CP in children. Coordinated with GMFCS scores, hip complications in CP are very frequent and the right treatment at right time is very important. Our observations put light in this issue and pleads for a functional approach.

MATERIAL \& METHODS: We observed and we evaluated (clinically, radiographs and gait analysis) 87 patients, age between 2 and 17 years with CP, 26 with Diparesis, 44 with tetraparesis and 17 with hemiparesis. 44 patients were with GMFCS levels of I-III and 41 were GMFCS levels of IV $-\mathrm{V}$.

RESULTS: After x-ray evaluation - 15 patients were normal, 16 with bilateral coxa valga, 12 with unilateral coxa valga , 9 with bilateral coxa recta, coxa magna/breva 5 patients, 6 patients with hip dysplasia, 9 with hip luxation - surgical treatment performed, hip luxation - non operated 5.

Patients with hip subluxation and luxation, GMFCS score of I-III are better functional without orthopedic surgical treatment - only soft tissue release.

Patient with GMFCS score of IV-V, surgery resolved orthopedic problems (hip luxation- subluxation) but did not improved function.

CONCLUSIONS: The exact timing of surgery and the indication of the right level of intervention is a result of a well prepared team who gives the surgery indications, after a well done evaluation with the latest evaluation tools (Multifactorial gait analysis). With surgery you can improve function in patients with GMFCS levels of I-III but not in patient with GMFCS levels of IV-V (only for comfort). 
OP043-MEDICAL REHABILITATION HEALTH UNITS EMPLOYEES' SATISFACTION SURVEY IN THE CONTEXT OF LEGISLATIVE CHANGES

C. Oprea ${ }^{1}$, P. Armean ${ }^{2,}$ E. R. Almăşan ${ }^{1}$, E. V. Ionescu ${ }^{1,3}$, M.G. Iliescu ${ }^{3,4}$

\author{
${ }^{1}$ Balneal and Rehabilitation Sanatorium Techirghiol \\ 2 "Carol Davila" University of Medicine and Pharmacy, Bucharest \\ 3 “Ovidius" University, Faculty of Medicine, Constanţa \\ ${ }^{4}$ Rehabilitation Hospital, Eforie Nord \\ *Corresponding author's email address: carmen_oprea_cta@yahoo.com
}

INTRODUCTION: The Romanian and European legislation foresees the evaluation of patient and staff's feedback in order to monitor the progress of medical service quality. As a consequence of implementing the legislative and organizational changes in the "Balneal and Recovery Sanatorium of Techirghiol", we decided to analyze the employees' satisfaction degree, given the interdependence of employees' and patients' satisfaction.

MATERIALS \& METHODS: 97 subjects (medical/non-medical staff) from a medical rehabilitation specialty unit, participated to the study, which consisted in a prospective investigation inflicted on the target group, in April-May 2015 based on questionnaires. The study targeted to establish their satisfaction regarding the medical rehabilitation services' quality and was focused on issues as legislation knowledge, medical research and work optimization.

RESULTS: Respondents consider medical research development to be necessary by attracting researchers, grants and research contracts. They believe the sanatorium is the right place for them to achieve their career plan, being professionally motivated by their hospital's progress premises. There is a dependency relationship between variables "Profession" and "Specific legislation awareness" or between variables "Ethics Council's duties awareness" and "Employees' rights and obligations awareness". The subjects correlate professional errors to quantitative overloading or stress, fatigue/ exhaustion/inattention.

CONCLUSIONS: The study reveals causal relationships between employee satisfaction and work performance. Certain aspects were also identified: the need of medical research development, implementing integrated informatics systems, hiring professional staff in order to avoid overloading errors and promoting legislation knowledge applicable to the medical field.

\title{
OP044-MULTIFACTORIAL GAIT ANALYSIS IN THE PHYSICAL AND REHABILITATION MEDICINE OF THE GAIT DISORDERS IN CHILDREN Liliana Padure, A.I. Grigoriu, A. Oprea, M. Bejan \\ ${ }^{1}$ CNCRNC Dr.Nicolae Robănescu
}

SCOPE. BACKGROUND: The Multifactorial Motion Analysis is instrumental method of evaluation of the body's motion on the basis of a biomechanical model. It quantifies the lower limb' segmental motion during walking and it has major benefits and application in clinical problems.

MATERIAL\& METHODS: 147 patients with age between 2 and 26 years and with different gait problems were evaluated in our Gait Lab from February 2015 to March 2016. The integrated system provides information about the spatial and temporal parameters of the gait, the 3D kinematics (lower limb joints' angle variation during gait cycle), the kinetics (ground reaction forces, joints' moments and powers) and the dynamic surface EMG (muscular activation).

RESULTS: Among the 147 patients, $60.5 \%$ were children with cerebral palsy, $17.6 \%$ children with gait problems of orthopedic origin, $8.1 \%$ peripheral neuropathies and muscular diseases, $5.4 \%$ post-trauma neurological status (brain or medullar injuries), 1.3\% malformative congenital syndromes. All these data provided by the gait analysis, considered into a clinical examination, helped us to understand and quantify the gait disorders, to identify the role of each pathological element in producing the gait anomalies and to ensure a correct management of the therapeutic recommendations : better defining the targets in physical rehabilitation process, indicating and adapting the most suitable walking orthotics (55.1\% patients), choosing the targeted muscles for the botulinum toxin injection protocol in order to improve function $(65.3 \%)$, directing the most suitable type of orthopedic interventions $(22.4 \%)$. It also an objective evaluation tool for the therapeutic benefits and for following up the evolution of gait problems in children during growth period.

CONCLUSIONS: The Multifactorial Gait Analysis is a very important and accurate method of evaluation of gait disorders, with a major role in the therapeutic approach of neurological and orthopedic pathology in children. 


\title{
OP045-PECULIARITIES OF PHYSICAL THERAPY APPROACH FOR CHILDREN WITH EXTRAPYRAMIDAL SYNDROME
}

Liliana Pădure, Dana Necula, - ${ }^{1}$ CNCRNC Dr.Nicolae Robănescu.

SCOPE. BACKGROUND: The extrapyramidal child has no neurological development like a healthy child or like a pyramidal child. Moreover, the athetosis child by not being obstructed by false spasticity develops one way to approach equilibrium, eager to go in feet. For these reasons, we wanted to identify a strategy for optimizing the kinetic treatment in children with extrapyramidal syndrome based on the development and stimulation of balance and coordination, characteristics unidentified by the cognitive of the small patient in his genetic motor baggage.

MATERIALS \& METHODS: Following the initial testing was designed and implemented results of recovery software customized to the needs of each child at the time of the testings. This program applied at the patient's was home thereby taking advantage of the environment with the child is accustomed with.

We made after a certain time a intermediate testing that helped us to highlight that the strengths and weaknesses of the above mentioned software. Following this assessment, were necessary changes made to acquire motor skills and improve behaviors based on other chronological age and corrected of the children included in the study.

At the end of the period of the final we performed testing to compare the time and check the recovery program.

RESULTS: Children who did not benefit from exercises and complex extero-proprioceptive programs stimulation, failed to gain even own body image and the sores are completely disorganized and twisted but sitting posture or standing can be controlled but not for long and as one rigid, brittle at the slightest movement

CONCLUSIONS. The approach of the kinetic program based on strengthening of the coordination and balance reactions, supplemented by stimulating of the sensory perceptions, allow the child with cerebral palsy, extrapyramidal syndrome early diagnosed, to realize preparatory a progress in autonomous movement.

\section{OP046-HEALTY-AGING PROPERTIES OF TECHIRGHIOL MUD THERAPY ASSESSED BY ENDOCRINE CHANGES OF PITUITARY-ADRENAL AXIS}

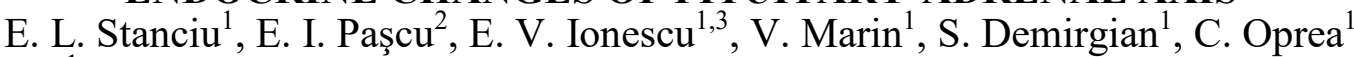

${ }^{1}$ Balneal and Rehabilitation Sanatorium Techirghiol, Constanta, Romania

${ }^{2}$ Sanamed Hospital, Bucharest, Romania

${ }^{3}$ Ovidius University of Medicine, Constanta, Romania

INTRODUCTION:Assessment of endocrine changes of pituitary-adrenal axis, as an indicator of biological aging under the influence of the peloido-therapy. Also is evaluated the persistence of endocrine pituitary-adrenal changes post thermal therapy with highlights on the healthy aging effects of Techirghiol mud.

MATERIALS AND METHODS:Prospective cohort clinical study conducted in Balneal and Rehabilitation Sanatorium Techirghiol(BRST). The study group comprised a total of 37 patients. Subjects were divided into 4 groups depending on the moment of thermal cure: 2 groups during the summer months (group 1 and 2) and 2 groups in the months of autumn, winter and spring (group 3 and 4). The patient was evaluated in terms of clinical signs of aging, hormonal laboratory determinations(cortisol) and biochemical general determinations at admission, at discharge, one month and 4 months after thermal cure.

RESULTS:Regarding cortisol variation evaluated at hospital discharge and 4 months after peloido-therapy stands at the end of treatment as in both control groups (group 2 and 4) values of cortisol were higher compared with the 2 groups study (group 1 and 3). The same results are maintained and 4 months post thermal cure in the 4 groups that we examined. Interestingly,one month after treatment the 2 study groups (group 1 and 3) recorded higher values of serum cortisol when compared with control groups (group 2 and 4). Analyzing pain intensity variation using visual analogue scale(VAS) in groups 1,2 and 3 on admission VAS were higher than at discharge. In group 4 VAS of admission were lower than the corresponding VAS at discharge. When analyzed together groups 1 and 2, VAS on admission were higher than VAS at discharge, while regarding groups 3 and 4, VAS on admission were lower than at discharge.

CONCLUSIONS: The research results to date highlights the beneficial properties of Techirghiol mud therapy, especially in the aging process. 


\title{
OP047-GUIDED INJECTION OF BOTULINUM TOXIN TYPE A IN CEREBRAL PALSY (OUR EXPERIENCE)
}

\author{
L. Pădure*, A. Oprea*,A. I. Grigoriu*,
}

\author{
* National Clinical Center of Neurological Rehabilitation for Children “Dr. N. Robanescu”, Bucharest, \\ Romania
}

SCOPE. BACKGROUND: Injection of botulinum toxin type A is the main important therapeutic tool against spasticity in cerebral palsy. To achieve the best results, the technique must be very precise and ultrasonography offers a reliable help to be sure that you are in the correct muscle. In comparison with EMG/ES the ultrasonography tehnique is superior and our observations showed that sometimes the combination of the 2 methods is the best injection technique.

MATERIAL \& METHODS: We injected from april 2015 until march 2016, 39 patients with CP (tetraparesis, diparesis, hemiplegia and pure diskinetic cerebral palsy). The patients were sedated for better control. 10 patients were injected in both the upper limbs and the lower limbs muscles, 30 patients were injected in the lower limbs muscles and 5 patients were injected only in the upper limb muscles. The injected muscles for the lower limb were soleus, gastrocnemius interior and exterior, semimembranosus, semitendinosus, tibialis posterior, gracilis, adductor longus, adductor magnus. The injected muscles for the upper limbs were pronator terres, biceps brahialis, brahialis, flexor carpi radialis, flexor carpi ulnaris, palmaris magnus, adductor policis brevis, dorsal interossei, opponens policis. Due to intense spasticity, anatomy was very much modified in the upper limb and we had to use needles with electric stimulation combined with ultrasonography to be sure that we injected the correct muscles. The injected muscles in the upper limb were pronator terres, aductor policis brevis, opponens policis and interossei and only tibialis posterior in the lower limbs with combined method.

RESULTS: Injection of muscles with ultrasonography is one of the most reliable method to use in CP. When the anatomy is very much changed the only way to be sure that you inject the correct muscle is to use both techniques. Evaluating the spasticity after injections showed that AS (Ashworth scale) score was lowered by minimum 1.

\section{OP048-OUR EXPERIENCE ON INTERMITTENT CATHETERISATION (IC) IN POST SPI- NAL CORD INJURY (SCI) PATIENTS WITH NEUROGENIC BLADDER (NB), USING HY- DROPHYLIC DEVICES}

\author{
Aura Spinu, C. Popescu, I. Andone, A. Anghelescu, C. Daia, G Onose \\ 1 The University of Medicine and Pharmacy"Carol Davila", Bucharest, Romania \\ 2 The Teaching Emergency Hospital "Bagdasar Arseni", Bucharest, Romania
}

BACKGROUND: This is a review of the related approaches in the field - including the newest ones, associated with a specific prospective study on in-patients from our Clinic Division.

SCOPE. To objectively assess whether there are significant differences regarding some specific biological and psychometric parameters related to the use of hydrophilic catheters vs. nonhydrophilic ones.

MATERIAL \& METHODS: We have comparatively evaluated the outcomes of long term IC using the afore mentioned two different types of catheters, on two lots (totally 117 patients with mainly retention type of neurogenic bladder): 61 post SCI patients, using exclusively hydrophilic catheters and respectively, 56 same kind of patients that used exclusively non hydrophilic catheters. The assessment methods used were primary data acquisition based on an unitary questionnaire and on two standard questionnaires elaborated by International Spinal Cord Society (ISCoS) and statistical analyses.methods: unvaried (Somers' concordance index and Pearson correlation coefficient), multivariate - standardized canonical discriminator function coefficients (SCDFC). We also used T student test combined with Levene test, triad of tests: chi- square, Fisher, $\mathrm{Z}$ of proportions and the non-parametric test Mann- Whitney.

RESULTS: Mainly: the patients that used exclusively hydrophilic type of catheters vs. those using exclusively non-hydrophilic type of catheters presented a significantly: lower number of inflammatory episodes at scrotal level ( $\mathrm{p}$-value $<0.0001 \mathrm{Z}$ test), lower number of post/intra/inter catheterization bleeding episodes ( $p$-value $<0.0001 \mathrm{Z}$ test), lower number of UTI activations ( $p$-value $<0.0001 \mathrm{Z}$ test).

CONCLUSIONS: The incidence of UTI and other urological complications is lower in patients on IC using hydrophilic devices in comparison to the patients that used non hydrophilic catheters. 


\title{
OP049-STRUCTURAL ORGANIZATION AND THERAPEUTIC EFFECTS OF NATURAL AND ARTIFICIAL MINERAL WATERS
}

Professor G. N. Ponomarenko

\author{
G.A.Albrecht's Saint-Petersburg scientific-practical center of medical-social \\ rehabilitation, Saint-Petersburg, Russia
}

INTRODUCTION. Today, there is no conclusive evidence of the identity of the properties and therapeutic effects of artificial and natural mineral waters of similar chemical structure. This led to the study of physical characteristics of drinking mineral waters that define their structural organization and properties.

MATERIALS AND METHODS. Assessment of the mobility of ions the most common drinking of mineral waters was carried out by the method low frequency conductometer, and the structural organization of water - using microwave dielectrometry. Eeffects of artificial and natural mineral waters on clinical and laboratory parameters, immune resistance and functional properties of the gastrointestinal tract in patients with duodenal ulcer and hyperacid gastritis are investigated.

RESULTS. The values of components of dielectric permittivity of natural mineral waters is less than $8 \pm 2 \%(p<0.05)$ than those of artificial mineral waters. The number of dipoles of water in the superstructure natural mineral waters are much higher. More structured natural mineral drinking water ensures optimum functioning of ensembles of enzymes of the mucosa of the stomach and intestines, particularly associated with the absorption and transport. After treatment with natural mineral water has seen significant improvement in endoscopic and radiological signs, some laboratory management indicators, motor functions of the stomach and clinical signs of disease. In the examined group of patients revealed increased non-specific resistance, functional activity of mononuclear phagocytes, a significant increase in the activity of tumor necrosis factor (FNP) and discovered the tendency to normalization of interleukin-1.

CONCLUSIONS. The results indicate heterogeneity structural organization and the clinical efficacy of different natural and artificial mineral waters.

\section{OP050-CLINICAL ASPECTS AND TERAPEUTICAL BENEFITS FOR CHILDREN WITH NEURO-PSYCHO-MOTOR DISORDERS UNDERGOING COMPLEX REHABILITATION TREATMENT USING TECHIRGHIOL AREAL NATURAL FACTORS G. Radu ${ }^{1}, 1$. Rizea ${ }^{1}$, i. Bănărescu ${ }^{1}, M$. Nedelea ${ }^{1}$, A. Prăjitură ${ }^{1}$, N. Calotă ${ }^{1}$, M. Minea ${ }^{1}$, E.V. Ionescu ${ }^{1,2}$ \\ ${ }^{1}$ Balneal and Rehabilitation Sanatorium Techirghiol; ${ }^{2}$ Ovidius University of Constanţa}

INTRODUCTION: The prevalence of neuropsychomotor disorders in children shows an increasing tendency. Considering that a regular program of rehabilitation is useful in increasing locomotory and social independence of these patients, we intend to evaluate the pathology of hospitalized patients and the benefits of recovery treatment.

MATERIAL \& METHODS: The study group included 679 patients, who received physical therapy in salt water pool, mud baths, alternative warm/hot mud pack, massage, electrotherapy, kinetics and speech therapy, if needed. Based on clinical examinations, we took note of demografic indicators, associated diseases, main symptom, first time admittions and frequency of treatment. A subgroup of 75 patients who underwent speech therapy was reviewed regarding speech disorders. The data was statistically processed using SPSS 23.0.

RESULTS: The study group was approximately balanced from gender and age point of view. The frequency of balneo-fizical treatment was twice/year in $39,82 \%$ of cases regardless of the level of locomotor disability and 38,64\% were at the first presentation. Almost 72,27\% walk without support, while $6,49 \%$ need a wheelchair. 35,84\% had lower limbs deficit, while $29,50 \%$ had no functional impairment. Speech disorders were identified in $16,81 \%$ of the patients and further analysis was conducted in the subgroup of patients undergoing speech therapy.

\section{CONCLUSIONS:}

1. Statistical analysis of the subgroup revealed a significant association between age, level of education, type of tuition, risk factors for neuro-motor sequelae, medical pathology and pronunciation disorders, dyslexia and dysgraphia.

2. Due to relatively low number of cases used to investigate the connection between speech disorders and probable influencing variables, further studies are needed.

3. Taking into consideration that the frequency of balneal treatment decreases for patients with higher levels of locomotor disability, the question emerges weather the access of such patients to treatment or patient's confidence in improvement is an impediment. 


\section{OP0451-TREATMENT OF CONGENITAL VARUS EQUIN FOOT \\ THE PONSETI METHOD}

M. Surdu ${ }^{1}$, T. Beiu ${ }^{2}$

${ }^{1}$ University Ovidius Constanta; monica@surdu.ro, ${ }^{2}$ Emergency Hospital of Constanta.

INTRODUCTION: The varus equin foot term refers to a congenital deformity characterized by equin hindfoot and adduction of the forefoot, accompanied by varus subtalar joint complex and: cavus in the tarso-metatarsal joint, talus and calcaneus abnormalities, vascular abnormalities, muscle injuries, abnormal muscle insertions and retractile fibrosis. It is a developmental abnormality similar to the hip dysplasia development and idiopathic scoliosis.

Ponseti technique is a method of correction by manipulation and successive immobilizations in gypsum devices and is known as the "golden standard" in the treatment of the varus equin foot.

AIM OF THE STUDY: Evaluation of the results by Ponseti method at the newborns with varus equin foot in Pediatric and Neonatal Clinic of Surgery and Orthopedics at SCJU Constanta and compare the results with those of other centers and with the specialty literature.

MATERIALS \& METHODS: We used the Ponseti method at 30 newborns who had unilateral or bilateral varus equin foot. The method was applied from the first week of birth. During treatment the patients were evaluated using scores Dimeglio - Bensahel and Catteral - Pirani.

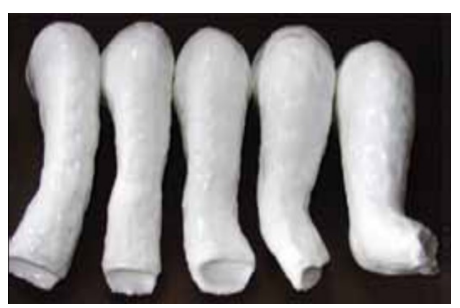

RESULTS: All patients had good results at the end of the immobilizations and at the 3 monthsrevaluation. Percutaneous tenotomy was performed in $72 \%$ of cases. All cases were indicated Denis-Browne splint. We do not established any correlation between the age of starting the treatment and the number of immobilizations in gypsum devices.

CONCLUSIONS: Ponseti technique, the varus equin foot can reach near normal functionality, morphological imperfect, but excellent functional.

The method can be applied up to the age of nine months, according to some authors even up to 6 years and it represents the gold standard in the treatment of varus equin foot.

Figure 1: The form of gypsum devices in successive stages of the Ponseti method

\section{OP052-IMPLEMENTING STRATEGIES FOR LAKE TECHIRGHIOL - CURRENT LEGIS- LATION AND THE DEMANDS OF BALNEAL TOURISM Elena Roxana Almasan, Madalina Gabriela Iliescu, Carmen Oprea \\ * Balneal and Rehabilitation Sanatorium of Techirghiol. ** Ovidius University of Constanta.}

INTRODUCTION Lake Techirghiol is Ramsar sit, included on the International Humid Areas of Importance List, as a habitat for water birds, falling under European legislation. The responsibility over Lake Techirghiol and the durable employment of its natural resources comes to Romanian Waters National Administration - Dobrogea - Littoral Water Basin Administration, equally distributed to Romanian Ornithic Society, to Demos Association and Techirghiol Mayor's Office, who possess the lake's custody, a national authority, alongside a non-governmental organization and local administration, each with its own regulations, decisions and norms.

MATERIALS AND METHODS We used the quantitative research method regarding the study of the current Romanian legislation corroborating data from environment, ecology, health system and social domains in order to unify the integrated concept of heath-tourism and ecotourism.

REZULTS The Institute for Physical Medicine and Medical Balneology commissions the exceptional health improvement qualities of mud and Techirghiol water in countless chronic diseases. Medical procedures bases on mud packing, salt water baths in the marine climate of the area are remarkably efficient in treating several impairments at low costs.

Currently, the Romanian authorities' strategies are directed towards capitalizing the Romania's balneal potential, and represent an economic, social and health-care priority of our country. At Balneal and Rehabilitation Sanatorium Techirghiol a scientific research center is successfully functioning in order to promote balneal and health tourism.

CONCLUSIONS Romania is at this time among the first countries to develop a system for acknowledging ecotourism destinations based on the European Standard for Ecotourism, the first globally appreciated system by the World Council for Durable Tourism, on which the quality of the services and destinations in ecotourism is already based on. Taking those facts into consideration, Techirghiol can represent such an ecotourism destination, since it benefits from internationally protected area, exceptional qualities of the lake and an excellent research center.

KEYWORDS: strategy, Techir ghiol, legisation 


\title{
OP053-NATURAL HUMUS ACIDS WATERS - THEIR POSSIBLE USE IN MEDICINE
}

\author{
N. Veryho ${ }^{1}$, I. Ponikowska ${ }^{1}$, T. Latour ${ }^{2}$
}

${ }^{1}$ Department of Balneology and Physical Medicine, Collegium Medicum in Bydgoszcz, Nicolaus Copernicus University, Toruń, Poland, ${ }^{2}$ Department of Health Resort Materials, National Institute of Public

Health -National Institute of Hygiene, Poznań, Poland

The aim of our presentation is to present the characteristic of the waters with content of humus acids - humus acids waters, which there are in Poland and get suggestions of their apply in medicine.

Humus acids waters are the natural organic-mineral waters from the Miocene aquifer formations, they are intensely colored of presence of humus acids - brown waters. They exist in several European countries, in Belarus and in Poland too, namely in the Wielkopolska region.

The main therapeutic component of these waters are humus acids. These compounds are composed of the aromatic core linked with amino acids, sugars, peptides, and other components in the aliphatic construction.

Humus acids have anti-inflammatory, regenerating, chelating, antibacterial and antiviral properties. Based on previous geological and balneochemical studies carried out in Poland in 2012-2014 years can suggest conclusions about their great usefulness in the treatment of many diseases.

We suppose that the use of this waters also in the form of drinking cure will be useful in the treatment of certain gastrointestinal diseases, especially in chronic liver diseases. In our previous studies during the treatment of drinking cure of one of these waters from Belarus it was observed anti-inflammatory and regenerating effects damaged liver in animals.

Currently, we are going to undertake study in patients with alcoholic liver damage. We assume that the effects demonstrated in animals will be confirmed in humans. We will use water from spring in Branczewo, which has been thoroughly tested for chemical and bacteriological points of view.

According to these studies, this water is physical and chemical stable, it is bicarbonate-sodium chloride, containing $123,36 \mathrm{mg} / \mathrm{dm}^{3}$ of humus acids.

This water was examined earlier in animals, where the elements of metabolism of carbohydrate, fat, protein, electrolytes were observed. It were examined the elimination of urine, bile, action of intestinal smooth muscles and acid-base balance of blood as well. The results of this study were similar of results of action of humus acids from peat.

Our new planned studies in patients will allow to make the conclusions on the possibility of therapeutic properties for the patients. These waters aren't use in balneotherapy in Poland yet.

We believe that the results of these studies will be the basis for the recognition of these waters as a new kind of specific therapeutic mineral waters.

\section{OP054-DETERMINATION OF RUBIDIUM IN MINERAL AND THERMAL WATERS IN THE PROVINCE OF OURENSE (SPAIN). POSSIBLE THERAPEUTIC USE} Souto Figueroa María G. ${ }^{1}$, Freire Magariños, A. ${ }^{2}$

1. Dr. Chemical Sciences, Chair of Physics and Chemical, Graduate in Pharmacy, Conseiller Technique de la Sociéte Française de Thermalisme et de Thalassothérapie pour la Santé Bucco-dentaire

2. Doctor specialist in Medical Hydrology, Medical director Auugas Santas (Lugo) and Rio Pambre (Lugo) spas (Spain)

OBJECTIVE: Determination of Rubidium in 30 thermal mineral water springs in the province of Ourense (Galicia), Spain, and establish its relationship with potassium, other chemical and physical-chemical parameters, present in each of studied spring, is established

INTRODUCTION: It discloses the quantitative determination of rubidium in thermal and mineral waters in the province of Ourense (Spain) and its relationship with other parameters such as set : potassium, lithium, beta radioactivity, alpha radioactivity.

Biological interest in rubidium has been stimulated by its close physicochemical relationship to potassium and its presence in living tissues in higher concentrations, relative to those of potassium, than in the terrestrial environment. Ringer had observed that rubidium affected the contractions of the isolated frog's heart in a manner similar to potassium. The metabolic interchangeability suggests that rubidium might act to some extent as a nutritional substitute for potassium.

METHOD: It is determined by atomic absorption spectrophotometry, to air-acetylene flame and electrodeless discharge lamp, using potassium concentration of $2000 \mu \mathrm{g} / \mathrm{mL}$ to prevent interference ionization, measuring at $780 \mathrm{~nm}$ in a spectrophotometer. The result is expressed in $\mu \mathrm{g} / \mathrm{L}$. Bermejo Barrera P. Bermejo Barrera A. Latorre CH. Souto M. 


\begin{tabular}{|c|c|c|c|c|c|}
\hline SOURCE & $\begin{array}{l}\text { RUBIDI- } \\
\text { UM mg/L }\end{array}$ & $\begin{array}{l}\text { POTASSI- } \\
\text { UM } \\
\mathrm{mg} / \mathrm{L}\end{array}$ & $\begin{array}{l}\text { LITHI- } \\
\text { UM } \\
\mathrm{mg} / \mathrm{L}\end{array}$ & $\begin{array}{l}\text { Radioactivi- } \\
\text { ty } \\
\mathrm{B} \\
\mathrm{mBq} / \mathrm{L}\end{array}$ & $\begin{array}{l}\text { Radioactiv- } \\
\text { ity } \\
\alpha \\
\mathrm{mBq} / \mathrm{L}\end{array}$ \\
\hline Fuente de Requejo & 0.577 & 18.46 & 2.75 & 8887 & 3659 \\
\hline Fuente do Sapo & 0,232 & 13,40 & 1.30 & 958 & 1413 \\
\hline Carregal de Abajo & 0,229 & 13,63 & 2,00 & 2129 & 96,8 \\
\hline Fuente del Bañiño & 0,219 & 7,83 & 0,40 & 694,257 & 885,7 \\
\hline Carregal de Arriba & 0,210 & 14,03 & 1,97 & 1151,187 & 657,8 \\
\hline $\begin{array}{l}\text { Baños de Molgas Fuente } \\
\text { exterior }\end{array}$ & 0,170 & 9,29 & 1,63 & 1243 & 1458 \\
\hline Balneario de Molgas & 0,165 & 9,00 & 1,60 & 1803 & 3659 \\
\hline Burgas de Abajo & 0,163 & 8,15 & 1,14 & 458,302 & 81,4 \\
\hline Burgas de Arriba & 0,137 & 7,31 & 1,15 & 651,736 & 91,5 \\
\hline Balneario de Laias & 0,135 & 6,63 & 0,96 & 341,411 & 418,1 \\
\hline Fuente ext. Partovia & 0,118 & $\overline{1,11}$ & 0,18 & 708,728 & 259,3 \\
\hline Balneario de Carballiño & 0,112 & 2,77 & 0,47 & 63,805 & 1810 \\
\hline Fuente del Tinteiro & 0,107 & 3,11 & 0,57 & 239,332 & 3117 \\
\hline Fuente del Prexigueiro & 0,107 & 3,90 & 0,77 & 59,325 & 17,2 \\
\hline Fuente de Piñeiroá & 0,096 & 2,26 & 0,54 & 132,567 & 105,4 \\
\hline Baños de Mende & 0,095 & 7,15 & 1,09 & 842,366 & 1264 \\
\hline Agua de Reza & 0,094 & 6,26 & 0,57 & 77,17 & 40,9 \\
\hline Fuente de la Rañoa & 0,088 & 0,94 & 0,15 & 143,176 & 21,4 \\
\hline Río Caldo & 0,085 & 3,72 & 0,29 & 106,526 & 11,7 \\
\hline Baños del Prexigueiro & 0,084 & 3,03 & 0,57 & 109,451 & 29,8 \\
\hline Balneario de Partovia & 0,083 & 1,00 & 0,17 & 49,85 & 73,6 \\
\hline Baños de Cortegada & 0,074 & 6,53 & 1,06 & 165,527 & 40,9 \\
\hline Balneario de Partovia & 0,069 & 3,53 & 0,17 & 49,85 & 43,8 \\
\hline Fuente de Arcos & 0,067 & 2,31 & 0,48 & 159,208 & 135,6 \\
\hline Balneario de Berán & 0,058 & 1,35 & 0,18 & 248,072 & 337,6 \\
\hline Fuente de Sás de Penelas & 0,052 & 1,16 & 0,38 & 123,948 & 158,4 \\
\hline Fuente de Ponterriza & 0,049 & 1,15 & 0,26 & 51,0 & 4,2 \\
\hline Fuente de Manzós & 0,046 & 0,88 & 0,31 & 195,542 & 44,6 \\
\hline Fuente de Brués & 0,038 & 1,36 & 0,26 & 41,37 & 14,2 \\
\hline Cueva del Prexigueiro & 0,074 & 3,46 & 0,66 & 56,502 & 51,2 \\
\hline
\end{tabular}

\section{RESULTS TABLE}

CONCLUSIONS: It is observed that sulfur water s has lower concentration of rubidium than others waters. It is observed that waters with high concentration of $\beta$ radioactivity has high concentration of potassium and rubidium.

Also the concentration of rubidium has relationship with presence of $\alpha$ radioactivity

KEY WORDS: rubidium, potassium, mineral water, ther mal water, nutritional substitute.

\section{REFERENCES}

1.Bargar, K., Beeson, M. Fournier,R. and Muffer,L. Present-day deposition of lepidolita from thermal waters in Yellostone National Park. Amer. Mineral. 58: 901-904. 1973.

2.Bermejo, P., Bermejo, A., Herrero, C., Bermejo,F. Rubidium determination in mineral and termal waters way atomic-absortion spectrometry. Analytical Letters 22, (6), 1610'1608. 1989.

3.Casares, A. Descubrimiento de dos nuevos metals Rubidio y Cesio en varias aguas minerals de Galicia. Revista de los progresos de las Ciencias, 5,(2): 74-78. 1866

4.Souto Figueroa Ma $\mathrm{M}^{\mathrm{a}}$ G. Tesis Doctoral Universidad de Santiago de Compostela. Estudio Quimico Analítico de las Aguas MineroMedicinales de la Provincia de Orense. Ourense. 1997.

5.Underwood E.J. Trace Elements in Human and Animal Nutrition. London, on-line edition 2012. 


\section{OP055-BENCHMARKING VALIDITY ANALYSIS OF RASTERSTEREOGRAPHY IN IDIO-}

PATHIC SCOLIOSIS

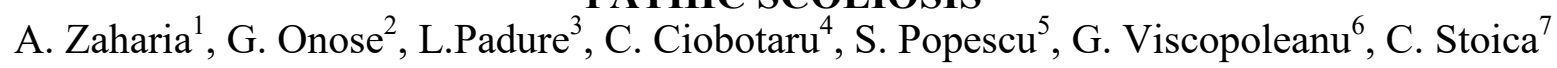

${ }^{1}$ The Emergency Hospital"Sf Apostol Andrei" Constanta

2 Emergency Hospital "Bagdasar-Arseni" Bucharest; RoSCoS, RoSNeRa; University of Medicine and Pharmacy "Carol Davila", Bucharest

${ }^{3}$ C.N.C.R.N. Dr Robănescu; University of Medicine and Pharmacy "Carol Davila", Bucharest 4,5 The Emergency Hospital "Sf Apostol Andrei", Constanta; University of Medicine Ovidius, Constanta ${ }^{6,7}$ Hospital Orthopedics - Traumatology and Osteoarticular Tuberculosis "Foisor", Bucuresti

INTRODUCTION: Referring to Idiopathic Scoliosis, the aesthetics change is a frequent reason for presentation to specialist. Diagnosis is based on clinincal and radiological exam. The spine radiography is the gold-standard for diagnostic and follow-up into Idiopathic Scoliosis, burdensome issue from radiation point of view.

MATERIAL AND METHOD: The study included 11 children hospitalized at C.N.C.R.N. Dr Robănescu Bucharest, aged 9-13 years (9 girls, 2 boys), investigated with radiography and rasterstereography, to assess comparative of its validity with the radiological gold-standard.

The parameters were: lateral deviation of the spine, main apex curvature deviation, vertebral rotation, pelvic obliquity, kyphosis angle and lordosis angle.

For statistical processing it was used Pearson linear regression method.

RESULTS: The correlation coefficients (Pearson $r=0,8$; Spearman rho $=0,9$ ) were calculated, which allows to affirm that there is a significant and the strong correlation between rasterstereographic method and the gold-standard of radiological evaluation.

Rasterstereographic measurements are undervalued when we compare them with the appropriate radiological measurements for apical deviation $(0,3 \mathrm{~mm})$ and the lordosis angle $\left(4,2^{\circ}\right)$; understated for "large" values and overstated for small values for lateral deviation; overstated for kyphosis angle $\left(7,9^{\circ}\right)$. For pelvic obliquity - conflicting data $(\mathrm{r}=0.7$; $\mathrm{rho}=0.6$, regression slope $=0.5)$. Vertebral rotation - special case: Nash-Moe scale, in accordance with radiologic evaluation, has a low number of graduations for being compared with vertebral rotation - assessed by rasterstereography. It requires greather number of patients. Comparison of linear and exponential curves shows that exponential function appears to be more close to the values given by rasterstereography as compared with the X-ray data.

CONCLUSION: Rasterstereographic measurement highlights key benchmarks values in strong correlation with parameters resulting from radiological gold-standard.

According to our knowledge, this demarche we have not meet before, at least in autochthonous literature. To increase the validity of the results we need to expand this study to a larger number of pacients.

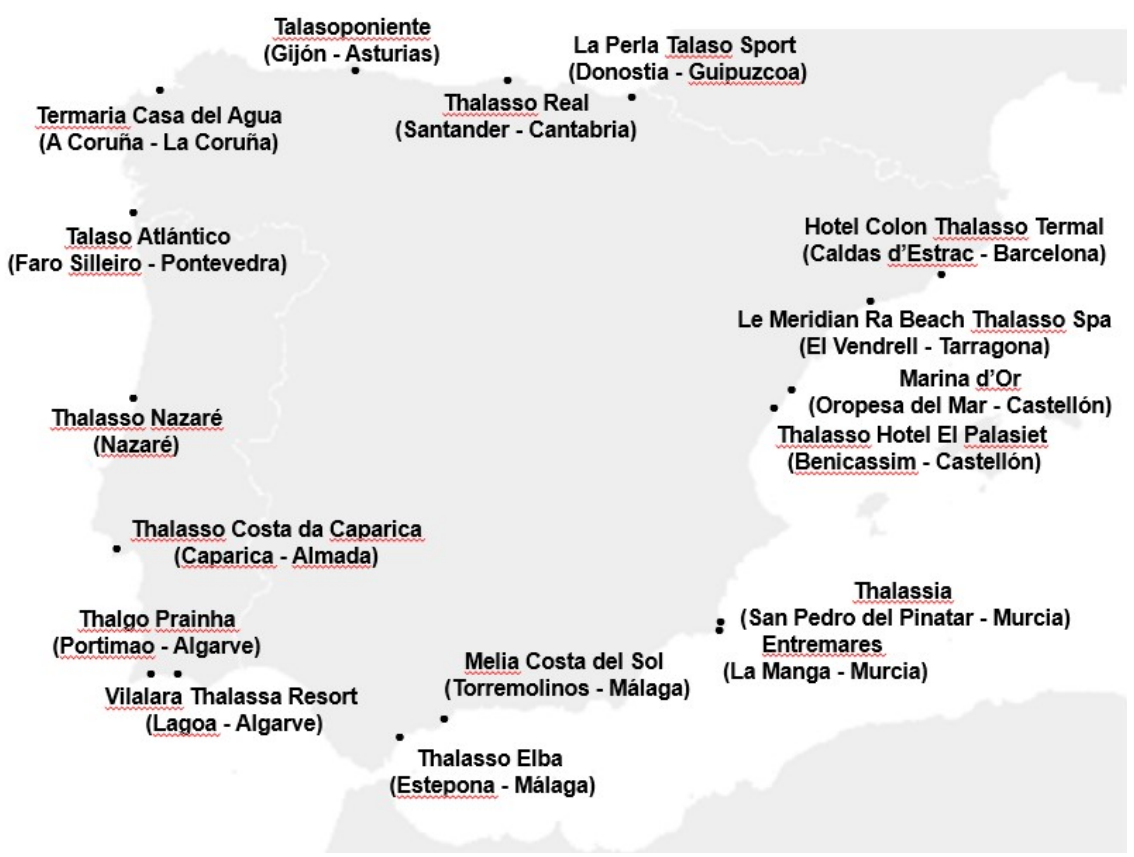




\title{
OP056-DO MINERAL WATERS HAVE ANTI-INFLAMMATORY EFFECTS? EVIDENCE
} FROM IN VITRO AND IN VIVO STUDIES

E.F. Burguera ${ }^{1,2^{*}}$, S. Cheleschi ${ }^{3}$, A. Vela-Anero ${ }^{1,4}$, N. Gómez-Prieto ${ }^{2}$, R. Meijide $\square$ Failde $^{4}$, A. Fioravanti ${ }^{3}$, F.J. Blanco $^{2}$

${ }^{1}$ CIBER de Bioingeniería, Biomateriales y Nanomedicina (CIBER-BBN), A Coruña, Spain.

${ }^{2}$ Rheumatology Group, Instituto de Investigación Biomédica de A Coruña (INIBIC). Complexo Hospitalario Universitario A Coruña (CHUAC). Sergas. A Coruña, Spain.

${ }^{3}$ Department of Medicine, Surgery and Neuroscience, Rheumatology Unit, University of Siena, Italy. ${ }^{4}$ Cellular Therapy and Regenerative Medicine, Department of Medicine, University of A Coruña (UDC), A Coruña, Spain.

INTRODUCTION: The objective of the present work was to review the information on the possible anti-inflammatory effects of mineral waters or single mineral components, chiefly hydrogen sulfide $\left(\mathrm{H}_{2} \mathrm{~S}\right)$, on in vitro and in vivo models of osteoarthritis $(\mathrm{OA})$.

MATERIALS \& METHODS: We conducted a search of the literature in April 2015 by systematically looking through PubMed, PED-ro, Scopus, Web of Science, (the period examined was 2000-2015) using the terms "chondrocyte" and/or "cartilage" in combination with "mineral water", "hydrogen sulfide" and/or "osteoarthritis". We only included the papers published in English.

RESULTS: Evidence of a possible anti-inflammatory role of mineral waters or mineral components was demonstrated by some studies in chondrocyte or fibroblast-like synoviocytes (FLS) in vitro cultures. Many authors investigated the activity of different compounds that release hydrogen sulfide $\left(\mathrm{H}_{2} \mathrm{~S}\right)$ in normal or OA chondrocytes stimulated by interleukin (IL)-1 $\beta$ or lipopolysaccharide. The incubation with exogenous $\mathrm{H}_{2} \mathrm{~S}$-forming compounds inhibited the release of nitric oxide (NO), prostaglandin E2, metalloproteinases, tumor necrosis factor $\alpha$, IL-6 and/or IL-8, and regulated the expression of genes implicated in $\mathrm{OA}$ pathogenesis and progression by reducing nuclear factor $\mathrm{kB}$ activation or the mitogen activated protein kinase signalling route. One study evaluated the role of a highly mineralized water in human OA chondrocytes exposed to IL-1 $\beta$. The mineral water significantly reduced NO production, the expression of the inducible form of the NO synthase and cell apoptosis induced by IL-1 $\beta$. Some in vivo studies of acute inflammation also found that intra-articular injection of $\mathrm{H}_{2} \mathrm{~S}$ compounds reduced pain and inflammation signs.

CONCLUSIONS: Reviewed literature suggests an anti-inflammatory activity of mineral waters or singular mineral elements and provides insights into their potential mechanisms of action. These reports contribute to the understanding of the clinical efficacy of balneotherapy in OA.

KEY WORDS: Mineral water, hydrogen sulfide, osteoarthritis, chondrocytes, inflammation

\section{OP057- CURRENT STATUS THASSOTHERAPY IN THE IBERIAN PENINSULA}

\author{
A. Muela*, C. Morer**, A. Cerrada***, S. Ramos****, F. Maraver** \\ * Thalasso Hotel El Palasiet (Benicassim - Castellón, Spain). \\ ** Research Groups UCM-911757 (Universidad Complutense de Madrid, Medical Hydrology). \\ *** Thasso Elba (Estepona - Málaga, Spain). \\ **** Talaso Atlántico (Faro Silleiro - Pontevedra).
}

INTRODUCTION: The Iberian Peninsula is located in southwest Europe; surrounded by the Mediterranean Sea and the Atlantic Ocean, with almost 4000 coast km where you can find few Thalassotherapy Centers which offers treatments for cure and wellness due to the beneficial properties of the marine environment and some sea specific derivate. The aim of this work is to collect information about them and show some of their particularities.

MATERIAL - METHODS: Internet search, textbooks and direct report of medical doctors working at the centers has been used to select the information. The inclusion and exclusion criteria were according International Quality Standards.

RESULTS - CONCLUSIONS: There are 13 Thalasso Centers in Spain and 4 in Portugal, six of them are part of the Thalassotherapy Spanish Society (SET). Nevertheless, even Thalassotherapy is absolutely developed with active centers offering good quality standards, you may find differences from Region to Region and there is lack of legislation able to protect the concept "Thalassotherapy" witch still can be used in an improper way; It's the responsibility of the medical and scientific community give the arguments of its efficacy and security by medical research.

\section{REFERENCES:}

[1] Bonsignori F. La Talassoterapia. Cure e benessere alle terme marine e al mare. Pisa: ETS, 2011.

[2] Lucchetta MC, Monaco G, Valenzi VI, Russo MV, Campanella J, Nocchi S, Mennuni G, Fraioli A. Le basi storicoscientifiche della talassoterapia: Stato dell'arte. Clin Ter 2007; 158: 533-541.

[3] Maraver F, Michan A, Morer C, Aguilera L. Is thalassothęrapy simply a type of climatotherapy?. Int J Biometeorol 2011; 55: $107-108$

[4] Morer C. Talasoterapia y enfermedad neurológica. Thesis, Universidad Complutense de Madrid, 2016. 


\title{
OP058-ASSESSMENT OF QUALITY PARAMETERS AND OF NATURAL RADIONUCLIDES CONCENTRATIONS IN NATURAL MINERAL WATER IN ROMANIA
}

M. R. Calin ${ }^{1}$, I. Radulescu ${ }^{1}$, A.C. Ion $^{2}$

\begin{abstract}
1'Horia Hulubei" National Institute for Physics and Nuclear Engineering - IFIN HH, 30 Reactorului Street, P.O. Box MG-6, 077125, Bucharest, Magurele, Romania

${ }^{2}$ Department of Analytical Chemistry and Environmental Engineering, University Politehnica of Bucharest, Polizu Street No. 1-7, Bucharest, Romania

Contact email: rcalin@nipne.ro
\end{abstract}

The paper presents data for the activity concentrations of ${ }^{238} \mathrm{U},{ }^{232} \mathrm{Th},{ }^{226} \mathrm{Ra}$ and also for ${ }^{40} \mathrm{~K}$ in nine carbonated and non-carbonated mineral waters. The study evaluates the levels of natural radionuclides and chemical components, their determination being useful as a direct input to environmental and public health studies. An extensive study was conducted on several mineral springs from Romania, located in the northern part of the country, for a period of two years and a half. The water originates from a volcanic aquifer containing carbonate rocks.

First, the gross $\alpha$ and $\beta$ activities were measured for screening purposes and for guidance to the competent authorities in determining whether the water can be used for human consumption. According to WHO guidelines, the recommended screening levels for drinking water below which no further action is required, are $0.5 \mathrm{~Bq} / \mathrm{L}$ for gross alpha activity and $1 \mathrm{~Bq} / \mathrm{L}$ for gross beta activity.

Secondly, activity concentrations of ${ }^{40} \mathrm{~K},{ }^{238} \mathrm{U},{ }^{232} \mathrm{Th}$ and ${ }^{226} \mathrm{Ra}$ were also determined, as well as the associate effective dose. The total effective doses for an adult member of the public in Romania deriving from the intake of naturally occurring alpha or beta radionuclides $\left({ }^{40} \mathrm{~K},{ }^{238} \mathrm{U},{ }^{232} \mathrm{Th}\right.$ and $\left.{ }^{226} \mathrm{Ra}\right)$ in natural water are: $0.66-2.17(\mu \mathrm{Sv} / \mathrm{yr})$ for ${ }^{40} \mathrm{~K} ; 1.12-1.71$ for ${ }^{238} \mathrm{U} ; 1.79-3.95(\mu \mathrm{Sv} / \mathrm{yr})$ for ${ }^{232} \mathrm{Th}$ and $5.75-20.61$ for ${ }^{226} \mathrm{Ra}$. This assessment on the natural radioactivity in natural mineral water samples update data on the activity concentrations and effective doses due to intake of natural radionuclides for Romania. The obtained values are below the WHO and UNSCEAR recommended reference levels.

The surveillance of the natural mineral water and their springs is not a new subject. However, this has to be done continuously to get consistent data with international rules. Analyzes done on samples of natural waters are consistent with the Directive 2009/54/EC of the European Parliament. The obtained data can provide basic information for consumers and competent authorities to be aware of the actual problem of radiation.

KEYWORDS: Mineral waters, Ground waters, Gross alpha and gross beta, Effective dose, Natural radionuclides, Natural radioactivity.

\section{REFERENCES:}

[1] M.R. Calin, A.C. Ion, I. Radulescu, Evaluation of quality parameters and of natural radionuclides concentrations in natural mineral water in Romania, Jour. Radioanal \& Nucl Chem, 303, 305-313, 2015.

[2] M.R. Calin, I. Radulescu, A.C. Ion, F. Sirbu, Radiochemical investigations on natural mineral waters from Bucovina region, Romania, Romanian Reports in Phys, 2015, in press.

[3] I. Ion, A. C. Ion, M. R. Calin, I. Radulescu, Chemical and radiometric studies on carbonated natural mineral waters from the Northern part of Romania, Hydrology Research, 2016, in press. 


\section{PI.01-REHABILITATION ON A PATIENT WITH COMPLETE TETRAPLEGIA AFTER POST SPINAL CORD INJURY ASSOCIATED WITH BILATERAL HIPS AND KNEES ANKYLOSIS DUE TO HETEROTOPIC OSSIFICATION}

Cristina Daia, Gelu Onose, Cristina Popescu, Dumitru Cristinel Badiu, Diana Nita, Doroteea TeoibasSerban, Nicolae Potra

\footnotetext{
${ }^{1}$ The University of Medicine and Pharmacy Carol Davila, Bucharest, Romania

${ }^{2}$ The Teaching Emergency Hospital Bagdasar Arseni, Bucharest, Romania

${ }^{3}$ The Rehabilitation Hospital Bradet, Bucharest Arges county, Romania
}

\section{Introduction:}

Heterotopic Ossification (HO) represents the storage of new bone surrounding joints resulting an impairing of range of motion (ROM). In spinal cord injury (SCI) HO occurs in $90 \%$ on hip than affects the knees, shoulders, and elbows. Main risk factors (cumulative) are adult age, complete lesions, male gender, spasticity, pressure sores, and deep venous thrombosis.

\section{Matherial and Methods:}

A 27 year old patient with complete tetraplegia, C5 as neurological level. After spinal cord injury (C5 fracture, after diving 2011) was admitted in our clinic division with complete knee and hip bilateral ankylosis due to $\mathrm{HO}$; his functional level was lowest: bedridden. He benefited for four orthopedic interventions: Girdlestone bilateral hips resection arthroplasty and Judet's quadriceps plasty for bilateral knees extension between November 2015 and March 2016, and additionally a plastic surgery intervention for a pressure sore on right knee. He benefited for a specific rehabilitation program and was evaluated according following scales: AIS, FIM, WOMAC and quality of life (QoL).

Results: After surgeries the patient have a complete mobility in knees and functional mobility in hips: ROM increases with $66 \%$ on flexion for hips and with $100 \%$ on flexion for knees, stiffness was reduced significantly (from 8 to 0 points) on WOMAC scale, FIM rose with 8 points and QoL with 16 points; functionality patient can use wheelchair for ambulation.

\section{Conclusion:}

Specifically surgeries interventions associate with rehabilitation program is useful to regain some functional important skills (ambulation) on a patient with severe tetraplegia after SCI (and all risk factors for $\mathrm{HO}$ ).

References:

-De Lisa, JA, Rehabilitation Medicine, Principles and Practice, Third edition, Lippincott- Williams and Wilkins - Rehabilitation after spinal cord injury, Steven Kirshblum and Monifa Brooks, 27: 695-696, 2010 -Braddom' Physical Medicine \& Rehabililitation (5 $5^{\text {rd }}$ edition). David X Cifu. W. B. Elsevier, Philadelphia, U.S.A, 49: 1134-1135, 2016

-Shahidul Islam et a1, Judet's Quadricepsplasty for Extension Contracture of the Knee (Stiff Knee), MOJ Orthopedics \& Rheumatology, Volume 2 Issue 6 - 2015

-Becker S W J, Röhl K, Weidt F, Endoprosthesis in paraplegics with periarticular ossification of the hip, Spinal Cord 41, 29-33, 2003 


\section{PI.02-REHABILITATION ON A PATIENT WITH TETRAPARESIS DUE TO DERMATOMYO- SITIS - CASE REPORT}

Assist. Prof. Cristina Daia ${ }^{1,2}, \mathrm{MD}, \mathrm{Ph} \mathrm{D}, \mathrm{MD}$, Prof. Gelu Onose, MD, $\mathrm{PhD}^{1}, \mathrm{PhD}$, Denisa Dragnea ${ }^{1,2}$ MD, Diana Nita ${ }^{1,2}$ MD, Doroteea Teoibas-Serban ${ }^{1,2}$ MD, Nicolae Potra ${ }^{1,2}$ MD, Anca Mihaescu ${ }^{1,2}$

${ }^{1}$ The University of Medicine and Pharmacy Carol Davila, Bucharest, Romania

${ }^{2}$ The Teaching Emergency Hospital Bagdasar Arseni, Bucharest, Romania

INTRODUCTION: Dermatomyositis (DM) is a connective tissue disease characterized by specific cutaneous findings, proximal muscle weakness and nonsuppurative skeletal muscle inflammation. DM often overlaps with other connective tissue diseases. Malignancies occur in up to $25 \%$ of cases.

MATERALS AND METHODS: Patient N.C., age 44, has been hospitalized in july 2015 for important physical asthenia, heliotrope rush, diffuse myalgias, symetrical proximal muscle weakness, dysphagia. Her laboratory tests showed: inflamatory syndrome, high muscle enzyme levels, highly positive Anti-SRP antibodies, positive lupic anticoagulant. The infectious and tumoral pathologies have been excluded, also any other autoimmune diseases, setting the dermatomyositis diagnosis. The efficient treatment was pulsed intravenous methylprednisolone and cyclophosphamide, followed by high-dose steroids with favorable evolution.

In February 2016 she was admitted in our service presenting quadriparesis: weak proximal motor control, partially intermediate and good distal. Her laboratory testings were slightly modified (minimal increase of muscle enzymes levels by CK-MB increase).

During the hospitalization the patient received vitamins, neurotrophics and physical therapy (electrostimulation to the muscles of the hip and shoulder, kinesiotherapy). She was evaluated according following scales: muscle strength (MRC), Functional Independence Measure (FIM), quality of life (QoL), (instrumental) activities of daily living (ADL, IADL).

RESULTS: Functional: the proximal muscle strength has increased with 1 point on MRC, FIM have risen with 4 points, QoL with 7 points: the trunk control and the transfers have improved, the patient can eat by herself and has moderately self-care. According ADL the patient has total dependence, yet.

CONCLUSIONS: Patients with Anti-SRP antbodies highly positive can present with acute onset severe myopathy with significant muscle enzyme elevation and systemic features including dysphagia, cardiac involvement, that can be refractory to standard steroids treatments. Despite of the quasinormalized laboratory tests the muscle weakness is maintaing (corticosteroids induced miopathy?). Rehabilitation program improved the patient's functionality and QoL.

KEYWORDS: tetraparesis, dermatomyositis

REFERENCES:

Callen J, Wortmann R, Dermatomyositis, Clinics in Dermatology (2006) 24, 363-373

Drake LA et al. Guidelines of care for dermatomyositis. American Academy of Dermatology. J Am Acad Dermatol. 1996 May; 34(5 Pt 1):824-829.

De Lisa, JA, Rehabilitation Medicine, Principles and Practice, Third edition, Lippincott- Williams and Wilkins - Rehabilitation after spinal cord injury, Steven Kirshblum and Monifa Brooks; 30:770, 40:1015-1023; 2010 


\section{PI.03-STUDY ON THE NUTRITIONAL IMPORTANCE IN THE RECOVERY OF LBP PACIENT \\ S. Silisteanu, Railway Clinical Hospital Iaşi - ,Ştefan cel Mare” University Suceava,}

SCOPE. BACKGROUND: The purpose of this study was to evaluate the importance of nutritional status and the physical exercise in the recovery of LBP pacient, and also the assurance of a suitable clinical-functional status. Any alteration of nutritional status may influence patients' recovery. Thus, the recovery time increases, also with the health care costs[1].

MATERIAL \& METHODS: Applying a complex motion-nutritional recovery plan, can improve the clinical-functional status and may influence the rehabilitation of patients with LBP. Nutritional status was determined by calculating the body mass index (BMI) and completing questionnaires. Evaluation of patients with LBP was made using rating scales : VAS, LBP-scale modules, and quality of life, using QQL scale. Evaluations were performed at the beginning of the rehabilitation treatment, after 15 days and at the examination (after 3 months)[1].

The study group (aged 25-79 years ) followed a complex program focused on reducing pain rehabilitation (electrotherapy), physical therapy program to improve the flexibility of the lumbar spine and postural reeducation.

RESULTS: The study of BMI during / after the recovery period showed increases in the percentage of overweight people ( 25 to 32 ) and a reduced number of obese people (28 to 16 ) both at the end of the treatment especially at the examination.[3]. BMI was influenced by age, gender and the activity performed.

CONCLUSIONS: The nutritional status of patients with LBP their health and recovery period. A BMI in the overweight-obesity caused unfavorable results in the recovery of patients with LBP. Physical activity can improve the health and correlated with a properly body mass index can induce increased quality of life of patients with LBP.

KEYWORDS: Low back pain, Body mass index, Obesity, Quality of life 1.Amabile B. Dario, Manuela L. Ferreira, Kathryn M. Refshauge, Thais S. Lima, Juan R. Ordoñana, Paulo H. Ferreira, The relationship between obesity, low back pain, and lumbar disc degeneration when genetics and the environment are considered: a systematic review of twin studies, The Spine Journal, May 1, 2015Volume 15, Issue 5, Pages 1106-1117

2.Vijayendra Murthy, David W. Sibbritt, Jon Adams, An integrative review of complementary and alterna- 


\title{
PI.04- EVALUATION OF RADON CONCENTRATION IN SOME NORTHERN ROMANIAN SALT MINES FOR SPELEO-THERAPEUTIC, MEDICAL PURPOSES AND BALNEO TOURISM
}

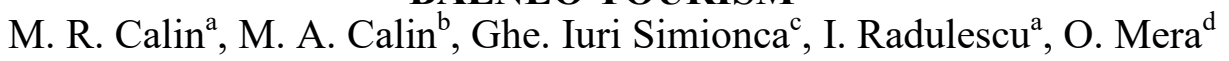

\author{
"'Horia Hulubei" National Institute for Physics and Nuclear Engineering - IFIN HH, 30 Reactorului \\ Str., P.O. Box MG-6, 077125, Bucharest, Magurele, Romania \\ ${ }^{b}$ National Institute of Research \& Development for Optoelectronics, INOE 2000, Bucharest, Magurele \\ ${ }^{\mathrm{c}}$ National Institute of Rehabilitation Physical and Balneoclimatology, Bucharest - INRMFB, Romania \\ ${ }^{\mathrm{d}}$ Turda Salt Mine, Cluj, Romania
}

INTRODUCTION: The knowledge of radon concentration levels in underground environments is essential for therapeutic purposes of different respiratory and rheumatic diseases. In order to develop speleotherapy in Romania, this paper presents the results of an indoor radon concentration levels survey in some salt mines in Romania, during multidisciplinary studies conducted in the years 2010 2015 in the presence and absence of tourists and patients with chronic respiratory diseases.

METHODS: The survey was carried out using a radon monitor system methodology. In order to investigate whether differences in depth and microclimate parameters translate into significant differences in salt mine indoor radon concentrations, have been chosen three salts mine test sites placed in the Northern part of Romania (Cacica [1, 4], Ocna Dej [2] and Ocna Turda [3, 5]) in stable areas of the mining field at 32-120 m depth. Environmental microclimate conditions (mean values of air temperature $10-14.5^{0} \mathrm{C}$, air humidity $65-80 \%$, air velocity $0.2 \mathrm{~m} / \mathrm{s}$ saline aerosols and low microbial factors) have anti-bacterial, anti-microbial, and anti-inflammatory properties and recognized therapeutically effects on human body's health.

RESULTS: Turda, Cacica and Ocna Dej salt mines' microclimate and low radon concentration levels offers optimal conditions for the implementation of various treatments and prophylaxis therapies of respiratory diseases through gradual and increasing exposure in physiotherapy sessions combined with physical exercises. Exposure to salt mine microclimate has beneficial effects on adult people with occupational risk factors, as well as for children, youth and adolescents for improving the respiratory function. Future development of speleo-therapy and possibly radon therapy in Romania must consider the results of this paper as a potential solution to optimize health services and raising quality of life in Romania. The measuring of the natural background ionizing radiation in salt mines was made using a portable integrated impulse debit meter (used in rate mode) equipped with a gamma probe - Counter-timer and at an integration times of $3600 \mathrm{~s} /$ measurement. The measurement and calibration procedures were conducted in conformity with the procedures of the accredited SALMROM laboratory (SR EN ISO/CEI 17025: 2005). Dose rates in various locations in salt mines were between $2 \mathrm{nSv} / \mathrm{h} \pm 4.9 \%$ and $4 \mathrm{nSv} / \mathrm{h} \pm 9.6 \%$.

CONCLUSIONS: The analyzed environmental conditions and recorded low levels of indoor mean radon concentration: $12.6 \pm 0.79 \mathrm{~Bq} / \mathrm{m}^{3}$ (Ocna Dej salt mine), $6.9 \pm 039 \mathrm{~Bq} / \mathrm{m}^{3}$ (Turda salt mine), and $96.5 \pm 4.76 \mathrm{~Bq} / \mathrm{m}^{3}$ (Cacica salt mine), demonstrated the best suitability of the investigated three salt mines in Romania for speleotherapeutic applications.

KEYWORDS: Salt mines and caves, Speleo-therapy, Balneo tourism, Radon concentration, Radiometric measurements.

REFERENCES:

[1] Calin MR, Calin MA, (2011) Investigations on the presence and distribution of Radon in the Cacica salt mine, Romania. Jour. Radioanal \& Nucl Chem 288(1): 203-206.

[2] Calin MR, Calin MA, (2010) Evaluation of the Radon concentration in Ocna Dej salt mine, Romania. Jour. Radioanal \& Nucl Chem, 286(1): 169-173.

[3] Calin MR, Calin MA, Simionca Ghe \& Mera O, (2012), Indoor radon levels and natural radioactivity in Turda salt mine, Romania, Jour. Radioanal \& Nucl Chem, 292(1): 193-201.

[4] M R Calin, C A Simion, Ghe. I. Simionca, M A Calin, A E Druker, (2011), The characterization of the radioactivity in the Cacica salt mine, Rom. Report in Phys, Vol. 63(2), p. 483-502.

[5] M R Calin, M Zoran, M A Calin, (2012), Radon levels assessment in some Northern Romanian salt mines, Jour. of Radioanal \& Nucl Chem, Vol: 293, p. 565-572, 2012. 


\section{PI.05-THE ROLE OF MARKETING RESEARCH IN PROMOTING A BALNEARY DESTI- NATION}

CASE STUDY: BAILE GOVORA

Victor-George Constantinescu

INTRODUCTION: In this article, we discuss the importance of marketing research in promoting the balneary resort Baile Govora. The first part of the article consists of a theoretical presentation of the main quantitative techniques and instruments in survey design with the goal of promoting balneary tourism. Building on these theoretical guidelines, the second part presents the results of a quantitative marketing analysis performed via an online survey.

MATERIALS AND METHODS: The main aim of the online survey was finding out how Romanian tourists of all ages interpret Romanian balneary tourism, particularly the Baile Govora resort. The survey was conducted on 385 respondents, over the course of 2 weeks and the data was analysed with SPSS. The respondents were aged between 18 and 25 years old and were University students. One limitation of the method of online surveys is that the respondents are usually exclusively chosen from the part of the population who not only has current Internet access, but is also familiar with browsing the Internet.

RESULTS: Our main finding was that more than $70 \%$ of the respondents view the Baile Govora resort as a holiday destination for old tourists, and do not regard it as modern. Moreover, the majority of respondents associated Baile Govora with "treatment". Throughout the analysis, the significance threshold used was 0.05 , and the maximal admissible error rate is $5 \%$.

CONCLUSIONS: Based on the results of the survey, we present a series of marketing strategies aiming to promote Baile Govora among young people, including possible improvements to our online surveying strategy. The resort will need to promote a fresh image of itself, consisting of several advantages over other Romanian resorts. Moreover, the current quality of services in Baile Govora needs to be carefully and objectively assessed, so that the services are efficiently improved. In addition to raising the awareness among young people, the online presence and publicity play very important roles in shaping the image of any balneary resort.

KEY WORDS: balneary tourism, marketing research, balneary destination, Baile Govor a

\section{PI.06-PERSONALIZED BALNEOTHERAPY IN PATIENTS WITH DISEASES OF THE JOINTS \\ Ponomarenko G. N., Cherkashina I. V. \\ G.A.Albrecht's Saint-Petersburg scientific-practical center of medical-social rehabilitation, Saint-Petersburg, Russia}

INTRODUCTION. The possibility of correction of motor function in patients with degenerative and inflammatory joint diseases balneology factors today are proved in sound scientific studies. However, the causes of the dissociation of the therapeutic effects of these factors can be attributed to clinical status, joint function and metabolism of patients.

MATERIALS AND METHODS. We examined 120 patients with osteoarthrosis and 120 patients with rheumatoid arthritis aged from 18 to 70 years. validated clinical, functional and laboratory methods of examination and methods of assessment of quality of life are used. All patients were administered mineral (iodine-bromine) and an aromatic bath temperature $35-37^{\circ} \mathrm{C}$, duration 10 minutes, every other day, a course -10 procedures.

RESULTS. Revealed different dynamics of clinical signs of diseases, parameters of motor function, psychological status and quality of life under different baths and determined their main therapeutic effects. Comprehensive analysis of treatment results revealed the determinants and predictors of the effectiveness of balneotherapy with the creation of a mathematical model for determining the weights of the different natural medical physical factors and predict the development of health effects. Presents the scientific rationale syndrome-pathogenic action of various kinds of baths on the leading links of pathogenesis of dystrophic and inflammatory diseases of the joints. Formulated the concept of personalized balneotherapy patients arthrological profile, which allows to objectively assess the current condition of patients and to correct the approaches to the treatment of patients of different mineral and aromatic baths.

CONCLUSIONS. Scientifically the expediency of application of various baths on the basis of differences in their therapeutic action on key links in the pathogenesis of patients with diseases of the joints. 


\title{
PI.07-SWALLOWING DISORDERS IN CHRONIC ISCHEMIC STROKE: A PREDICTOR OF UNFA- VORABLE OUTCOME \\ Ioana Stanescu' ${ }^{1}$ Gabriela Dogaru ${ }^{1}$
}

\author{
1. "Iuliu Hatieganu" University of Medicine and Pharmacy Cluj-Napoca \\ Clinical Rehabilitation Hospital Cluj-Napoca
}

INTRODUCTION: Swallowing is a complex process which implies integrity of brainstem structures and of cortical areas. In $20 \%$ of patients with ischemic stroke, a second stroke appear in the first year after the first one. Many strokes, especially lacunary strokes with small vessel involvement remains silent, and could impair brainstem structures involved in swallowing control. Swallowing disorders which are identified one year after the onset of a first stroke could reflect evolution of the atherosclerotic disease, with an unfavorable outcome compared with patients without dysphagia.

MATERIALS AND METHODS:We followed patients aged between 50 and 70 years, one year after a first ever ischemic stroke, confirmed on CT scan or MRI. Patients with swallowing difficulties during the first stroke, patients with brainstem strokes, with recurrent strokes and with severe cognitive impairment were excluded. Swallowing was assessed clinically (using TOR-BSST and GUSS tests) and, if impairments were seen , paraclinically (Pulsoximetry and videofluorography). A native CT scan examination was performed in all patients. A MMSE examination was performed in all patients.

REZULTS:Patients with dysphagia occurring one year after onset of ischemic stroke were more likely to have new silent ischemic lesions on CT scan, and more severe cognitive impairments on psychological assessment.

CONCLUSION:Swallowing disfunction could reflect the ongoing atherosclerotic process in the cerebral vessels, affecting territories involved in supranuclear swallowing controle, but also diffuse brain vascular territories.

\section{PI.08-EXPERIMENTAL STUDY ON THE HEPATOPROTECTIVE EFFECT OF BAILE TUSNAD CARBONATED MINERAL WATER ON ALCOHOLIC LIVER} Gabriela Dogaru', Marieta Motricală², Molnár Ákos ${ }^{2}$, Constantin Craciun ${ }^{3}$

1. "Iuliu Hatieganu" University of Medicine and Pharmacy Cluj-Napoca

Clinical Rehabilitation Hospital Cluj-Napoca

2. Tusnad Spa Complex - Baile Tusnad

\section{Department of Experimental Biology, Center of Electron Microscopy of UBB, Cluj-Napoca}

INTRODUCTION: The natural mineral water from spring 3 in Baile Tusnad has a total mineralization of $3351.0 \mathrm{mg} / \mathrm{l}$; it has a carbonated, sodium chloride, ferruginous, calcic, boric composition. It is used for therapeutic purposes in chronic liver diseases.

AIM: The electron microscopy study of the biological effects of mineral water on hepatic tissue in experimentally induced alcoholic liver disease. There are currently no clinical or experimental studies on this mixed carbonated mineral water.

MATERIAL AND METHOD: Male Wistar rats with an average weight of $350 \mathrm{~g}$, ethyl alcohol 12\%, mixed carbonated mineral water from spring 3 in Băile Tuşnad. Group I, control group, 5 animals, consumed food and tap water, and group II, 20 animals, were administered food and ethyl alcohol $12 \%$ for 10 weeks. Group II-1, 5 animals, had food and tap water, while group II-2, 12 animals, had food and carbonated mineral water daily, for one month. Liver tissue samples were collected for histological examination.

RESULTS: The electron microscopy analysis of the liver in group I evidenced a normal liver structure with normal metabolic activity. In group II, a marked increase of smooth endoplasmic reticulum was found, which indicated a stimulation of lipid synthesis, a decrease of rough endoplasmic reticulum profiles, suggesting a reduction of protein synthesis capacity; mitochondria had rarefied matrix and cristae, with a low metabolic activity. In group II-1, the diminution in time of the action of alcohol and the drinking of tap water maintained alcohol-induced changes, which were reversible. The group treated with ethyl alcohol and mineral water, II-2, exhibited a normal hepatocyte ultrastructure, an increase in the number of lysosomes indicating a mobilization of the defense capacity of hepatocytes against alcohol intoxication; a number of double-nucleated hepatocytes were present, suggesting an increased hepatic regeneration capacity in response to the action of a toxic agent.

CONCLUSIONS. These data suggest the fact that mineral water has hepatoprotective properties, through its capacity to reduce the toxic action of alcohol in hepatocytes. 


\section{PI. 09 OUR CLINICAL EXPERIENCE CONCERNING PATIENTS DIAGNOSED OR SUS- PECTED OF BORRELIOSIS/ LYME DISEASE}

I Andone*, C Daia***, T Spircu**, C Popescu****, L Onose***, M Chircu****, CD Badiu***, A-R Stoian *,**, D Blendea ************ G Onose $* * *$

* Teaching Emergency Hospital “Bagdasar-Arseni” (TEHBA), Berceni Av., No.12, postal code: 041915, 4th Sector, Bucharest, Romania; E-mails: ioanaandone11@yahoo.com , crsti-

na popescu recuperare@yahoo.com,

**“Carol Davila" University of Medicine and Pharmacy (CDUMP), Dionisie Lupu Av. No. 37, postal code: 020021, 1st Sector, Bucharest, România, E-mails: geluonose@gmail.com , cristdaia@yahoo.com , spircut@gmail.com ,doctorcristianbadiu@yahoo.com,dr.raresstoian@yahoo.com

***Metrorex SA - The Medical Service, Dinicu Golescu Av., No. 38, postal code: 010873, 1st

Sector, Bucharest, România, E-mail: lilianaonose@gmail.com

****Rehabilitation Hospital-Bradet Arges County, postal code: 117147 Romania Email: cristinamiha2004@yahoo.com

*****,Titu Maiorescu” University - Faculty of Medicine, Gheorghe Petraşcu Av., No. 67A, postal code: 031593,3rd Sector 3, Bucharest, Romania, E-mail: danblendea@gmail.com

****** Teaching Emergency Hospital of the Ilfov County, Basarabia Av. No.49-51, postal code: 22104, 2nd Sector,Bucharest, România E-mail: danblendea@gmail.com

INTRODUCTION: This article presents our clinical expertise regarding Borreliosis. We proposed as objectives of this work, a clinical, laboratory and therapeutic evaluation of patients diagnosed with Borreliosis, within a retrospective study.

MATERIALS \& METHODS: Small but consistent with prevalence study lot of 11 cases: 7 inpatients and 4 outpatients, during June 2008 - May 2013. Their evaluation was based on epidemiological, clinical and para-clinical related items. Measurement of pre- and post- therapy parameters, evaluated the specific treatment responsivity. We used descriptive statistics, graphical distribution of parameters, "Wilcoxon Signed Rank" test.

RESULTS: The majority were mid-aged, urban women, with positive specific serologic tests; most of their symptoms/ lesionios were: neurologic, ocular, articular, psychiatric, cardio-vascular. 82\% received appropriate antibiotherapy (including ceftriaxone). Except for two patients, antibiotherapy produced statistically significant decrease of ESR values $(\mathrm{p}=0.042)$. Eosinophilia's values variation, "before" and "after" treatment, ( $p=0.5)$, is placed in "absolute ambivalence". Other investigated parameters, showed no significant changes. For clinical symptoms, the small number of cases prevented valid statistical assessments; none of the cases worsened.

CONCLUSIONS: Positive aspect of antibiotic therapy: lowering ESR; possible, but doubtful negative one: eosinophilia's values equivoque variation. Borreliosis more precise and earlier diagnosis - complicated but necessary - may produce better - including rehabilitative - outcomes allowing promptly given appropriate treatment

KEYWORDS: Borr eliosis, Lyme disease, neuro-borreliosis, antibiotherapy

ACKNOWLEDGMENTS: This work was done also with the punctual efforts of several dedicated junior doctors - who have achieved their specific professional training in the Physical (neuralmuscular) Rehabilitation Clinic Division of the TEHBA- contributing to primary data collection.

\section{SELECTED REFERENCES:}

1. Onose G.; Stănescu-Răutzoiu L.; Pompilian V.-M., "Spondilartropatiile” Volumul 2 Ed. Academiei Române, 2000, pp. 348-353

2. Rebedea I. "Boli infecţioase", Ed. Medicală,, 2000, pp. 358-365

3. Andone I.; Daia C.; Berdila O.; Popa V.; Popa M-I.; Onose G.; Blendea D. Actual synthetic overview on Boreliosis (Lyme disease), Infectio.ro anul IX, 2013, No. 34(2): 18-24.

Mygland A.; Ljøstada U.; Fingerle V.; Rupprecht T.; Schmutzhard E.; Steiner I. EFNS guidelines on the diagnosis and management of European Lyme neuroborreliosis European Journal of Neurology, 2010, $17,8-16$ 


\section{PI.10-INCREASING THE QUALITY OF LIFE OF PATIENTS WITH PARKINSON'S DIS-}

EASE BY TREATMENT WITH NATURAL THERAPEUTIC FACTORS IN BAILE TUSNAD

Gabriela Dogaru ${ }^{1}$, Denisa Muresan ${ }^{1}$, Marieta Motricală ${ }^{2}$, Molnár Ákos ${ }^{2}$

1. "Iuliu Hatieganu" University of Medicine and Pharmacy Cluj-Napoca Clinical Rehabilitation Hospital ClujNapoca, 2. Tusnad Spa Complex - Baile Tusnad

INTRODUCTION: Primary Parkinson's disease is a progressive disorder of the central nervous system. Baile Tusnad resort is recognized for its role in the rehabilitation treatment of cardiovascular, neurological, renal, digestive, rheumatic diseases through the presence of natural therapeutic factors: carbonated mineral waters due to their peripheral and central vasodilator effects, mofettes, and a stimulating bioclimate. Aim. The aim of this study was to evaluate the clinical efficiency of natural therapeutic factors in Baile Tusnad in order to continue the rehabilitation treatment of patients with Parkinson's disease in a balneoclimatic resort.

MATERIAL AND METHODS:The study included 17 patients (5 women and 12 men) with Parkinson's disease, Hoehn-Yahr stages I-III, treated in the Baile Tusnad treatment facility. The patients underwent rehabilitation treatment consisting of carbonated mineral baths for 15 minutes, aerotherapy for 30 minutes, massotherapy and kinesitherapy, performed daily for 16 days. All patients were clinically evaluated before and at the end of treatment using the Tinetti Balance Assessment Tool, the 10-m walking test, the Webster Scale, the Quality of Life Scale, and adverse reactions.

RESULTS: At the end of treatment, a statistically significant improvement of the walking distance and speed, of the quality of gait was found, $p<0.05$. Statistically significant results $(p<0.001)$ were also obtained for balance. The Webster Scale, which assesses the limits of movement and autonomy, evidenced a $p$ value $<0.01$. For the Quality of Life Scale, a statistically significant $p$ value $<0.05$ was obtained. There were no side reactions to the treatment.

CONCLUSION: Natural therapeutic factors influenced the clinical and functional picture, determining a significant improvement of the quality of gait, balance, bradykinesia and the quality of life.

\section{PII.01-INTERFACE ANALYSIS OF TEMPERATURE INSIDE THE PROSTHESIS WITH EFFECT IN IMPROVING THE QUALITY OF LIFE OF PATIENTS \\ Marius Turnea ${ }^{1,}$, Dragos Arotaritei ${ }^{2}$, Robert Filep ${ }^{3}$, Gheorghita Andrei ${ }^{4}$, Rotariu Mariana ${ }^{5}$, Cristian Budacu ${ }^{6}$}

INTRODUCTION: People with amputations of limbs are exposed to temperatures variation in daily activities. We are not referring necessarily to the index of thermal comfort that combines air temperature and relative humidity in an attempt to determine the sensation of heat equivalent perceived by the human body (or how we perceive heat under different humidity). An analysis and study of component and that of all the variables involved in this process (Thermo-biomechanics tissues, thermal properties of the cup and sleeve respectively, thermal stress points on major blunt, etc.) will result in a prosthesis that eliminates heat effectively.

MATERIAL AND METHODS: It is proposes a system for recording temperature curves inside the prosthesis consists of thermocouple, signal amplifiers, analogic signal acquisition board and PC application that targets people with transtibial amputations. The graphical interface allows signal analysis conversed in temperature values inside the prosthesis and their correlation with ambient temperature during normal cycles of full motion.

CONCLUSIONS: It is proposes an application that can record the temperature inside the prosthesis for processing and subsequent interpretation. The application takes into account the situation (which has never been seen in any work after science authors) where the ambient temperature is very low (if cold and in regions in the winter season) and their effect on patient quality of life. 


\section{PII.02-OBJECTIVE MEASURE OF PERFORMANCE PROSTHETIC CUP ASSEMBLY \\ BLUNT FOR A SPEEDY RECOVERY OF THE PATIENT WITH LEG AMPUTATION}

Rotariu Mariana $^{1}$, Marius Turnea ${ }^{2}$, Dragos Arotaritei ${ }^{3}$, Gheorghita Andrei ${ }^{4}$, Robert Filep ${ }^{5}$

INTRODUCTION: The main solicitation of limb in interface blunt stump sleeve is a mechanical type. Movement cycle involves variations in pressure (load) for the same area requested, but only certain areas peak at higher pressure than the surrounding areas. It is proposed a new objctive measure to assess patient comfort, a measure based on mathematical calculations and not modified by the patient's subjective assessment.

MATERIAL AND METHODS: Areas with heavy use, are mainly those who create medical problems, structural integrity stump and ultimately contributes to a feeling of comfort / discomfort of the patient. Movement cycle involves variations in pressure (load) for the same area requested, but only certain areas peak at higher pressure than the surrounding areas. These areas usually coincide with greater demand areas during the whole cycle of movement.

The measure is a linear combination of forces between the sum of the discrete forces requesting that point mediated by the number of records (mean strain) weighted sum of the maximum values of the critical point. The values obtained are compared to values based by survey technique with 5 levels of patient satisfaction. This method can achieve optimal combination of cup and sleeve customized for a specific type of pacient making the procedure of adaptation immediately after amputation.

CONCLUSIONS: It proposes a new type of objective measure of performative cup-prosthesis, personalized on patient benefit can be obtained through simulations that take into ocnsideration the shape of the patient's.

\section{PII.03-USING POSTURAL ANTIGRAVITATIONAL DYNAMIC SYSTEM IN KI- NETOTERAPHY}

Gheorghita Andrei ${ }^{1}$, Dragos Arotaritei ${ }^{2}$, Mihai Ilea ${ }^{3}$, Marius Turnea ${ }^{4}$, Rotariu Mariana ${ }^{5}$

INTRODUCTION: During human evolution, we've known various forms of locomotion including: swimming, dragged on the ground, flying, walking. All these have in common the characteristic of relying on rhythmic movements and alternate the entire body. Walk disorders can have multiple causes, from very severe (tumors, infections Musculoskeletal) to simple causes (transient synovitis of the hip) and even trivial (inadequate footwear).

\section{MATERIAL AND METHODS}

Machine Components

1- pneumatic belt; 2- traction ropes for suspending weight; 3- belt realignment basin in the foreground; 4 adjustable arms for fixing the shoulder and pelvis; 5- treadmill; 6- arms adjustable for fixing the dorsal and sacral spine.

\section{Technical Working}

RESULTS: This type of " training" requires the use of a treadmill that can be adapted at low speeds, with a gradual suspension system harnesses body weight. It takes two rehabilitation therapists that assist walking. The firs therapist, "facilitates" the swing phase, secure heel contact on treadmill, knee hyperextension control phase "mid-stance", promotes symmetry and stride length during phase "stance". The second therapist is positioned on the edges of the walking belt, behind the patient and facilitates the transfer member phase weight "stance" extension hip, pelvic rotation, and maintain the correct position of the trunk.

CONCLUSIONS: Training (treatment) on the treadmill or walking reeducation specific treatments appear to be more effective as part of the conventional therapy for locomotor recovery, especially post-stroke. Remains still premature a correct assessment of available technologies on the market, as robotic gait training. Use body weight suspension (BWS) appears to be more effective than no use. It is not yet clear which parameters can be modified to optimize recovery, both for patients and for those chronically acute. However, most studies are turning to start treatment with a suspension of between $20 \%$ and $40 \%$ of body weight. 


\section{PII.04-USE OF MULTI JOINT SYSTEM IN \\ RECOVERY OF SCAPULOHUMERAL JOINT \\ Dragos Arotaritei ${ }^{1}$, Gheorghita Andrei ${ }^{2}$, Rotariu Mariana ${ }^{3}$, Marius Turnea ${ }^{4}$, Mihai Ilea $^{5}$}

INTRODUCTION: Health is the state of being when human works best in all areas of his life, it feels really happy and moving towards achieving its potential maximum interior. For optimum performance, happiness and achievement potential can take place, it is necessary to have physical, mental, emotional and spiritual. Thus, the recovery of shoulder mobility is one of the main objectives in a recovery program. An innovative approach in the recovery of shoulder mobility is represented by using a new device called the Multi Joint System.

MATERIAL AND METHOD: In the field of rehabilitation, first thing you need to know when starting a effective treatment is to know the anatomy of the segment to be rehabilitated, leaving nothing to chance. Once they have reviewed all the anatomical and functional components necessary to establish how to start rehabilitation.

The treatment of shoulder may use techniques like: articulation, hydrokinetic, manual and instrumental. We focused on the latter technique associating it with a tool that allows us to work in proprioceptive MJS (Multi-Joint-System) is a device capable to perform functions of:

- Passive mobilisation in the early stages of treatment;

- Active-assisted and then reinforced through feedback orientation monitor;

- Corrections execution through auditifeed-back system;

- Strengthening muschulaturii system using ligt-g- against resistance

- truly innovative aspect of the system is the fact that anthropomorphic arm is driven directly by the patient and that can move freely in a three-dimensional joint space.

CONCLUSIONS: The patient, after several consecutive sessions, managed to integrate treatment system (Custom) set by the computer. We can conclude that: familiarity interaction with the patient uses Softer allows a positioning member awareness and movement in space; reduce fear of pain, because the act is voluntary; makes movement smoother; develop mobility shoulder with decreased pain also increases the force that is able to produce limb during movement.

\section{PII.05 - THE INFLUENCE OF RECOVERY TREATMENT BASED ON HALOAEROSOLTHERAPY ON CELL-IMMUNE INDICIES AT FREQUENTLY ILL CHILDREN}

Olha I. Lemko, Nataliya V. Vantyukh, Svitlana V. Lukaschuk

Government Institution "The Scientific-practical Medical Centre "Rehabilitation"

INTRODUCTION. Recurrent respiratory infections in children are among the most common causes of morbidity due to immune system's disturbances. Their frequent appearance in early period of life is associated with asthma and reduced lung functions in elderly. That's why proper diagnosis with detailed immunological investigation is necessary. Simultaneously, the frequency of adverse effects when using immunostimulatory medicines grows. That is why the interest to natural immunomodulating factors is increasing and haloaerosoltherapy is among them.

AIM: to examine the dynamics of cellular immunity at frequently ill children under the influence of medical complexes (MC) based on haloaerosoltherapy.

MATERIALS AND METHODS: 40 frequently ill children aged 5 - 10 years were examined. Immunological examination included evaluation of cellular immunity $\left(\mathrm{CD}^{+}, \mathrm{CD} 22^{+}, \mathrm{CD}^{+}, \mathrm{CD} 8^{+}\right) .18$ patients received treatment beyond MC-1 with daily seances of haloaerosoltherapy with duration of 30 min (14 - 16 procedures per course). Other 22 children received MC-2, in which treatment, similar to MC-1 was completed with singlet-oxygen therapy and Vitaphone. Besides, 20 health children formed control group.

RESULTS. Before immunor ehabilitative treatment cellular immunity in observed children was characterized by significantly decrease of T- lymphocytes level and their subpopulations on the background of 0 -cell amount increasing which confirmed the persistent inflammation.

The positive dynamics of the studied indices were registered under the influence of both MC. It manifested in significant increase in the levels of T-lymphocytes, $\mathrm{CD}^{+}-, \mathrm{CD}^{+}$-cells and the ratio of $\mathrm{CD}^{+} / \mathrm{CD}^{+}$and was accompanied with decrease of 0-lymphocytes number to normal values. It must be underlined that after the MC-2 the increasing of $\mathrm{CD}^{+}$and $\mathrm{CD}^{+}$levels were more expressed, compared to $\mathrm{MC}-1$ ( $\mathrm{p}<0,001$ and $\mathrm{p}<0,05$ accordingly), indicating the complete recovery to normal relation of the main T-lymphocytes subpopulations.

CONCLUSION: Haloaerosoltherapy combined with singlet-oxygen therapy and Vitaphone in the immunorehabilitation of frequently ill children promotes significant increasing of T-lymphocytes' level compared to single haloaerosoltherapy. 


\section{PII. 06-BALNEOREACTIONS TO HALOAEROSOL IN CHILDREN WITH RECURRENT}

\section{BRONCHITIS}

${ }^{1}$ Olha I. Lemko, ${ }^{1}$ Svitlana V. Lukaschuk, ${ }^{1}$ V. I. Popova, ${ }^{2}$ Andriy A. Major

${ }^{1}$ Government Institution «The Scientific-practical Medical Centre «Rehabilitation»

${ }^{2}$ Ukrainian Allergological Hospital, Solotvino, Transcarpathia, Ukraine

INTRODUCTION. The evidence of balneoreactions when using therapeutic physical factors is commonly recognized factor. The consideration of their presence and severity is essential for adequate treatment, especially in children.

The artificial rock salt medium (haloaerosoltherapy) is known to be an effective method of treatment for adults and children with recurrent and chronic pathology of bronchopulmonary system.

AIM: To study the peculiarities of balneoreactions in children with recurrent bronchitis during the haloaerosoltherapy course with high intensity of haloaerosol influence.

MATERIALS AND METHODS. The study involved 75 children with recurrent bronchitis aged 6-10 years who received haloaerosoltherapy course (14 seances) with haloaerosol concentration of $40-35 \mathrm{mg} / \mathrm{m}^{3}$ (at standard procedure the aerosol concentration is $12-4 \mathrm{mh} / \mathrm{m}^{3}$ ). Daily peakflowmetry was performed in the morning and in the evening. Spirography was carried out at the beginning, in the middle and by the end of treatment.

RESULTS. Balneor eactions were observed beginning from $2^{\mathrm{d}}-4^{\text {th }}$ haloaerosoltherapy seances at $29.7 \%$ of children. They were manifested as rhinorrhea ( $24.5 \%$ of cases), occurrence of mild dry cough (5.3\% of patients), appearance and / or intensification of wet cough from mild to moderate in $16.2 \%$ of children without signs of acute respiratory disease. Taking into account that the mucosa is the first line of defense, these changes can be explained as a physiological response to the hyperosmolar factor.

The balneoreaction symptoms as changes in lung auscultation data were observed rarely. However, in $9.3 \%$ of patients wet wheezing were registered. These manifestations were observed till $8-10^{\text {th }}$ seances of treatment. Clinical manifestations were confirmed by pulmonary functional tests. Thus, since only from the $10^{\text {th }}$ haloaerosoltherapy seance the significant increase of morning and evening PEF were noted. Valuable growth of spirography data were observed only by the end of treatment.

CONCLUSION. So, the balneoreaction manifestations which are observed during the haloaerosoltherapy with high haloaerosol concentration are expressed slightly, and do not need special treatment. This confirmed as the purposefulness of its usage in children with recurrent bronchitis so the adequacy of haloaerosol concentration choice and duration of treatment.

\section{PII.07- QUANTITATIVE EVALUATION OF ALKALIZING FEATURES OF NATURAL MINERAL WA- TERS}

Margarita O. Haysak, Lyudmila V. Dychka, Olena P. Holubka, Sergij T. Shubert

Government Institution "The Scientific-practical Medical Centre "Rehabilitation"

Health Ministry of Ukraine", Uzhhorod, Ukraine

INTRODUCTION: Natural mineral waters (MW), which contain bicarbonates, represent one of the effective methods of detoxification therapy. Their main effect is alkalizing - is characteristic in fact for all MW with alkaline or neutral $\mathrm{pH}$. At the same time its' degree of expressiveness and clinical effect depend on the peculiarities of chemical composition of the given MW.

OBJECTIVES: Analysis of alkalizing features of MW of Transcarpathia using different methods of evaluation.

MATERIALS AND METHODS: In vitro evaluation of natural alkalinity of MW was conducted for 12 types of MW using three methods - assessment $\mathrm{pH}$, buffer and acid-neutralizing capacity (modified after J.S.Fordtran) and calculation of potential renal acid load (PRAL) using physiologically based calculation model (T.Remer F.Manz).

RESULTS: It was found that the level of $\mathrm{pH}$ for the majority of MW varies in a small range $(6,8-7,2)$ and according to their acid-neutralizing capacity may be classified into two groups:

- acid-buffering MW with the index of acid-neutralizing capacity $>40 \mathrm{mmol} / 100 \mathrm{ml}$; the acidneutralizing $\mathrm{pH}$ profile and alkalizing features of these MW are characteristic for antacids;

- MW with slightly expressed alkalinity with the index of acid-neutralizing capacity $<40 \mathrm{mmol} / 100$ $\mathrm{ml}$; their acid-neutralizing is due to diluting and low concentration; they may be used only for the preventive purposes.

Potential renal acid load was calculated for each MW. Most of Transcarpathian MW had PRAL $<0$, its value varied between - 7,1 (for MW with mineralization 1,8 g/l) and - 115,6 (for MW with mineralization $11,6 \mathrm{~g} / \mathrm{l})$ indicating their pronounced alkalising features. It was also found that PRAL negatively correlated with $\mathrm{HCO}_{3}, \mathrm{Na}, \mathrm{Mg}, \mathrm{Ca}, \mathrm{K}$ content $(\mathrm{P}<0.001)$.

CONCLUSION: Thus, MW waters with different content of bicarbonates and mineralization have pronounced alkalizing features which may be evaluated quantitatively using in vitro procedure and calculation of PRAL. 


\title{
PII.08-INFLUENCE OF THE RECOVERY TREATMENT ON THE INDICES OF LIPID PE- ROXIDATION, ANTIOXIDANT PROTECTION AND ENDOGENOUS INTOXICATION AT FREQUENTLY ILL CHILDREN AND CHILDREN WITH RECURRENT BRONCHITIS
}

\author{
Magdalyna L. Gabor, Olha I. Lemko, Diana V. Reshetar, Olha M. Tymkanich
}

\section{Government Institution "The Scientific-practical Medical Centre "Rehabilitation” Health Ministry of Ukraine", Uzhhorod}

INTRODUCTION. It is known that free radical oxidation is one of the leading universal mechanisms of damaging membrane structures of cells, which lead to changes in their metabolism and promotes development of oxidative stress (OS).

OBJECTIVES. Peculiarities of the influence of the recovery treatment on the base of two medical complexes (MC) - haloaerosoltherapy (HAT) and its combination with singlet oxygen therapy (SOT) on the parameters of lipid peroxidation (LPO), antioxidant protection (AOP) and endogenous intoxication were studied at frequently ill children (FIC) and children with recurrent bronchitis (RB) beyond the acute phase.

MATERIALS AND METHODS. 75 children aged 6 to 10 were examined, among them 37 with recurrent bronchitis, 38 - frequently ill children. The main indices of LPO, AOP system and levels of the middle mass molecules (MMM) were studied before and after the recovery treatment.

RESULTS. It was found that the recovery treatment using both complexes had a positive effect on the studied systems - in both groups of children significant decrease and normalization of several indices of LPO was observed (concentration of malone dialdehid and final products of LPO). These changes were conditioned by the similar regularities of metabolic processes and were associated with the activation of AOP, particularly its enzymatic link, the expression of which depended on the form of the disease and applied medical complex.

It must be noted that complex HAT in children of both groups resulted in the valuable decrease of the MMM levels, which indicate the antiinflammatory effect of treatment.

CONCLUSION. In general both MC based on HAT resulted in positive changes of the studied metabolic processes associated with the level of inflammation. At the same time more pronounced results were observed in the group of children with $\mathrm{RB}$ and under the influence of MC with combined use of HAT and SOT.

\section{PII.09-METHOD OF BALNEOLOGICAL REHABILITATION TREATMENT OF THE RHEUMATOID ARTHRITIS \\ Ivan S.Lemko ${ }^{1}$, Tatjana V.Chaikovska ${ }^{1}$, Marianna V.Shvardak ${ }^{2}$, Svitlana I.Horitska ${ }^{2}$ \\ ${ }^{1}$ Government Institution "The Scientific-practical Medical Centre "Rehabilitation" Health Ministry of Ukraine", Uzhgorod; ${ }^{2}$ Spa "Sinyak"; Ukraine}

INTRODUCTION: Spa treatment occupies an important place in the treatment and rehabilitation of patients with rheumatoid arthritis (RA).

OBJECTIVES: The method of combined external and internal use of slightly sulfide $(15-34 \mathrm{mg} / \mathrm{L})$ mineral water Sinyatska (SMW) and its' effectiveness in the treatment and rehabilitation of patients with rheumatoid arthritis in conditions of the sanatorium "Sinyak" were studied.

MATERIALS AND METHODS: The clinical and immunological parameters, including antiinflammatory and pro-inflammatory cytokines and their correlation were studied at 50 patients with rheumatoid arthritis during the sulfide balneotherapy and SMW intake.

RESULTS: It was found that at the beginning of treatment 78,0-98.0\% of patients with RA had decreased levels of anti-inflammatory cytokines (IL-4, IL-10) and increased levels of pro-inflammatory cytokines (TNF- $\alpha$, IL-8), mainly due to activation of IL- 8 - in $94,0 \%$ of patients. Besides, low ratio of anti-inflammatory and pro-inflammatory cytokines levels was revealed at $100,0 \%$ of patients. These results served as a base for the development of a method of differential complex use of SMW, depending on the value of anti-inflammatory and proinflammatory cytokines ratio at patients with RA.

It was found that positive therapeutic effect was reached in $94 \%$ of patients under the influence of treatment with SMW. It is important, that normalization of cytokine balance was observed at $50 \%$ of patients with due to considerable increasing (in 1,95 times) the level of anti-inflammatory cytokines, reduction (in 2,1 times) of average and elevated levels of IL- 8 and in 1,4 times - the level of TNF- $\alpha$. It was revealed that the efficiency of complex treatment is in 2 times higher at patients who received the basic therapy (methotrexate), when compared to the group of patients who did not receive it.

CONCLUSION: Thus, the developed method of SMW complex use has both anti-inflammatory and immune-regulating effects on the cytokine profile of blood in patients with RA, thus creating conditions for increasing the effectiveness of basic anti-inflammatory therapy, and the effectiveness of treatment and rehabilitation in general. 


\section{PII.10 SUBSTANTIATION FOR THE INTERNAL USE OF BICARBONATE-SODIUM MINER-}

AL WATER IN THE PREVENTION OF LATENT METABOLIC ACIDOSIS

Tatjana V.Chaikovska, Margarita O.Haysak, Viktoria G.Malinovska,

Olena P.Holubka, Nadiya A.Jakovenko, Lyubov M.Gitter, Marina M.Lyahova

Government Institution "The Scientific-practical Medical Centre "Rehabilitation"

Health Ministry of Ukraine", Uzhgorod, Ukraine

INTRODUCTION: Bicarbonate-rich mineral waters are known to be one of the effective methods of alkalizing therapy through their multicomponent effect on the function of the GUT system, kidneys et al.

OBJECTIVES: The physiological effects of internal use of slightly mineralized bicarbonate sodium mineral water (MW) Shayanska on the function of pancreas and kidneys were studied.

MATERIALS AND METHODS: The urine $\mathrm{pH}$, rate of diuresis, net acid excretion, concentration and debit of urine ammonium. activity and debit of urine $\alpha$-amylase, level of glucose in serum were studied in fasting period and during 120 minutes after administration of $200 \mathrm{ml}$ of degassed MW in 20 healthy subjects.

RESULTS: Following effects of the single dose of MW were found: a tendency to increase the $\mathrm{pH}$ level, which lasted for 60 minutes (from $6,35 \pm 0,15$ to $6,8 \pm 0,2, \mathrm{p}<0,1$ ), the tendency to decrease the net acid excretion during 2 hours (from $0,34 \pm 0,09$ to $0,17 \pm 0,05 \mathrm{ml}$ of $0,1 \mathrm{n} \mathrm{Na}_{2} \mathrm{CO}_{3}, \mathrm{p}<0,1$ ), decreasing the concentration and increased debit of ammonium (from 19,7 $\pm 4,1$ to $44,4 \pm 6,2 \mathrm{mmol} / \mathrm{l} / \mathrm{min}, \mathrm{p}<0.01$ ).

Internal use of MW was accompanied by a tendency to increase the debit of $\alpha$-amylase urinary excretion due to secretin effects of MW (from 868,5 $\pm 105,0$ to $1137,3 \pm 168,0 \mathrm{~g} / \mathrm{h} * 1, \mathrm{p}<0,2$ ). Also, there was a tendency of reduction the level of glucose in serum for two hours after MW intake (from 4,69 $\pm 0,18$ $\mathrm{mmol} / \mathrm{l}$ to $4,23 \pm 0,17 \mathrm{mmol} / \mathrm{l}, \mathrm{p}<0.1)$.

CONCLUSION: The received data testify a stimulating effect of bicarbonate and sodium containing MW on the excretory processes, activating of secretin mechanisms of pancreas secretion, improving the function of ammonium buffer, which contributes the optimization of buffer compensatory mechanisms role in the prevention of the latent metabolic acidosis development.

\section{PII.11-THE MODIFICATION OF QUALITY OF LIFE PARAMETERS IN CHRONIC LOW BACK PAIN UNDER SPECIFIC TECHIRGHIOL LAKE BALNEAL TREATMENT} Andreea-Alexandra Lupu ${ }^{1,2}$, Mihaela Botnarciuc ${ }^{1,2}$, Camelia Ciobotaru ${ }^{1,2}$, Elena-Valentina Ionescu ${ }^{1,3}$ Sandica Albina ${ }^{4}$, Irina Albadi ${ }^{2}$, Madalina-Gabriela Iliescu ${ }^{1,4^{*}}$

${ }^{1}$, ,Ovidius” University of Constanţa, Faculty of Medicine, ${ }^{2}$ Emergency County Hospital "St. Andrew" Constanta, ${ }^{3}$ Balneal and Rehabilitation Sanatorium of Techirghiol, Romania

${ }^{4}$ Rehabilitation Hospital of Eforie Nord, Romania

INTRODUCTION. Low back pain affects almost $80 \%$ of the population over a lifetime. Chronic low back pain is defined as symptoms persisting loger than 12 weeks.

The aim of this study was to evaluate the modification of quality of life parameters under specific balneal treatment with warm and cold mud baths on patients with low back pain.

MATERIAL AND METHODS. We evaluated 50 patients, aged between 30 and 65 years, with chronic low back pain, hospitalized for rehabilitation treatment in Balneal and Recovery Sanatorium Techirghiol, for a period of 2 weeks. The patients were divided into 2 groups: the first group received treatment with warm mud baths and the second group received treatment with cold mud baths. Both groups received electrotherapy, kinetotherapy and massage. All patients were evaluated with Visual Analogue scale and Roland Morris disability questionnaire before and after the treatment.

RESULTS. There were significant improvement in Visual Analog Scale and Roland Morris disability scale in both groups, which demonstrates the beneficial effects on pain and disability parameters on patients with chronic low back pain under balneal treatment specific to Techirghiol Lake

CONCLUSIONS. Balneotherapy and mud baths improved the quality of life in patients with low back pain, this therapy being the most recomanded and without negative side effects.

KEY WORDS: low back pain, balneal, disability 


\section{PII.12-CLINICAL TRIAL REGARDING SPASTICITY \\ HYDRO-/THERMO-/KINESIO-/THERAPEUTICAL \\ APPROACHES - STUDY DESIGN}

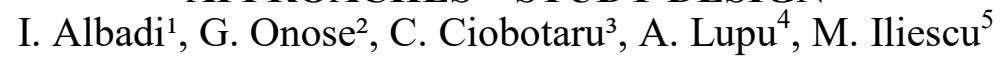

${ }^{1}$ Division of Physical and Rehabilitation Medicine \& Balneology, Eforie Sud, Romania; „Ovidius” University of Constanţa, Romania

${ }^{2}$ The teaching Emergency Hospital "Bagdasar-Arseni” Bucharest, Romania; RoSCoS, RoSNeRa; University of Medicine and Pharmacy "Carol Davila" Bucharest, Romania

${ }^{3}$ Emergency Hospital "Sf. Apostol Andrei”, Laboratory of Rehabilitation, Physical Medicine \& Balneology Constanta, Romania; ,Ovidius” University of Constanţa, Romania

${ }^{4}$ Emergency Hospital “Sf. Apostol Andrei”, Constanta, „Ovidius” University of Constanţa, Romania

${ }^{5}$ Rehabilitation Hospital of Eforie Nord, Romania, „Ovidius” University of Constanţa, Romania

Corresponding author: irina.albadi@yahoo.com

INTRODUCTION: "Spasticity is a motor disorder characterized by a velocity-dependent increase in tonic stretch-reflexes (muscle tone) with exaggerated tendon jerks, resulting from hiperexcitability of the stretch reflex" - Lance (1980), being estimated to affect $>12$ million people worldwide.

Our study aims to analyze the results of the spasticity hydro-/thermo-/therapeutical approaches in patients hospitalized in the Division of Physical and Rehabilitation Medicine \& Balneology, Eforie Sud.

MATERIALS \& METHODS: The study will take place over a period of about 3 years and it will include 2 groups of 50 patients each, aged over 18. The study group will consist of patients with spasticity (stroke, spinal cord injury, traumatic brain injury, multiple sclerosis) that will perform physical therapy and hidro-/thermo-/kinesio-/therapy (HTKT) approaches in our therapeutic pool. The control group will be formed by patients (matched as age, gender and spasticity causes) with spasticity who will perform only physical therapy and kinesiotherapy, according to inclusion/exclusion criteria.

The patients within both groups will be evaluated pre- and post the above mentioned therapeutical interventions according to an unitary evaluation protocol represented by Aschworth, Penn, FIM, ADL, Visual analogue scales.

Data processing and graphic representations of descriptive statistics, according to the standards of normal distribution of the populations it will be used, meant to distinguish between parametric and/or non -parametric differentiated tests.

RESULTS: The onset of this survey and its related results, directly depend of infrastructure: the Ambulatory of Rehabilitation from our Division - where the HTKT interventions for spasticity treatment will be done - is part of a project with European funded which is due for completion in June 2016.

CONCLUSIONS: This approach, dedicated to objectifying outcomes after HTKT interventions for spasticity treatment, is both necessary and pathless especially in the inner literature, thus justifying it's being chosen as an important theme of medical research.

Nathaniel H. Mayer, MD and David M, Simpson, MD - Spasticity- Etiology, Evaluation, Management and the role of Botulinum Toxin- We move/september 2002

Allison Brashear, Elie Elovic - Spasticity - Diagnosis and management-

The upper motor neuron syndrome and spasticity: Pathophysiology and Management Robert J. Coni, DO - Neurology - Grand Strand Regional Medical Center 


\title{
PII.13-RESEARCH ON POSSIBLE BONE METABOLIC, OF OSTEOPOROTIC TYPE AND FUNCTIONAL, IMPAIRMENTS IN CHILDREN WITH NEUROPSYCHOMOTOR PATHOL- OGY (CEREBRAL PALSY) - PRELIMINARY RESULTS
}

Cristian Gabriel Morcov ${ }^{1}$ and Gelu Onose ${ }^{2}$

\begin{abstract}
${ }^{1}$ National Clinic Center for Neuropsychomotor Rehabilitation in Children „Dr.N.Robanescu”,
"'Carol Davila" University of Medicine and Pharmacy, Str.Dionisie Lupu nr.37, district 1, Bucharest

INTRODUCTION. The aim of this study was to examine possible changes related to bone metabolism and basic functionality, in cerebral palsy: neuropsychomotor disease generating mobility issues and possibly osteoporosis.
\end{abstract}

MATERIAL AND METHODS. We analyzed 2 groups (the first, sub-divided in 2 sub-groups -totally resulting in 3 popilations), of children: 5 to 11 years old:

- 8 ambulating patients with cerebral palsy (sub-group 1, group 1)

- 8 non-ambulating patients with cerebral palsy (sub-group 2, group 1)

- 8 patients with scoliosis (group 2)

Evaluating parameters and statistical processing: Functional independence Measure (FIM) scale, Body Mass Index (BMI), Tyroid-Stimulating Hormone (TSH), Free Thyroxine $\left(\mathrm{FT}_{4}\right)$, urinary calcium and phosphorus concentrations.

RESULTS. No significant diferences $(\mathrm{p}>0.05)$ between all the lots and groups/ sub-groups, except for FIM (sub-group 1 versus sub-group 2: $\mathrm{p}<0.001$; sub-group $1+2$ versus group 2: $\mathrm{p}<0.001$; sub-group 2 versus group 2: $\mathrm{p}<0.001$ ). Parameters' contributivity and correlations (Spearman's rho): values were close to 0 ( showing non-correlated items) except for urinary calcium and phosphorus concentrations, (Spearman's rho $=0.61$ ): they are positively correlated, yet (as well) not redundant.

CONCLUSIONS. Preliminary results, confirm the - predictable - clinical-functional differences between the 2 lots/ sub-groups and the chosen evaluation parameters are appropriate.

KEY WORDS: cerebral palsy, scoliosis, osteopor osis

\section{PII.14-CLINICAL EVOLUTION PARTICULARITIES IN A SPINAL INJURY WITH SURGI- CAL TREATMENT GIVEN 7 YEARS AFTER THE TRAUMA - CASE REPORT \\ Doiniţa Oprea*, Ghiulcin Nurla*, Andreea Mihaela Mirita*, Mihaela Minea *, Nicoleta Calota*}

\author{
Balneal And Rehabilitation Sanatorium Of Techirghiol, Constanta, Romania *
}

INTRODUCTION: Spinal injury causes serious damage either in their complexity or by association with neurological complications, and occurs in about $40 \%$ cervical injuries and $15-20 \%$ in the thoraco lumbar injuries. Spinal trauma occurs, mainly, in young active population, but also in the elderly due to vertebral osteoporosis. The most common etiology of spinal trauma is road traffic collision (49\%), followed by falls $(22 \%)$ and assaults $(21 \%)$.

MATERIAL \& METHODS: We present a case of a 52 years old Romanian woman, victim of a motorcycle accident, which caused an unstable L1 lumbar vertebral fracture with a spinal injury, without medullar compression phenomena. After 2 months hospitalization, the patient was transferred to her residence in Cyprus, where she received symptomatic treatment prescribed by her doctor and prolonged bed rest on her own decision.

For socio- economic reasons, the surgical treatment required was possible 7 years later, when a T11-L3 arthrodesis was done, followed by a complex rehabilitation treatment in Balneal and Rehabilitation Sanatorium of Techirghiol (SBRT).

RESULTS: Taking into consideration the fact that the patient is unable to move by herself, although medullar structures were not affected, we are looking to improve her functional level and prevent the possible complications by developing a complex rehabilitation treatment in SBRT.

CONCLUSIONS: Vertebral lesion gravity with minimum neurological sequelae, in the absence of a proper treatment for a long period of time. Functional impotence walking without a neurological etiology, possibly associated with anxious depressive syndrome. 


\section{PII. 15-PARTIAL RESULTS REGARDING THE ANALYSIS OF AOFH RISK FACTORS IN INFLAMMATORY RHEUMATIC DISEASES}

MS Marinica $^{l}$, CM Brailescu ${ }^{1,2}$, AE Covaleov ${ }^{1,2}$

${ }^{1}$ Clinic Hospital of Rehabilitation, Physical Medicine and Balneology, Eforie Nord

2 „Carol Davila” University of Medicine, Bucharest

INTRODUCTION. The AOFH has a progr essive evolution, with severe joint distruction in 2 -3 years after diagnosis for $80-90 \%$ of the cases, with great dysfunctionality for the patients. One of the newest and largest international study „Nationwide Epidemiologic Survey of Idiopathic Osteonecrosis of the Femoral Head" (Wakaba et al, 2010) describes the inflammatory rheumatic diseases as risk factors $31.2 \%$ SEL, $0.9 \%$ RA, $4.9 \%$ polimyositis and dermatomyosistis, $2.8 \%$ collagen diseases; also, corticoid treatment (51\%) and alcohol consumption (31\%).

MATERIAL AND METHODS. It was a retrospective comparative study on two groups of patients with AOFH: the A group consists in 53 patients without inflammatory rheumatologic diseases and group B consisting in 23 patients with inflammatory rheumatisms (11 RA, 10 AS, 2 SEL).

The aim of the study was identification of the demographic, biologic, clinic and evolutive particularities of the AOFH patients and rheumatologic inflammatory pathology as risk factors.

\section{RESULTS}

The average age of the first clinic symptoms was lower in the B group (43.27years) than in the A group

The first clinic symptoms and the AOFH diagnosis were in the same time in $65.21 \%$ of cases

$82.6 \%$ of all cases presented clinic and biologic active inflammatory disease

All the patients had in their medical history, the corticoid treatment

Bilateral ONACF in $43.47 \%$ of cases (43.39\% in A group)

\section{CONCLUSIONS}

Rapid progressive evolution with severe distruction of the joint and ankilosis with arthroplasty indication for $37.5 \%$ of the patients

The inflammatory rheumatic diseases have higher risk factors for rapid destructive AOFH

KEY-WORDS: Aseptic Osteonecrosis of the Femoral Head (AOFH); inflammatory rheumatic diseases; risk factors.

\section{PII.16-FIBROMYALGIA AND BALNEOTHERAPY. A RANDOMIZED CONTROLLED CLINICAL STUDY IN THE LUGO ROMAN BATH SPA (NW SPAIN)}

Rosa Meijide-Failde ; Sofía López-Linares ${ }^{2}$; $\mathrm{M}^{\mathrm{a}}$ Carmen López-Silva ${ }^{2}$;

Ascensión Sánchez-Carrion ${ }^{3}$, Mercedes Seoane-Bouzas ${ }^{1}$, Ángela Vela-Anero ${ }^{1}$, Elena F. Burguera ${ }^{4}$

${ }^{1}$ Cellular Therapy and Regenerative Medicine, Department of Medicine, University of A Coruña (UDC), INIBIC, A Coruña,

Spain. ${ }^{2}$ Primary Care Center Plaza de Ferrol Sergas, Lugo, Spain. ${ }^{3}$ Medical Director Lugo Roman Bath Spa; ${ }^{4}$ CIBER de Bio-

ingeniería, Biomateriales y Nanomedicina (CIBER-BBN), Rheumatology Group, Instituto de Investigación Biomédica de A Coruña (INIBIC). Complexo Hospitalario Universitario A Coruña (CHUAC). Sergas. A Coruña, Spain

INTRODUCTION: Fibromyalgia (FM) is characterized by chronic widespread pain, fatigue, and sleep disturbances. The prevalence of fibromyalgia among the woman population is $3.5 \%$. Fibromyalgia management requires a combination of pharmacologic and non $\square$ pharmacologic treatment modalities. Several guidelines indicate that balneotherapy is one of the non-pharmacologic treatment options proved to be effective in the treatment of FM. We aimed to evaluate the effectiveness of balneotherapy in Lugo Roman Bath Spa (NW Spain) in FM management with a randomised, controlled clinical study.

MATERIAL \& METHODS: Seventy-six women with FM under pharmacological treatment were randomly assigned to either the balneotherapy (38) or the control (38) group. The patients in the balneotherapy group had mud therapy and aquatic therapy in a sulfur thermomineral water pool in Lugo Spa two days a week for three months. The patients in the control group continued to have their medical treatment and routine daily life. An investigator, blinded to the study arms, assessed the patients. All patients were assessed two times, at the beginning of the study, and after balneotherapy at the end of the $3^{\text {rd }}$ month. Outcome measures of the study were pain intensity, Fibromyalgia Impact Questionnaire (FIQ), Short Form 36 Health Survey (SF-36) scores, and tender point count as compared to the control group

RESULTS: Significant improvements were observed in pain, tender point count, FIQ, subscales of SF-36 and decrease in antidepressants and anti-inflammatory drugs consumption at the end of the study period at 3 months in the balneotherapy group; however, no such improvement was observed in the control group.

CONCLUSIONS: It was concluded that balneotherapy provides beneficial effects in patients with fibromyalgia.

KEY WORDS: fibromyalgia; spa therapy; balneother apy; aquatic therapy 


\section{PII.17-AQUATIC THERAPY IMPROVES THE MOBILITY IN PEOPLE WITH SEVERE MENTAL ILLNESS}

Mercedes Seoane-Bouzas ${ }^{1}$; Rainer Oberguggenberger ${ }^{2}$; Elena F. Burguera ${ }^{3}$; Rosa Meijide-Failde ${ }^{1}$

${ }^{1}$ Cellular Therapy and Regenerative Medicine, Department of Medicine, University of A Coruña (UDC), INIBIC, A Coruña, Spain. ${ }^{2}$ Psychiatry chef medical. Hospital Universitario Son Espases. Mallorca Spain. ${ }^{3}$ CIBER de Bioingeniería, Biomateriales y Nanomedicina (CIBER-BBN), Rheumatology Group, Instituto de Investigación Biomédica de A Coruña (INIBIC). Complexo Hospitalario Universitario A Coruña (CHUAC). Sergas. A Coruña, Spain

INTRODUCTION: Severe Mental Illness (SMI) comprises several psychiatric diagnostics (schizophrenia, bipolar disorder, depression). The aim of this study was to assess the effectiveness of aquatic therapy techniques included in a program of Occupational Therapy on the mobility (transfer, balance, ambulation and speed) of patients with SMI.

MATERIAL \& METHODS: 16 individuals (10 men; mean age \pm SD, 37,56 \pm 9.7$)$ with SMI from Mental Health services in Mallorca, Spain were included in a randomized control trial. The experimental group ( 8 persons) participated in an aquatic therapy program ( 24 sessions over 3 months, 2 times a week, lasting 40 minutes) and the control group (8 persons) continued treatment as usual. Patients in both groups were evaluated a week before treatment (baseline) and at the end of the intervention. The instrument used to assess program effectiveness was "Timed Up and Go". This test measures the time (in seconds) it takes a person to get up from a chair, walk 3 meters, back and sit again. Normal healthy people usually complete the task in ten seconds or less. Wilcoxon test was applied to analyze the differences between control and intervention groups. The study followed the CONSORT recommendations.

RESULTS: A total of 14 subjects completed the study (88,5\%). The results pre vs. post intervention of the "Timed Up and Go" test showed an improvement of times in the experimental group (mean time in seconds \pm SD change: $9,72 \pm 2.8$ vs. 7,06 \pm 1.8 ) in comparison with the control group $(8,53 \pm 2.5$ vs. $8,68 \pm 2.4)$. The results show that there are statistically significant differences between the control group and the intervention group, $(p=0.026<0,05)$.

CONCLUSIONS: The results demonstrated the effectiveness of techniques including aquatic therapy in the treatment of occupational therapy in people with SMI in terms on the mobility (transfer, balance, ambulation and speed).

KEY WORDS: aquatic therapy; mental illness; mobility; Occupational ther apy

REFERENCES: Podsiadlo D, Richardson S. The Timed 'Up \& Go': a test of basic functional mobility for frail elderly persons. J Am Geriatr Soc 1991;39:142-8. 


\section{PII.18-IMPACT OF MUD TREATMENT ON PERIPHERAL BLOOD CIRCULATION Viorica Marin*, Olga Surdu**, Daniela Profir***, \\ * Balneal and Rehabilitation Sanatorium of Techirghiol. ** Ovidius University of Constanta. *** Balneal and Rehabilitation Sanatorium of Techirghiol,}

INTRODUCTION: In Techirghiol Balneal and Rehabilitation Sanatorium is used mud and salty water from Techirghiol Lake for treatment. Mud therapy consists in: bath mud and heated mud packing. Salty lake water is used in pool for hidrokinetotherapy, or in tubs for bath. Aim of study was to evaluate the impact of mud therapy on partial blood gas pressure in order to determine the impact of mud bath on peripheral circulation.

\section{MATERIAL \& METHODS:}

The study was performed on 43 patients hospitalized in Sanatorium. All patients were treated with mud bath alternative with salt bath. Blood samples were collected from all patients in first day before and after first bath, at 24 hours after first bath and in the end of treatment. The following parameters were determined:

-blood acidity $(\mathrm{pH})$,

-oxygen partial blood pressure $\left(\mathrm{pO}_{2}\right)$,

-dioxide of carbon partial blood pressure $\left(\mathrm{pCO}_{2}\right)$,

-blood saturation in oxygen $\left(\mathrm{SO}_{2} \%\right)$,

-bicarbonate ion $\left(\mathrm{HCO}_{3}^{-}\right)$,

-total value of dioxide of carbon $\left(\mathrm{TCO}_{2}\right)$,

-hemoglobin capacity to link oxygen $\left(\mathrm{O}_{2} \mathrm{CAP}\right)$,

-oxygen content in hemoglobin $\left(\mathrm{O}_{2} \mathrm{CT}\right)$ and

-total lactate level (LAC).

RESULTS: After the first mud bath there was an increase in level of $\mathrm{O}_{2} \mathrm{CT}$, of $\mathrm{pO}_{2}$, of $\mathrm{O}_{2} \mathrm{CAP}$ and $\mathrm{SO}_{2} \%$ and decreased of LAC level. It's not found any change in level of $\mathrm{pH}$, of $\mathrm{pCO}_{2}$ and $\mathrm{TCO}_{2}$.

CONCLUSIONS: The evaluation confirm improve in periphery vascularization induce by mud bath and salt bath, more important in mud bath therapy, demonstrate by significant statistic and concordant modifications of partial blood gases pressure.

\section{REFERENCES:}

1.Teleki N., Munteanu L., Stoicescu C., Teodoreanu Elena, Grigore L., Cura balneoclimatica în România, Editura Sport-Turism, Bucureşti, 1984, 50-52.

2.Lupu N. GH., Medicină internă, volumul I, Semiologie şi terapeutică generală, Editura Medicală Bucureşti, 1956, Capitolul balneologie - prof. Dr. E. Moraru, 378. 
Romanian Association of Balneology

E-mail: ismh2016@bioclima.ro

Website: http://bioclima.ro/ismh2016.html

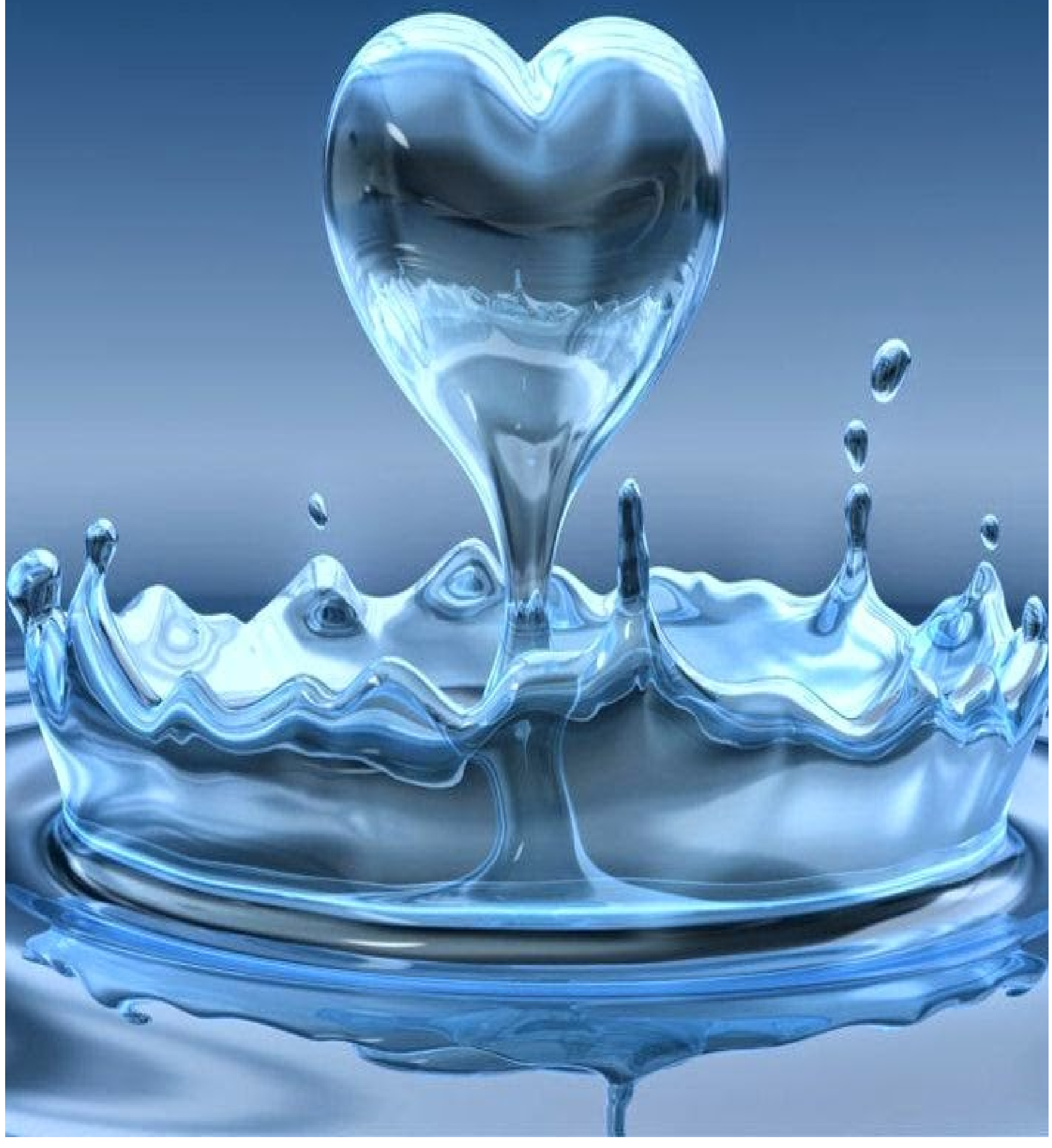

